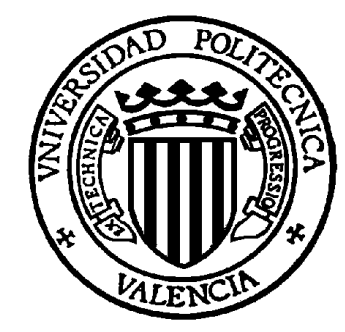

TESIS DOCTORAL

\title{
METODOlOGía PARA LA ASIGNACIÓN DE LOS COSTES DE LOS SERVICIOS DEL AGUA BASADA EN LA TEORÍA DE JUEGOS COOPERATIVOS: APLICACIÓN A LA CUENCA DEL RÍO TURIA.
}

\author{
DOCTORANDO: \\ Davide Deidda \\ DIRECTORES: \\ Prof. Joaquín Andreu Álvarez \\ Prof. Miguel Ángel Pérez Martín
}

Abril de 2009 



\section{AGRADECIMIENTOS}

Para empezar quiero agradecer a Joaquin Andreu y Miguel Ángel Pérez, directores de esta tesis, por la confianza depositada en mí y en mi trabajo. A Miguel Ángel por la asistencia académica y el apoyo y guía constante durante estos años. A Joaquín también por el esfuerzo que supuso conciliar la dirección de la tesis con el cargo de director técnico en la Confederación Hidrográfica del Júcar.

A los profesores del Departamento de Ingeniería Hidráulica y Medio Ambiente, y en particular a Abel Solera, por compartir su amplio conocimiento en el tema de la planificación y gestión de los recursos hídricos de manera desinteresada.

A los Profesores Nanni Sechi y Paola Zuddas de la Universidad de Cagliari, por su inestimable colaboración y el entusiasmo por la investigación que me han transmitido. Les agradezco por la disponibilidad demostrada en el utilizo y desarrollo del modelo WARGI y por el trabajo conjunto en la redacción de la contribución al XXXIX congreso anual de la asociación italiana de investigación operativa.

A Riccardo Zucca quiero agradecer la valiosa colaboración en la aplicación de la metodología desarrollada a los casos de estudio.

A Vito Fragnelli y Fioravante Patrone, investigadores y expertos de teoría de juegos, por su guía y su aporte en mis primeros pasos en la investigación de los juegos cooperativos.

Quiero agradecer a Luis Ángel Alonso por las interminables conversaciones que hicieron de mi estancia doctoral una experiencia más amena y provechosa.

A los compañeros de doctorado y amigos Chiara, Miguel, Carlos, Diana, Matías, César, que han terminado o continúan en el desarrollo de sus respectivos trabajos, por las experiencias compartidas.

A mis padres y a mi hermana, que desde la distancia han seguido e impulsado el desarrollo de esta tesis. Su apoyo incondicional y el ejemplo de lealtad, tenacidad, honestidad y dedicación han sido para mí el mayor estímulo para la conclusión de este trabajo.

Finalmente, agradezco a Juliane por su comprensión, apoyo, paciencia, compañía y demás durante estos años y sobretodo en los momentos que le he robado para dedicarme a esta empresa, que espero compensar en el futuro. 



\section{RESUMEN}

La naturaleza interdisciplinar de los problemas relacionados con el uso del agua requiere el desarrollo de metodologías de análisis que integren los aspectos técnicos, económicos, medioambientales, sociales y legales para la definición de estrategias de gestión eficientes y sostenibles.

En esta tesis doctoral se ha desarrollado una metodología para la asignación de los costes de los servicios del agua a escala de cuenca basada en el uso de la teoría de juegos cooperativos. La teoría de juegos cooperativos proporciona las herramientas para analizar los problemas de asignación de costes comunes entre los beneficiarios de las inversiones en servicios hidráulicos y definir los incentivos adecuados para la cooperación entre los usuarios del agua. Su fortaleza reside en la capacidad de implementar, a través de formulaciones matemáticas, los principios de eficiencia, equidad y aceptabilidad que guían los procesos de reparto justo de costes bajo un punto de vista estratégico, en el que las decisiones de un jugador pueden afectar el comportamiento de otros jugadores.

La metodología propuesta consiste en la definición de un juego de asignación de costes a partir de la modelación de un sistema hídrico y se basa en el concepto de responsabilidad de los usuarios en el uso de los servicios del agua, es decir en la determinación del conjunto mínimo de inversiones que permitan alcanzar los niveles de servicio exigidos por cada usuario del sistema. Se propone el uso combinado de modelos de simulación (SIMGES, Andreu et al. 1996) y de optimización (WARGI, Sechi G.M. y Zuddas P., 2002) de la gestión de los sistemas de recursos hídricos para calcular las configuraciones de infraestructuras hidráulicas óptimas para cada usuario o coaliciones de usuarios.

El resultado de la aplicación de la metodología es el cálculo de un insumo de pagos, que corresponden a la contribución de cada uno de los usuarios a los costes de los servicios del agua del sistema en condiciones de eficiencia de la gestión y de equidad en el reparto de costes.

Se propone la aplicación de la metodología al caso de estudio de la cuenca del río Turia, situada en las provincias de Valencia y Teruel (España). 



\section{ABSTRACT}

The interdisciplinary nature of water problems requires methods to integrate the technical, economic, environmental, social and legal aspects into a comprehensive framework that allows the development of efficient and sustainable water management strategies.

The research presents a methodology for allocating costs among water uses with a cooperative game theory approach based on the integral river basin modelling at monthly time detail. Cooperative game theory provides the tools to consider cost allocation problems by means of the analysis of incentives to cooperation. The game theoretic approach relies on considering the principles of rationality, equity and efficiency in an axiomatic perspective to achieve a fair and just cost allocation process on a strategic basis, where the decisions of a subject are relevant on the behavior of the other actors.

The proposed approach starts from the hydrologic and economic characterization of the system to be modelled and is based on the concept of the users' responsibility on the water services, in other words, the minimal set of investments to achieve a certain service level for each water use. Decision support systems for water resources management (SIMGES, Andreu et al. 1996; WARGI, Sechi G.M. and Zuddas P., 2002) have been applied to retrieve water system performances and to calculate the characteristic function of each one of the user coalitions that may arise in the water resources system.

The solution of a cooperative game is the amount of money each player should pay as a fair and efficient cost allocation of the water services.

As a case of study, has been analyzed the Turia river basin (Spain). 



\section{RESUM}

La naturalesa interdisciplinar dels problemes relacionats amb l'ús de l'aigua requerix el desenrotllament de metodologies d'anàlisi que integren els aspectes tècnics, econòmics, mediambientals, socials i legals per a la definició d'estratègies de gestió eficients i sostenibles.

En esta tesi doctoral s'ha desenrotllat una metodologia per a l'assignació dels costos dels servicis de l'aigua a escala de conca basada en l'ús de la teoria de jocs cooperatius. La teoria de jocs cooperatius proporciona les ferramentes per a analitzar els problemes d'assignació de costos comuns entre els beneficiaris de les inversions en servicis hidràulics i definir els incentius adequats per a la cooperació entre els usuaris de l'aigua.

La seua fortalesa residix en la capacitat d'implementar, a través de formulacions matemàtiques, els principis d'eficiència, equitat i acceptabilitat que guien els processos de repartiment just de costos baix un punt de vista estratègic, en el que les decisions d'un jugador poden afectar el comportament d'altres jugadors.

La metodologia proposada consistix en la definició d'un joc d'assignació de costos a partir de la modelació d'un sistema hídric i es basa en el concepte de responsabilitat dels usuaris en l'ús dels servicis de l'aigua, és a dir en la determinació del conjunt mínim d'inversions que permeten abastar els nivells de servici exigits per cada usuari del sistema.

Es proposa l'ús combinat de models de simulació (SIMGES, Andreu et al. 1996) i d'optimació (WARGI, Sec-hi GM i Zuddas P., 2000) de la gestió dels sistemes de recursos hídrics per a calcular les configuracions d'infraestructures hidràuliques òptimes per a cada usuari o coalicions d'usuaris.

El resultat de l'aplicació de la metodologia és el càlcul d'un insumo de pagaments, que corresponen a la contribució de cada u dels usuaris als costos dels servicis de l'aigua del sistema en condicions d'eficiència de la gestió i d'equitat en el repartiment de costos.

Es proposa l'aplicació de la metodologia al cas d'estudi de la conca del riu Túria, situada en les provincies de València i Terol (Espanya). 



\section{RIASSUNTO}

La natura interdisciplinare dei problemi relazionati con l'uso dell'acqua richiede lo sviluppo di metodologie di analisi capaci di integrare gli aspetti tecnici, economici, ambientali, sociali e legali per la definizione di strategie di gestione delle risorse idriche efficienti e sostenibili.

In questa tesi di dottorato viene presentata una metodología per l'assegnazione dei costi dei servizi idrici a scala di bacino basata nella applicazione della teoria dei giochi cooperativi. La teoria dei giochi fornisce gli strumenti per l'analisi dei problemi di allocazione dei costi comuni fra i beneficiari degli investimenti nei servizi idrici e per la definizione degli incentivi adeguati alla cooperazione fra gli utenti. La principale virtú della teoría dei giochi risiede nella capacitá di implementare, mediante formulazioni matematiche, i principi di efficienza, equitá e razionalitá che guidano i processi di reparto giusto dei costi da un punto di vista strategico, nel quale le decisioni di un soggetto possono influire nel comportamento degli altri giocatori.

La metodologia proposta consiste nella definizione di un gioco di assegnazione dei costi a partire dalla modellazione di un sistema idrico e si basa sul concetto di responsabilitá degli utenti nell'uso dei servizi idrici, ovvero nella determinazione del complesso di investimenti che permettono di raggiungere $\mathrm{i}$ livelli di servizio richiesti dagli utilizzatori del sistema. Si propone l'uso combinato di un modello di simulazione (SIMGES, Andreu et al. 1996) e di un modello di ottimizzazione (WARGI, Sechi G.M. e Zuddas P., 2002) della gestione di sistemi idrici per il calcolo delle configurazione infrastrutturale ottimale per ogni utente o coalizioni di utenti, allo scopo di determinare la funzione caratteristica del gioco.

Il risultato della applicazione della metodologia é costituito dal calcolo dei contributi corrispondenti ad ogni utente per il finanziamento dei servizi idrici in condizioni di efficienza e equitá nel reparto dei costi.

Si propone la applicazione della metodologia al caso di studio del bacino del fiume Turia, situato nelle province di Valencia e Teruel, in Spagna. 



\section{ÍNDICE GENERAL}

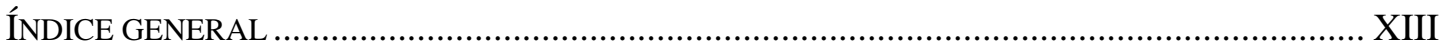

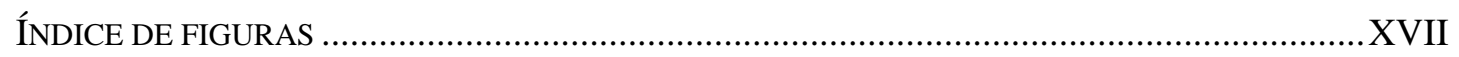

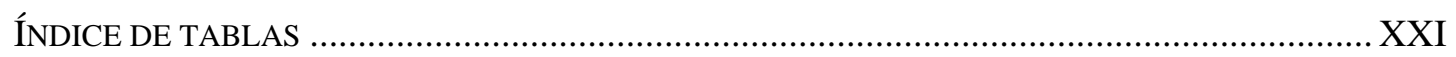

ÍNDICE DE SÍMBOLOS Y NOTACIONES........................................................................XXV

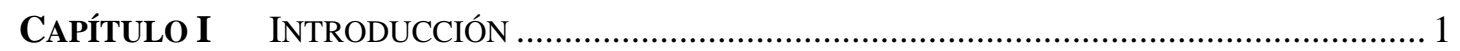

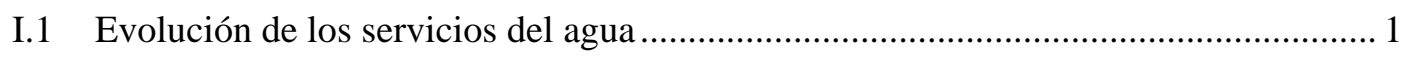

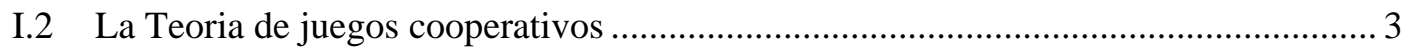

I.3 Herramientas para el análisis económico de los recursos hídricos .............................. 3

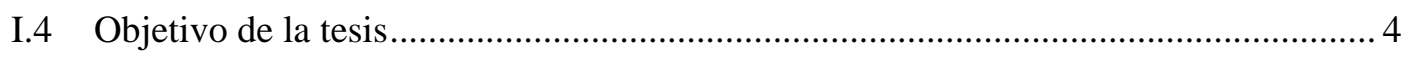

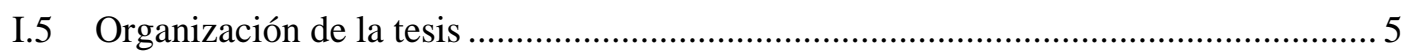

CAPÍTULO II FINANCIACIÓN DE LOS SERVICIOS DEL AGUA …............................................... 7

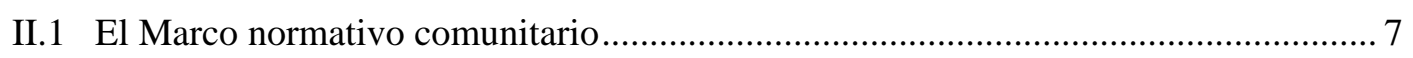

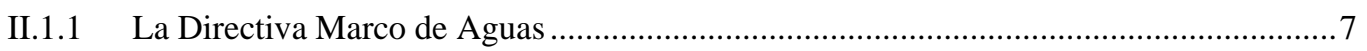

II.1.1.1 Artículo 5. Análisis económico del uso del agua. ....................................................

II.1.1.2 Artículo 9. Recuperación del coste de los servicios. ................................................

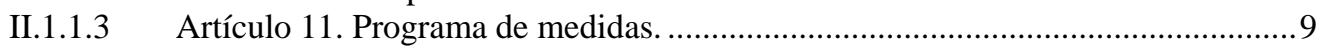

II.1.1.4 Anexo III. Contenidos del análisis económico.................................................10

II.2 Organización de los servicios del agua en España.................................................... 11

II.2.1 Servicios de captación, embalse y transporte.....................................................................11

II.2.2 Servicios de abastecimiento, alcantarillado y depuración de aguas urbanas....................12

II.2.3 Servicios de distribución del agua de riego...................................................................12

II.3 Régimen económico-financiero de las aguas continentales en España ....................... 13

II.3.1 Tributos sobre el uso del dominio público hidráulico:....................................................14

II.3.1.1 Canon de utilización de los bienes del dominio público hidráulico. ......................14

II.3.2 Tributos recuperadores del coste de las infraestructuras:................................................15

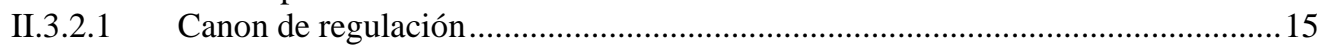

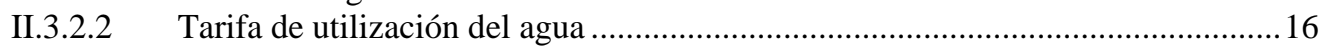

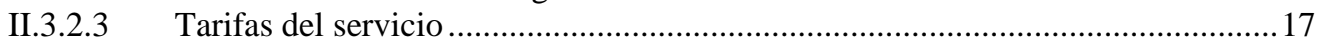

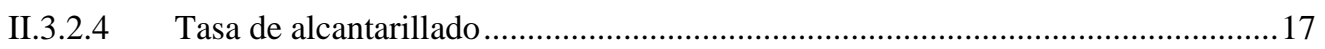

II.3.2.5 Tarifas y derramas del servicio de distribución de agua para riego.........................18

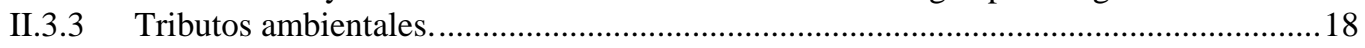

II.3.3.1 Competencia estatal: canon de control de vertidos............................................18

II.3.3.2 Competencia autonómica: cánones de saneamiento autonómicos..........................19

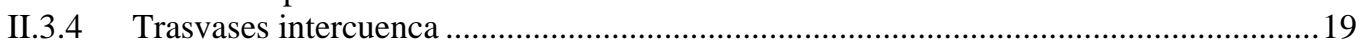

II.4 El principio de la recuperación de los costes en la legislación española ..................... 20

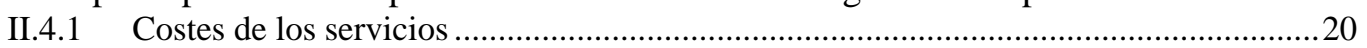

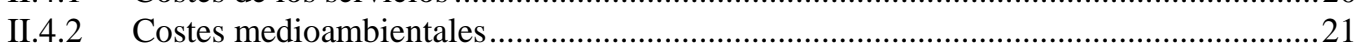

II.4.3 El coste del recurso …………………………….................................................22

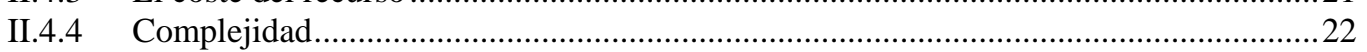

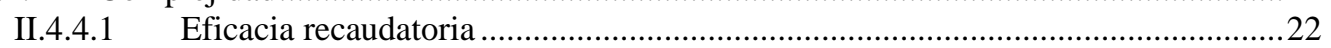


II.4.4.2 Contribución adecuada de los usuarios ............................................................23

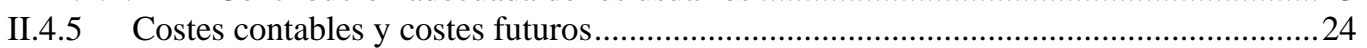

CAPÍTULO III ASIGNACIÓN DE COSTES: CONCEPTOS, MÉTODOS Y APLICACIONES.............. 25

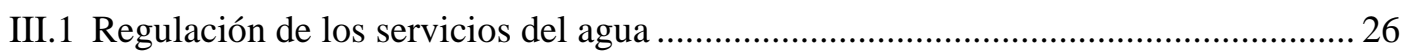

III.1.1 Modelos de uso de agua y análisis económico..............................................................22

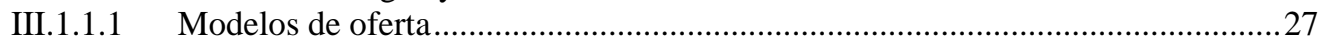

III.1.1.2 Modelos de demanda.....................................................................................28

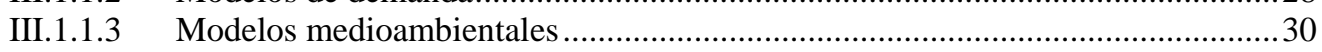

III.2 El monopolio natural y la regulación de los servicios hídricos ..................................... 31

III.2.1 La fijación del precio en un monopolio natural ...............................................................31

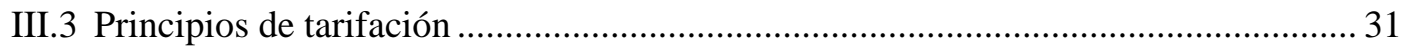

III.3.1 Eficiencia económica, justicia distributiva y equidad ........................................................31

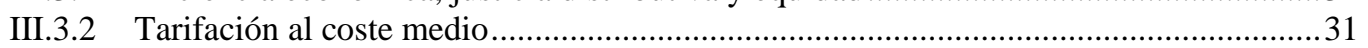

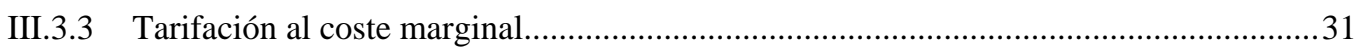

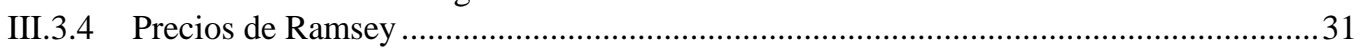

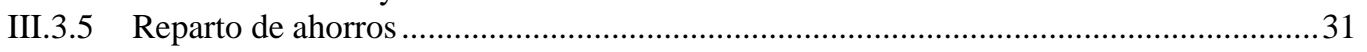

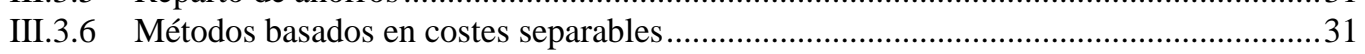

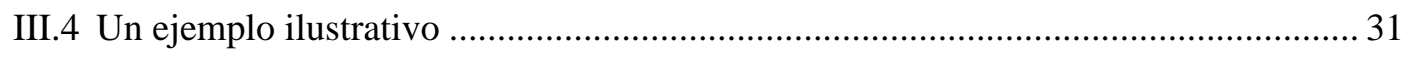

III.5 Equidad, eficiencia y procesos de negociación........................................................ 31

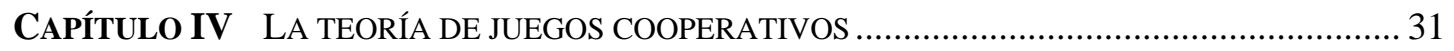

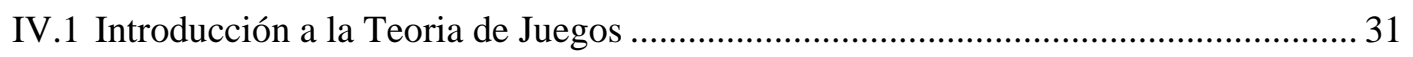

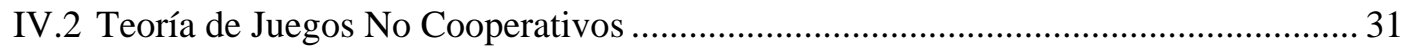

IV.3 Teoría de Juegos Cooperativos ........................................................................... 31

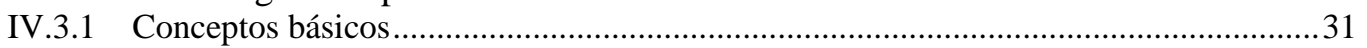

IV.3.2 Función característica y configuración de pagos ................................................................31

IV.3.3 Principios de equidad, racionalidad y eficiencia en la TJC.............................................

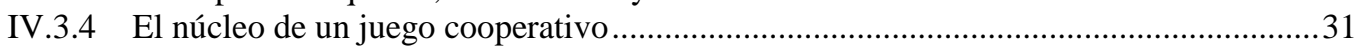

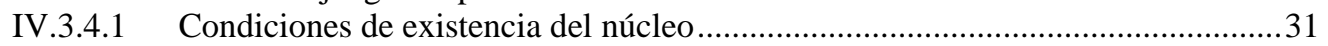

IV.3.5 Extensiones del núcleo: cuasi núcleos y nucleolos ...........................................................31

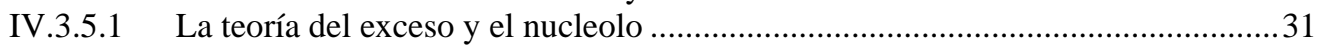

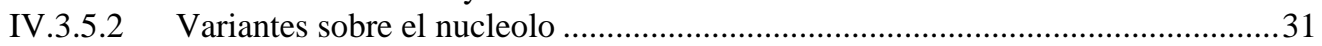

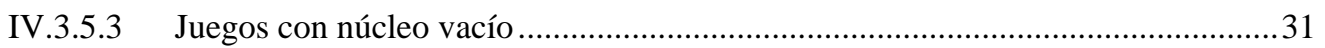

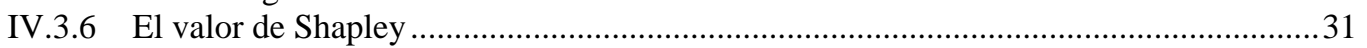

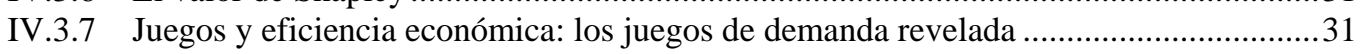

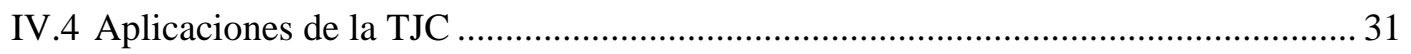

IV.5 Aplicación de la TJC a la asignación de los costes de los servicios del agua............. 31

CAPÍTULO V MODELOS DE GESTIÓN DE RECURSOS HÍDRICOS ............................................. 31

V.1 Modelos de gestión hidrológico-económicos: antecedentes ........................................ 31

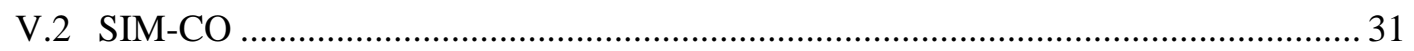

V.2.1 Evaluación del coste de los servicios del agua en cada punto del sistema........................31

V.2.1.1 Caracterización económica de los elementos del sistema ..........................................31

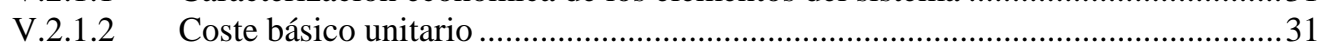

V.2.1.3 Definición de la red de flujo....................................................................................31

V.2.1.4 Definición del sistema de ecuaciones asociado a la red de flujo ..............................31

V.2.1.5 Resultados del proceso de evaluación de costes......................................................31

V.2.2 Definición de las tarifas y recuperación de costes .............................................................31

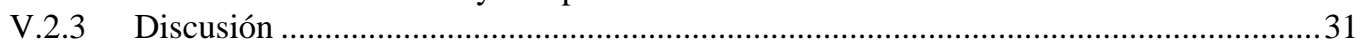

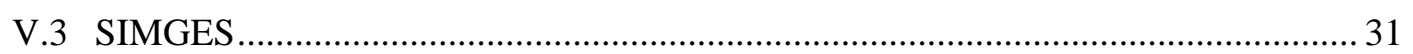

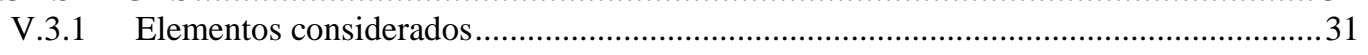

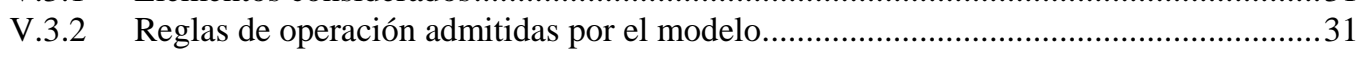

V.3.3 Explicación del funcionamiento del modelo...............................................................31 
V.3.4 Utilidad del modelo SIMGES .............................................................................

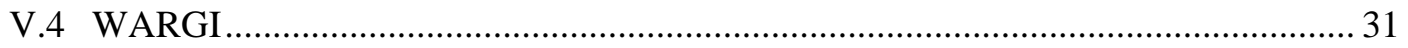

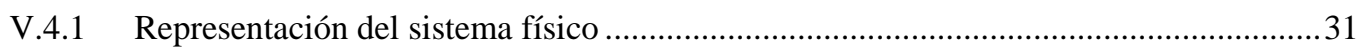

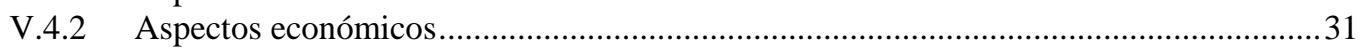

V.4.3 El proceso de optimización ............................................................................................

V.4.4 Modificaciones aportadas al programa WARGI...............................................................

V.5 Indicadores de eficiencia en la gestión de los servicios del agua .................................. 31

V.5.1 Criterios prácticos de garantía .........................................................................................31

V.5.2 Criterios utilizados en España...................................................................................

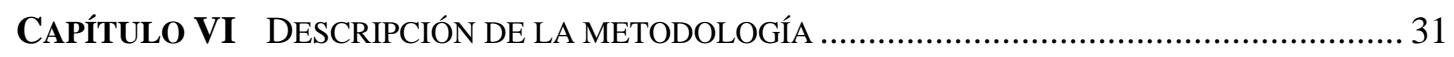

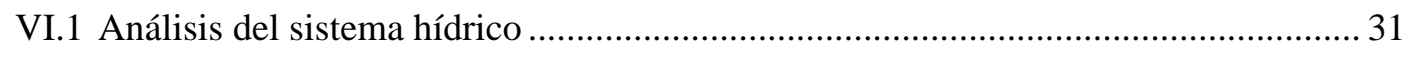

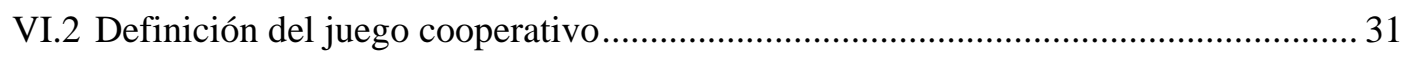

VI.3 Cálculo de la Función Característica ..................................................................... 31

VI.3.1 Responsabilidad de los usuarios en el uso del sistema.....................................................31

VI.3.2 Cálculo del coste para cada coalición ..............................................................................31

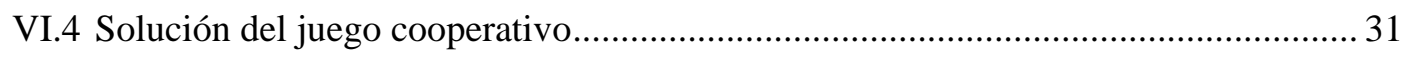

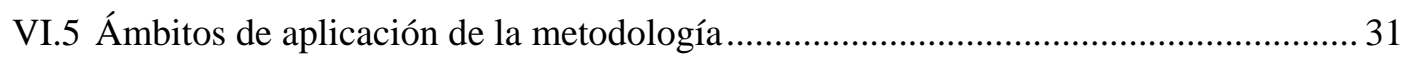

CAPÍTUlO VII APLICACIÓN DE LA METODOLOGÍA AL CASO DEL RÍO TURIA …...................... 31

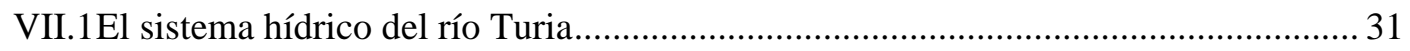

VII.1.1 Descripción general del sistema....................................................................................

VII.1.2 Prioridades y reglas de gestión. ……………………........................................................31

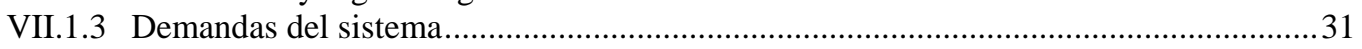

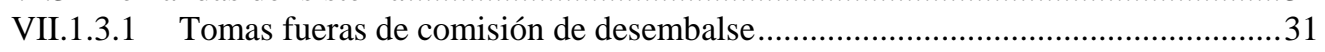

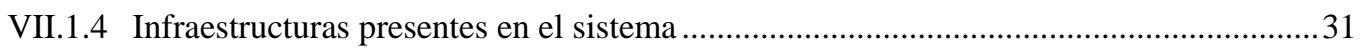

VII.1.5 Simulación de la asignación del recurso mediante SIMGES ...........................................31

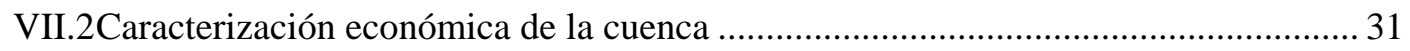

VII.2.1 Cálculo de las funciones de coste ..............................................................................31

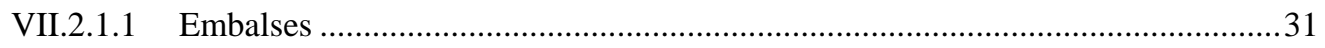

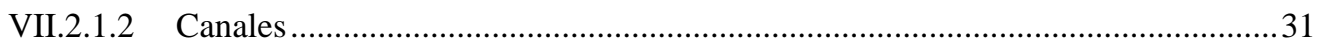

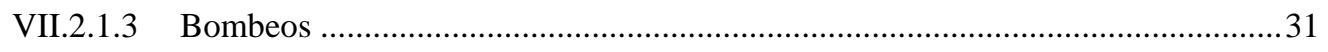

VII.2.1.4 Reutilización. .....................................................................................................

VII.2.1.5 Desalinización.....................................................................................................31

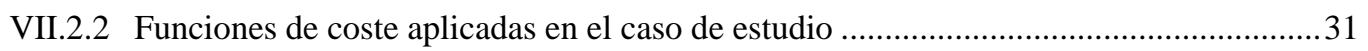

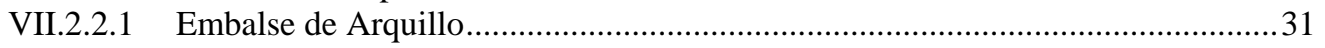

VII.2.2.2 Embalse de Benagéber .........................................................................................31

VII.2.2.3 Embalse de Loriguilla ........................................................................................

VII.2.2.4 Canales y obras de distribución................................................................................31

VII.2.2.5 Instalaciones de bombeo ................................................................................... 31

VII.2.2.6 Reutilización de las aguas residuales del área urbana de Valencia .........................31

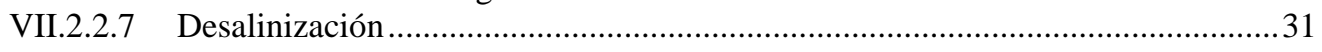

VII.3Definición del juego y formación de las coaliciones ................................................ 31

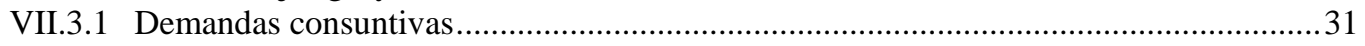

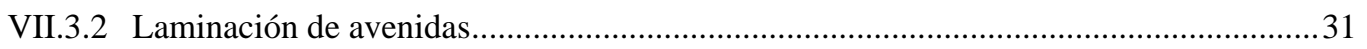

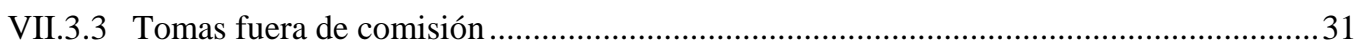

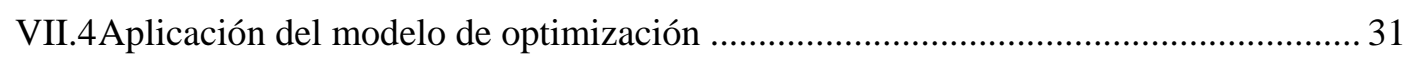

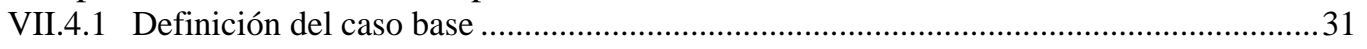

VII.4.2 Optimización de las coaliciones....................................................................................31

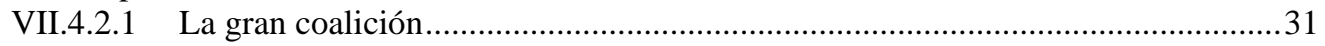

VII.4.2.2 La función característica ....................................................................................31

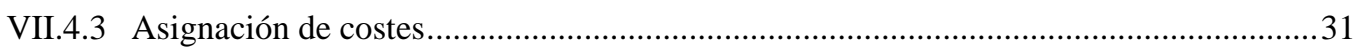

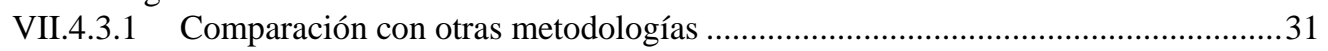


VII.5Consideraciones ........................................................................................ 31

VII.5.1 Núcleo y asignación de costes ...........................................................................31

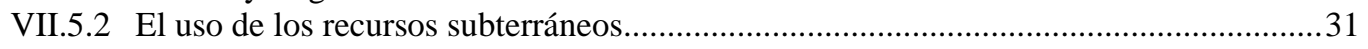

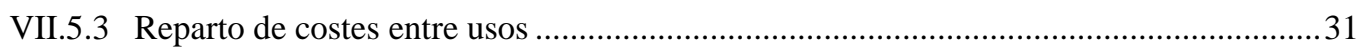

VII.5.4 Laminación de avenidas y regulación de caudales.....................................................31

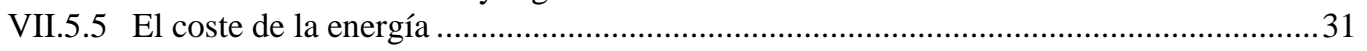

CAPÍTULO VIIIASIGNACIÓN DEL COSTE DE NUEVAS ACTUACIONES .................................. 31

VIII.1 Definición del juego y formación de coaliciones.......................................... 31

VIII.2 Cálculo de la función característica ....................................................... 31

VIII.3 Propuesta de solución mediante subvenciones públicas ................................. 31

VIII.4 Modificación del criterio de formación de coaliciones................................. 31

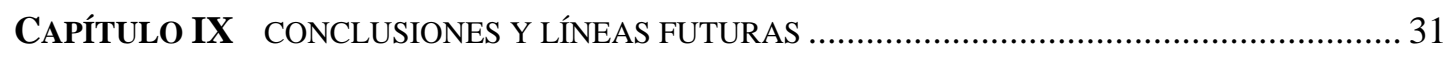

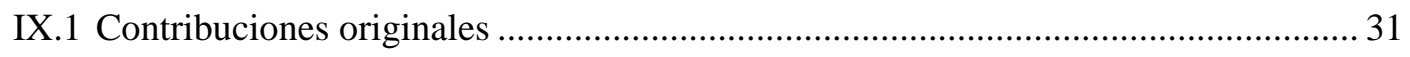

IX.2 Líneas futuras de investigación.................................................................... 31

CAPÍtUlo X CONCLUSIONI E LINEE FUTURE ........................................................... 31

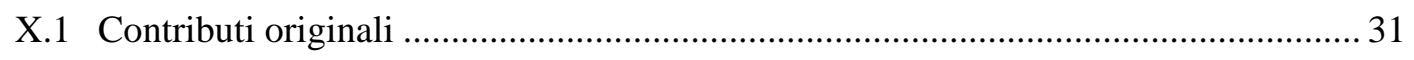

X.2 Linee future di ricerca ......................................................................... 31

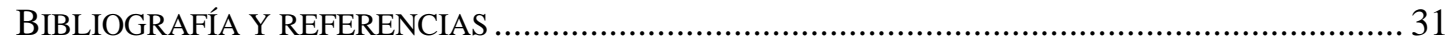




\section{ÍNDICE DE FIGURAS}

Figura 1: Monopolio natural, fijación del precio. ....................................................................... 31

Figura 2: Tarifación basada en el coste marginal....................................................................... 31

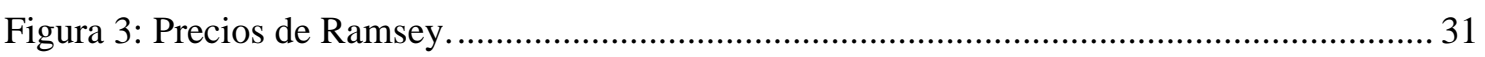

Figura 4: Caso de ejemplo de asignación de costes. ................................................................... 31

Figura 5: Caso de ejemplo, serie histórica de aportaciones. ....................................................... 31

Figura 6: Caso de ejemplo, demandas mensuales. …................................................................. 31

Figura 7: Caso de ejemplo, eficiencia de las agregaciones de usuarios. .................................... 31

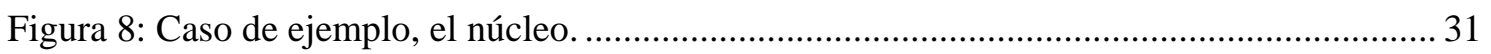

Figura 9: SIMCO, generación de la matriz estructural. ............................................................... 31

Figura 10: SIMCO, ordenación de la red de flujo...................................................................... 31

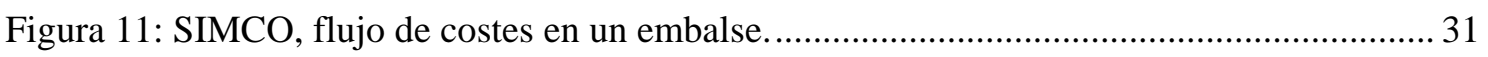

Figura 12: SIMCO, sistema de ecuaciones asociado a la red de flujo. ...................................... 31

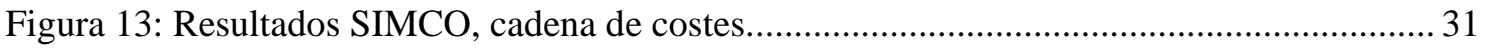

Figura 14: Resultados SIMCO, series de costes....................................................................... 31

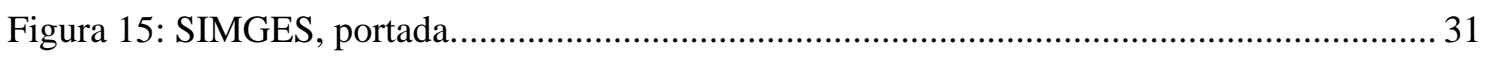

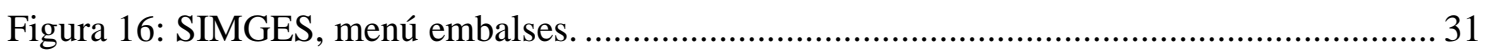

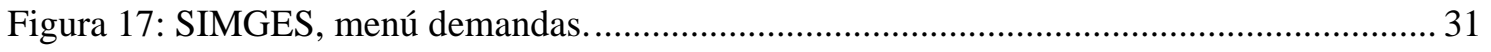

Figura 18: Esquema de un SRH elaborado mediante SIMGES. ............................................. 31

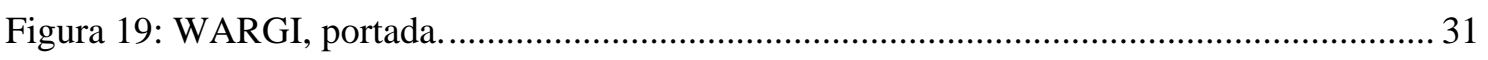

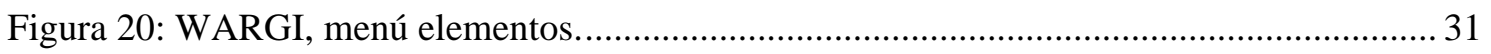

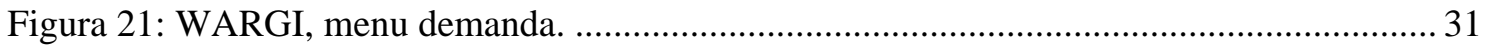

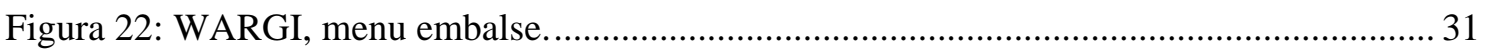


Figura 23: WARGI, esquema conceptual de un sistema hídrico.............................................. 31

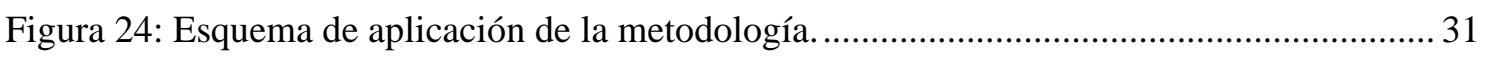

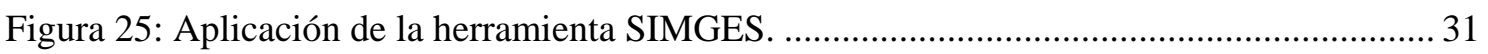

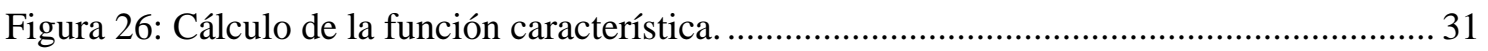

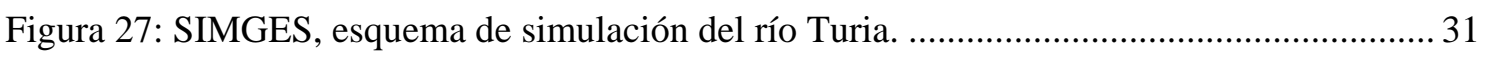

Figura 28: Curvas de la distribución porcentual mensual de las demandas. ................................ 31

Figura 29: Simulación del sistema Turia, aportaciones. .......................................................... 31

Figura 30: Simulación del sistema Turia, volúmenes almacenados........................................... 31

Figura 31: Simulación del sistema Turia, déficit anual a las demandas..................................... 31

Figura 32: Bombeos, parametrización de costes (MIMAM, 2000).......................................... 31

Figura 33: EDAM, coste de inversión en m³/día del agua desalinizada (Fariñas, 1999)............. 31

Figura 34: EDAS, coste de inversión en m³/día del agua desalinizada (Fariñas, 1999)............... 31

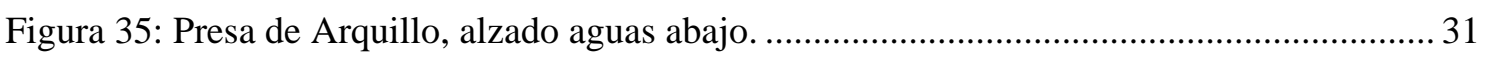

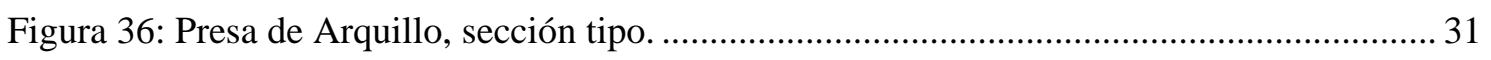

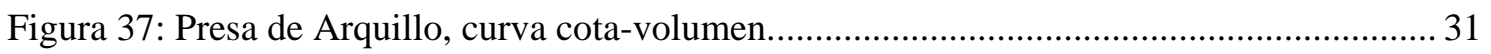

Figura 38: Presa de Arquillo, función de coste. ........................................................................... 31

Figura 39: Presa de Benagéber, alzado aguas abajo.................................................................... 31

Figura 40: Presa de Benagéber, sección tipo............................................................................ 31

Figura 41: Presa de Benagéber, curva cota-volumen................................................................. 31

Figura 42: Presa de Benagéber, función de coste......................................................................... 31

Figura 43: Presa de Loriguilla, alzado aguas abajo................................................................... 31

Figura 44: Presa de Loriguilla, sección tipo............................................................................... 31

Figura 45: Presa de Loriguilla, curva cota-volumen................................................................... 31

Figura 46: Presa de Loriguilla, función de coste........................................................................... 31

Figura 47: Canal Campo del Turia, función de coste.................................................................. 31

Figura 48: Benagéber, volúmenes autorizados........................................................................ 31

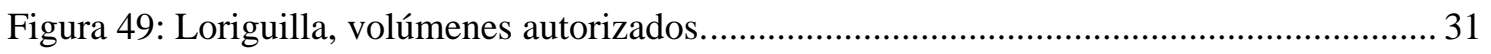


Figura 50: WARGI, esquema de simulación del río Turia........................................................ 31

Figura 51: Gran coalición, volúmenes requeridos en los embalses............................................ 31

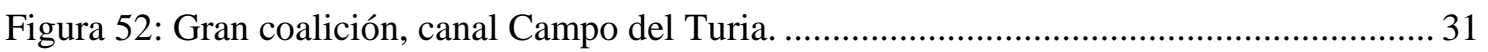

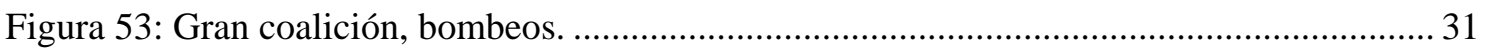

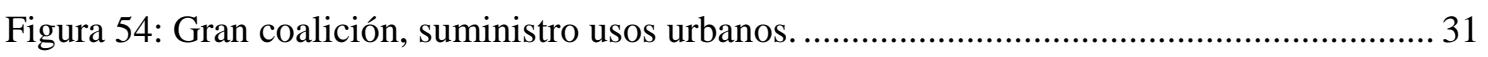

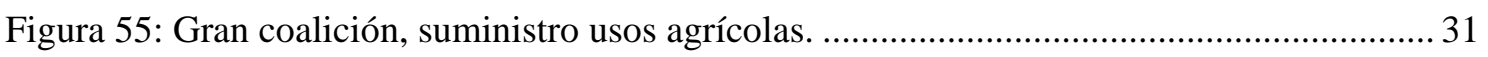

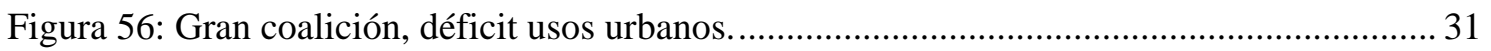

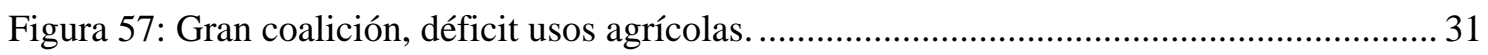

Figura 58: Gran coalición, reparto de coste de las infraestructuras. ........................................... 31

Figura 59: Gran coalición, reparto del coste según el tipo de infraestructura............................. 31

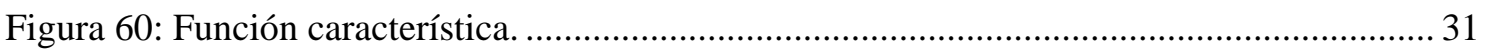

Figura 61: Condición de eficiencia de la gran coalición........................................................... 31

Figura 62: Valor de Shapley, asignación de costes (valores en M€)......................................... 31

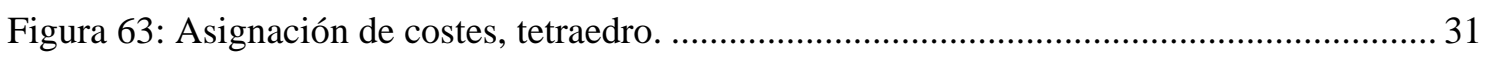

Figura 64: Incremento de las extracciones en el Campo del Turia. ............................................. 31

Figura 65: Valor de Shapley sin costes de bombeo y canal (valores en M€)............................... 31

Figura 66: Aumento del coste de la energía, eficiencia de la gran coalición. ............................. 31

Figura 67: Aumento del coste de la energía, reparto de costes (valores en M€).......................... 31

Figura 68: Aumento del coste de la energía, tetraedro................................................................ 31

Figura 69: Nuevas actuaciones, volúmenes de los embalses. ..................................................... 31

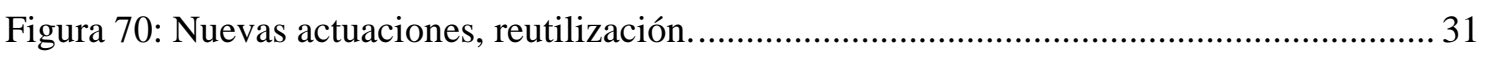

Figura 71: Nuevas actuaciones, desalinización.......................................................................... 31

Figura 72: Nuevas actuaciones, función característica. ................................................................. 31

Figura 73: Nuevas actuaciones, condición de eficiencia............................................................... 31

Figura 74: Nuevas actuaciones, caso modificado, función característica................................... 31

Figura 75: Nuevas actuaciones, caso modificado, condición de eficiencia. ................................. 31

Figura 76: Nuevas actuaciones, caso modificado, tetraedro. ..................................................... 31 
ÍNDICE DE FIGURAS

$X X$ 


\section{ÍNDICE DE TABLAS}

Tabla 1: Organización de los servicios del agua en España (MIMAM, 2007)

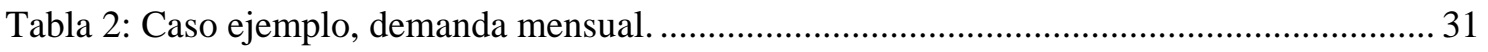

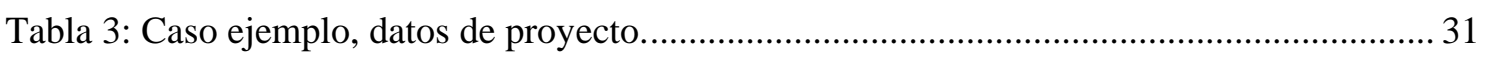

Tabla 4: Caso de ejemplo, reparto de coste volumétrico. .............................................................. 31

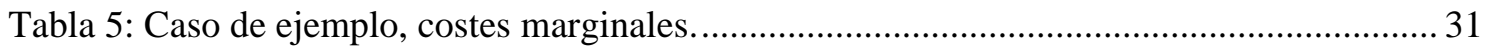

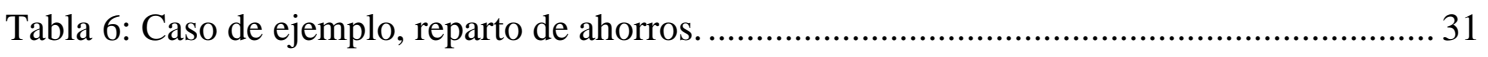

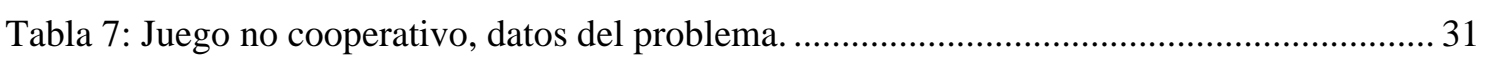

Tabla 8: Nivel de garantía para demandas urbanas (MMARM, 2008) ........................................ 31

Tabla 9: Nivel de garantía para demandas agrarias (MMARM, 2008) ........................................ 31

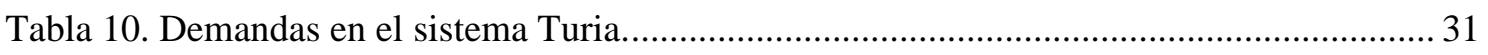

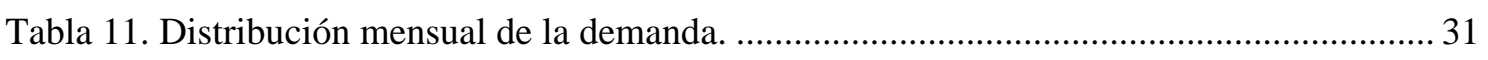

Tabla 12: Presas, otras partidas de costes (MIMAM, 2000) ...................................................... 31

Tabla 13: Canales en tierra, parámetros de diseño (MIMAM, 2000) .......................................... 31

Tabla 14: Canales en roca, parámetros de diseño (MIMAM, 2000) ............................................ 31

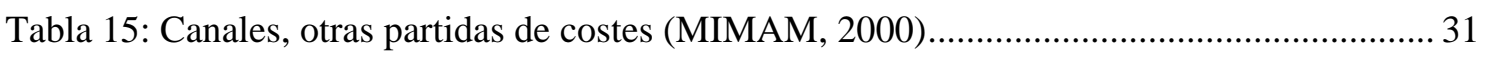

Tabla 16: Bombeos, otras partidas de costes (MIMAM, 2000), .................................................. 31

Tabla 17: Coste regeneración tratamiento tipo 1 (CEDEX, 2008)................................................ 31

Tabla 18: Coste regeneración tratamiento tipo 2 (CEDEX, 2008)............................................. 31

Tabla 19: Coste regeneración tratamiento tipo 4 EDR (CEDEX, 2008)..................................... 31

Tabla 20: Coste regeneración tratamiento tipo 4 OI (CEDEX, 2008). ......................................... 31

Tabla 21: Métodos de desalinización (Valero et al., 2001).......................................................... 31

Tabla 22: Características deseables de los métodos de desalinización (Valero et al., 2001)...... 31 
Tabla 23: Desalinización de agua de mar, coste energía.

Tabla 24: Desalinización, porcentaje de inversión y periodo de amortización (Fariñas, 1999).. 31

Tabla 25: Presa de Arquillo de San Blas, características. 31

Tabla 26: Presa de Arquillo, tabla altura-longitud-volumen-coste. ............................................. 31

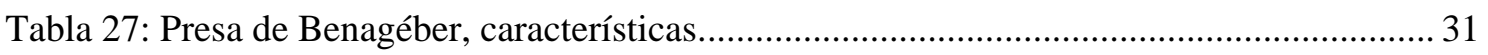

Tabla 28: Presa de Benagéber, tabla cota-longitud-volumen-coste. .......................................... 31

Tabla 29: Presa de Loriguilla, características técnicas................................................................ 31

Tabla 30: Presa de Loriguilla, tabla cota-longitud-volumen-coste. ............................................. 31

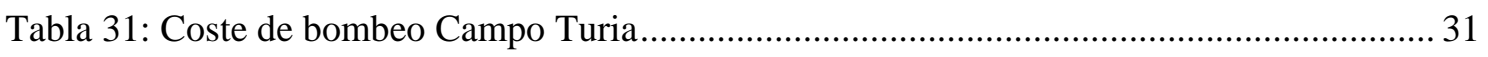

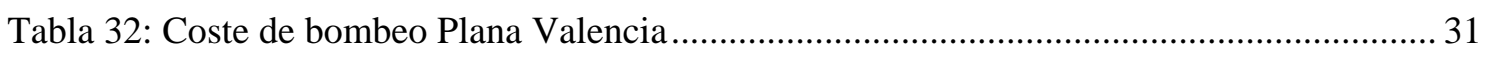

Tabla 33: Niveles de garantía calculados en el caso base. ............................................................ 31

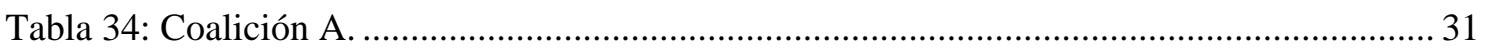

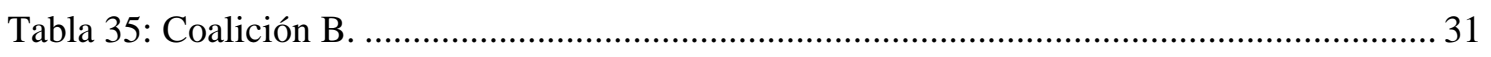

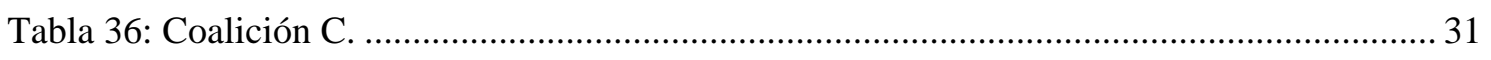

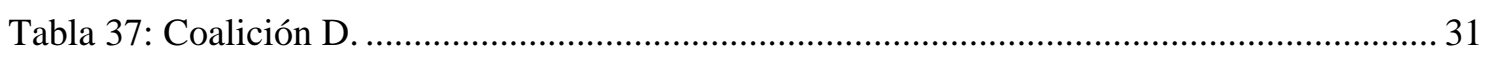

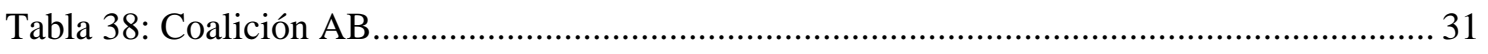

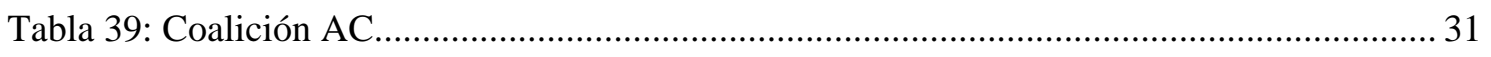

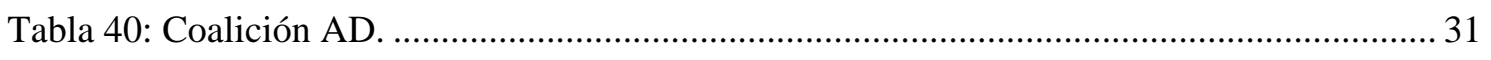

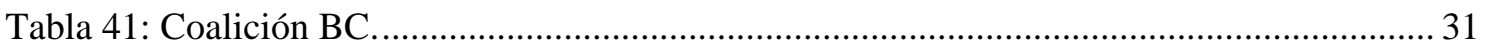

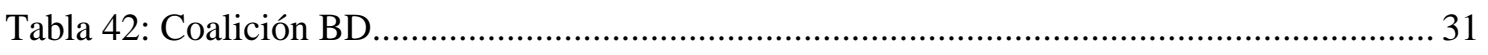

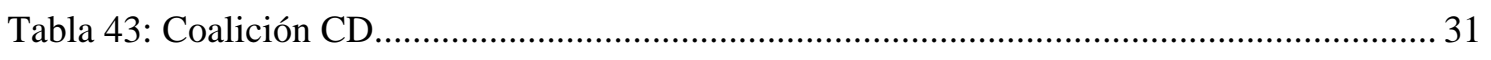

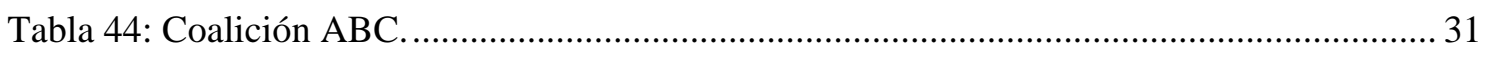

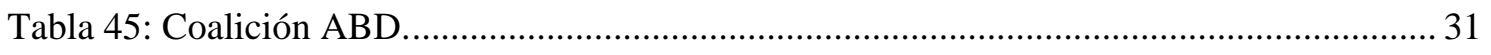

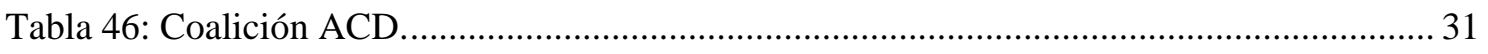

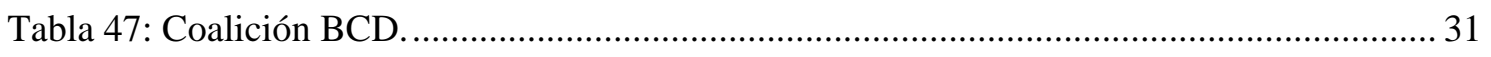

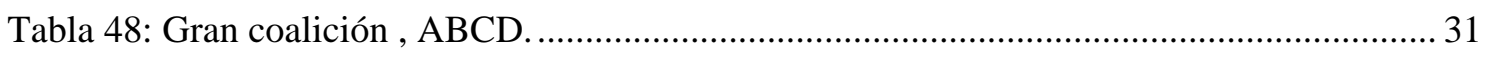

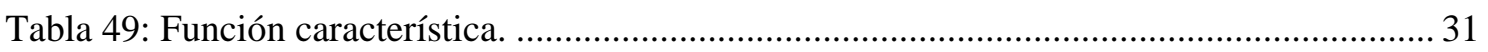


Tabla 50: Valor de Shapley, contribución marginal de los jugadores......................................... 31

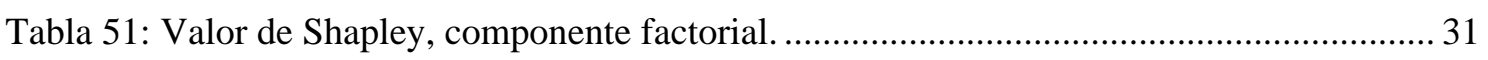

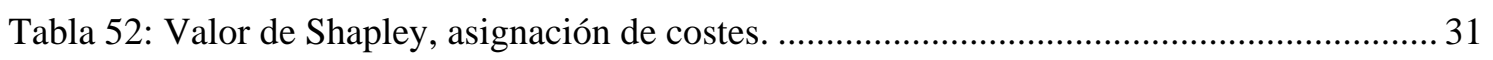

Tabla 53: Volúmenes suministrados a las demandas. .................................................................... 31

Tabla 54: Metodologías de asignación de costes, tabla comparativa......................................... 31

Tabla 55: Comprobación de pertenencia al núcleo. ............................................................... 31

Tabla 56: Uso conjunto de embalses de laminación y regulación.................................................. 31

Tabla 57: Aumento del coste de la energía, función característica............................................. 31

Tabla 58: Disminución de las aportaciones por efecto del cambio climático (MMARM, 2008).

Tabla 59: Nuevas actuaciones, déficit de suministro a las demandas. ........................................ 31

Tabla 60: Nuevas actuaciones, costes de regeneración y desalinización...................................... 31

Tabla 61: Nuevas actuaciones, función característica.................................................................. 31

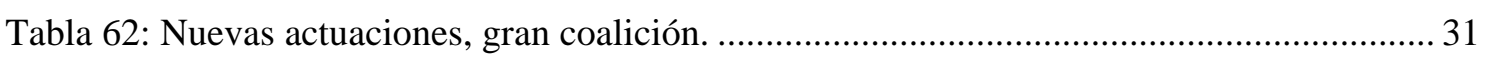

Tabla 63: Nuevas actuaciones, caso modificado, función característica..................................... 31

Tabla 64: Nuevas actuaciones, caso modificado, asignación de costes. ...................................... 31

Tabla 65: Nuevas actuaciones, caso modificado, pertenencia al núcleo....................................... 31 



\section{ÍNDICE DE SÍMBOLOS Y NOTACIONES}

La teoría de juegos, y en general los estudios de asignación de costes, se apoyan en un lenguaje simbólico formal que sigue una serie de convenciones propias. En la lista siguiente se muestran algunos símbolos y notaciones utilizadas en el texto. Si a algún símbolo le han sido adjudicados varios significados, el contexto dejará claro de cuál de ellos se trata en cada momento.

$N$ : conjunto finito que integra el número total de jugadores representados en el juego (puede englobar también el número de usuarios participantes en un proyecto).

S: indica una coalición (o agregación) genérica de jugadores.

c(i): coste que ha de soportar el jugador (o usuario) " $i$ " para satisfacer autónomamente a sus exigencias.

$c(S)$ : coste que ha de soportar la coalición de jugadores (o usuarios) S para satisfacer autónomamente a las exigencias de los jugadores que la componen.

$c(N)$ : coste total del proyecto que incluye a todos los jugadores (o usuarios)

NSC: costes no separables de un proyecto.

sc(i): coste separable asociado al usuario " $i$ ".

$b(i)$ : beneficio asociado al usuario " $i$ ".

$x_{i}$ : solución del juego, definida como el pago (coste) asignado al jugador " $i$ ".

$X_{N}$ : vector de pagos, representa el conjunto de pagos asociados a cada jugador.

$e(X, S)$ : exceso asociado al vector de pagos " $X$ " y a la coalición "S".

u(i): utilidad del jugador " $i$ ", disponibilidad de pago para el uso del agua. 
XXVI 


\section{CAPÍTULO I INTRODUCCIÓN}

\section{I.1 EVOLUCIÓN DE LOS SERVICIOS DEL AGUA}

El agua, bien básico por su condición de elemento imprescindible para la vida y factor indispensable de desarrollo social, se considera desde hace muchos años como un "bien social" en contraposición a bien puramente económico. El incremento de las obras hidráulicas que caracterizó el desarrollo del siglo XX de casi todos los países europeos ha tenido como objetivos la protección de bienes y personas y el aumento de la disponibilidad del recurso a bajo coste, para sostener el crecimiento de la población y fomentar la competitividad de ciertas actividades económicas como la agricultura y la producción energética.

Los cambios ocurridos en las ultimas décadas, tanto el fuerte aumento demográfico y de bienestar económico, junto con el masivo proceso de urbanización de las zonas costeras, así como la expansión de los sectores agrícola, turístico y recreativo, han llevado a situaciones cada vez más frecuentes de escasez del recurso y empeoramiento de su calidad.

La creciente afirmación de la conciencia ambiental de los ciudadanos, los conflictos políticos entre administraciones y los factores técnicos relacionados con la carencia de sitios idóneos para nuevas infraestructuras, plantean la necesidad de nuevas inversiones en la mejora del estado ecológico de las masas de agua y originan enormes dificultades en la realización de nuevas obras de regulación y trasporte, lo que resalta la necesidad de una mayor eficiencia y coordinación en la gestión y planificación de los recursos hídricos.

Por otro lado la implantación de nuevas políticas económicas más restrictivas, por parte de los gobiernos nacionales y de los organismos financieros europeos, impone sensibles restricciones al tradicional modelo de financiación del dominio público hidráulico basado principalmente en subvenciones públicas. 
La fase actual, común a muchos países desarrollados, se denomina economía madura del agua (Randall 1981) y se caracteriza por:

- costes elevados para el incremento de la oferta de agua;

- directa e intensa competencia entre los usuarios;

- interdependencia entre usos y fuertes limitaciones medioambientales;

- limitada disponibilidad de recursos financieros públicos, recuperación de los costes de los servicios del agua.

Los problemas que esta fase plantea imponen nuevas políticas de gestión que superen el enfoque tradicional, orientado principalmente a la maximización de la oferta, y comprendan aspectos fundamentales como la internalización de los costes relacionados con el uso del agua, la gestión de la demanda y la racionalización y eficiencia económica de las inversiones públicas.

La reciente normativa europea en materia de recursos hídricos (Directiva Marco de Aguas 2000/60/CE) trata de responder a estas nuevas necesidades impulsando el principio de recuperación de costes de los servicios del agua con el objetivo de promover la mejora ambiental del medio hídrico mediante un aumento de la eficiencia y racionalidad en la asignación del recurso y en la realización de nuevas infraestructuras hidráulicas.

También hay que destacar que históricamente en España la tarifa agregada del agua representa una parte minoritaria de los costes de los servicios; por eso las políticas tarifarias han tenido una importancia solo relativa en la gestión del agua, siendo una parte importante de las preocupaciones de los gestores la captación de subvenciones que paliasen las deficiencias de financiación (Fernández y Revilla, 1994). La progresiva aplicación del principio de autosuficiencia tarifaria acabará otorgando a las tarifas del agua un papel central en la gestión y un mayor protagonismo en la financiación de las obras hidráulicas, una vez suprimidas las subvenciones públicas.

En este contexto, el establecimiento de unas políticas tarifarias solidamente fundamentadas a través de un estudio detallado de asignación de costes se considera una tarea fundamental para garantizar la viabilidad financieras de las inversiones y lograr acuerdos vinculantes entre los usuarios en la gestión de los servicios hidráulicos.

En el presente trabajo se ha llevado a cabo una revisión de los distintos criterios que guían los procesos de asignación de costes y se ha propuesto una metodología basada en la Teoría de Juegos Cooperativos que responde a los requisitos de garantizar la eficiencia económica de las actuaciones y fomentar el consenso entre los usuarios. 


\section{I.2 LA TEORIA DE JUEGOS COOPERATIVOS}

La Teoría de Juegos Cooperativos (en adelante TJC) ha demostrado ser una herramienta eficaz en la tarea de asignación de costes comunes. Su fortaleza reside en la capacidad de implementar, a través de formulaciones matemáticas, los principios de eficiencia, equidad y aceptabilidad que guían los procesos de reparto justo de costes.

El planteamiento teórico de la teoría de juegos consiste en la modelización de un sistema de varios agentes que interactúan en la gestión de un servicio o producción de un bien de manera racional (con el objetivo de maximizar el beneficio individual) y, por lo tanto, están interesados en agruparse formando coaliciones en la medida que puedan obtener un beneficio en términos de reducción de costes o mejora de la eficiencia económica. La teoría de juegos cooperativos permite analizar los procesos de negociación, en los que se fundamentan los acuerdos de cooperación, a través de la axiomatización de las expectativas de los usuarios e interpretar y adelantarse a la toma de decisiones.

Sin embargo, la aplicación de la teoría de juegos se ha limitado hasta ahora al ámbito de las ciencias económicas o matemáticas, quedando en ocasiones muy distante de la complejidad y de la heterogeneidad de los problemas de carácter ingenieril. El cálculo de la función característica de un juego cooperativo requiere un análisis del coste mínimo asociado a cada posible coalición del sistema, lo que implica un proceso de optimización cuya magnitud crece exponencialmente en razón del número de agentes del sistema. La necesidad de disponer de adecuadas herramientas de modelización para simular la generación de escenarios de coalición ha sido el principal obstáculo a la hora de abordar los problemas de asignación de costes en sistemas complejos.

\section{I.3 HERRAMIENTAS PARA EL ANÁLISIS ECONÓMICO DE LOS RECURSOS HÍDRICOS}

El proceso de asignación de coste de los servicios hidráulicos a escala de cuenca está caracterizado por una elevada interconexión entre los elementos del sistema (el entorno físico, las infraestructuras, las demandas), una regla de gestión establecida, y por la variabilidad aleatoria de los recursos disponibles. Una excesiva simplificación de estos factores puede conducir a una incorrecta interpretación del funcionamiento del sistema, y finalmente a errores significativos en los resultados económicos. 
La metodología desarrollada en esta tesis está basada en el uso combinado de los algoritmos de teoría de juegos y de los modelos de simulación y optimización de la gestión de los sistemas hídricos.

La nueva propuesta metodológica realiza una integración de los aspectos económicos en los tradicionales modelos de gestión de recursos hídricos. Sus principales características son:

- Análisis económico integrado a escala de cuenca. La cuenca hidrográfica es considerada la escala ideal para la estimación del coste del recurso (Directiva Marco de Aguas, 2000/60/CE);

- Caracterización económica de los servicios del agua. Las infraestructuras del sistema son caracterizadas por un coste de amortización de la inversión, de mantenimiento y de explotación que se repercute a los usuarios del sistema según el nivel de utilización de la infraestructura, dependiendo de la localización de la infraestructura y del estado hidrológico de la cuenca.

- Responsabilidad de los usuarios en el uso de los servicios del agua. Se pretende determinar las condiciones que relacionan los niveles de servicio requeridos por un usuario del agua con el coste que estos implican en términos de infraestructuras y servicios hidráulicos.

El uso de modelos de simulación y de optimización de recursos hídricos a escala de cuenca permite la implementación de los algoritmos de la teoría de juegos cooperativos en sistemas hídricos complejos y contribuye al proceso de asignación de costes y definición de tarifas de los servicios del agua.

\section{I.4 OBJETIVO DE LA TESIS}

El objetivo principal de la tesis es el desarrollo de una metodología basada en la aplicación de la teoría de juegos cooperativos que contribuya al proceso de definición de las tarifas de los servicios del agua, conforme con los criterios de recuperación de costes, equidad y eficiencia enunciados por la DMA.

La metodología desarrollada ha de ser de carácter genérico o general, adaptable a las condiciones de distintos sistemas hídricos y compatible con las herramientas en uso para la modelización de cuencas hidrográficas y de los sistemas hidráulicos. Su ámbito de aplicación se extenderá a la solución de problemas de asignación de costes, tanto de carácter local (actuaciones singulares y mancomunadas), como a nivel regional (planes de tarifas para la gestión multipropósito y multiagente de las obras hidráulicas). Se pretende implementar dicha metodología mediante las herramientas de simulación 
(SIMGES, Andreu et al. 1996) y optimización (WARGI, Sechi G.M. e Zuddas P., 2002), actualmente en uso para la planificación y gestión de recursos hídricos a escala de cuenca.

La metodología debe permitir la caracterización económica de todos los elementos constituyentes de un sistema hidráulico y su modelización en función de distintos escenarios de gestión. Tiene, además, que considerar los efectos de la variabilidad hidrológica y de los usos del agua con el fin de proporcionar soluciones robustas para un horizonte de aplicación de las tarifas tanto a corto como a largo plazo. Cabe esperar que la definición de unas políticas de precio más rigurosas actúe de estímulo para la selección de actuaciones más eficientes y la reducción de la conflictividad entre sujetos interesados.

Se propone la aplicación de la metodología para la asignación de los costes de las infraestructuras en la cuenca del río Turia, situada en las provincias de Valencia y Teruel.

\section{I.5 ORGANIZACIÓN DE LA TESIS}

La tesis se estructura en diez capítulos, incluyendo el primer capítulo introductorio, organizados de la siguiente forma:

En el Capítulo II se presenta un análisis crítico del marco normativo que regula la gestión de los servicios del agua. Se efectuará una revisión de la normativa nacional en materia de tarifas de los servicios hidráulicos, tratando de evidenciar sus logros y limitaciones respecto a los principios enunciados por la normativa europea vigente.

En el Capítulo III se ofrece una revisión de las metodologías de asignación de los costes de los servicios del agua, y de las políticas de precios, a través del análisis del contexto histórico, económico y normativo en los que se desarrollan los usos hídricos.

En el Capítulo IV se define el marco teórico en el que se realiza un juego, y los distintos algoritmos propuestos por la teoría e juegos para su solución, con especial atención a los juegos cooperativos. Se revisarán distintos casos de aplicación a los problemas de asignación de costes y se analizarán las complejidades inherentes a la aplicación de la teoría de juegos al problema del reparto de costes de los servicios del agua.

El Capítulo V versa sobre los modelos matemáticos para la planificación y gestión de los sistemas de recursos hídricos. Se ofrece una revisión de los 
modelos actualmente en uso, con especial atención a los modelos que integran variables hidrológicas y económicas. A continuación se describen con detalle las herramientas utilizadas en esta tesis: el modelo de simulación SIMGES (Andreu et al., 1996) y el modelo de optimización WARGI (Sechi y Zuddas, 2002).

En el Capítulo VI se describe la metodología desarrollada para la asignación de costes de los servicios basada en el uso de herramientas de gestión de sistemas de recursos hídricos y en la aplicación de la teoría de juegos cooperativos.

El Capítulo VII presenta una aplicación de la metodología al reparto de costes de las infraestructuras de la cuenca del río Turia. Se define el esquema conceptual del sistema hídrico y se obtienen las funciones de coste de las principales obras hidráulicas. A continuación se plantea el juego de asignación de costes y se obtiene el reparto de los mismos entre los usuarios del agua mediante la aplicación del algoritmo de Shapley (Shapley, 1953).

En el Capítulo VIII se realiza una aplicación de la metodología a la asignación de coste de nuevas actuaciones. Se propone un escenario futuro de gestión del sistema Turia caracterizado por la reducción de los recursos disponible y el aumento de la demanda y se plantea un juego de asignación del coste de las nuevas inversiones entre los sujetos beneficiarios.

Finalmente, en el Capítulo IX se exponen las conclusiones de este trabajo, se resumen las contribuciones originales, y se indican las posibles líneas futuras de investigación.

En el Capítulo $X$ se ofrece una traducción en lengua italiana de las conclusiones de la tesis, en cumplimiento de los requisitos dictados por el Art. 22 del Real Decreto 1393/2007 para conseguir la mención europea en el título de doctor. 


\section{CAPÍTULO II}

\section{FINANCIACIÓN DE LOS SERVICIOS DEL AGUA}

En el presente capítulo se pretende realizar un análisis crítico del marco normativo que regula la gestión de los recursos hídricos, con especial atención hacia los aspectos económicos. Se efectuará una revisión de la normativa nacional en materia de políticas tarifarias y de asignación del agua, tratando de evidenciar sus logros y limitaciones respecto a los principios enunciados por la normativa europea vigente.

\section{II.1 EL MARCO NORMATIVO COMUNITARIO}

\section{II.1.1 La Directiva Marco de Aguas}

Uno de los factores que más han contribuido a impulsar el cambio de orientación de la política del agua de los Estados miembros de la UE es la Directiva 2000/60/CE del Parlamento Europeo y del Consejo, de 23 de octubre de 2000, comúnmente conocida como DMA (DMA).

En la línea de incrementar la utilización de instrumentos económicos para favorecer la racionalización del consumo, la DMA contempla la necesidad de establecer en cada demarcación hidrográfica un programa de medidas (Art. 11) con el fin de alcanzar los objetivos ambientales previstos en el Art. 4, que incluya los aspectos relativos a la recuperación de los costes de los servicios relacionados con el agua, incluidos los costes medioambientales y los relativos a los recursos (Art. 9), teniendo en cuenta los resultados del análisis económico del uso del agua (Art. 5 y Anexo III). 


\section{II.1.1.1 Artículo 5. Análisis económico del uso del agua.}

El artículo 5 de la DMA establece que cada Estado Miembro velará por que se efectúe en cada demarcación:

- un análisis de las características de la demarcación;

- un estudio de las repercusiones de la actividad humana en el estado de las aguas superficiales y de las aguas subterráneas;

- un análisis económico del uso del agua, de conformidad con las especificaciones técnicas fijadas en los anexos II y III.

\section{II.1.1.2 Artículo 9. Recuperación del coste de los servicios.}

"Los Estados miembros tendrán en cuenta el principio de la recuperación de los costes de los servicios relacionados con el agua, incluidos los costes medioambientales y los relativos al recurso, a la vista del análisis económico efectuado con arreglo al anexo III, y en particular de conformidad con el principio de que quien contamina paga."

Según el artículo 2 de la DMA se entiende por servicios relacionados con el agua todos los servicios en beneficio de los hogares, las instituciones públicas o cualquier actividad económica, consistentes en:

- La extracción, el embalse, el depósito, el tratamiento y la distribución de aguas superficiales o subterráneas;

- La recogida y depuración de aguas residuales, que vierten posteriormente en las aguas superficiales.

Se establece que se tenga en cuenta el principio de la recuperación de los costes a los efectos de un uso eficiente del agua, contribuyendo de este modo a los objetivos ambientales de la Directiva.

Como se puede observar, en ningún caso se plantea la recuperación íntegra de costes como objetivo ni siquiera a largo plazo, lo que resulta lógico considerando los objetivos ambientales de la Directiva y la naturaleza no comercial del agua. La lógica subyacente es que unos precios adecuados, capaces de reflejar el efectivo coste de los servicios del agua para cada uno de los usuarios, podrían implicar un uso más eficiente del recurso y, en consecuencia, un menor consumo y unas mejores condiciones ambientales. Ha de entenderse también como expresión del principio de transparencia en la economía del agua. 
“Los Estados miembros garantizarán, a más tardar en 2010:

- que la política de precios del agua proporcione incentivos adecuados para que los usuarios utilicen de forma eficiente los recursos hídricos y, por tanto, contribuyan a los objetivos medioambientales de la presente Directiva;

- una contribución adecuada de los diversos usos del agua, desglosados, al menos, en industria, hogares y agricultura, a la recuperación de los costes de los servicios relacionados con el agua, basada en el análisis económico efectuado con arreglo al anexo III y teniendo en cuenta el principio de que quien contamina paga.

Al hacerlo, los Estados miembros podrán tener en cuenta los efectos sociales, medioambientales y económicos de la recuperación y las condiciones geográficas y climáticas de la región o regiones afectadas.

Se fundamenta el principio de discriminación tarifaria al establecer que la recuperación debe caracterizarse por sectores en función de su contribución al coste de los servicios, a su garantía y prioridad, al nivel de contaminación y a su disponibilidad económica. Este planteamiento se orienta a mejorar la eficiencia de la gestión incluyendo un principio de marginalidad en la asignación de costes que tiende a limitar subvenciones cruzadas intersectoriales sin perjudicar el cumplimiento del equilibrio presupuestario. Prevé, además, elementos de ponderación socioeconómica y ambiental de la recuperación de costes, de forma que pueda, si oportunamente justificado, no tenerse en cuenta esta recuperación a partir de consideraciones sociales, económicas y geográficas.

\section{II.1.1.3 Artículo 11. Programa de medidas.}

"Los Estados miembros velarán por que se establezca para cada demarcación hidrográfica, o para la parte de una demarcación hidrográfica internacional situada en su territorio, un programa de medidas, teniendo en cuenta los resultados de los análisis exigidos con arreglo al artículo 5, con el fin de alcanzar los objetivos ambientales planteados en el artículo 4. Estos programas de medidas podrán hacer referencia a medidas derivadas de la legislación adoptada a nivel nacional y que cubran la totalidad del territorio de un Estado miembro. En su caso, un Estado miembro podrá adoptar medidas aplicables a todas las demarcaciones hidrográficas $y / o$ a las partes de demarcaciones hidrográficas internacionales situadas en su territorio."

Las «medidas básicas» son los requisitos mínimos que deberán cumplirse y consistirán, entre otros, en "las medidas que se consideren adecuadas a efectos del artículo $9^{\prime \prime}$. 


\section{II.1.1.4 Anexo III. Contenidos del análisis económico.}

"El análisis económico contendrá la suficiente información lo suficientemente detallada (teniendo en cuenta los costes asociados con la obtención de los datos pertinentes) para:

- efectuar los cálculos necesarios para tener en cuenta, de conformidad con el artículo 9, el principio de recuperación de los costes de los servicios relacionados con el agua, tomando en consideración los pronósticos a largo plazo de la oferta y la demanda de agua en la demarcación hidrográfica y, en caso necesario, las previsiones del volumen, los precios y los costes asociados con los servicios relacionados con el agua, y

- estudiar la combinación más rentable de medidas que, sobre el uso del agua, deben incluirse en el programa de medidas de conformidad con el artículo 11, basándose en las previsiones de los costes potenciales de dichas medidas."

En este anexo se define el objetivo del análisis económico previsto en el Art.5 como el de generar los datos necesarios para poder efectuar los cálculos de recuperación de costes (considerando previsiones de oferta y demanda) y para poder estudiar la combinación óptima de medidas basándose en sus previsiones de coste. 


\section{II.2 ORGANIZACIÓN DE LOS SERVICIOS DEL AGUA EN ESPAÑA}

La prestación de los servicios del agua en España está caracterizada por la participación de numerosos agentes públicos y privados, como se muestra en la siguiente tabla.

\begin{tabular}{|c|c|c|}
\hline Servicio & $\begin{array}{c}\text { Agentes } \\
\text { (Competentes o financiadores de } \\
\text { infraestructuras) }\end{array}$ & $\begin{array}{l}\text { Instrumentos de } \\
\text { "Recuperación de Costes" }\end{array}$ \\
\hline $\begin{array}{l}\text { Embalses y transporte en } \\
\text { alta (aguas superficiales) }\end{array}$ & $\begin{array}{l}\text { Organismos de Cuenca, } \\
\text { Sociedades Estatales y otros } \\
\text { agentes }\end{array}$ & $\begin{array}{l}\text { Canon de Regulación } \\
\text { Tarifa de Utilización de Agua }\end{array}$ \\
\hline Aguas subterráneas & $\begin{array}{l}\text { Organismos de Cuenca, } \\
\text { colectivos de riego y usuarios } \\
\text { privados (autoservicios) }\end{array}$ & $\begin{array}{l}\text { Las fijadas por los } \\
\text { ayuntamientos } \\
\text { Las fijadas por las CCRR }\end{array}$ \\
\hline Abastecimiento urbano & $\begin{array}{l}\text { Ayuntamientos, } \\
\text { Mancomunidades, Comunidades } \\
\text { Autónomas y otros }\end{array}$ & Tarifa de abastecimiento \\
\hline $\begin{array}{l}\text { Recogida de Aguas } \\
\text { Residuales Urbanas }\end{array}$ & $\begin{array}{l}\text { Ayuntamientos, } \\
\text { Mancomunidades, Comunidades } \\
\text { Autónomas y otros }\end{array}$ & Tasa de Alcantarillado \\
\hline $\begin{array}{l}\text { Tratamiento de Aguas } \\
\text { Residuales Urbanas }\end{array}$ & $\begin{array}{l}\text { Ayuntamientos, } \\
\text { Mancomunidades Comunidades } \\
\text { Autónomas y otros }\end{array}$ & $\begin{array}{l}\text { Canon de saneamiento } \\
\text { Tarifas de servicio }\end{array}$ \\
\hline $\begin{array}{l}\text { Distribución de agua de } \\
\text { riego }\end{array}$ & $\begin{array}{l}\text { Organismos de Cuenca, } \\
\text { Comunidades de Regantes y } \\
\text { otros colectivos de riego }\end{array}$ & $\begin{array}{l}\text { Derramas y tarifas/cuotas de } \\
\text { los colectivos de riego (Que } \\
\text { incluyen el importe del pago } \\
\text { de Canon y Tarifa a los } \\
\text { Organismos de Cuenca) }\end{array}$ \\
\hline Control de vertidos & Organismos de Cuenca & Canon de Control de Vertidos \\
\hline
\end{tabular}

Tabla 1: Organización de los servicios del agua en España (MIMAM, 2007)

\section{II.2.1 Servicios de captación, embalse y transporte}

De acuerdo con la Ley de Aguas y el Reglamento del Dominio Público Hidráulico, los servicios de extracción, embalse y transporte en las redes principales de aguas superficiales de competencia estatal, son prestados por las Confederaciones Hidrográficas en las cuencas intercomunitarias, y por las Comunidades Autónomas (CCAA) en las cuencas intracomunitarias. Los servicios de agua citados se prestan considerando las concesiones existentes y de acuerdo con el régimen de explotación vigente y con los planes de cuenca. 
Las Comisarías de Aguas de las Confederaciones Hidrográficas se encargan de las tareas de registro, autorización, inspección, vigilancia y guardería fluvial del dominio público hidráulico.

Las sociedades estatales de aguas actúan como instrumento de gestión directa de las competencias que corresponden a la Administración General del Estado en materia de obras hidráulicas en el ámbito de las cuencas hidrográficas de competencia estatal. Se ocupan de la construcción y/o explotación de las obras hidráulicas en colaboración con las Instituciones Públicas o mediante el cobro de contraprestaciones por parte de los usuarios y la venta de bienes y servicios resultantes de la explotación.

En el caso de cuencas intracomunitarias la gestión de las competencias a cargo de las CCAA no es homogénea y puede realizarse a través de sociedades o agencias reguladas por el Derecho Público o, en otros casos, adscribiendo las competencias a la estructura administrativa de la Comunidad Autónoma.

\section{II.2.2 Servicios de abastecimiento, alcantarillado y depuración de aguas urbanas}

Los servicios de abastecimiento (tratamiento y distribución del agua potable), alcantarillado y depuración de las aguas urbanas son competencia de los municipios (Artt. 25 y 26 de la Ley 7/1985 de Bases de Régimen Local), que pueden prestar el servicio directamente, en régimen de mancomunidad o a través de concesiones a empresas públicas, mixtas o privadas. Los servicios de depuración de las aguas residuales urbanas en algunos casos son prestados por las administraciones autonómicas mediante empresas especializadas.

\section{II.2.3 Servicios de distribución del agua de riego}

Desde 1879 (Ley de Aguas de 13 de junio) los usuarios del agua superficial destinada al riego que disfruten de la misma toma o concesión están constituidos en comunidades de regantes. Los colectivos de riego o comunidades de regantes se encargan de gestionar la distribución, reparto y mantenimiento de las redes colectivas que llevan el agua desde los canales principales hasta las parcelas particulares. Las comunidades de regantes de base pueden estar agrupadas en Comunidades Generales de Usuarios e integrarse a su vez en un Sindicato Central que gestiona las tomas de agua del cauce público. En García Mollá (2000) se detallan las siguientes tipologías de entidades asociativas: 
a) Comunidades de regantes tradicionales: tienen derecho al uso del agua superficial con anterioridad a los Planes del Estado, son propietarias de todas las instalaciones de riego, incluyendo el canal principal. Se han beneficiado de la actuación del Estado en obras orientadas al incremento de la regulación, mantenimiento y mejora de las redes de riego. Se establecen, además, diferencias entre las mismas comunidades en relación con la naturaleza del recurso utilizado: si es de procedencia exclusivamente superficial, si es integrado por recursos subterráneos o si es regulado por embalses privados.

b) Comunidades de regantes de Planes del Estado (Nuevos Regadios), constituidas e impulsadas por los planes estatales de expansión del regadío. Los derechos de uso de aguas superficiales han sido posibilitados por obras del Estado, que se ha encargado de construir, mantener y explotar los embalses y canales principales, mientras que las comunidades gestionan los canales secundarios y las infraestructuras de riego particulares. En muchas de ellas los recursos superficiales se complementan con aguas subterráneas.

c) Comunidades de usuarios de aguas subterráneas, constituidas para la explotación en común de pozos para el riego, que hasta la Ley de Aguas de 1985 era un derecho de apropiación privada. Pueden tomar formas jurídicas distintas: cooperativas de riego, sociedades civiles de pozos, sociedades agrarias de transformación, o constituirse como comunidades de regantes.

\section{II.3 RÉGIMEN ECONÓMICO-FINANCIERO DE LAS AGUAS CONTINENTALES EN ESPAÑA}

El régimen económico-financiero de las aguas continentales en España se estructura en la actualidad en tres bloques principales de tributos:

- Tributos sobre el uso del dominio público hidráulico;

- Tributos recuperadores del coste de las infraestructuras;

- Tributos ambientales. 


\section{II.3.1 Tributos sobre el uso del dominio público hidráulico:}

II.3.1.1 Canon de utilización de los bienes del dominio público hidráulico.

En el artículo 112 del Texto Refundido de la Ley de Aguas (TRLA, 20 julio de 2001) se afirma que la ocupación, utilización u aprovechamiento de los bienes del dominio público hidráulico (DPH) que requieran concesión o autorización administrativa, devengarán a favor del organismo de cuenca competente una tasa denominada canon de utilización de los bienes del dominio público hidráulico, destinada a la protección y mejora de dicho dominio. Los concesionarios de aguas estarán exentos del pago del canon por la ocupación o utilización de los terrenos de dominio público necesarios para llevar a cabo la concesión. Puesto que el dominio público hidráulico es de titularidad estatal, este tributo es competencia del Estado. En el artículo 2 de la TRLA se definen los bienes que constituyen el DPH del Estado, entre ellos:

- Las aguas continentales, tanto las superficiales como las subterráneas renovables, con independencia del tiempo de renovación.

- Los cauces de corrientes naturales, continuas o discontinuas.

- Los lechos de los lagos y lagunas y los de los embalses superficiales en cauces públicos.

- Los acuíferos subterráneos, a los efectos de los actos de disposición o de afección de los recursos hidráulicos.

- Las aguas procedentes de la desalinización del agua del mar una vez que, fuera de la planta de producción, se incorporen a cualquiera de los elementos señalados en los apartados anteriores.

Según el Art. 59 del TRLA, requiere concesión administrativa todo uso privativo del agua no incluido en el Art. 54 (pluviales y estancadas en una finca y las procedentes de manantiales en el interior de la finca cuando el volumen total anual extraído no sobrepase los $7000 \mathrm{~m}^{3}$ ).

El gravamen será aplicado sobre la base imponible, determinada por el Organismo de cuenca según los supuestos siguientes:

a) En el caso de ocupación de terrenos del $\mathrm{DPH}$, por el valor del terreno ocupado, tomando como referencia el valor de mercado de los terrenos contiguos. 
b) En el caso de aprovechamiento de bienes del DPH, por el valor de dicha utilización o del beneficio obtenido con la misma.

c) En el caso de aprovechamiento de bienes del DPH, por el valor de los materiales consumidos o la utilidad que reporte dicho aprovechamiento.

d) En los supuestos previstos en los párrafos a) y b) el tipo de gravamen será el 5\% anual. En el c) será el 100\% anual.

Podemos resumir, por tanto, que el régimen establecido por el TRLA en este sentido se caracteriza por:

- gravar la ocupación, utilización y aprovechamiento de aquella parte del DPH que no es el agua, es decir, los cauces y los lechos de lagos, lagunas y embalses;

- no gravar el uso o aprovechamiento privativo del agua, que es en consecuencia, gratuito.

II.3.2 Tributos recuperadores del coste de las infraestructuras:

\section{II.3.2.1 Canon de regulación}

El canon de regulación (Art. 114.1 TRLA, Art. 296.1 RDPH) es un tributo que grava a los beneficiados por las obras de regulación de las aguas superficiales y subterráneas, realizadas total o parcialmente con cargo al Estado. Está destinado a compensar los costes de inversión y atender a los gastos de conservación y explotación de las obras.

Bajo el título de canon de regulación se incluyen los conceptos de:

a) gastos de explotación y conservación de las obras;

b) gastos de administración imputables a dichas obras;

c) gastos de amortización de las inversiones soportadas por la administración estatal.

En el cálculo de la cantidad a pagar por el concepto de amortización se considera el 4 por 100 del valor de las inversiones realizadas por el Estado, debidamente actualizado, teniendo en cuenta la amortización técnica de las obras e instalaciones y la depreciación de la moneda. 
Según el Art. 301 del RDPH las cantidades resultantes de los apartados a) y b) del Canon de Regulación se repartirán entre la totalidad de usuarios o beneficiarios, incluido el Estado, dadas las funciones de defensa contra las inundaciones que desempeñan las obras de regulación. La cantidad resultante del apartado c) se repartirá "entre los usuarios equitativamente en razón a la participación en los beneficios o mejoras producidas por las obras". La definición del beneficio resultante para los distintos grupos de usuarios se resuelve en las Juntas de Explotación mediante unas tablas de equivalencia que tienen en cuenta la estimación del beneficio teórico que reportan las obras. El beneficio teórico viene determinado analizando la diferencia entre el beneficio neto del cultivo de regadío respecto al secano imputable a la mejora en la disponibilidad del recurso producida por la obra de regulación.

Los sujetos interesados por el pago son las personas naturales o jurídicas y demás Entidades, titulares de derechos al uso del agua, beneficiadas por la regulación. El concepto de sujeto beneficiado tiene un significado más amplio que el de usuario, en cuanto incluye:

a) los beneficiarios directos: usuarios que tienen su toma en un embalse o aguas abajo del mismo, o se abastecen de un acuífero recargado artificialmente;

b) los beneficiados indirectos: concesionarios de aguas públicas cuyos derechos se fundamentan en la existencia de una regulación que permita la reposición de los caudales concedidos. Es decir los usuarios que gracias a la presencia de un embalse de regulación ven mejoradas sus garantías de suministro.

La obligación de pago es de carácter periódico y anual y puede determinarse por hectárea o por metro cúbico.

\section{II.3.2.2 Tarifa de utilización del agua}

De acuerdo con el Art. 114.2 del TRLA, las otras obras hidráulicas específicas (no de regulación) financiadas total o parcialmente por el Estado están sujetas al pago de la tarifa de utilización del agua, que está destinada a compensar los costes de inversión y atender a los gastos de conservación y explotación de las obras.

Como en el caso del canon de regulación, la tarifa de utilización del agua incluye los conceptos de:

d) gastos de explotación y conservación de las obras;

e) gastos de administración imputables a dichas obras; 
f) gastos de amortización de las inversiones suportadas por la Administración estatal.

En el cálculo de la cantidad a pagar por el concepto de amortización se considera el $4 \%$ de la inversión pendiente de amortización (amortización técnica de la obra y depreciación) en un periodo de retorno de 25 años.

Están sujetos al pago de la tarifa de utilización los titulares de los derechos al uso del agua, que utilicen las obras hidráulicas específicas realizadas a cargo del Estado. El pago tendrá carácter periódico y anual y se calculará de acuerdo a las siguientes bases:

- por hectárea: dividiendo los gastos totales por el total de las hectáreas regadas;

- por metro cúbico: al establecer un precio por unidad de volumen utilizado;

- de forma binómica: se compone de una parte correspondiente a los gastos generales de conservación calculada por hectárea y la parte restante calculada por metro cúbico.

\section{II.3.2.3 Tarifas del servicio}

Tienen la finalidad de recuperar los costes de los servicios de potabilización y distribución de aguas para uso urbano. Incluyen los costes de captación y embalse, si se utilizan aguas superficiales, y los de extracción si se hace uso de aguas subterráneas.

La fijación de las tarifas es responsabilidad de los poderes públicos locales y está sometida a regulación y aprobación por parte de los gobiernos autonómicos. Los periodos de facturación pueden comprender un periodo temporal anual, mensual o intermedio entre éstos.

\section{II.3.2.4 Tasa de alcantarillado}

De acuerdo con la Ley 8/1989 de Tasas y Precios Públicos y con la Ley 7/1985 de Bases de Régimen Local, la prestación del servicio de alcantarillado, de competencia municipal, puede exigir el pago de una tasa (ingreso de naturaleza tributaria). Su aprobación y sus niveles están sujetos a aprobación del pleno municipal y presentan características distintas: algunos municipios exigen un porcentaje con respecto a la facturación de la tarifa del servicio, otros aplican una tasa fija por cada usuario o domicilio, independiente de los consumos de agua. 
II.3.2.5 Tarifas y derramas del servicio de distribución de agua para riego

Las formas de cobro utilizadas por las entidades de riego son las siguientes (García Mollá, 2000):

- Una cantidad anual por superficie que cubre todos los costes de las comunidades. Es la más habitual en las comunidades tradicionales;

- Cantidades fijas por unidad de superficie (derramas) dedicadas a cubrir los gastos fijos que dan derecho al riego, unidas a otras cantidades variables en función de las horas de riego o del volumen consumido;

- Cobro por riego aplicado, independientemente de la cantidad utilizada en cada riego;

- Cobro por la utilización de un caudal teórico durante un tiempo;

- Facturación por volumen;

- Pago al regador, cuyo coste puede ser facturado por la comunidad de acuerdo con los puntos anteriores o abonado directamente por el usuario por hora o por unidad de superficie regada.

En las comunidades de regantes tradicionales sin problemas de escasez de recurso el sistema más extendido es el pago anual por unidad de superficie. En las comunidades con dotaciones mixtas y en los nuevos regadíos con recursos superficiales y subterráneos el sistema tarifario empleado suele ser binómico. Prácticamente todas las comunidades que se abastecen de recursos subterráneos cobran una tarifa por tiempo de riego o por volumen, cuya recaudación irá destinada en su mayoría a la energía eléctrica consumida.

\section{II.3.3 Tributos ambientales.}

\section{II.3.3.1 Competencia estatal: canon de control de vertidos.}

El canon de control de vertidos ha ido evolucionando desde la Ley de Aguas de 1985 para intentar desvincularse de los cánones de saneamiento y depuración que emiten los gobiernos regionales. En el Art. 113 del TRLA (20 julio de 2001) aparece como una tasa destinada al estudio, control, protección y mejora del medio receptor de cada cuenca hidrográfica, es decir, tiene como objetivo financiar las actuaciones de control que realizan los organismos de cuenca. 
El importe del canon de control de vertidos será el producto del volumen de vertido autorizado por el precio unitario de control de vertido. El precio unitario se calculará multiplicando el precio básico por un coeficiente de mayoración o minoración, que depende de las condiciones químicas del vertido y del medio receptor y se establecerá reglamentariamente (modif. RDPH, mayo 2003). El coeficiente de mayoración será como máximo 4 y el precio básico se fija en $0.012 €(2 \mathrm{Pts}) \mathrm{m}^{3}$ para el agua residual urbana y en $0.03 €$ ( $5 \mathrm{Pts}$ ) para el agua residual industrial. Estos precios básicos podrán revisarse periódicamente en las Leyes de Presupuestos Generales del Estado.

Cuando se compruebe la existencia de un vertido, cuyo responsable carezca de autorización administrativa (según Art. 100 TRLA), con independencia de la sanción que corresponda, el Organismo de cuenca liquidará el canon de control de vertidos por los ejercicios no prescritos, calculando su importe por procedimientos de estimación indirecta aplicando un factor de mayoración igual a 4 .

El canon de control de vertidos es de competencia estatal y es independiente de los cánones o tasas que puedan establecer las Comunidades Autónomas o Corporaciones Locales para financiar las obras de saneamiento y depuración.

\section{II.3.3.2 Competencia autonómica: cánones de saneamiento autonómicos.}

Estos cánones también han ido evolucionando. En la actualidad, en muchos casos, son impuestos que gravan el consumo de agua y que afectan a la financiación de las inversiones realizadas por las Comunidades Autónomas en saneamiento y depuración. La estructura del Canon de Depuración o Saneamiento autonómico, como en el caso de la Comunidad Valenciana (Ley 2/1992, Generalitat Valenciana), es similar a las tarifas de suministro de agua, con una parte fija por abonado y una parte variable en función del consumo de agua, pudiendo establecer una diferenciación de precios en función del tamaño del municipio y del uso (doméstico o industrial) al que se destina el agua.

\section{II.3.4 Trasvases intercuenca}

Los trasvases intercuenca realizados en España ofrecen un ejemplo de efectiva recuperación del coste de las infraestructuras (Cabezas, 1987). Los procesos de negociación entre las cuencas cedentes y los beneficiarios de las transferencias han determinado una situación de mayor control sobre el equilibrio financiero de las actuaciones, lo que ha llevado al sustancial cumplimiento de los 
principios de recuperación de costes, incluyendo los relativos a las indemnizaciones para las cuencas cedentes.

En el Análisis Económico del Plan Hidrológico Nacional (MIMAM, 2000; en adelante PHN-2000), a pesar del gran esfuerzo que se profuso en explicar los fundamentos del análisis económico y financiero que justifican la sostenibilidad de las inversiones, se manifiesta un interés marginal al problema de la asignación de costes. En el apartado del PHN-2000 dedicado al análisis de costes se menciona la importancia de establecer un adecuado sobre criterio de reparto de costes en un sistema multipropósito y multiagente, se realiza una revisión superficial de algunas metodologías de reparto de costes y finalmente se pospone la definición del criterio de reparto de coste a una fase posterior al análisis del coste financiero.

\section{II.4 EL PRINCIPIO DE LA RECUPERACIÓN DE LOS COSTES EN LA LEGISLACIÓN ESPAÑOLA}

Al hacer referencia a la recuperación de costes, en la DMA se diferencian tres conceptos básicos:

- Costes de los servicios;

- Costes medioambientales;

- Coste del recurso;

Es posible reconducir parcialmente los cánones y tarifas definidos por la legislación española en las categorías anteriores. Sin embargo se manifiestan complejidades en la adecuación de los mismos a los principios enunciados por la normativa comunitaria.

\section{II.4.1 Costes de los servicios}

Se entienden como servicios, todas las actividades relacionadas con la gestión de las aguas que posibilitan su utilización tales como la extracción, el almacenamiento, la conducción, el tratamiento y la distribución de aguas superficiales o subterráneas, así como la recogida y depuración de aguas residuales, que vierten posteriormente en las aguas superficiales. Asimismo, se entenderán como servicios las actividades derivadas de la protección de personas y bienes frente a las inundaciones. Las tarifas relativas al coste de los servicios coinciden a grandes rasgos con los tributos recuperadores del coste 
de las infraestructuras descritos en el apartado II.3.2, pero incluyen además la partida de tributos ambientales destinada a la financiación de las inversiones en saneamiento y depuración y a la gestión de la red de medición.

\section{II.4.2 Costes medioambientales}

Se pueden incluir aquellos que tuvieran como finalidad recobrar el daño ambiental producido por el uso del agua o reducir el impacto, internalizando su coste. Coinciden parcialmente con los denominados anteriormente tributos ambientales en cuanto a que:

- el canon de control de vertidos es una tasa de ámbito estatal, que debe financiar el coste del servicio del control de la calidad;

- los cánones autonómicos son instrumentos de recaudación destinados a restituir la calidad de las aguas empleadas en el uso urbano, antes de su reincorporación al DPH.

Los cánones por el concepto de compensación previstos en el supuesto de transferencias de recursos hídricos entre cuencas (Artt. 22 y 23 de la Ley del PHN 2000) constituyen otra forma de recuperación del daño medioambiental, aunque no sean directamente relacionados con la calidad del agua en el ecosistema cedente.

\section{II.4.3 El coste del recurso}

Es el coste generado por la escasez del recurso debido al aumento de la disponibilidad de pago de los usuarios por el agua. Se trata de un coste oculto en ausencia de mecanismos de asignación de mercado que permitan explicitar la formación de precios según la ley de la demanda y de la oferta.

La Ley 46/1999 de modificación de la Ley de Aguas introduce el concepto de cesión temporal del derecho al uso privativo del agua entre concesionarios, lo que abre el camino al establecimiento de mecanismos de mercado y de los bancos de agua. También se abre la posibilidad a la creación de bancos de agua como una de las medidas para paliar los problemas de escasez e ineficiencia en la asignación del recurso.

En octubre de 2004, el Consejo de Ministros aprobó la creación de Centros de Intercambio de derechos de agua en tres cuencas hidrográficas (Segura, Júcar y Guadiana). A la vez, la Directiva Marco del Agua justifica la creación de un banco de agua siempre y sólo mientras éste sirva para mejorar, en términos de 
calidad y cantidad, el estado de las masas de agua superficiales y subterráneas. En la práctica la implementación de estos mecanismos ha sido hasta ahora mínima, impidiendo de hecho que se explicitara el coste de escasez del agua.

\section{II.4.4 Complejidad}

El régimen económico y financiero de la Ley de Aguas, con las modificaciones introducidas en 1999 y orientadas a penalizar los consumos excesivos o los vertidos contaminantes, puede servir parcialmente de base para la nueva política de precios exigida por la DMA, en concreto para el cumplimiento del principio de recuperación de los costes de los servicios de agua, al menos de los servicios de provisión en alta, y de los daños ambientales. El traslado de los costes a los usuarios presenta varios elementos de complejidad, individuados sobretodo en la eficacia recaudatoria de la política de precios, la fragmentación de la gestión económica de los recursos hídricos y la disparidad en la asignación de los coste entre los distintos usuarios.

\section{II.4.4.1 Eficacia recaudatoria}

El canon de regulación y la tarifa de utilización del agua pretenden, al menos en teoría, recuperar los costes de obtención y transporte de agua en alta a los usuarios. Las modificaciones introducidas recientemente tratan de estimular un uso más eficiente del agua, al penalizar consumos superiores a los técnicamente suficientes para el uso a los que están acometidos. La realidad es que, en su aplicación práctica, se ha producido una escasa internalización de estos costes por parte de los usuarios y una muy escasa recuperación de los recursos financieros necesarios para la protección del dominio público hidráulico y para el mantenimiento y gestión de las infraestructuras hidráulicas.

Numerosos estudios reflejan que el canon de regulación y la tarifa de utilización del agua no han cumplido estos objetivos. Según el Libro Blanco del Agua (MIMAM, 1998) y el reciente informe elaborado por el Ministerio de Medio Ambiente (MIMAM, 2007) la liquidación por estos conceptos es mínima en relación con los gastos de inversión del Estado en materia de obras de regulación y transporte (menos del 15\%), y la recaudación apenas alcanza al $70 \%$ de la liquidación, de tal manera que los recursos generados por esta vía "no llegan a cubrir siquiera los costes de personal asignado a estas funciones" (MOPT, 1993). El canon de regulación representa "menos del 0,2 \% del valor de la reposición de la infraestructura de regulación existente", y la tarifa de utilización del agua menos del "0,5\% del valor de reposición de los canales" (MIMAM, 1998). 
Por otra parte, los usuarios que han obtenido el derecho al uso del agua, superficial o subterránea, sin mediar obras del Estado no están sujetos a estos cánones. El régimen económico actual afecta sustancialmente poco más que la tercera parte de los regadíos y menos del 50\% de los abastecimientos urbanos, por lo que en conjunto los precios no ejercen de estimulante para un uso eficiente del agua.

Existen sin embargo servicios y costes que presentan una elevadísima tasa de recuperación entre los usuarios. Se trata principalmente de los servicios de baja distribución del agua de uso urbano o agrícola y de las extracciones de aguas subterráneas, cuyos costes directos se repercuten en su totalidad entre los usuarios, aunque quedan sin contabilizar las posibles afecciones a terceros provocadas por la sobre-explotación de las reservas subterráneas y sus efectos en el sistema superficial.

\section{II.4.4.2 Contribución adecuada de los usuarios}

El problema de la disparidad en la facturación de los servicios del agua tiene origen en la fragmentación del régimen de concesiones y en la superposición de distintas normativas inherentes a la gestión y financiación de los servicios del agua (García Mollá, 2000). En (MIMAM, 2007) se evidencia una situación muy dispar tanto en el coste repercutido a los distintos usuarios, como entre los diferentes sectores, así como una disparidad territorial:

- En cuanto al coste repercutido entre los usuarios existe disparidad incluso dentro de un mismo sector. Así, algunos regantes, y por razones diversas, no pagan ningún tributo y otros pagan tributos muy actualizados, sobretodo cuando la inversión por parte del estado es muy reciente. Los suministros urbanos presentan también importantes diferencias en sus tarifas que no siempre corresponden a reales diferencias en los costes de los servicios;

- Los distintos sectores también presentan disparidad. El usuario doméstico suele pagar por el suministro de agua (en alta) una cantidad muy superior a lo que paga el usuario agrícola, que en general se justifica con la prioridad más elevada asignada a estos usos, aunque no sea siempre el resultado de un análisis equitativo de asignación intersectorial de costes;

- Existe una disparidad territorial, con situaciones diversas entre las distintas cuencas, dentro de la misma cuenca e incluso dentro de la misma zona regable. Las diferencias entre ciudades son también importantes y no siempre se deben a la repercusión de sus distintos costes de suministro; 
La fragmentación en la gestión, que se traduce en las disparidades desglosadas anteriormente, supone enormes problemas a la hora de plantear una propuesta orgánica de política de precios que facilite la aplicación de los principios de recuperación de costes y de contribución adecuada de los usuarios definidos por la DMA.

\section{II.4.5 Costes contables y costes futuros}

Los métodos de tarifación de los servicios del agua llevados a la práctica se basan mayoritariamente en la asignación de costes contables o históricos (sunk costs) correspondientes a inversiones realizadas en el pasado y se configuran como un simple instrumento de recaudación para el conseguimiento del equilibrio presupuestario. El criterio de reparto de coste queda determinado por imposición legal (Ley de Aguas) y los usuarios tienen escaso margen de decisión acerca de las posibles alternativas. El consenso en torno a una determinada actuación se logra principalmente en condiciones de fuertes economías de escala o a través de subvenciones públicas que consiguen abaratar los costes generales de la inversión.

Se puede también afirmar que los métodos de tarifación de los servicios del agua hasta ahora analizados y llevados a la práctica se basan mayoritariamente en la redistribución de los costes medios según criterios volumétricos o según el beneficio estimado de la inversión. Las políticas de precios ignoran por lo tanto el papel económico que pueden desempeñar las discriminaciones tarifarias o el análisis de los costes marginales en la mejora de la eficiencia de las inversiones y atienden fundamentalmente al equilibrio financiero del servicio.

Una política de precios distinta sería de esperar en el caso de nuevas inversiones, en las que el criterio de asignación de costes juega un papel estratégico en la búsqueda de soluciones más eficiente, fomentando la cooperación entre usuarios especialmente en ausencia de subvenciones públicas. Otro aspecto relevante es la gestión de los servicios en alta, donde el principio de equidad adquiere una particular relevancia en cuanto actúa como un criterio de cohesión y estabilidad en los proceso de adhesión voluntaria que requieren los grandes planes de inversión multisectoriales. Finalmente el abandono de las políticas de precios basadas en el coste medio podría facilitar el proceso de actualización de las tarifas de los servicios por efecto del progresivo abandono de las subvenciones (Fernández y Revilla, 1994). 


\section{CAPÍTULO III}

\section{ASIGNACIÓN DE COSTES: CONCEPTOS, MÉTODOS Y APLICACIONES}

La asignación de los costes es una tarea propia de cualquier organización. Las empresas reparten sus costes entre los distintos productos y sectores de producción. Las compañías de teléfonos reparten los costes de mantenimiento y de operación de la red entre las distintas categorías de llamadas y de clientes. Cuando dos profesionales comparten un despacho se comprometen a contribuir al pago de los gastos de alquiler, del equipo técnico y del personal de secretaría. Dos municipios que proyectan un sistema de abastecimiento en común tienen que llegar a un acuerdo sobre la asignación de los costes de construcción y explotación. Los grandes organismos internacionales como la OTAN o la UE establecen sistemas de financiación a la hora de definir acuerdos comunes de cooperación. Existen multitudes de ejemplos en la vida social en los que la determinación del precio de determinados bienes o servicios no está vinculada a las lógicas del mercado sino regulada por acuerdos mutuos entre los sujetos interesados o por imposición administrativa (Young H.P., 1994).

En estas circunstancias el criterio de asignación de costes ejerce una influencia fundamental en la definición de acuerdos vinculantes entre los sujetos interesados, estimulando la cooperación para el conseguimiento de soluciones más eficientes y asegurando la estabilidad de las soluciones anteriormente consensuadas. La imposibilidad de definir un criterio de asignación de coste que sea satisfactorio para todas las partes puede llevar al abandono total o parcial de los proyectos de cooperación con consecuente pérdida de economías de escala y aumento de las externalidades producidas por actuaciones individuales y no reguladas.

En este capítulo se ofrece una revisión de las metodologías de asignación de los costes de los servicios del agua y de las políticas de precios a través del análisis del contexto histórico, económico y normativo en los que se desarrollan los usos hídricos. 


\section{III.1 REGULACIÓN DE LOS SERVICIOS DEL AGUA}

El agua es, en España y en gran parte de los países desarrollados, un bien de dominio público cuya gestión representa un caso emblemático de monopolio natural. Las razones que han contribuido a hacer del agua un recurso distinto de la mayoría de otros bienes y mercancías están convenientemente explicadas por Young R.A. (1996) y se resumen a continuación.

- Movilidad: el agua se halla en forma líquida y por su tendencia a fluir, infiltrarse, evaporarse y rezumar plantea dificultades en la medición y comporta elevados costes de exclusión. El carácter de bien público de acceso abierto penaliza el establecimiento de derechos de propiedad exclusiva del recurso, que están a la base de una economía de mercado.

- Incertidumbre en el suministro: la oferta del recurso es variable e impredecible en el tiempo y en el espacio. La necesidad de garantizar el suministro de agua obliga por lo tanto a ejecutar importantes inversiones.

- Propiedades solventes: el agua tiene una elevada capacidad solvente de muchas sustancias, adecuada para absorber desechos y contaminantes, diluirlos y degradarlos y/o transportarlos a otros lugares. La capacidad de auto-depuración de un sistema hidrológico es un activo público limitado que es necesario preservar de las actuaciones particulares.

- Interdependencia entre usuarios: existe un elevado nivel de relación entre los usuarios del agua de una misma cuenca o acuífero, en particular de los usuarios aguas abajo respecto a los situados aguas arriba. Estas interdependencias pueden generar externalidades negativas (efectos no compensados de las actividades individuales respecto a terceros) que pueden influir negativamente en la balanza de costes/beneficios de una actuación y llevar a la toma de decisiones con resultados sub-óptimos.

- Infraestructuras y servicios: los procesos de captación, almacenamiento, transporte $y$ distribución suelen precisar actuaciones de tamaño y complejidad técnica considerable. La necesidad de efectuar importantes inversiones con remuneración a largo plazo dificulta el acceso a los inversores privados y favorece la intervención de sujetos públicos, sobretodo en contextos de economías en desarrollo.

- Variedad de usos: el uso de agua a través de su consumo destructivo o no destructivo produce múltiples beneficios. Es un bien de consumo imprescindible para las necesidades humanas y materia prima en los procesos productivos agrícolas e industriales. Junto con su función de depósito y diluyente de vertidos contaminante el agua juega a la vez un papel importante como elemento embellecedor del medio ambiente, hábitat 
para la vida silvestre y medio de desarrollo turístico y recreativo. Otros usos de tipo no consuntivo son la generación de energía eléctrica o el transporte de mercancías, cuyos beneficios no son excluyentes respecto con respecto a otros usos. Mención a parte merecen las medidas de control y laminación de avenidas, que producen impactos notables sobre el medio hídrico y generan beneficios a largo plazo a veces difíciles de contabilizar y de asignar a los usuarios.

- Rol estratégico: la disponibilidad de recursos hídricos a bajo coste ha representado históricamente un factor primario en el desarrollo de las poblaciones. Ahora la tecnología aplicada a la captación, almacenamiento y el transporte del agua ayuda a superar los obstáculos geográficos e hidrológicos, sin embargo la disponibilidad y el control de los recursos hídricos mantienen una relevancia estratégica a la hora de determinar las directrices de desarrollo de un territorio y representan un importante factor de movilización política y social.

Los argumentos citados anteriormente resumen las condiciones que hacen del agua un recurso especial, distinto de los demás bienes comerciales, lo que ha justificado y sigue justificando en muchos casos la intervención de la administración pública en la gestión y asignación de los derechos sobre el uso del agua.

\section{III.1.1 Modelos de uso de agua y análisis económico}

El nivel de regulación de los recursos hídricos, y en consecuencia el grado de libertad por parte de los usuarios en la promoción de inversiones en los servicios, pueden ser muy dispares según el contexto histórico y social en el que se enmarquen. En (Carles Genovés y García Mollá, 2003) y (Aguilera, 1997) se define con claridad el proceso evolutivo de los modelos de uso del agua en las economías desarrolladas. Las circunstancias históricas que llevan a la adopción y posterior superación de esos modelos suponen también un cambio en las metodologías de análisis económico de los servicios del agua, que han evolucionado como se detalla a continuación.

\section{III.1.1.1 Modelos de oferta}

En los modelos de oferta se considera el agua como un factor de producción y se pretende incrementar su uso como elemento estimulante del crecimiento económico. El objetivo de las políticas hidráulicas es conseguir la movilización del recurso a través de grandes planes de inversión pública subvencionados por 
el Estado y proceder a su asignación a los usuarios mediante concesiones a condiciones muy favorables.

En un contexto de asignación pública de los derechos sobre el uso del agua y de intervención directa de la administración en la planificación y gestión del recurso, el Estado ejerce de promotor y gestor de las principales infraestructuras hidráulicas y a la vez de recaudador de financiación. Las políticas de precios adoptadas premian objetivos de desarrollo social y de fomento al uso del agua por encima de la recuperación de los costes. El déficit tarifario está compensado por subvenciones públicas, avaladas por el análisis coste-beneficio que justifica la viabilidad económica (no necesariamente financiera) de las inversiones con base en el desarrollo económico y social asociado a la disponibilidad de recursos hídricos.

La quiebra de este modelo se ha manifestado en los años recientes, cuando el agua ha empezado a considerarse un bien escaso en distintas regiones, donde la obtención de nuevos recursos disponibles es cada vez más compleja y con costes marginales crecientes, lo que pone en compromiso la financiación pública de las obras hidráulicas. En este contexto la permanencia de los derechos de uso establecidos entra en contradicción con los nuevos demandantes, produciendo conflictos en número y magnitud crecientes; se produce un intolerable malgasto de agua en las redes urbanas y agrarias, técnica y económicamente ineficientes, asociado a un creciente deterioro de la calidad de las aguas continentales y fuertes impactos negativos en humedales y en el entorno biológico de los ríos.

\section{III.1.1.2 Modelos de demanda}

Los modelos de demanda surgen en contextos de economías desarrolladas en las que los procesos de inversión pública y de fomento al uso del agua han llevado a la consolidación de un tejido social y económico capaz de competir en el uso del agua y de contribuir financiariamente a la gestión de los servicios hídricos. En los modelos de gestión de la demanda de agua sigue siendo considerada fundamentalmente como un factor de producción, pero en este momento su disponibilidad es escasa y en consecuencia se ha transformado en un bien económico. El objetivo de la política hidráulica ya no es asegurar el recurso a bajo coste para propiciar la actividad económica, sino fomentar su uso más eficiente en términos no únicamente técnicos sino de óptimo económico, lo que se traduce con la movilización de los derechos entre actividades en competencia para el uso del agua.

En esta línea se enmarca la reforma de la Ley de Aguas de 1985 sobre la revisión de las concesiones existentes, la inclusión de la posibilidad de cesión de derechos entre usuarios, y la de creación de centros de intercambio de derechos 
por parte de la administración (Ley 1985 de Aguas. Art. 61.bis.). También con el objetivo de movilizar los derechos de uso ya concedidos a favor de actividades alternativas se justifica la aparición de los mercados de aguas en países como California (Howitt, 1994 y 1998), Chile, Australia, Pakistán, India (Easter et al. 1998). Otro ejemplo muy actual en España se halla en determinados contextos de actividades agrarias de iniciativa privada, abastecidas con aguas subterráneas, en las que la escasez y el alto coste del recurso se traduce en la implantación de sistemas de riego técnicamente muy eficientes y ha fomentado la consolidación de mercados de agua entre usuarios y sociedades de riego (García Mollá, 2000).

La existencia de instituciones y mercados financieros amplios, unido a la búsqueda de mayor eficiencia económica en la gestión del agua llevan a la progresiva sustitución de la administración pública en la promoción y financiación de las infraestructuras hidráulicas, así como en su explotación y gestión a favor de la iniciativa privada. El objetivo es promover la implantación de mercados del agua en los que las inversiones en los servicios del agua se realicen allí donde sean rentables y financiariamente sostenibles, con el fin de maximizar el óptimo económico en la gestión del agua y limitar las subvenciones públicas. En este contexto las tarifas de los servicios hídricos asumen una función secundaria, en cuanto el precio del agua corresponde al valor comercial del bien, que resulta de la suma del coste de escasez y del coste propio de los servicios. Las metodologías de análisis económico adoptadas en estos casos tienen fundamento en la teoría micro-económica y se han concretado en una amplia bibliografía acerca de los mercados de agua (Howitt, 1993 y 1998; Lee y Jyravlev, 1998; Lund, 1993 ; Lund e Israel, 1995; Newlin et al., 2002), de los modelos de optimización económica de sistemas hídricos (Pulido Velázquez, 2003) y de análisis del coste del recurso (Collazos, 2004).

Los problemas asociados a los modelos de demanda están vinculados con los posibles fallos de mercado, sobretodo en términos de externalidades no compensadas, que se traducen en impactos ambientales, perjuicios a terceros y agotamiento de los recursos con consecuente pérdida de beneficio para la comunidad y para las generaciones futuras. En condiciones de elevada demanda de agua por parte del mercado, aún cuando se adopten las tecnologías más ahorradoras y se alcancen consumos unitarios muy bajos, los ahorros se utilizarán en nuevas actividades o en la ampliación de las existentes, con el resultado de mantener condiciones de explotación insostenibles del medio hídrico. Cabe también destacar que la disparidad en la disponibilidad económica de los usuarios y de los usos hídricos puede llevar a conductas oligopolistas, fenómenos de acaparamiento y alteración injustificada de los precios, lo que conllevaría graves repercusiones económicas y sociales, como se aprecia en los estudios de Barragán et al. (1998), Donoso (1999) y Garrido (2000). 
En la geografía española se ofrecen múltiples ejemplos relacionados con la sobreexplotación o contaminación de recursos superficiales y subterráneos que tienen como consecuencia afecciones ambientales y perjuicios a los demás usuarios del agua. En el Capítulo IV.2 se explicará como la Teoría de Juegos No Cooperativos proporciona herramientas válidas para el estudio de las interacciones estratégicas entre usuarios en un entorno competitivo y escasamente regulado.

\section{III.1.1.3 Modelos medioambientales}

En la Conferencia Internacional sobre el agua y el medio ambiente celebrada en Dublín en Enero de 1992, se declaró que "la escasez y el uso abusivo del agua dulce plantea una creciente y seria amenaza para el desarrollo sostenible y la protección del medio ambiente. La salud y el bienestar humanos, la seguridad alimenticia, el crecimiento industrial y los ecosistemas que de ella dependen se hallan en peligro, a no ser que la gestión de los recursos hídricos y del suelo se efectúe de forma más eficaz en el presente decenio que en el pasado". Con esta intención surge la llamada Directiva Marco para la política común de aguas de la Unión Europea que esboza un tercer modelo del uso del agua en el que se considera el agua como un activo eco-social a la vez que un factor de producción y se propone un modelo de crecimiento sostenible. En este modelo, la calidad del medio hídrico es una restricción para el desarrollo de la actividad económica y los precios del recurso deben ser fijados de forma que, además de reflejar la escasez y los daños producidos en el medio, se incentive un uso eficiente del agua. El papel de la administración pública es coordinar y vigilar la gestión sostenible del agua, priorizando los objetivos de calidad.

En este contexto gana relevancia un modelo de gestión de tipo asociativo, en el que las fuerzas de mercado dejan de ejercer un peso dominante y la competencia entre usuarios cede el paso a soluciones consensuadas y vinculadas a objetivos de sostenibilidad y de eficiencia. La búsqueda de soluciones a los problemas de gestión del recurso pasa por la individuación de aquellas actuaciones que maximicen el beneficio individual de los usuarios en un contexto fuertemente regulado por un sujeto público que ejerce de promotor y garante de los acuerdos. Los modelos de análisis macroeconómico de asignación de recursos se ven superados por herramientas multi-objetivo que permiten analizar conjuntamente el comportamiento de los usuarios y las posibles afecciones a terceros. La Teoría de Juegos Cooperativos ofrece las herramientas para el estudio de soluciones que maximicen el beneficio individual en un entorno estratégico en el que la posibilidad de alcanzar acuerdos vinculantes entre usuarios permita maximizar la eficiencia global de la gestión. 


\section{III.2 EL MONOPOLIO NATURAL Y LA REGULACIÓN DE LOS SERVICIOS HÍDRICOS}

El concepto de monopolio natural está relacionado con la estructura de costes de un determinado bien o servicio. En (Baumol, 1977) se afirma que existe un monopolio natural cuando una sola empresa puede atender el mismo mercado a un coste inferior al que se incurriría si se repartiera entre dos o más empresas. La definición anterior corresponde a una estructura de coste sub-adictiva, que para el caso de un solo producto se puede expresar matemáticamente de la siguiente forma:

$$
C\left(Q_{T}\right) \leq \sum_{i=1}^{n} C\left(q_{i}\right)
$$

donde:

$$
Q_{T}=\sum_{i=1}^{n} q_{i}
$$

n: número de empresas

Q, q : producción (cantidad de bienes o servicios ofrecidos)

$\mathrm{C}(\mathrm{Q}), \mathrm{C}(\mathrm{q})$ : funciones de costes

En un monopolio natural se justifica que la administración retire un determinado servicio del libre juego de la competencia con el fin de evitar una duplicación estéril de esfuerzos y recursos en cuanto se supone que sea más conveniente prestar el servicio en términos de monopolio que en el régimen competitivo de libre mercado. Las fuerzas de mercado no son operativas y acabarían por convertir el servicio en un monopolio de hecho que la administración no quiere dejar explotar a un sujeto privado. Mediante la regulación pública se crea un monopolio de derecho en el que la acción de los mecanismos de libre mercado es sustituida por una serie de cláusulas administrativas que tienen el objetivo de garantizar la calidad del servicio y regular las tarifas que han de pagar los usuarios.

Ejemplos de monopolios naturales se pueden encontrar prácticamente en todos los servicios que necesiten una red capilar de distribución o supongan grandes impactos ambientales. En estos casos la existencia de crecientes economías de ámbito (varios usuarios pueden utilizar la misma infraestructura) y de escala (una infraestructura más grande cuesta menos respecto a varias infraestructuras particulares), junto con la dificultad de duplicar determinadas inversiones 
(imagínese la realización de redes gemelas de distribución de agua o de gas), ha determinado el establecimiento de monopolios naturales, bien de gestión pública, bien por concesión pública a sujetos privados.

La gestión de los servicios hídricos, con escasas y circunstanciadas excepciones, reúne todas las características propias de un monopolio natural:

- necesita grandes obras de regulación y captación difícilmente repetibles por su magnitud y ubicación;

- utiliza sistemas de transporte caracterizados por elevadas economías de escala;

- precisa una capilar red de distribución;

- genera afecciones a terceros.

Las excepciones más evidentes se dan en el caso de aprovechamientos de agua subterráneas, en los que la estructura de costes es precisamente súper-aditiva, en cuanto puede resultar preferible por razones hidrogeológicas y económicas la realización de un sistema de pozos particulares respecto a una única central de bombeo asociada a una extensa red de transporte. De hecho los sistemas alimentados con aguas subterráneas responden mayoritariamente a gestiones de carácter privado escasamente reguladas por la administración. 


\section{III.2.1 La fijación del precio en un monopolio natural}

Una vez establecidos los niveles de calidad de los servicios, el aspecto clave en los monopolios naturales es la fijación del precio en un contexto de ausencia de competencia y costes medios decrecientes.

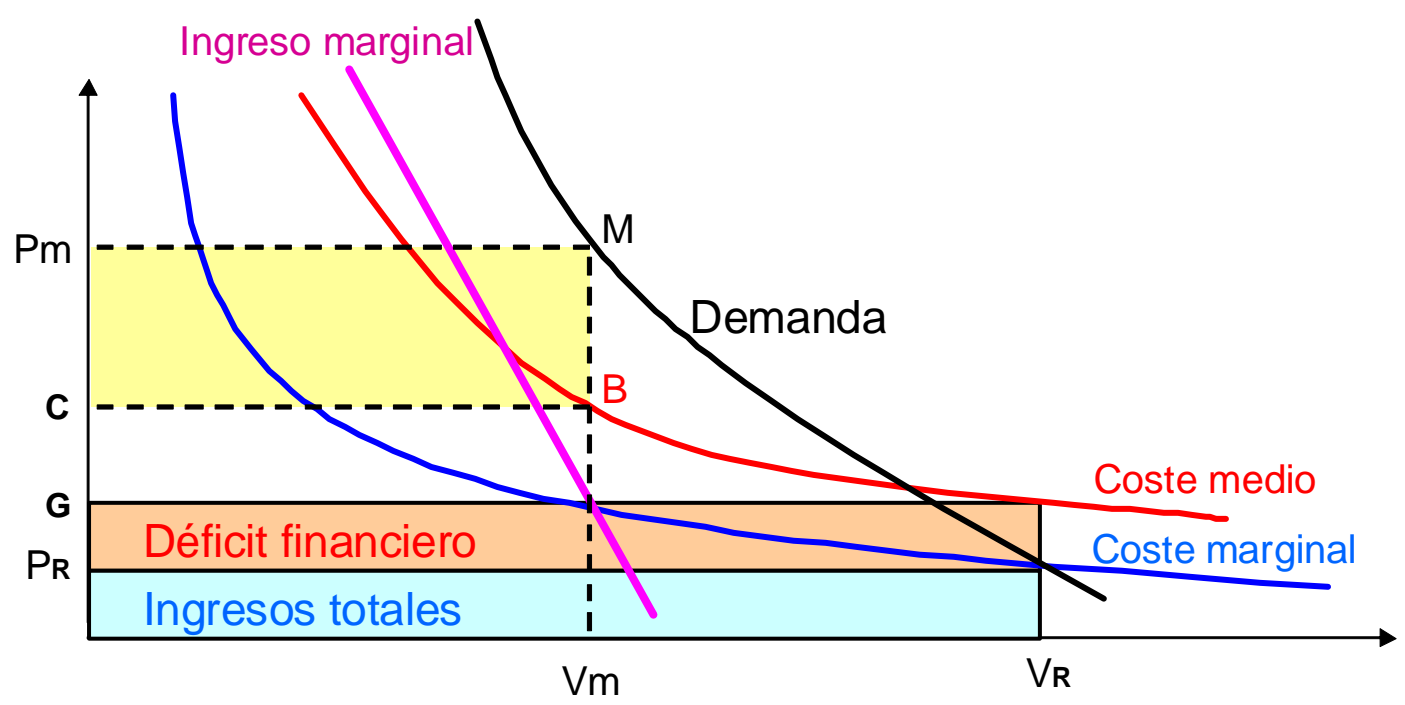

Figura 1: Monopolio natural, fijación del precio.

En una situación de monopolio, como se muestra en la figura anterior, el productor monopolista tenderá a fijar un precio Pm y un nivel de servicio $\mathrm{Vm}$ en el que el ingreso marginal iguala el coste marginal y se obtiene el máximo beneficio para el productor, representado por el área amarilla $\left(\mathrm{P}_{\mathrm{m}} \mathrm{MBC}\right)$. El consumidor sin embargo sufriría en estas circunstancias una pérdida de bienestar debido a la ineficiencia en la asignación del recurso, al no poderse alcanzar los niveles de suministro $V_{R}$ que resultarían de un mecanismo de asignación eficiente.

$\mathrm{Si}$, siguiendo una política de asignación eficiente del recurso, se regula por intervención pública un precio $\left(\mathrm{P}_{\mathrm{R}}\right)$ igual al coste marginal, la cantidad demandada aumenta hasta $V_{R}$. Puesto que los costes medios son decrecientes, el coste marginal es inferior al coste medio y en estas condiciones se produce un déficit crónico de financiación del servicio.

Para equilibrar el déficit presupuestario el gestor tiene tres alternativas:

1. Adoptar una política de asignación del recurso "eficiente" (tarifa al coste marginal) y subvencionar el déficit presupuestario;

2. Establecer una política de coste medio en lugar del coste marginal y asumir la pérdida de eficiencia económica; 
3. Establecer una política de discriminación tarifaria, ofreciendo precios inferiores a los usuarios marginales (los que sólo están dispuestos a utilizar el servicio a un coste muy bajo) y compensando el desequilibrio presupuestarios mediante un aumento de la tarifa de otros usuarios con disponibilidad de pago más elevada.

La tercera alternativa se considera más eficaz en un contexto en el que se promueve la autosuficiencia tarifaria y la búsqueda de la máxima eficiencia económica, en cuanto permite ofrecer la cantidad óptima de servicio que se daría en el caso de un mercado perfecto, sin incurrir en déficit de financiación. La discriminación de precios es además una práctica habitual en la gestión de los servicios públicos: se establecen grupos homogéneos de usuarios, identificados como causantes del coste o mediante una valoración de su disponibilidad de pago con el fin de individuar las distintas clases de tarifas.

Una política de discriminación tarifaria no constituye necesariamente un sistema de subvenciones cruzadas, siempre que la solución encontrada permita aprovechar las economías de escala y abaratar los precios para todos los usuarios, sin que los sujetos discriminados positivamente supongan un perjuicio para los que están discriminados negativamente.

En este trabajo se pretende investigar los criterios de asignación que están a la base de un sistema tarifario eficiente para los servicios del agua, en el cumplimiento de los principios de equidad y justicia.

\section{III.3 PRINCIPIOS DE TARIFACIÓN}

Las políticas tarifarias se orientan hacia la consecución de diversos objetivos (Fernández y Revilla, 1994; Rogers et al., 2002), entre ellos:

1. Promover una gestión eficiente del recurso (objetivo económico);

2. Recaudar unos determinados ingresos (objetivo financiero);

3. Satisfacer determinados requisitos de equidad, distribución de la renta o justicia social (objetivo social);

4. Incentivar la innovación, el progreso tecnológico en la gestión;

5. Objetivos coyunturales, como el soporte o estímulo a determinados sectores económicos.

En el presente trabajo se centra la atención en los tres primeros objetivos. Se enunciarán los principios que orientan los objetivos económico y financiero y se 
ofrecerá una formulación precisa de los conceptos de equidad y justicia y de las metodologías que permiten compatibilizarlos con los objetivos anteriores.

\section{III.3.1 Eficiencia económica, justicia distributiva y equidad}

El concepto de eficiencia económica, establecido por el economista italiano Vilfredo Pareto, responde a una visión de la vida económica en la que la mayoría de las transacciones se producen porque compradores y vendedores se benefician a través del cambio. Un objetivo social deseable sería agotar todas las ganancias generadas por el intercambio hasta llegar a una situación en la que nadie puede mejorar su situación si no es a costa de otro. Se define una distribución eficiente de recursos cuando no existe otra posible capaz de generar más beneficios para la sociedad.

Si el concepto de eficiencia tiene una clara interpretación desde el punto de vista económico, no existe una teoría de la justicia en términos económicos ni un consenso sobre lo que debe significar. La literatura anglosajona suele emplear el término equity para referirse a aquellas consideraciones de justicia que tienen que ver con la capacidad económica de los usuarios en relación con el coste de la prestación. Se suele hablar de fairness para referirse a la justicia en relación con el coste que debe soportar cada usuario.

En los países desarrollados los aspectos relativos a la disponibilidad de pago de los usuarios tienen una importancia relativa en los contextos urbanos y cobran mayor relevancia en contextos multisectoriales, donde conviven tipologías de usos agrícolas, urbanos e industriales (Fernández y Revilla, 1994). En la práctica la tarifación de los servicios públicos urbanos ha ido asumiendo un concepto de equidad y justicia más próximo al principio de reparto equitativo de costes (similar al concepto de fairness anglosajón), caracterizado por una asignación libre de discriminaciones y de subvenciones cruzadas entre usuarios, mientras que los servicios en alta admiten una regulación de los precios que responda a las diferencias en la distribución de la renta entre los usuarios.

\section{III.3.2 Tarifación al coste medio}

En un contexto de costes medios decrecientes la tarifación al coste medio se fundamenta en la necesidad de mantener el equilibrio presupuestario aunque esto suponga una pérdida de bienestar social. Los precios calculados al coste medio se obtienen dividiendo el coste total del servicio por el número de unidades de servicio producidas, ya sean las hectáreas regadas, el volumen 
consumido o la población servida, en función de los acuerdos que se alcancen entre las partes interesadas.

Se trata de una metodología ampliamente utilizada para la asignación de los costes históricos pero de escasa eficacia en la asignación del coste de actuaciones futuras en cuanto no aporta información alguna con respecto al coste-oportunidad de una inversión y no contribuye a la consecución de los objetivos de eficiencia de la gestión y al proceso de selección de las actuaciones más rentables.

Un caso particular de tarifación al coste medio aplicado a la tarifación de los servicios del agua a nivel de cuenca es el método SIM-CO, desarrollado por (Deidda, 2006). La metodología, la cual se tratará con más detalle en el capítulo V.1, está basada en la asignación del coste de las infraestructuras de un sistema hídrico a través de un cálculo secuencial del coste medio en cada tramo de una red de flujo y permite calcular series temporales del coste de los servicios en cada punto de una cuenca hidrográfica.

\section{III.3.3 Tarifación al coste marginal}

Según la teoría económica la tarifación al coste marginal representa una condición necesaria para la optimización de la función de bienestar o paretiana. Para que se produzca una asignación eficiente de recursos es necesario que el precio de los servicios ofertados sea igual al coste marginal de producirlos.

El coste marginal es el coste de producir una unidad adicional (o el coste que se ahorraría produciendo una unidad menos). Cuando los precios son ineficientes siempre cabe la posibilidad de introducir modificaciones en los mismos con el fin de aumentar el bienestar general en la medida en que los usuarios beneficiados compensen con creces los perjudicados por el cambio. 


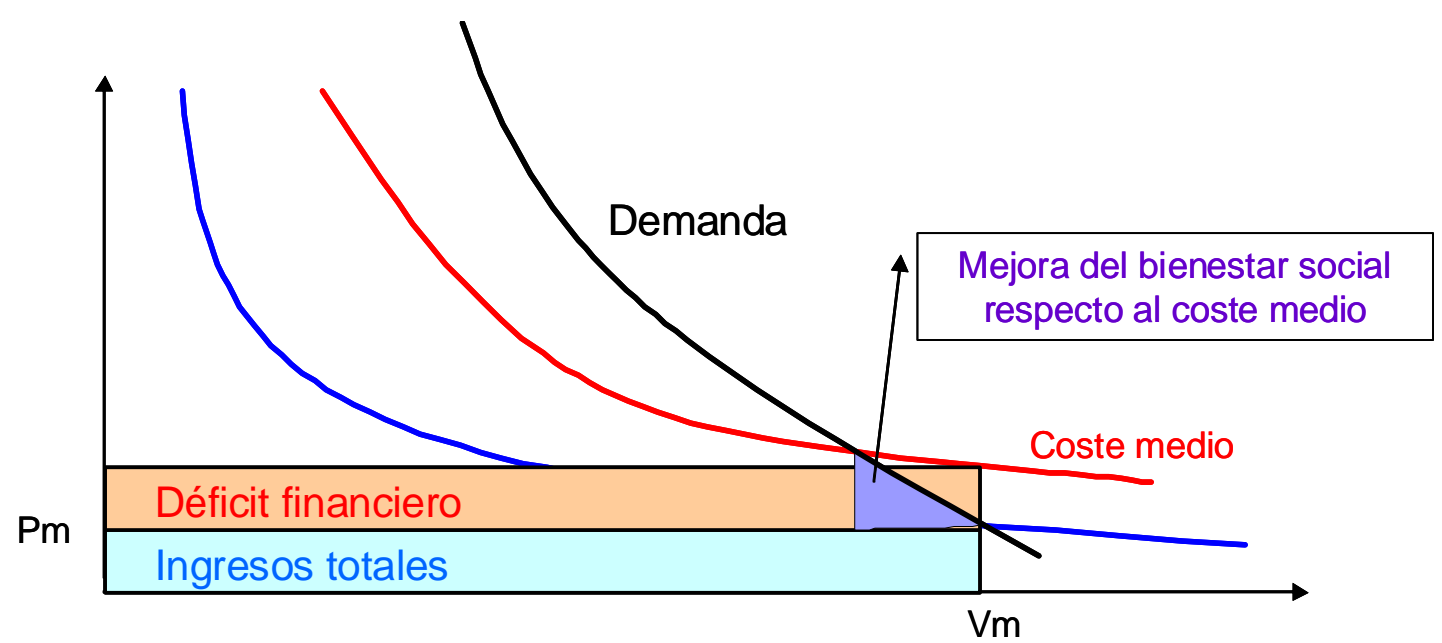

Figura 2: Tarifación basada en el coste marginal.

Como se aprecia en la Figura 2, el principal problema que conlleva un sistema de tarifación al coste marginal es la imposibilidad de asegurar el equilibrio presupuestario en condiciones en las que el coste marginal se sitúe por debajo (economías de escala) o por encima (diseconomías de escala) del coste medio. En este caso las tarifas pueden proporcionar ingresos inferiores (o superiores) a los gastos necesarios para prestar el servicio con la consecuencia de generar un déficit financiero (o un abuso monopolista) de la gestión.

\section{III.3.4 Precios de Ramsey}

Las tarifas de Ramsey (Ramsey, 1927 ; Baumol y Bradford, 1970) se basan en un criterio de asignación del coste de los servicios que sea eficiente según Pareto, consiguiendo el equilibrio presupuestario mediante un ajuste de tarifa sobre el coste marginal realizado en valor relativo y proporcional a la elasticidad de la demanda de los usuarios.

El método se basa en una discriminación tarifaria relacionada con la sensibilidad de los usuarios frente a una modificación de los precios, realizada a través de una mayor tasación de los usuarios que presentan una demanda más rígida, sin alterar la condición de aquellos usuarios cuya demanda se sitúa en valores muy próximos al coste marginal. 
Los precios de Ramsey presentan la siguiente formulación:

$$
\frac{P_{i}-C M_{i}}{P_{i}}=\frac{P_{j}-C M_{j}}{P_{j}} E_{j}=\text { const }
$$

s.a.: Ingresos totales $=$ Gastos totales

donde:

P: precio de Ramsey;

CM: coste marginal;

E: elasticidad de la demanda.

En la Figura 3 se muestra (área azul) una representación de los ingresos obtenidos mediante la aplicación de los precios de Ramsey, cuyo incremento de tarifa para demandas más inelásticas permite compensar el déficit resultante de la aplicación de una tarifa al precio marginal para las demandas con mayor elasticidad (área naranja).

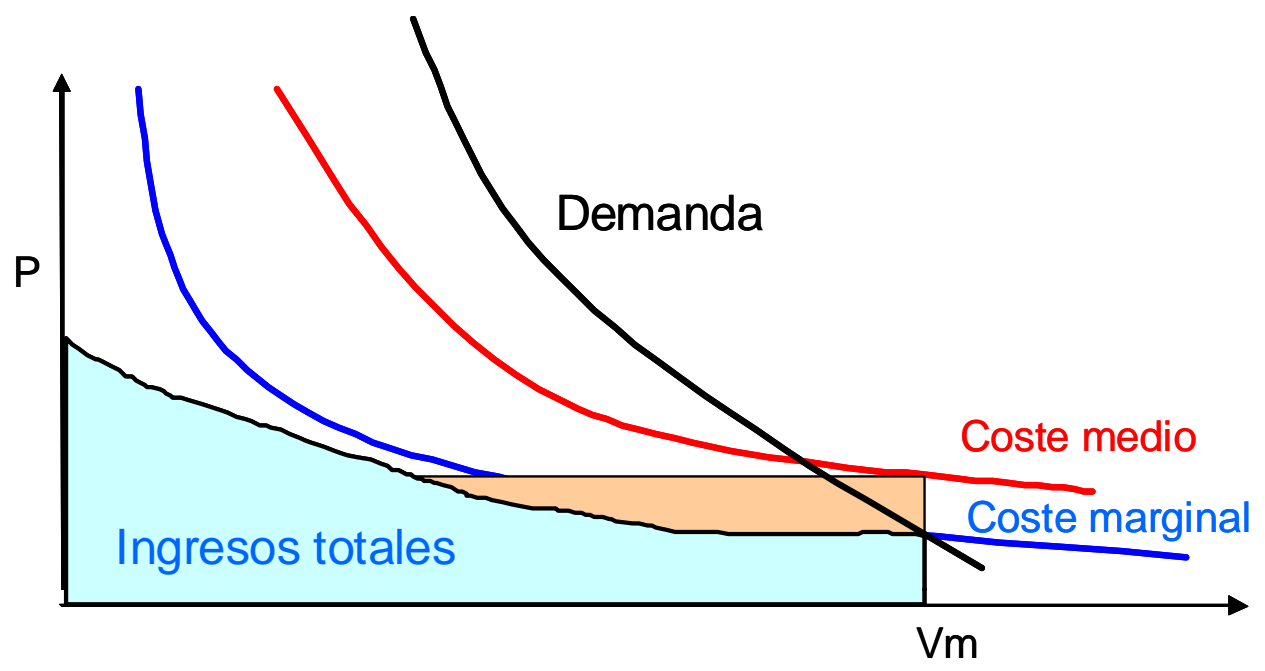

Figura 3: Precios de Ramsey.

Si bien los precios de Ramsey logran el objetivo de alcanzar el equilibrio presupuestario en condiciones de eficiencia y con una pérdida mínima de bienestar, la puesta en práctica de estas medidas evidencia importantes dificultades de orden social. En un contexto de escasez de recursos los usos más perjudicados por las políticas de precios serían el consumo mínimo doméstico y los riegos de elevada eficiencia técnica, en los que los márgenes de ahorro son reducidos y cuya elasticidad se considera mínima o casi nula. Por el contrario 
los usos no prioritarios (como el llenado de piscinas o riego de jardines) o los cultivos ineficientes, dotados de amplios márgenes de ahorro, resultarían premiados con tarifas más bajas al ser considerados consumos marginales.

\section{III.3.5 Reparto de ahorros}

Una aplicación de los criterios basados en el reparto de ahorro se ha presentado en el ejemplo del apartado III.4. Estos criterios se basan en el cálculo de los ahorros conseguidos por la ejecución de un proyecto común con respecto a las actuaciones individuales y en su posterior reparto entre los beneficiarios del proyecto de forma igualitaria, volumétrica etc. Los participantes al proyecto están sujetos al pago del coste de la actuación individual menos la parte de ahorro que le corresponde según el criterio de reparto empleado.

$$
\begin{gathered}
\text { AHORRO }=\sum_{i=1}^{N} c(i)-c(N) \\
A U=\frac{A H O R R O}{\sum_{i \in N} K_{i}} \\
X_{i}=c(i)-A U \cdot K_{i}
\end{gathered}
$$

donde:

$N$ : número total de participantes al proyecto;

$A U$ : ahorro unitario calculado según el criterio K (volumétrico, etc.);

c(i): coste de la actuación individual para el usuario " $\mathrm{i}$ ";

$\mathrm{c}(\mathrm{N})$ : coste del proyecto mancomunado ( $\mathrm{N}$ usuarios);

$K_{i:}$ criterio de reparto de costes para el usuario "i";

$x_{i}$ : coste asignado al usuario " $\mathrm{i}$ ".

Los criterios basados en el reparto de ahorros permiten alcanzar el equilibrio presupuestario y no requieren un análisis de los costes marginales del proyecto en cuanto se fundamentan en las diferencias de costes existentes entre las soluciones individuales y la solución mancomunada. Sin embargo se ha 
demostrado en el ejemplo anterior que no aseguran la individuación de una solución aceptable por parte de todos los participantes al proyecto.

\section{III.3.6 Métodos basados en costes separables}

Los métodos basados en costes separables tratan de efectuar una discriminación de precios con el fin de conjugar los aspectos beneficiosos del reparto marginal con las exigencias dictadas por el equilibrio presupuestario.

En la base de estos métodos está la separación de los costes de una inversión en costes separables, asociados exclusivamente a la presencia de un usuario en un proyecto común, y costes no separables, que no es posible asignar directamente a ningún usuario. Se pretende asignar directamente a cada usuario su coste separable y repartir los costes indirectos entre todos los usuarios mediante algún criterio cuantitativo con el fin de limitar las subvenciones cruzadas entre usuarios.

$$
\begin{aligned}
& s c(i)=c(N)-c(N-i) \\
& N S C=c(N)-\sum_{i \in N} s C_{i}
\end{aligned}
$$

donde:

sc(i): coste separables para el usuario "i";

$N$ : número total de participantes al proyecto;

NSC: coste no separable;

$\mathrm{c}(\mathrm{N})$ : coste total de la actuación ;

$\mathrm{c}(\mathrm{N}-\mathrm{i})$ : coste de la actuación excluido el usuario "i".

El aspecto clave es la definición de un criterio para la asignación de los costes comunes o no separables.

\section{Reparto igualitario}

Se asigna directamente el coste separable y se reparte de manera igualitaria entre todos los participantes o según otra medida (volumen, hectáreas) el coste no separable. Un ejemplo de reparto igualitario se presenta cuando en una 
comunidad de regantes cada usuario se ocupa del mantenimiento de su ramal particular de acequia y se reparte el coste de los canales principales entre todos los regantes por hectáreas regadas o por consumo.

$$
x_{i}=s C(i)+\frac{N S C}{N}
$$

donde:

$x$ : coste asignado al sujeto " $\mathrm{i}$ ";

sc(i): coste separables para el usuario "i";

$N$ : número total de participantes al proyecto u otra medida;

NSC: coste no separable.

Coste Alternativo Evitado (Gately, 1974, Owen, 1993)

Los costes no separables se reparten proporcionalmente respecto a los costes alternativos evitados por cada jugador al pertenecer a un proyecto común. El coste alternativo evitado corresponde al coste de la alternativa de proyecto más barata para cada usuario.

La presente metodología mantiene una visión estratégica del reparto de coste, incentivando la presencia en el proyecto de los usuarios que cuentan con una alternativa más barata con el fin de lograr los beneficios de las economías de escala para el conjunto de los participantes.

$$
x_{i}=s c(i)+\frac{c(i)-s c(i)}{\sum_{j \in N}[c(j)-s c(j)]} N S C
$$

donde:

$\mathrm{x}$ : coste asignado al usuario "i";

sc(i): coste separables para el usuario "i";

$c(i)$ : coste alternativo para el usuario " $\mathrm{i}$ ";

NSC: coste no separable;

$N$ : número total de participantes al proyecto. 
Coste Separable y Beneficio Remanente (Separable Cost Remaining Benefit)

Considera el beneficio derivado de una inversión para calcular la disponibilidad de pago máxima de cada jugador (James and Lee, 1971). Se trata de la metodología utilizada por el Inter-Agency Comité on Water Ressources de EEUU para el reparto de costes de las grandes obras hidráulicas.

La disponibilidad de pago de los usuarios se calcula como el valor mínimo entre el beneficio generado al usuario por la inversión y el coste alternativo para el mismo usuario. El fundamento de la metodología reside en cargar con una tarifa mayor a los usuarios que obtienen más beneficios por la inversión.

$$
x_{i}=s c(i)+\frac{\min [b(i), c(i)]}{\sum_{j \in N}(\min [b(j), c(j)]-s c(j))} N S C
$$

donde:

$\mathrm{x}$ : coste asignado al usuario " $\mathrm{i}$ ";

sc(i): coste separables para el usuario " $\mathrm{i}$ ";

$b(i):$ beneficio del usuario " $i$ ";

$c(i)$ : coste alternativo para el usuario " $\mathrm{i}$ ";

NSC: coste no separable;

$N$ : número total de participantes al proyecto.

\section{III.4 UN EJEMPLO ILUSTRATIVO}

Consideremos un ejemplo constituido por tres usuarios, una comunidad de regantes $(\mathrm{A})$ y dos núcleos urbanos $(\mathrm{B}, \mathrm{C})$, que están considerando realizar un proyecto de suministro hídrico en común. El proyecto consiste en la realización de un canal de $50 \mathrm{Km}$. para la toma de agua del río y de una balsa para la regulación de los caudales fluviales.

En las Figura 4 se muestra un esquema conceptual del proyecto, a seguir, en la Figura 5, se presenta la serie mensual de aportaciones en régimen natural que representa los recursos disponibles en el sistema. 


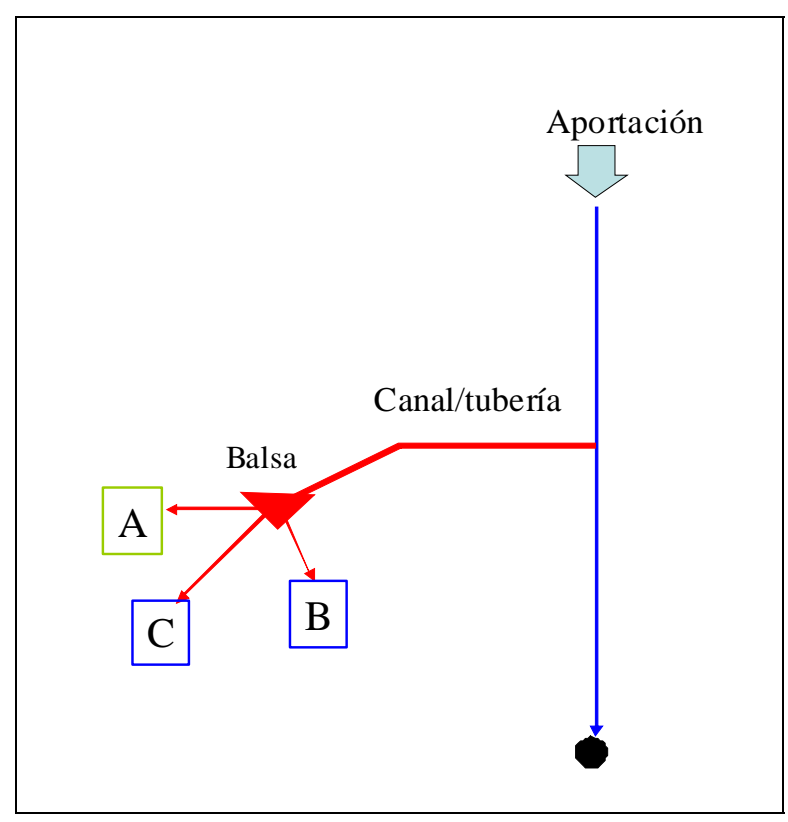

Figura 4: Caso de ejemplo de asignación de costes.

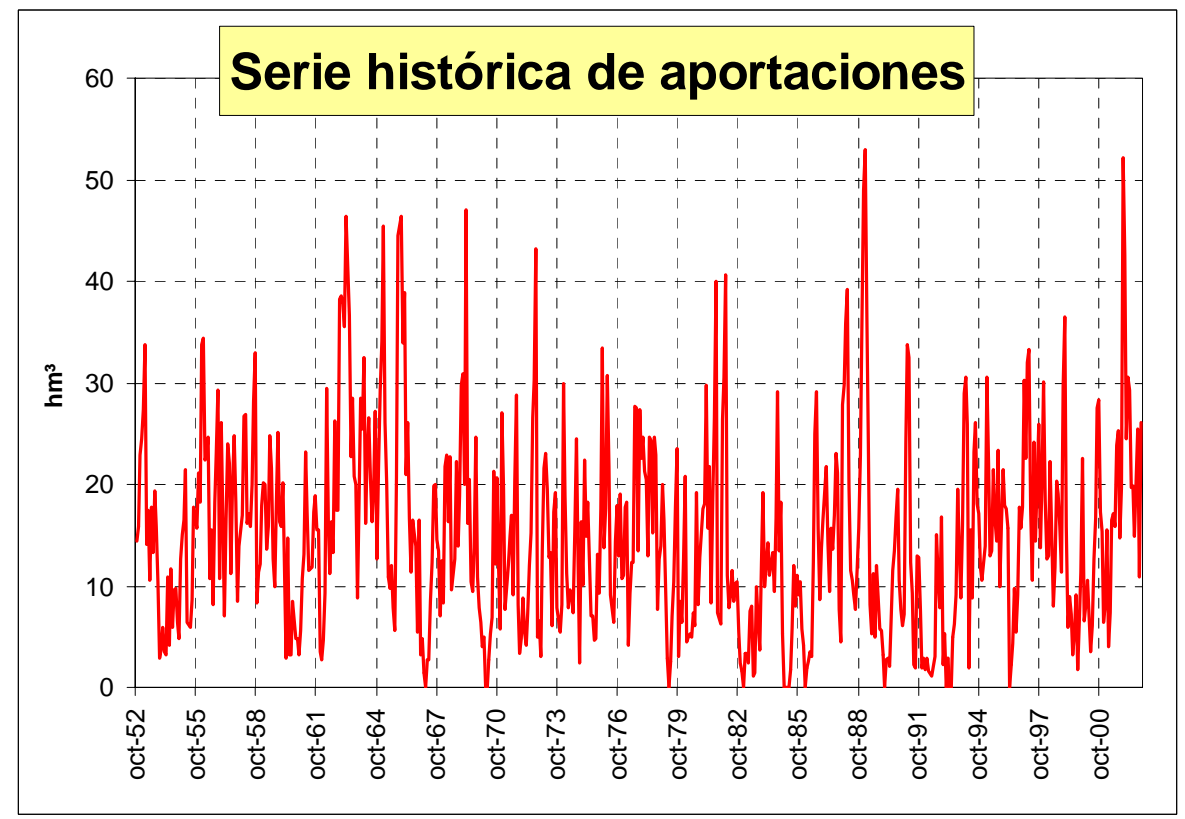

Figura 5: Caso de ejemplo, serie histórica de aportaciones.

Los valores correspondientes a las demandas mensuales se muestran en la Tabla 2 y en la Figura 6 y evidencian las diferencias sustanciales tanto en los consumos anuales como en los patrones de consumo mensuales. 


\begin{tabular}{|c|c|c|c|}
\hline $\mathbf{h m}$ /mes & Demanda A & Demanda B & Demanda C \\
\hline oct & 1 & 1 & 0,17 \\
\hline nov & 0,1 & 1 & 0,17 \\
\hline dic & 0,1 & 0,9 & 0,15 \\
\hline ene & 0,1 & 0,9 & 0,15 \\
\hline feb & 0,1 & 1 & 0,17 \\
\hline mar & 0,1 & 1 & 0,17 \\
\hline abr & 0,5 & 1 & 0,17 \\
\hline may & 1 & 1 & 0,17 \\
\hline jun & 2 & 1 & 0,17 \\
\hline jul & 2 & 1,1 & 0,18 \\
\hline ago & 3 & 1,1 & 0,18 \\
\hline sep & 2 & 1 & 0,17 \\
\hline Total (hm ${ }^{3}$ ) & $\mathbf{1 2}$ & $\mathbf{1 2}$ & $\mathbf{2}$ \\
\hline
\end{tabular}

Tabla 2: Caso ejemplo, demanda mensual.

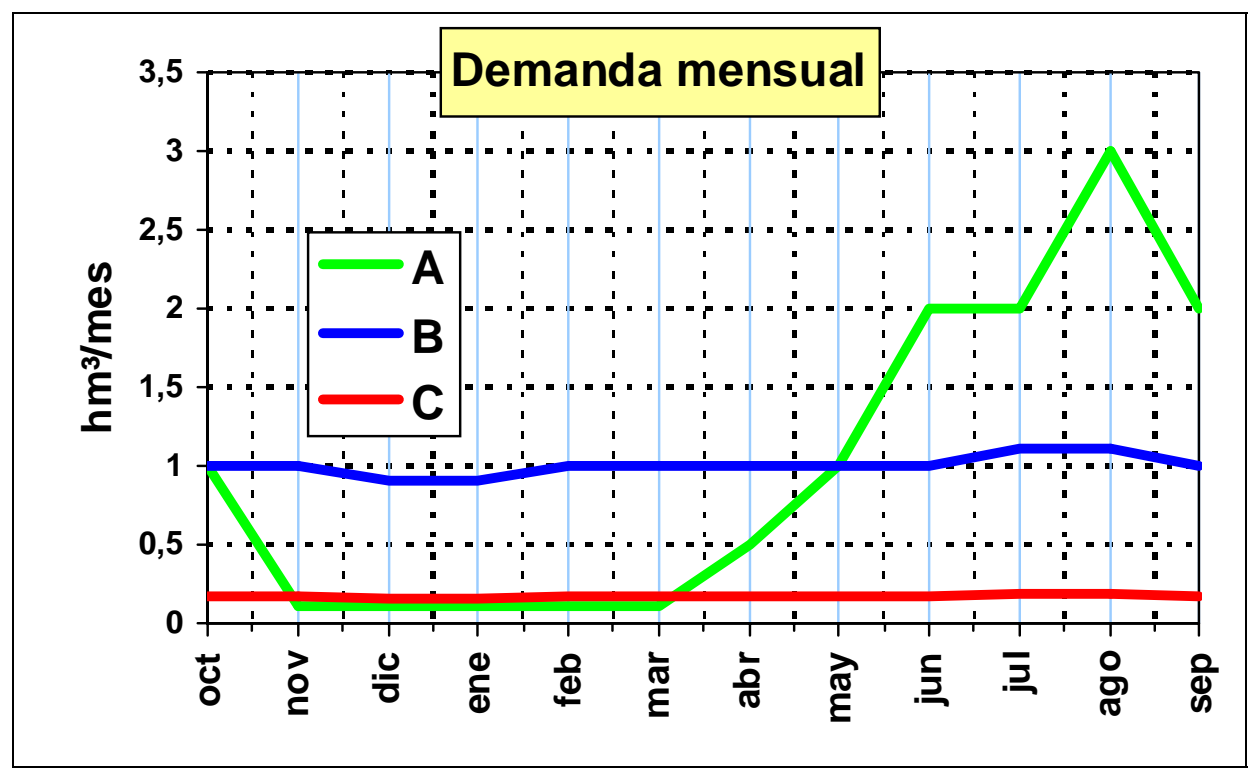

Figura 6: Caso de ejemplo, demandas mensuales.

El usuario A podría realizar el proyecto por su cuenta a un coste de $72 \mathrm{M} €$, mientras el usuario B por $43 \mathrm{M} €$ y $\mathrm{C}$ por $30 \mathrm{M} €$. Si deciden llevar a cabo un proyecto común el coste total ascendería a $100 \mathrm{M} €$. Se muestra claramente que una actuación conjunta permitiría el ahorro de $50 \mathrm{M} €$, casi un tercio respecto al coste de las actuaciones individuales. La realización de una actuación 
mancomunada queda subordinada a la definición de un acuerdo sobre el reparto de los costes de la inversión.

Cabe también la posibilidad que los 3 usuarios decidan cooperar entre ellos mediante acuerdos de tipo bilateral, lo que daría lugar en total a 7 posibles agregaciones (A, B, C, AB, AC, BC, $\mathrm{ABC}$ ).

En la Tabla 3 es posible consultar los datos de diseño y el análisis de los costes de las distintas agregaciones de usuarios, mientras en la Figura 7 se ofrece un resumen del coste correspondiente a las distintas actuaciones, en el que la solución mancomunada resulta ser la más favorable económicamente

\begin{tabular}{|c|c|c|c|c|c|c|c|}
\hline Usuarios & A & B & C & AB & AC & BC & ABC \\
\hline Consumo $\left(\mathrm{hm}^{3}\right)$ & 12 & 12 & 2 & 24 & 14 & 14 & 26 \\
\hline Caudal diseño $\left(\mathrm{m}^{3} / \mathrm{s}\right)$ & 0,77 & 0,39 & 0,08 & 1,16 & 0,96 & 0,49 & 1,20 \\
\hline Vol. regulación $\left(\mathrm{hm}^{3}\right)$ & 8,00 & 3,00 & 0,30 & 13,00 & 9,00 & 3,50 & 14,00 \\
\hline Coste canal $(\mathrm{M} €)$ & $\mathbf{4 5} €$ & $\mathbf{4 0 €}$ & $\mathbf{2 8} €$ & $\mathbf{5 1} €$ & $\mathbf{4 6} €$ & $\mathbf{4 3} €$ & $\mathbf{5 1} €$ \\
\hline Coste regulación $(\mathrm{M} €)$ & $\mathbf{2 5} €$ & $\mathbf{5 €}$ & $\mathbf{2 €}$ & $\mathbf{3 9} €$ & $\mathbf{2 9} €$ & $\mathbf{7 €}$ & $\mathbf{4 9} €$ \\
\hline Coste total $(\mathrm{M} €)$ & $\mathbf{7 0}$ & $\mathbf{4 5}$ & $\mathbf{3 0}$ & $\mathbf{9 0}$ & $\mathbf{7 5}$ & $\mathbf{5 0}$ & $\mathbf{1 0 0}$ \\
\hline
\end{tabular}

Tabla 3: Caso ejemplo, datos de proyecto.

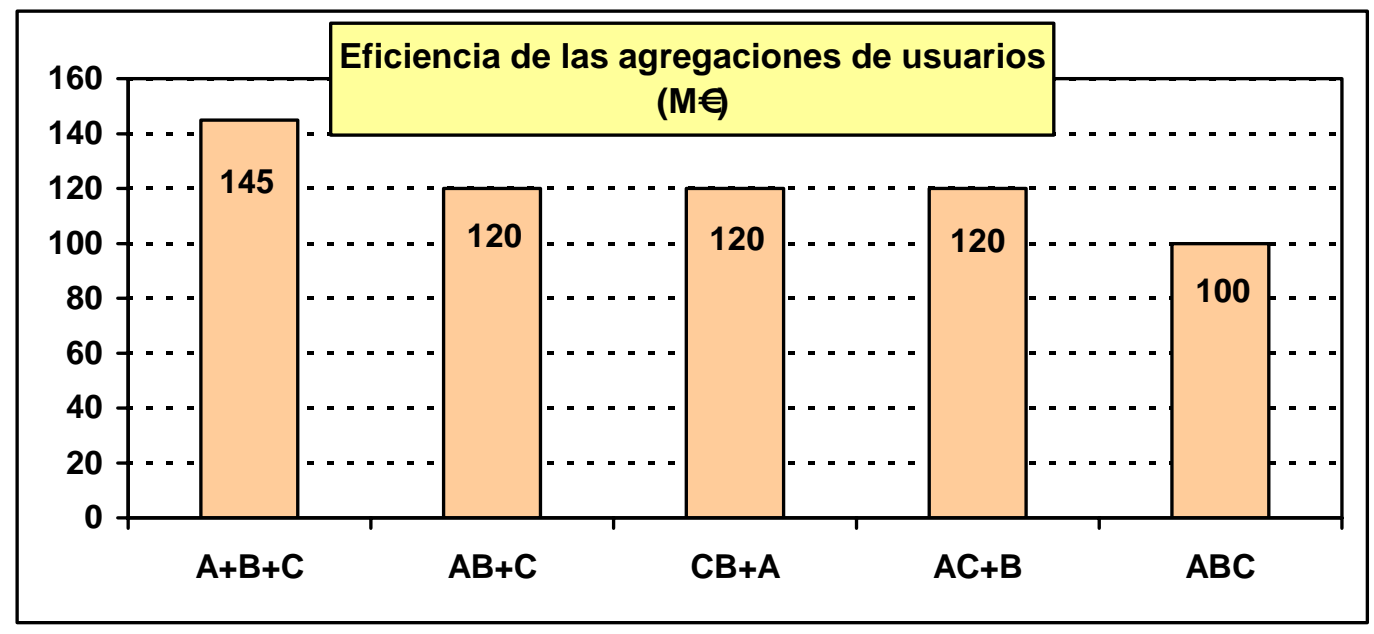

Figura 7: Caso de ejemplo, eficiencia de las agregaciones de usuarios.

Se analizan distintos criterios de asignación de costes, empezando por un reparto igualitario de costes, obtenido dividendo el coste total entre los 3 participantes al proyecto $(100 \mathrm{M} € / 3=33 \mathrm{M} €)$. Se muestra claramente como la 
solución dejaría insatisfecho el usuario C, que dispone de una solución individual de menor coste.

Otra propuesta consiste en el reparto de costes en función del volumen suministrado anualmente. Los resultados de la Tabla 4 muestran como la tarifa obtenida sería rechazada por el usuario B, en cuanto el coste asignado es superior al coste de una actuación individual.

\begin{tabular}{|c|c|c|}
\hline Volumétrico & & M€ \\
\hline A & $46 \%$ & 46,15 \\
\hline B & $46 \%$ & 46,15 \\
\hline C & $8 \%$ & 7,69 \\
\hline & total & $\mathbf{1 0 0 , 0 0}$ \\
\hline
\end{tabular}

Tabla 4: Caso de ejemplo, reparto de coste volumétrico.

Se deduce que un reparto igualitario o proporcional al volumen consumido, a pesar de responder a criterios de equidad estrictos, no resulta satisfactorio para los usuarios.

El recurso a un sistema de costes marginales (Tabla 5) se demuestra en este caso inadecuado frente a las exigencias de mantener el equilibrio presupuestario. El coste marginal de A equivale a 50M€ (aumento del coste del proyecto BC al incluir el usuario A), el de B se valora en $25 \mathrm{M} €$, y $10 \mathrm{M} €$ para el usuario C; es evidente que en un contexto de economías de escala crecientes la suma de los costes marginales de los distintos usuarios $(85 \mathrm{M} €)$ no llega a cubrir el coste total de la inversión.

\begin{tabular}{|c|c|c|}
\hline Coste marginal & & M€ \\
\hline A & $58 \%$ & 50 \\
\hline B & $29 \%$ & 25 \\
\hline C & $13 \%$ & 10 \\
\hline & total & $\mathbf{8 5 , 0 0}$ \\
\hline
\end{tabular}

Tabla 5: Caso de ejemplo, costes marginales.

Para introducir en la solución adecuados incentivos a la cooperación se procede enfocando el problema en los ahorros que los usuarios pueden conseguir y sobre la manera de repartir estos ahorros entre los beneficiarios. 
Una solución se podría calcular repartiendo los 45M€ de ahorro conseguidos por la actuación mancomunada de manera igualitaria $(45 / 3=15 \mathrm{M} €)$ entre los usuarios y restar esta cantidad al coste de las actuaciones individuales, lo que supondría una asignación de $55 \mathrm{M} €$ para $\mathrm{A}, 30 \mathrm{M} €$ para B y $15 \mathrm{M} €$ para $\mathrm{C}$. También se podría repartir el ahorro en función del volumen consumido, de manera que A pagaría $49 \mathrm{M} €$, B pagaría $24 \mathrm{M} €$ y a C corresponderían $27 \mathrm{M} €$.

Los valores correspondientes al reparto de ahorros se ven en la Tabla 6.

\begin{tabular}{|c|c|c|}
\hline $\mathbf{M} €$ & Igualitario & Volumétrico \\
\hline $\mathbf{A}$ & 55 & 49 \\
\hline $\mathbf{B}$ & 30 & 24 \\
\hline $\mathbf{C}$ & 15 & 27 \\
\hline total & $\mathbf{1 0 0}$ & $\mathbf{1 0 0}$ \\
\hline
\end{tabular}

Tabla 6: Caso de ejemplo, reparto de ahorros.

Cada una de las dos últimas propuestas de reparto incentiva la cooperación en cuanto sitúa el pago de cada usuario por debajo del coste que le supondría una actuación individual. Sin embargo el análisis de los posibles acuerdos bilaterales entre usuarios muestra que en el caso de reparto volumétrico los centros B y C pagarían una cantidad mayor de lo que supondría una actuación $\mathrm{BC}$ conjunta, $\mathrm{o}$, en otras palabras, están subvencionando la entrada de A en la coalición.

A raíz de los ejemplos citados es posible formular las siguientes consideraciones:

1. No existe una respuesta obvia al problema de asignación de costes; conceptos básicos como igualdad y equidad se enfrentan a menudo a realidades desiguales en las que soluciones demasiado simplistas pueden llevar a resultados inaceptables para los usuarios.

2. El problema no puede ser evitado, es necesario llegar a un acuerdo sobre el reparto de costes antes de proceder a la realización del proyecto; en presencia de un marco jurídico que impone la recuperación integral de costes se pierde también el incentivo a la cooperación constituido por las subvenciones públicas.

3. El reparto de costes no puede ser resuelto mediante mecanismos de mercado; el problema no es en absoluto competitivo, la solución más eficiente pasa por la cooperación entre usuarios. 
Queda evidente como, en el caso examinado, los criterios de asignación tradicionales no proporcionan una solución aceptable. Sin embargo, es necesario llegar a un acuerdo para obtener los beneficios asociados a la cooperación.

En la práctica, este tipo de problemas se resuelven mediante procesos de negociación en los que se formulan distintas propuestas hasta lograr un acuerdo alrededor de un criterio de asignación de costes que sea satisfactorio para todas las partes. Cada usuario participa a la negociación con el objetivo de obtener una asignación más beneficiosa de los costes, consciente sin embargo de la posibilidad que, en caso de desacuerdo, se produciría un empeoramiento de las condiciones para todos.

Uno de los objetivos de esta tesis es definir a priori un criterio de reparto de costes que sea eficiente y que resulte aceptable por todos los usuarios.

\section{III.5 EQUIDAD, EFICIENCIA $\quad Y \quad$ PROCESOS DE NEGOCIACIÓN}

En los apartados anteriores se han enunciado las diferentes metodologías de asignación de costes en relación con la eficiencia económica y a las distintas interpretaciones de los conceptos de equidad y racionalidad. Se puede afirmar que no existe escasez de metodologías para la asignación de costes, sin embargo la esencia del problema no reside en la definición de una ecuación matemática sino en la formulación de principios y convenciones que puedan guiar el proceso de asignación de costes y a partir de los cuales definir el criterio de reparto.

Las metodologías hasta ahora analizadas se aproximan a los conceptos de eficiencia y equidad bajo enfoques alternativos y a veces contradictorios. La elección entre uno u otro método es el resultado de un proceso de negociación y se realiza en función del nivel de cumplimiento de las expectativas individuales de los usuarios. La negociación entre los sujetos interesados sigue siendo el proceso a la base de la definición de las tarifas de los servicios del agua, mientras el criterio de asignación de costes se reduce a una simple herramienta para formular en términos cuantitativos el acuerdo sobre el reparto de costes que se ha ido delineando en el proceso de negociación. La elección de un criterio práctico de reparto de costes no actúa como soporte para la toma de decisiones, más bien se presenta como el resultado de decisiones sobre el reparto de costes asumidas con anterioridad.

El avance fundamental de una metodología para la definición de tarifas reside por lo tanto en la capacidad de interpretar los mecanismos que rigen el proceso 
de negociación con el fin de proporcionar a priori soluciones que, además de ser eficientes, sean consideradas justas y razonables por parte de los usuarios. Para hacer esto es necesario reproducir las condiciones que están en la base del comportamiento estratégico de los usuarios, incluyendo en el proceso de cálculo la información relativa a la interacción entre agentes y los costes asociados a las soluciones alternativas. 



\section{CAPÍTULO IV LA TEORÍA DE JUEGOS COOPERATIVOS}

El concepto de teoría de juegos debe su origen al intento de solucionar situaciones de conflicto de intereses entre sujetos en condiciones de cooperación o competencia con otros agentes. La teoría de juegos se define como "una rama de las matemáticas, creada para el estudio de estructuras y la resolución de conflictos, que son representados mediante un juego de estrategias" (Kahn y Rapaport, 1984).

La solución a un problema de asignación de costes puede interpretarse por lo tanto como una clase de juego en el que los beneficios o costes tienen que ser repartidos entre los participantes. El organizador del juego busca un criterio de asignación que sea eficiente, equitativo y que proporcione incentivos adecuados a la participación para los sujetos potencialmente interesados. La teoría de juegos (en adelante TJ) proporciona distintos enfoques procedimentales y normativos para analizar el problema de competencia y cooperación entre usuarios teniendo en cuenta sus posibles estrategias.

En este capítulo se define el marco teórico en el que se realiza un juego y los distintos algoritmos propuestos para su solución, con especial atención a los juegos cooperativos. Se revisarán distintos casos de aplicación a los problemas de asignación de costes y se analizarán las complejidades inherentes a la aplicación de la TJ al problema del reparto de costes de los servicios del agua.

\section{IV.1 INTRODUCCIÓN A LA TEORIA DE JUEGOS}

La teoría de juegos trata sobre la modelización matemática del comportamiento estratégico de unos agentes (jugadores) en situaciones en las que las decisiones de un jugador pueden afectar el comportamiento de otros jugadores. Los primeros estudios comienzan con trabajos de Zermelo (1913), quien muestra que juegos como el ajedrez son resolubles. Von Neumann (1928) y Borel en los años '20 estudian los equilibrios de tipo minimax en juegos de suma cero, es decir, juegos en los que lo que gana un jugador lo pierde su rival. Sin embargo, el primer avance importante ocurre en los años '40 con la publicación del libro sobre Teoría de Juegos de von Neumann y Morgenstern (1944), que divulgaron 
una formalización general de juegos en su forma extendida y normal, introdujeron el concepto de estrategia en juegos extensivos y propusieron distintas aplicaciones.

En los años 50 hubo un desarrollo importante de estas ideas en Princeton, donde Shapley (1953) definió un algoritmo para resolver los juegos cooperativos (es decir, aquellos en los que los jugadores pueden establecer contratos para actuar en forma mancomunada) y por fin Nash (1950) definió el equilibrio que lleva su nombre y permitió extender la teoría a juegos nocooperativos más generales que los de suma cero. Durante esa época, el Departamento de Defensa de los EE.UU. fue la entidad que financió las investigaciones en el tema, debido a que la mayor parte de las aplicaciones de los juegos de tipo suma-cero se concentraban en temas de estrategia militar.

En los años ‘60 Harsanyi (1962) extendió la investigación a juegos de información incompleta, es decir, aquellos en que los jugadores no conocen todas las características del juego: por ejemplo, no saben lo que obtienen los otros jugadores como recompensa.

Actualmente la TJ representa la forma de análisis más utilizada para el estudio de las interacciones estratégicas entre dos o más agentes, constituyéndose en la disciplina del ámbito económico donde más publicaciones han surgido en los últimos 15 años. A raíz del éxito de esta disciplina, en los años 1994 Nash, Harsanyi y Selten, y en 1996 Mirrless y Vickrey, han obtenido el premio Nobel de Economía por sus estudios relacionados con la TJ.

El campo de aplicación de la TJ es enorme y se extiende desde las ciencias militares a la economía, a continuación se muestran algunos ejemplos:

1. El análisis de las negociaciones. Las negociaciones entre sindicato y empresa, por ejemplo, se pueden analizar como juegos en los que las partes tratan de dividir el excedente de la empresa antes de pagar los salarios.

2. El análisis de las licitaciones. Las empresas y la Administración utilizan procesos de licitación para comprar o vender bienes y servicios. Es importante saber cuales son los mecanismos adecuados ante cada tipo de licitación y sus debilidades.

3. El reparto de beneficios de una inversión. Varios usuarios pueden llegar a un acuerdo para realizar una inversión conjunta y abaratar los costes aprovechando las economías de escala.

4. El comportamiento de las firmas ante la entrada de competencia. Las firmas pueden ser agresivas frente a la nueva competencia, reduciendo 
precios y aumentando el gasto publicitario o pueden acomodar la entrada, tratando de llegar a un entendimiento con la firma entrante.

5. Los juegos de atrición, en los que se evalúa la capacidad para resistir y responder a un ataque externo y que permiten evaluar el sistema de defensa de un país.

6. Estrategias en comercio internacional. En el comercio internacional, los gobiernos pueden adoptar medidas para proteger la producción nacional frente a la competencia de las empresas extranjeras, evaluando el coste que podría tener una posible reacción de los gobiernos extranjeros o de la comunidad internacional.

7. Análisis político. Los sistemas electorales alteran las plataformas electorales de los candidatos y es posible estudiar las consecuencias de los distintos sistemas. También la formación de coaliciones de gobierno responde a un juego de estrategias que refleja las expectativas y relaciones de poder entre los grupos parlamentarios.

8. Evolución de las especies biológicas. Las especies catalogadas son el producto de un largo proceso de interacciones con otras especies. Los genes y la influencia de éstos sobre su comportamiento y características físicas hacen que individuos de una especie tengan distinta capacidad reproductora, con lo que los genes más exitosos en el juego reproductivo son los que sobreviven;

9. Desarrollo de enfermedades. El desarrollo de muchas patologías se debe a la acción conjunta de distintos factores de tipo ambiental o genético. La aplicación de la teoría de juegos se suma a los tradicionales análisis estadísticos en el proceso de individuación y selección de los factores dominantes para el desarrollo de éstas enfermedades.

En la base de la TJ están los conceptos de:

Juego: modelo de situación conflictiva/cooperativa en el que varios sujetos (jugadores) concurren para obtener el máximo beneficio individual.

Jugador: agente racional que interactúa en el juego con otros agentes en búsqueda del máximo beneficio individual. Dependiendo del contexto, el jugador puede ser un ente individual, como un ciudadano o un consumidor, o puede representar un colectivo de personas o agentes con intereses comunes.

Estrategia: mejor respuesta de un jugador frente a las acciones de otros jugadores. 
Solución del juego: conjunto de pagos asignados a cada jugador en función de su estrategia y de las condiciones en las que se desenvuelve el juego. Los pagos pueden representar cantidades a pagar o beneficios según cual sea la naturaleza del juego.

La TJ se divide en dos disciplinas: la Teoría de Juegos No Cooperativos (en adelante TJNC) y la Teoría de Juegos Cooperativos (TJC).

\section{IV.2 TEORÍA DE JUEGOS NO COOPERATIVOS}

La Teoría de Juegos No Cooperativos centra su atención en las interacciones estratégicas entre agentes que persiguen sus objetivos sin la posibilidad de establecer acuerdos vinculantes entre ellos. El contexto es un entorno competitivo en el que cada sujeto actúa autónomamente con el fin de maximizar su beneficio en función de las posibles acciones de sus competidores. Los mercados perfectamente desarrollados y los acuerdos internacionales son el ámbito de aplicación ideal de la TJNC, que ha demostrado como en situaciones competitivas la búsqueda del óptimo individual para cada sujeto puede llevar a una pérdida general de bienestar, contrariamente a lo enunciado por la teoría del libre mercado.

En el siguiente ejemplo se propone un ejemplo clásico de aplicación de la TJNC en su adaptación a la gestión compartida de los recursos hídricos. Se evidencia como la desconfianza y falta de coordinación lleva a resultados sub-optimos pero perfectamente coherentes con las expectativas de los responsables de la toma de decisiones.

Pongamos el caso de dos regantes (A, B) que se abastecen del mismo recurso, limitado en cantidad o calidad y que se enfrentan al dilema acerca de la posibilidad de poner en marcha unas determinadas medidas de ahorro y mejora de la eficiencia con el fin de garantizar el suministro futuro de agua. Si ambas partes renuncian a realizar estas medidas se enfrentan a restricciones en el suministro, que comportarían unas pérdidas anuales estimadas de $500 € /$ ha, mientras la adopción de estas medidas permitiría salvar parte de la cosecha y obtener un beneficio de $500 € /$ ha. Si solamente un regante realizara las medidas de ahorro se enfrentaría a una condición de escasez de recurso agravada por el gasto relativo a las inversiones con un perjuicio estimado en $1000 € /$ ha, mientras su competidor se beneficiaría de los ahorros conseguidos sin tener que pagar inversión alguna y podría cerrar la temporada sin pérdidas. En la Tabla 7 se muestra una síntesis de los datos del problema. 


\begin{tabular}{|c|c|c|}
\hline Beneficios ( $€ /$ ha/año) & Ahorro & Riego \\
\hline Ahorro & $500 / 500$ & $-1000 / 0$ \\
\hline Riego & $0 /-1000$ & $-500 /-500$ \\
\hline
\end{tabular}

Tabla 7: Juego no cooperativo, datos del problema.

Este ejemplo corresponde a una actualización en la gestión de recursos hídricos del dilema del prisionero (Tucker, 1950). En ausencia de acuerdos vinculantes entre las partes cada jugador seguiría una estrategia minimax, consistente en buscar racionalmente la solución menos arriesgada, que le permitiría minimizar las posibles pérdidas (o maximizar los beneficios) independientemente de las acciones de los demás usuarios. En este caso la desconfianza mutua llevaría a ambos usuarios a la decisión de seguir regando sin invertir en medidas de ahorro, lo que aseguraría una pérdida cierta estimada entre 0 y 500€, contra la solución alternativa que podría generar pérdidas de hasta $1000 €$. Es más, en una condición de partida de riego ineficiente ningún usuario tendría incentivos para invertir en medidas de ahorro en ausencia de medidas coercitivas que impongan a los demás usuarios la puesta en marcha de las mismas medidas o impidan utilizar los recursos ahorrados. Cabe notar como la posibilidad de realizar una solución concertada y pactada entre los jugadores llevaría en este caso a un acuerdo para la inversión conjunta en medidas de ahorro que se reflejaría en una mejora del beneficio para ambas partes.

El "dilema del prisionero" es un ejemplo de situación no cooperativa de enorme importancia en cuanto evidencia las dificultades existentes para establecer la colaboración en cualquier situación en la que la quiebra de los acuerdos genera un beneficio inmediato para algunas de las partes. Además demuestra como las condiciones de libre competencia en la gestión de recursos compartidos no siempre conllevan una mejora del beneficio general (Gordon, 1954). La TJNC tiene aplicaciones en los problemas de explotación de los recursos naturales, incluidos los recursos hídricos, donde la falta de acuerdo puede llevar a la sobreexplotación o al aumento de la contaminación, con pérdidas de beneficio para la colectividad.

Como se ha explicado en los capítulos anteriores, la especificidad de los servicios hídricos hace que difícilmente éstos se gestionen de acuerdo con los mecanismos propios de los mercados competitivos. Las actuaciones en materias de recursos hídricos son el resultado de decisiones compartidas, negociadas y cuya aplicación está sometida a acuerdos vinculantes entre las partes interesadas y sujeta a la vigilancia por parte de un sujeto regulador. Bajo estos supuestos se considera la teoría de juegos cooperativos la más apropiada para el análisis de problemas de asignación de costes de los servicios del agua. 


\section{IV.3 TEORÍA DE JUEGOS COOPERATIVOS}

Tras los trabajos sobre la teoría de juegos realizados en 1928, John von Neumann definió una primera aproximación a los problemas de cooperación y competición en 1944 en un tratado que publicó con el economista Oskar Morgenstern, titulado Theory of games and economic behavior. En este libro definieron el concepto de juego cooperativo de $n$-personas e introdujeron las ideas relacionadas con la solución del juego. Todo el trabajo que se ha llevado a cabo desde entonces sobre los juegos de $n$-personas ha estado fuertemente influenciado por esta obra. En ella, un juego cooperativo es una situación derivada de una actividad en la que los sujetos que intervienen (personas, instituciones, empresas, etc.) persiguen alcanzar un determinado objetivo (ganar una votación, buscar mayores beneficios empresariales, mejorar la eficiencia de la gestión, repartir costes etc.) mediante la colaboración entre ellos. A diferencia de los denominados juegos competitivos o no cooperativos (enfocados al análisis de las estrategias que puede seguir cada uno de los jugadores), en un juego cooperativo no es necesario analizar con detalle las estrategias de los jugadores; es suficiente conocer los posibles resultados de la cooperación y determinar los pagos asociados a cada uno de ellos.

\section{IV.3.1 Conceptos básicos}

Un juego cooperativo está constituido por un conjunto finito $N=\{1,2, \ldots, n\}$, cuyos elementos se denominan jugadores. Si bien los jugadores actúan de forma autónoma, podrían estar interesados en realizar acuerdos de cooperación para maximizar su propio beneficio. Tales acuerdos de carácter vinculante se denominan coaliciones y se definen como un subconjunto $S \in 2^{\mathrm{N}}$.

Las coaliciones formadas reúnen las mismas condiciones que si fueran un jugador individual, son autónomas y capacitadas para tomar decisiones. El conjunto $m$ de coaliciones posibles en el entorno $\mathrm{N}$ se define estructura de coaliciones $\delta=\left\{S_{1}, \ldots, S_{m}\right\}$ y constituye una partición de $\mathrm{N}$ tal que:

$$
\begin{aligned}
& S_{j} \neq \phi \quad j=1, \ldots m \\
& S_{i} \cap S_{j}=\phi \quad \forall i \neq j \\
& \cup S_{j}=N \quad \forall S_{j} \in \delta
\end{aligned}
$$

Las condiciones anteriores indican que no hay coaliciones vacías, y que cada jugador pertenece a una y solamente una de las $\mathrm{m}$ coaliciones, siendo la gran 
coalición la unión de todas las coaliciones. Destacan las estructuras de coaliciones individuales, formadas por $m=N$ coaliciones de un solo jugador y la gran coalición con $m=1$ que agrupa la totalidad de los jugadores.

Un juego termina con un resultado, salida, pago o asignación (payoff) para cada uno de los jugadores. La colección de pagos para todos los jugadores se expresa mediante un vector llamado vector de pagos o función de pagos:

$$
X=\left(x_{A}, x_{B}, \ldots, x_{N}\right)
$$

El pago constituye el valor de cada jugador como resultado del juego. En la mayoría de los casos es posible expresar el valor en términos monetarios y se postula que cada jugador actúa de forma racional: en igualdad de condiciones siempre prefiere recibir más dinero que menos, o bien, asumir menos costes que mayores costes.

\section{IV.3.2 Función característica y configuración de pagos}

El concepto de función característica c(S) fue introducido por Von Neumann y Morgenstern (1944) y se define como la cantidad mínima que puede obtener la coalición $S$ si todos sus miembros actúan conjuntamente, independientemente de las acciones de los jugadores que no pertenecen a $S$.

Definido como $c(i)$ el coste para el usuario $i$ de satisfacer sus exigencias autónomamente y c(S) el coste de una medida conjunta para la coalición $\mathrm{S} \subseteq \mathrm{N}$, se considera por convención $\mathrm{c}(\varnothing)=0$ y c $(\mathrm{N})$ el coste de la gran coalición, formada por todos los jugadores potencialmente interesados en el proyecto.

En la definición de un juego cooperativo se asumen las siguientes suposiciones:

- Si es posible expresar el valor de la función característica en términos monetarios, se considera que cada coalición actúa de forma racional.

- Al final del juego el coste c(S) es distribuido entre los miembros de la coalición S mediante consentimiento unánime.

- El valor de c(S) es conocido por todos los participantes en el juego. 
Definición 1: Dada una partición de un proyecto común $S$ en dos o más subcoaliciones $S^{\prime}$ y $S^{\prime \prime}$, la función característica se considera subaditiva si:

$$
c\left(S^{\prime} \cup S^{\prime \prime}\right) \leq c\left(S^{\prime}\right)+c\left(S^{\prime \prime}\right)
$$

donde:

$\mathrm{c}(\mathrm{S})$ : coste asociado a la coalición "S"

Definición 2: La función característica es definida monotona si el coste aumenta a medida que aumenta el número de participantes al proyecto:

$$
c(S) \leq c\left(S^{\prime}\right) \quad \forall \quad S \subseteq S^{\prime}
$$

donde:

c(S): coste asociado a la coalición "S"

La razón principal que lleva a realizar proyectos mancomunados reside en el ahorro de coste que esos comportan. Para cada coalición $S$ el potencial de ahorro de coste se calcula como la diferencia entre el coste de la suma de actuaciones individuales y el coste de la actuación mancomunada.

$$
v(S)=\sum_{i \in S} c(i)-c(S)
$$

La función $v$ constituye el juego de ahorro de costes; si c es subaditiva, entonces:

a) $v$ es definida positiva y monótona

b) $v(N) \geq v(S) \forall S \subseteq N$

En un juego cooperativo la función característica evidencia las expectativas de cada jugador o coalición de jugadores y define implícitamente las condiciones en el que se tiene que desarrollar el proceso de asignación de costes.

Una configuración de pagos corresponde a un par $(\mathrm{x} ; \delta)$ constituido por una estructura de coalición $\delta$ y un vector de pagos $X=\left\{x_{1}, \ldots, x_{n}\right\}$ sujeto a la condición de equilibrio financiero :

$$
\sum_{i \in N} x_{i}=c(N)
$$


donde $x_{i}$ corresponde a la cantidad a pagar por parte del usuario " $\mathrm{i}$ " como participante en el proyecto, al que participan $\mathrm{N}$ jugadores, cuyo coste total asciende a la cantidad $\mathrm{c}(\mathrm{N})$.

Un método de asignación de costes es una función $\phi(\mathrm{c})$ que asocia una única asignación de costes a cada estructura de coalición. Objetivo de la TJC es definir los criterios que definen un método de asignación de coste eficiente y aceptable por parte de los usuarios.

\section{IV.3.3 Principios de equidad, racionalidad y eficiencia en la TJC}

Si se formula el problema de asignación de costes en términos más generales, se pueden considerar los n-jugadores como un conjunto de $\mathrm{N}=\{1,2, \ldots, n\}$ prestaciones en forma de bienes o servicios que pueden tener un coste distinto si obtenidas de manera individual o conjunta. La TJC define un conjunto de reglas y condiciones que, a partir del cálculo de la función característica, permiten alcanzar soluciones eficientes y satisfactorias para todos los jugadores mediante el establecimiento de acuerdos vinculantes de cooperación. La aplicación de la TJC se concreta por lo tanto en la traducción de los principios de equidad, justicia y aceptabilidad en términos axiomáticos, para su posterior implementación en algoritmos de cálculo.

\section{Principio de racionalidad}

En 1942 Ransmeier pone las bases para la definición de una metodología de asignación de costes definiendo el llamado "stand alone cost test", conocido también como el principio de racionalidad individual:

$$
x_{i} \leq c(i)
$$

La extensión de este principio a las posibles coaliciones se denomina racionalidad de grupo y se define como:

$$
x(S)=\sum_{S} x_{i} \leq c(S)
$$

De acuerdo con los principios de racionalidad individual y colectiva ningún jugador o grupo de jugadores pertenecientes a un proyecto mancomunado aceptarían una tarifa superior al coste que tendrían que pagar actuando individualmente. 


\section{Principio de marginalidad}

Otra forma de expresar el principio de racionalidad de grupo es el principio de marginalidad, según el cual cada jugador o grupo de jugadores debería pagar al menos el coste marginal que supondría su inclusión en un proyecto desarrollado por otra coalición:

$$
x(S) \geq c(N)-c(N-S) \quad \forall \quad S \subseteq N
$$

La violación del principio de marginalidad supondría que una coalición preexistente está subsidiando la entrada de otros usuarios en el proyecto. Es posible demostrar la equivalencia entre el principio de racionalidad de grupo y de marginalidad si se cumple la condición de equilibrio financiero $\sum x_{i}=c(N)$. $\mathrm{Al}$ ser las dos condiciones equivalentes se puede afirmar que, si algún usuario no cubre su coste incremental, algún otro usuario lo estará pagando por él y por consecuencia estaría pagando más que su coste individual (Faulhaber, 1975).

\section{IV.3.4 El núcleo de un juego cooperativo}

Los elementos hasta ahora considerados introducen el concepto de núcleo de un juego cooperativo, definido por Gillies en 1953. En un juego de asignación de costes el núcleo corresponde al espacio de soluciones $X=\left\{x_{1}, \ldots, x_{n}\right)$ que cumplen los principios de racionalidad y marginalidad.

Es posible representar el núcleo de un juego de tres jugadores mediante un diagrama triangular, como se puede mostrar en la Figura 8, que corresponde al caso de ejemplo descrito en el apartado III.4. En caso de juegos con un número de jugadores $N>3$ el núcleo se define el un multiespacio vectorial de $N-1$ dimensiones. 


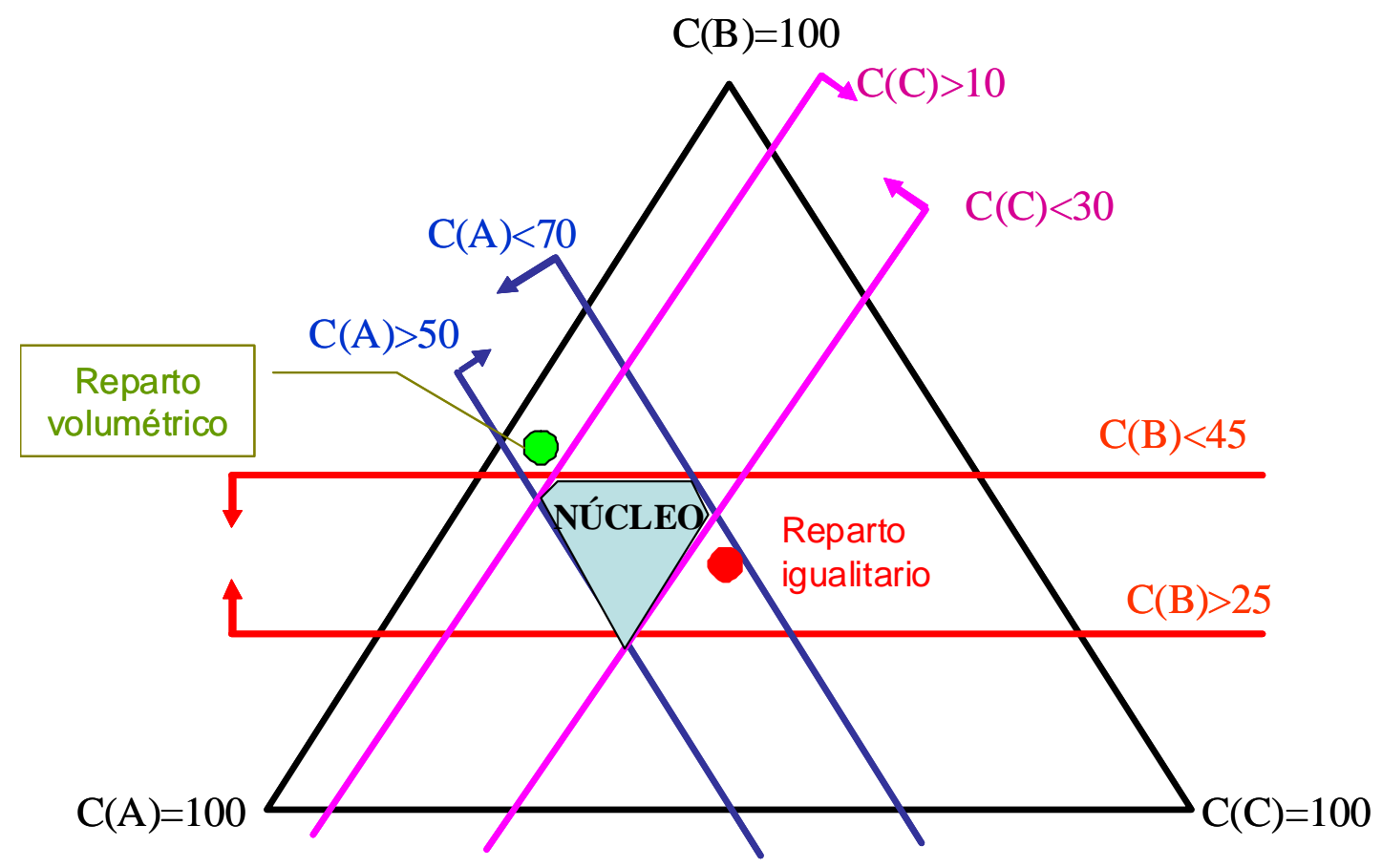

Figura 8: Caso de ejemplo, el núcleo.

En la figura anterior, cada vértice corresponde a una situación en la que los costes son asignados integralmente a un usuario. Las líneas paralelas dispuestas al lado opuesto de cada vértice marcan las fronteras de los costes máximos/mínimos determinados por los principios de racionalidad individual y de marginalidad. El baricentro del triángulo corresponde a la asignación igualitaria $\mathrm{c}(\mathrm{N}) / 3$.

Se puede observar como las asignaciones correspondientes a los criterios analizados en el ejemplo descrito en el apartado III.4 (reparto volumétrico, igualitario) quedan fuera del núcleo y, por lo tanto, no pueden considerarse soluciones aceptables.

La definición del núcleo puede presentar ciertas complejidades para números elevados de jugadores; en este caso es necesario analizar todas las estructuras de coalición para definir una función característica y calcular todas las configuraciones de pagos que cumplan los requisitos de eficiencia, racionalidad y marginalidad.

El concepto de núcleo es quizás el más sencillo y persuasivo de todos los conceptos de solución cooperativos, en cuanto permite individuar la actuación más eficiente y repartir integralmente los costes a los usuarios. Desde el punto de vista económico representa una asignación de los costes en la que ningún jugador podría mejorar su condición sin perjudicar a otros miembros de la 
coalición. Cabe destacar la equivalencia entre el concepto de núcleo de un juego cooperativo y el principio de optimalidad según Pareto.

\section{IV.3.4.1 Condiciones de existencia del núcleo}

El núcleo ayuda a definir el reparto de costes en cuanto reduce el abanico de soluciones posibles y permite comprobar la aceptabilidad de una política de precios. Sin embargo, no todos los juegos cooperativos presentan soluciones en el núcleo. Un juego de asignación de costes en el que es imposible definir un conjunto de soluciones que estén contenidas en el núcleo se define juego de núcleo vacío.

Las condiciones de existencia del núcleo están determinadas por la función característica del juego. Si la subaditividad es condición necesaria para la existencia de economías de escala en proyectos mancomunados, la existencia del núcleo requiere condiciones más estrictas.

Shapley, en 1971, demostró que, si la función característica es cóncava, el núcleo de un juego cooperativo es no-vacío. En un problema de asignación de costes una función característica cóncava está relacionada con la existencia de economías de escala crecientes a medida que vaya aumentando el número de participantes al proyecto.

$$
c(S \cup\{i\})-c(S) \leq c\left(S^{\prime} \cup\{i\}\right)-c\left(S^{\prime}\right) \quad \forall i, \forall S^{\prime} \subseteq S \subseteq N
$$

Una función característica cóncava es condición suficiente pero no necesaria para la existencia del núcleo, pueden existir juegos de núcleo no-vacío cuyas economías de escala no sean crecientes.

En (Shapley y Shubik, 1954) se muestra que un juego con núcleo no vacío es sociologicamente neutral, es decir, cada coalición puede ser satisfecha y no son necesarios mecanismos sociales para solucionar conflictos y resolver prioridades. Por otro lado, en juegos de núcleo vacío la sociedad debe vigilar para el cumplimiento de los criterios de eficiencia y, si es necesario, intervenir en la formación de coaliciones mediante oportunos incentivos/desincentivos.

Si la inexistencia del núcleo representa un problema debido a la falta de incentivos a la cooperación, la existencia de un núcleo excesivamente amplio plantea dificultades a la hora de definir una configuración de pagos en cuanto reduce la capacidad de negociación de las sub-coaliciones y puede dar lugar a asignaciones de costes muy dispares aunque igualmente racionales. En este caso, como en el caso de juegos con núcleos vacíos, la TJC proporciona las herramientas matemáticas para analizar las situaciones de conflicto y ayuda a calibrar los incentivos adecuados para fomentar la cooperación. 


\section{IV.3.5 Extensiones del núcleo: cuasi núcleos y nucleolos}

Los mecanismos para resolver los problemas relacionados con el tamaño del núcleo, la multiplicidad o no existencia de soluciones, se basan en la relajación (o refuerzo) del conjunto de inecuaciones que definen el núcleo.

\section{IV.3.5.1 La teoría del exceso y el nucleolo}

En condiciones de núcleo amplio resultan razonables distintas configuraciones de pago, las cuales pueden resultar más beneficiosas para unos $\mathrm{u}$ otros jugadores y generar desigualdades entre usuarios. La teoría del exceso trata de mejorar la estabilidad y balance en la asignación de coste en cuanto se basa en medir la actitud de un jugador o de una coalición hacia la solución propuesta.

Dada una coalición $S$ y un vector de pagos $X$, el exceso se define como la diferencia entre el valor de la función característica correspondiente a $S$ y la suma de las asignaciones de costes de los jugadores pertenecientes a la misma coalición.

Matemáticamente:

$$
e(X, S)=c(S)-\sum_{i \in S} x_{i}
$$

En otras palabras el exceso mide los ahorros o perjuicios que los jugadores obtendrían de una determinada configuración de pagos respecto al coste de la solución alternativa de menor coste. Si el valor de $\mathrm{e}(X, S)$ es positivo la configuración de pagos es aceptable para la coalición, sin embargo el objetivo de cada jugador es obtener una tarifa que le proporcione el máximo exceso posible.

\section{El nucleolo (Schmeidler, 1969)}

El nucleolo se define como la configuración de pagos que maximiza lexicograficamente el mínimo exceso. En otras palabras el nucleolo representa la configuración de pagos en la que el valor del mínimo exceso es el mayor posible y se produce en el menor número de sub-grupos de jugadores.

La solución se basa en maximizar el mínimo exceso asociado a cada posible coalición, el problema se resuelve a través de métodos de programación lineal. 


$$
\begin{gathered}
\max \delta \\
\text { sujeto a: } \quad \sum_{i \in S} x_{i}+\delta \leq c(S) \forall S \neq \phi, N \\
\sum_{i \in N} x_{i}=c(N)
\end{gathered}
$$

Si el núcleo dispone de una única solución, $\mathrm{X}=\left(x_{1}, x_{2}, \ldots, x_{N}\right)$, esta es el nucleolo. Si el núcleo es amplio y hay distintas soluciones posibles se procede con la siguiente regla:

- Para cada configuración de pagos $X$ se define el vector $z(X)$, cuyos valores representan los excesos $\mathrm{e}(\mathrm{x}, \mathrm{S})$ correspondientes a las $2^{\mathrm{N}}-1$ coaliciones posibles;

- Se ordenan, para cada configuración de pago, los elementos e(x,S) del vector $z(X)$, por orden creciente;

- Se escoge el vector $z(X)$ lexicograficamente mayor comparando uno a uno los componentes.

El nucleolo proporciona una solución única al problema de la asignación de costes cuando el núcleo está constituido por un conjunto amplio de soluciones factibles. Mediante el nucleolo se aplica rigurosamente el principio de equidad en cuanto se realiza un balance en la configuración de pagos tal que la coalición más desfavorecida sea lo menos perjudicada posible.

\section{IV.3.5.2 Variantes sobre el nucleolo}

Las variantes sobre el nucleolo se basan en modificar la fórmula del exceso $e(x, S)$ para que el reequilibrio en la asignación de costes sea calculado en función de otros parámetros como: el coste de cada coalición c(S), del número (S) de participantes a la coalición, la propensión al abandono de la coalición.

Nucleolo proporcional (Young et al., 1982).

Se concede un beneficio en la asignación del coste proporcional al coste de cada sub-coalición.

$$
e(x, S)=\frac{c(S)-\sum_{i \in S} x_{i}}{c(S)}
$$


La solución se encuentra resolviendo el siguiente problema de optimización a través de la programación lineal.

$$
\begin{gathered}
\max \sigma \\
\text { sujeto a: } \quad \sum_{i \in S} x_{i} \leq c(S)(1-\sigma) \quad \forall S \neq \phi, N \\
\sum_{i \in N} x_{i}=c(N)
\end{gathered}
$$

Nucleolo normalizado (Grotte, 1971)

Se define el exceso proporcional al número de componentes de un sub-grupo, según un criterio per capita.

$$
e(x, S)=\frac{c(S)-\sum_{i \in S} x_{i}}{S}
$$

Nucleolo disyuntivo ( Littlechild and Vaidya, 1976; Michener et al., 1981)

$$
d(x, S)=\frac{c(N \backslash S)-\sum_{i \in N \backslash S} x_{i}}{C(S)-\sum_{i \in S} x_{i}}
$$

Define la propensión al abandono de la sub-coalición $d(x, S)$ como el cociente entre cuanto perderían las coaliciones $N / S$ y $S$ si se abandonara un determinado criterio de asignación de costes. La finalidad del método es determinar una configuración de pago más favorable para las coaliciones que tienen una mayor propensión al abandono del proyecto. El método de búsqueda de la solución es idéntico al cálculo del nucleolo precedentemente descrito.

\section{IV.3.5.3 Juegos con núcleo vacío}

El proceso inverso puede ser aplicado en casos de núcleos vacío para estimular la formación de un conjunto de soluciones factibles. En un juego con núcleo vacío determinadas coaliciones gozan de alternativas de proyecto excepcionalmente buenas si se compara con la gran coalición que, sin embargo, representa la alternativa más eficiente para el conjunto de jugadores. Se puede por lo tanto estimular la participación de determinados sub-conjuntos en la 
gran coalición a través de una imposición $\varepsilon$ que penalice la realización de proyectos alternativos individuales.

\section{Mínimo núcleo apreciable (Least Core)}

La definición de least core (Einy et al., 1998) se basa en la individuación de la mínima imposición $\varepsilon$ que proporcione un desincentivo adecuado a la nocooperación hasta conseguir una coalición completa de N-elementos.

$$
\begin{gathered}
\min \varepsilon \\
\text { sujeto a: } \quad \sum_{i \in S} x_{i} \leq c(S)+\varepsilon \quad \forall S \subset N \\
\sum_{i \in N} x_{i}=c(N)
\end{gathered}
$$

Obsérvese la similitud con el cálculo del nucleolo: en este caso se tasan las subcoaliciones más favorecidas hasta que se encuentre un núcleo estable, en el otro caso se busca el mínimo incentivo para las coaliciones más perjudicadas que permita reducir el espacio del núcleo a un solo punto.

\section{El núcleo debil (Weak least core)}

El núcleo débil se basa en la imposición de una tasa a cada usuario singular que se desvincula de la gran coalición. La definición del núcleo débil corresponde al siguiente proceso de optimización:

$\min \varepsilon$

$$
\begin{aligned}
& \text { sujeto a: } \quad \sum_{i \in S} x_{i} \leq c(S)+\varepsilon|S| \quad \forall S \subset N \\
& \sum_{i \in N} x_{i}=c(N)
\end{aligned}
$$

donde $|S|$ representa la cardinalidad de S. 


\section{IV.3.6 El valor de Shapley}

El valor de Shapley (Shapley, 1953) introduce un concepto de solución bajo una perspectiva axiomática, es decir que la solución está definida como consecuencia de la satisfacción de determinadas propiedades.

Shapley demostró que existe solamente una configuración de pagos $\mathrm{X}=\left(x_{1}, x_{2}, \ldots, x_{N}\right)$, que satisface los siguientes axiomas:

Axioma 1: Simetría y tratamiento igualitario. Dos jugadores que presentan la misma función de costes obtendrán la misma asignación de costes. El valor del juego no depende de la designación de los jugadores.

Axioma 2: Optimalidad de Pareto y eficiencia. La tarifa permite asignar la totalidad de los costes correspondientes a la actuación más eficiente.

Axioma 3: Jugador nulo o fantasma. Se define un jugador nulo como aquel que no aporta ningún beneficio a la coalición en términos de economías de escala.

$$
\mathrm{c}(\mathrm{S})=\mathrm{c}(\mathrm{S} \backslash\{i\})+\mathrm{c}(i) \quad \forall \mathrm{S} \rightarrow i \in \mathrm{S}
$$

Un jugador nulo no se verá beneficiado por la regla de asignación de costes.

Axioma 4: Aditividad. La configuración de pagos derivada de la suma de dos juegos es igual a la suma de las configuraciones de pago de los dos juegos calculadas por separados. La condición de aditividad permite articular la realización de un proyecto en distintas fases o unificar distintas actuaciones manteniendo invariada la asignación de costes de los usuarios.

Axioma 5: Monotonía en costes. Todos los miembros de una coalición participan de un eventual aumento del coste del proyecto. Ningún participante conseguirá un beneficio/perjuicio en la asignación de coste a causa de un aumento/disminución de costes del proyecto. Esta propiedad resulta particularmente útil en caso que:

- Haya incertidumbre sobre el coste final del proyecto;

- Sea necesario alcanzar un acuerdo de cooperación que incluya el reparto de costes en fase de anteproyecto.

El valor de Shapley es la única configuración de pagos que satisface a priori los axiomas anteriores, y se calcula mediante la siguiente fórmula: 


$$
x_{i}=\sum_{S \subseteq N-i} \frac{|S| !(|N-S|-1) !}{|N| !}[c(S+i)-c(S)]
$$

donde:

$x_{i}$ : coste asignado al jugador " $\mathrm{i}$ ";

$|S|$ : cardinalidad de la coalición S;

$|N|$ : número de componentes del proyecto, cardinalidad de la gran coalición;

$c(S+i)$ : función de costes asociada a la coalición $(\mathrm{S}+i)$;

$c(S)$ : función de costes asociada a la coalición $S$.

El método asigna a cada jugador el promedio de sus contribuciones marginales a la coalición, considerando cada posible coalición equiprobable, y goza de las siguientes propiedades:

- Permite encontrar una solución única al problema de asignación de costes, también en casos de núcleo vacío en los que daría lugar a soluciones inestables.

- La solución pertenece al núcleo si la función de costes es cóncava, en este caso será el baricentro del núcleo.

- Es típicamente aditivo, la asignación de coste de los servicio puede considerarse como la suma del coste correspondiente a distintos servicios calculados independientemente.

- El cálculo no comporta la ejecución de procesos de optimización.

Por sus características, el valor de Shapley representa una forma directa y simple de encontrar una solución racional y eficiente de un juego cooperativo, independiente del número de jugadores. Sin embargo, sólo es posible asegurar que la configuración de pagos encontrada se encuentre en el núcleo en caso que la función característica sea cóncava. Una amplia literatura sobre aplicaciones de la TJC a ejemplos reales demuestra la utilidad del valor de Shapley como primer método de cálculo de la configuración de pagos. 
IV.3.7 Juegos y eficiencia económica: los juegos de demanda revelada

Las configuraciones de pagos determinadas por la TJC en los apartados anteriores se basan únicamente en el análisis de la función de costes del proyecto. Sin embargo el proceso de definición de las tarifas puede requerir que los costes sean asignados teniendo en cuenta la disponibilidad de pago o los beneficios generados por la inversión. Si una configuración de pagos asignara a un usuario un coste superior a los beneficios esperados, éste se desvincularía de la coalición.

Los datos relativos al beneficio económico suelen ser más subjetivos que los costes, en cuanto cada usuario se siente incentivado a declarar menos ingresos y enviar falsas señales con el fin de beneficiarse de una asignación de costes más favorable. En general no existe una metodología que permita definir soluciones justas y económicamente eficientes en ausencia de datos fiables sobre el beneficio económico de los usuarios, pero es posible definir mecanismos de demanda revelada que aseguren la recuperación de costes a través de la selección de una sub-coalición (S) económicamente eficiente.

Los juegos de demanda revelada (Young H.P., 1980) se basan en la declaración de la disponibilidad de pago por parte de cada usuario y en el cálculo de una configuración de pagos eficiente en función de las declaraciones de los usuarios, según el proceso que se muestra a continuación:

1. Cada jugador declara su disponibilidad de pago $\left(u_{i}\right) \mathrm{y}$, a partir del coste $c(S)$, se calcula el beneficio asociado a cada coalición S:

$$
b(S)=\sum_{i \in S} u_{i}-c(S)
$$

2. A partir de las declaraciones de cada uno se define la coalición "aparentemente" más eficiente $S^{*}$ :

$$
v\left(S^{*}\right)=\max \beta(S) \quad S^{*} \subseteq N
$$

3. Definida $v\left(S^{*}\right)$ es posible calcular, mediante el valor de Shapley, nucleolo u otros métodos, una configuración de beneficios $Y=\left(y_{1}, y_{2}, \ldots, y_{n}\right)$ para los jugadores pertenecientes a la coalición $S^{*}$, tal que $\sum_{N} y_{i}=v(N)$.

4. Para cada asignación de beneficios $Y$ se define el equivalente vector de asignación de costes $X$ según la siguiente: 


$$
x_{i}=\left\{\begin{array}{ccc}
u_{i}-y_{i} & \text { if } \quad i \in S \\
0 & \text { if } & i \notin S
\end{array}\right.
$$

5. Los jugadores que pertenecen a la coalición $\left(S^{*}\right)$ pagarán el coste $\left(x_{i}\right)$ asignado y se repartirán el beneficio $\mathrm{v}\left(S^{*}\right)$ generado por la cooperación;

6. Los que no entran en la coalición $\left(S^{*}\right)$ por tener (o por haber declarado) una disponibilidad de pago excesivamente baja no participarán en los costes del proyecto y recibirán un beneficio nulo.

Las declaraciones de cada jugador se podrán modificar hasta alcanzar una coalición estable de $\mathrm{R} \subseteq \mathrm{N}$ elementos, en la que ningún jugador mejorará su situación al modificar su declaración. El punto de equilibrio calculado al final del proceso es por definición eficiente y recupera los costes.

\section{IV.4 APLICACIONES DE LA TJC}

En este apartado se muestran varios ejemplos de aplicaciones de la TJC a problemas relacionados con la asignación de los costes de actuaciones conjuntas. Se presentan casos de disputas en la asignación de costes en distintos contextos (recursos hídricos, transportes, electricidad) y los conceptos de soluciones aplicados en los que aparecen las metodologías analizadas anteriormente.

\section{Embalse multipropósito: el caso de la Tennessee Valley Authority}

La Tennessee Valley Authority (TVA) representa quizás el primer y más completo caso de estudio que permitió a los investigadores analizar un problema práctico de asignación de coste, bajo el punto de vista de la TJC. El problema tiene fecha de 1930 y consistió en la búsqueda de un criterio de asignación de costes para la definición de las tarifas de un embalse artificial para la regulación de recursos superficiales, la laminación de avenidas y la navegación fluvial. Los costes del proyecto exhibían evidentes economías de escala en función del tamaño de la presa y los beneficios marginales eran decrecientes para los usuarios. Los ingenieros de la época consideraron diferentes métodos de asignación de costes y concibieron de forma embrional los conceptos de núcleo, nucleolo y nucleolo disyuntivo que posteriormente fueron formulados rigurosamente en los primeros estudios de la TJC. El problema fue analizado a posteriori por Ransmeier (1942), que desveló el proceso de negociación y los distintos métodos de asignación de costes propuestos. 
Asignación de costes de los servicios hídricos municipales: el caso de la región de Skåne

El segundo ejemplo es un estudio realizado por Young y Okada (1982) sobre el proyecto de un sistema de transporte y distribución de agua mancomunado entre 18 municipios de la región de Skåne en el sur de Suecia, en la cual se incluye la ciudad de Malmö. Cada municipio necesita incrementar la disponibilidad de agua y dispone de varias alternativas de suministro, entre las cuales se consideran las actuaciones individuales mediante pozos y un proyecto conjunto de abastecimiento mediante un trasvase intercuencas. En el estudio se propone la racionalización de los 18 municipios del sistema en 6 macrousuarios homogéneos e independientes en base a sus características geográficas y socio-económicas con el fin de simplificar el análisis. Sigue el cálculo de la función característica y la aplicación de 7 métodos distintos de asignación de costes: proporcional a la población, proporcional a la demanda, SCRB, valor de Shapley, nucléolo, nucleolo proporcional, coste marginal. Los resultados obtenidos son comparados y evaluados en base a los criterios definidos por los autores: racionalidad individual, marginalidad, asignación de costes directos, monotonía, jugador nulo, simplicidad de cálculo. El estudio muestra la dificultad de individuar un criterio de asignación de coste que pueda cumplir con todos los requisitos planteados por los autores y que a la vez resulte de fácil aplicación e interpretación por parte de los usuarios.

Otro ejemplo interesante de asignación de costes para usos urbano se describe en el trabajo de Lippai y Heaney (2000), en el que se propone una metodología basada en la TJC para el reparto de los costes del suministro de agua urbano entre tres clases de demandas: barrios residenciales de elevada densidad habitativa, barrios residenciales de baja densidad y zonas comerciales. Los resultados muestran que la aplicación de la TJC permite obtener asignaciones de costes más equitativas y eficientes respecto a las metodologías tradicionales basadas en un reparto de tipo volumétrico.

\section{Asignación del coste de las infraestructuras basada en el valor de Shapley}

En el estudio de Littlechild y Thompson (1977) se define una metodología basada en la aplicación del valor de Shapley para el cálculo de las tarifas aeroportuarias en función de la longitud requerida de la pista de aterrizaje y el número de movimientos anuales por parte de las distintas tipologías de aviones. Se muestra como el valor de Shapley permite repartir el coste de manera eficiente y racional en ausencia de mecanismos de mercado.

Un estudio similar ha sido realizado por Fragnelli et al. (2002) en el ámbito de la asignación de los costes de las infraestructuras ferroviarias, en el que se extiende la aplicación del valor de Shapley al cálculo de los costes de mantenimiento y reposición. 
Otro trabajo publicado por Fragnelli y Iandolino (2004) muestra la utilidad de la TJC en el cálculo de las tarifas del servicio mancomunado de recogida y tratamiento de residuos sólidos urbanos en la región de Ovadese-Valle Scrivia (Italia). En el estudio se presenta un modelo de cálculo basado en el valor de Shapley que supera las políticas de precios tradicionales basadas en el reparto proporcional al volumen de residuos producidos por cada municipio.

\section{Aplicaciones a la contaminación de las aguas}

Giglio and Wrightington (1972) abren un importante campo de investigación dedicado a la aplicación de la TJC a los problemas de tratamiento de aguas residuales. Se estudian los beneficios en términos de ahorro de coste y mejoras ambientales, derivados de la realización de una planta de tratamiento de aguas residuales mancomunada y se calcula la función característica del proyecto en relación con los impactos de la carga contaminante generada por cada usuario sobre el medio hídrico. Finalmente se define la asignación de costes mediante métodos tradicionales (proporcional a la carga contaminante, SCRB, coste marginal) y aplicación de juegos cooperativos.

Otras aplicaciones de la TJC a problemas de asignación de costes de tratamiento de aguas residuales se desarrollan también en: Loehman (1995) , Holler y Li (1996). En Dinar et al. (2003) se estudia la influencia de consideraciones estocásticas en la solución de un juego cooperativo aplicado a una planta de tratamiento de aguas residuales, en función de la actitud frente al riesgo de los usuarios y de la función característica del proyecto.

\section{Aplicaciones a sistemas complejos: tarifación del sistema de transmisión eléctrica}

El trabajo realizado por Contreras (1997) sobre la tarifación del sistema de transporte eléctrico ha abierto una importante rama de investigación acerca de la aplicación de la TJC en la asignación de costes de los sistemas complejos. Los trabajos posteriores de Zolezzi Cid (2002), Evans Miranda (2002) y Sore Osorio (2003) muestran las potencialidades de la aplicación de modelos de simulación asociados a la TJC en la definición de una política de precios para el sistema eléctrico descentralizado chileno. Los trabajos citados superan las limitaciones que han relegado la aplicación de la TJC a contextos reducidos por extensión territorial y nivel de interconexión entre usuarios y abren nuevos horizontes para su aplicación a sistemas complejos, multisectoriales y multiagentes; como son los servicios hídricos.

Más información sobre la aplicación de la TJ en la gestión de los recursos naturales se puede encontrar en (Zara et al, 2006). 


\section{IV.5 APLICACIÓN DE LA TJC A LA ASIGNACIÓN DE LOS COSTES DE LOS SERVICIOS DEL AGUA}

En los apartados anteriores se han revisado las distintas posibilidades de aplicaciones de la TJC para el reparto de los costes de actuaciones mancomunadas. Se ha demostrado como el proceso de asignación de costes no es un simple ejercicio matemático sino un problema práctico que consiste en trasladar los condicionantes físicos, técnicos, económicos e institucionales al lenguaje matemático.

Los servicios del agua presentan todas las características de los sistemas de monopolio natural en el que los precios no son el resultado del libre mercado sino de acuerdos y negociaciones entre los usuarios y el organismo regulador. La elevada interconexión entre usuarios, la característica de bien social del agua y la elevada reglamentación del sector, junto con los recientes avances normativos que imponen la recuperación de costes y la reducción de los subvenciones públicas, hacen de los servicios hídricos un campo de aplicación ideal de la TJC y un desafío para los investigadores que a través de la TJC pretendan desarrollar nuevas metodologías para la definición de las tarifas del agua.

El análisis sobre la posible aplicación de los algoritmos de la TJC a los problemas relacionados con los servicios del agua ha puesto de manifiesto los siguientes aspectos:

- Sujetos involucrados en el juego. Hay que definir las unidades de análisis, sean estas municipios, comunidades de regantes, empresas suministradoras, personas, hectáreas regadas, etc.

- Nivel de escala del juego. El juego tiene que ser definido en un marco territorial, es posible definir juegos a diferente escala territorial en función del servicio del que se pretende asignar el coste. Se puede individuar un juego a escala municipal para el reparto de los costes de distribución entre distintas categorías de usuarios (comerciales, domésticos, industriales, residenciales, turísticos...), al que se asocia un juego a nivel comarcal para la asignación de los costes de un planta de depuración mancomunada y finalmente un juego a escala regional para el reparto de los costes de regulación, laminación o trasvase intercuenca.

- El número de jugadores. En un problema con $\mathrm{N}$ jugadores involucrados el número de coaliciones crece en razón de $2^{\mathrm{N}}-1$. Esto puede aumentar enormemente la complejidad del cálculo y la necesidad de información en caso de sistemas excesivamente atomizados. Aunque las prestaciones de los ordenadores actuales ofrezcan una capacidad de cálculo cada vez mayor, se plantea la necesidad de racionalizar el número de jugadores en 
cuanto la individuación de un número mínimo de actores independientes comporta un menor requerimiento de información y favorece la comprensión y divulgación de los resultados del cálculo.

- Los objetivos del proceso de asignación de costes. Se han individuado distintos métodos de asignación de costes basados en la TJC, cada uno con sus propiedades y limitaciones. La elección de un algoritmo de cálculo determinado se fundamenta por lo tanto en los objetivos de la tarifación, en el contexto en el que se desarrolla el proyecto y en la información disponible y requerida sobre sus costes.

- Información económica. La aplicación de la TJC requiere un largo trabajo de preparatorio destinado a la recopilación y generación de toda la información necesaria para la definición del juego. Para definir la función característica del juego no es suficiente estimar los costes finales del proyecto, es necesario definir y ajustar una propuesta de proyecto óptima para cada una de las coaliciones.

- Análisis de escenario. El análisis de sistema complejos e interconectados como los servicios hídricos plantea la necesidad efectuar pronósticos a largo plazo, previsiones de demandas, volúmenes, disponibilidad del agua e infraestructuras para distintos escenarios de coalición. Estos análisis serían absolutamente inviables sin la ayuda de modelos de simulación de la gestión que permitan reproducir con suficiente precisión el comportamiento de una cuenca hidrográfica o de un sistema hidráulico en relación con las distintas propuestas de proyecto.

La TJC puede jugar un papel importante en el proceso de definición de las tarifas de los servicios del agua, proporcionando las herramientas necesarias para el análisis de situaciones conflictivas tanto a nivel local como en ámbito regional. El uso de modelos de simulación ayuda a generar la información necesaria y permite extender la aplicación de la TJC a los sistemas complejos. 


\section{CAPÍTULO V MODELOS DE GESTIÓN DE RECURSOS HÍDRICOS}

Un Sistema de Recursos Hídricos (en adelante SRH) se define como la parte continental del ciclo hidrológico, es decir como el conjunto de elementos responsables de transportar el agua desde el lugar de precipitación hasta el mar o la atmósfera. Puede comprender distintas cuencas hidrográficas conectadas entre ellas o partes de las mismas y está constituido por distintos elementos geográficos y antrópicos: cauces, canales, conducciones, embalses, acuíferos, áreas de riego, zonas de interés ambiental, abastecimientos a ciudades, centrales hidroeléctricas, zonas recreativas, deportivas, etc.

La comprensión del funcionamiento de un sistema hídrico está condicionada por el elevado nivel de complejidad y de interdependencia entre los elementos que lo componen. En sistemas grandes o fuertemente interconectados puede resultar difícil efectuar previsiones sobre su comportamiento y cuantificar las respuestas del sistema bajo distintas hipótesis de gestión.

Los modelos de gestión de sistemas hídricos ofrecen una representación conceptual y simplificada de la realidad de un SRH, en la que se preservan las características esenciales del mismo con el fin de interpretar los procesos que están en la base del ciclo hidrológico. En el presente trabajo, al hablar de modelos, se hace referencia únicamente a los modelos matemáticos, en los que las relaciones entre elementos se representan a través de sistemas de ecuaciones y se resuelven mediante herramientas informáticas.

Todos los modelos matemáticos se caracterizan por los siguientes componentes:

a) Parámetros: son valores numéricos conocidos y considerados fijos en cada paso de cálculo. Para estudiar como influye la variación de un parámetro en el resultado del modelo se realiza un estudio de sensibilidad mediante múltiples ejecuciones con diversos valores del parámetro. Un ejemplo de parámetros son el coeficiente de evaporación de un embalse o el coeficiente de desagüe de un acuífero. 
b) Variables: son los valores numéricos que interesa conocer y que cuantifican la respuesta del sistema, como por ejemplo el caudal en un tramo del río, el suministro de agua, el volúmen de un embalse, el caudal bombeado por una instalación.

c) Restricciones: representan las relaciones que vinculan las variables y los parámetros del modelo y describen el funcionamiento del sistema. Un ejemplo de restricciones son las ecuaciones de continuidad en las confluencias de los ríos, la ecuación de balance en los embalses u objetivos particulares de eficiencia de la gestión.

En la práctica de la gestión de los recursos hídricos y en la literatura científica se han afirmado dos clases de modelos, de acuerdo al papel que juegan las variables en el proceso de cálculo:

\section{Modelos de simulación}

También llamados de causa-efecto, en los que las reglas de operación se establecen a priori y las variables describen un estado del sistema como respuesta a unos datos de entrada del mismo. Su utilidad reside en la posibilidad de efectuar una representación, lo más detallada posible, de la realidad del sistema. Los modelos de simulación permiten efectuar previsiones sobre la respuesta del sistema frente a eventos extremos, como las sequías, o evaluar y comparar la eficiencia de distintas alternativas de gestión del sistema. La búsqueda de una solución óptima de gestión (en términos de infraestructuras o de reglas de operación) se realiza mediante ensayos de prueba y error al modificar los datos de entrada o los parámetros del modelo.

\section{Modelos de optimización}

En los modelos de optimización (o prescriptivos) el objetivo del cálculo es determinar el valor de unas variables que optimicen una función objetivo prefijada. Las variables tienen por lo tanto cierta libertad dentro de un rango de valores y se calculan mediante técnicas de investigación operativa en las que quedan definidas con claridad la estructura y las restricciones de la función objetivo.

El enfoque de optimización se diferencia por lo tanto de la simulación en cuanto que el ensayo de prueba y error, que en la simulación permite alcanzar soluciones de gestión más eficientes, se realiza internamente en el proceso de cálculo mediante un algoritmo matemático que utiliza el valor de la función objetivo como indicador de la bondad de la solución. 
La mayor limitación de los modelos de optimización reside en la necesidad de reducir los procesos complejos de un SRH en una función objetivo cuya solución sea abordable mediante técnicas numéricas, lo que puede llevar a una excesiva simplificación del sistema. Al contrario, los modelos de simulación no están sujeto a la búsqueda de una combinación óptima de variables y permiten una representación más detallada de las relaciones y procesos del sistema. Por esta razón los dos enfoques se suelen usar de forma complementaria, mediante procedimientos mixtos de simulación-optimización que tratan de combinar ambos métodos mediante el siguiente procedimiento:

- En la primera fase se realiza la búsqueda de la regla de explotación más beneficiosa de acuerdo con una determinada serie de aportaciones mediante los procedimientos clásicos de optimización;

- En la segunda fase se simula intervalo a intervalo el comportamiento del sistema y se ajustan con un mayor nivel de detalle las reglas de operación precedentemente obtenidas.

Los modelos de gestión de SRH también se pueden clasificar de acuerdo a algunas de sus características:

- Versatilidad:

- a medida: solución de casos particulares, consiguen una mayor adaptación a las características del SRH considerado;

- genéricos: aplicables a distintos sistemas hídricos, bajo ciertas condiciones.

- Discretización espacial:

- agregados: variables y parámetros homogéneos en todo el sistema;

- distribuidos: se consideran diferencias entre las distintas partes del sistema.

- Discretización temporal:

- estacionarios o estáticos: no se considera explícitamente el tiempo como una variable;

- dinámicos: se considera explícitamente la variable temporal.

- Estructura de la función objetivo:

- lineal: se considera una función objetivo y unas restricciones lineales;

- no lineal: las restricciones y/o la función objetivo son definidas nolineales.

- Técnica de optimización utilizada: 
- programación dinámica;

- programación lineal;

- programación entera;

- de redes de flujo;

- multiplicadores de Lagrange;

- programación cuadrática;

- programación no lineal.

- Tratamiento de la incertidumbre:

- deterministas: los parámetros tienen asignado un valor fijo;

- estocásticos o probabilísticas: los parámetros se definen como variables aleatorias.

\section{V.1 MODELOS DE GESTIÓN HIDROLÓGICO- ECONÓMICOS: ANTECEDENTES}

Si bien el objetivo primario de la gestión ha sido tradicionalmente la reducción de los fallos en el suministro y la maximización del suministro de agua, en los últimos años las expectativas de los sujetos interesados en el proceso de planificación y los requerimientos legales han llevado a incorporar objetivos más articulados y ambiciosos, como la sostenibilidad financiera y ambiental, la equidad y la integración social. Los nuevos objetivos requieren el desarrollo de nuevas herramientas de gestión, como los modelos hidrológico-económico.

Un modelo hidrológico-económico se basa en la integración de los elementos tradicionales de un SRH con aspectos de ámbito económico, sean esos inherentes los costes de gestión o los datos macroeconómicos relacionados con el uso del agua. Según Young (1995) los estudios hidrológicos-económicos a nivel de cuenca están mejor preparados para valorar problemas de gestión y política de aguas.

La definición de las tarifas de los servicios del agua es una tarea compleja en cuanto está relacionada no solo con la estimación del coste industrial del agua sino con aspectos como la equidad social, la disponibilidad de pago y el comportamiento estratégico de los usuarios. Se hace necesario por lo tanto realizar una integración de las variables hidrológicas y económicas a nivel de cuenca, mediante una discretización espacial y temporal del flujo de agua que incluya las demandas de agua, los usos no consuntivos y medioambientales, costes y beneficios de los servicios, reglas institucionales y los incentivos económicos por parte de la administración. 
En este apartado se presenta una revisión de los modelos de gestión de SRH actualmente en uso que incluyen variables y parámetros de tipo económico:

AQUARIUS (Diaz et al., 1999; Brown et al., 2002): es un modelo general de asignación del agua entre usos basado en criterios de eficiencia económica. Presenta una escala temporal variable a elección del usuario (día, mes, año) y admite unas funciones económicas de los elementos de tipo lineal $o$ exponencial. El horizonte de optimización puede incluir una serie completa de aportaciones (full deterministic) o dejar al usuario la libertad de definir periodos de optimización limitados e imponer las condiciones iniciales y finales (quasi simulation). El algoritmo de optimización maximiza el beneficio de la gestión mediante técnicas de programación cuadrática secuencial a partir de una solución inicial factible. El modelo está dotado de una interfaz de usuario amigable.

WEAP: desarrollado por el Stockholm Environmental Institute de Boston (Hansen, 1994; Yates et al., 2005), es un modelo de simulación de uso general de sistemas de recursos hídricos orientado al análisis de escenario que permite la implementación de aspectos económicos y de calidad de agua. La simulación se efectúa a escala temporal mensual y permite la representación de varios elementos de un sistema hídrico, incluidas las aguas subterráneas. Trabaja con algoritmos de balance hídrico mediante redes de flujo basados en técnicas de programación lineal.

CALVIN (Howitt et al., 1999): es un modelo de paso mensual desarrollado a medida para el análisis del sistema de recursos hídricos interconectado de California. Se basa en una red de flujo generalizada que se resuelve mediante el algoritmo HEC-PRM (USACE, 1994) maximizando el beneficio neto del sistema. La función objetivo no es lineal pero se linealiza a tramos para su resolución. Permite representar las infraestructuras del sistema, las restricciones de operación, las demandas de agua y las interconexiones entre el sistema superficial y subterráneo. La información económica requerida incluye los beneficios económicos relacionados con el uso del agua por parte de los usuarios, los costes de explotación unitarios (bombeo, distribución, recarga, reutilización) y las pérdidas vinculadas con la calidad del agua (salinidad).

ECOGES (Collazos, 2004): realiza la asignación del agua cruda de forma económicamente eficiente, repartiendo el agua con criterios de mercado. El programa considera la hidrología, las infraestructuras o condicionantes físicos y los costos de movilización o disposición a pagar por el uso del agua, para distribuir el recurso entre los usuarios a lo largo del tiempo. Internamente se optimiza una función de beneficio neto no lineal en una red de flujo.

MEVALGES (Collazos, 2004): el programa efectúa múltiples evaluaciones económicas de la asignación del agua, obteniendo indicadores económicos que 
permiten detectar situaciones altamente ineficientes o de despilfarro en la gestión del recurso. En este caso la valoración del agua no determina la asignación, sino que ésta se realiza de acuerdo con los criterios actualmente en uso. El proceso de simulación se resuelve mediante el modelo SIMGES (Andreu et al., 1996).

SIM-CO (Deidda, 2006): analiza la estructura del coste financiero del agua en un sistema de recursos hídricos y valora la eficacia recaudatoria de una política de precios. El modelo SIM-CO se ha desarrollado a partir de los trabajos realizados por Kil Seong Lee (Kil et al., 1999) sobre la aplicación de una metodología para la asignación del coste de distribución del agua basada en la segmentación de la red de abastecimiento y ha sido presentado por el autor ante el tribunal para el conseguimiento del Diploma de Estudios Avanzados. Al considerarse parte integrante del trabajo preparatorio de esta tesis y al representar un avance importante en el conocimiento de la estructura del coste financiero del agua, se estima conveniente ofrecer una descripción detallada de la metodología en el apartado V.2.

Las herramientas analizadas están marcadamente orientadas hacia la modelización de los SRH según la teoría de mercados. El objetivo prioritario de la modelización es la asignación óptima de los recursos hídricos entre usuarios en competencia entre ellos, en un contexto desregulado de perfecta movilidad del recurso, sin limitaciones de tipo legal en la asignación del agua. La estimación de los costes de los servicios es una consecuencia del proceso de optimización económica de la asignación del recurso y por lo tanto su validez está restringida a la configuración de equilibrio del mercado calculada por el modelo.

Sin embargo, como se explicó en los capítulos anteriores, los servicios hídricos se desarrollan en un contexto fuertemente regulado, donde el intercambio de derechos de agua resulta a veces complicado o impracticable por razones de naturaleza legal y administrativa. Esto implica un análisis más detallado de los costes industriales de los servicios del agua y la necesidad de calcular la asignación de los costes dentro del marco vigente de gestión de los recursos hídricos que, a menudo, no responde a criterios de eficiencia económica y a los mecanismos de asignación de mercado.

La aplicación de la teoría de juegos cooperativos trata de responder a la necesidad de definir una asignación eficiente y equitativa de los costes de los servicios respectando el marco legal y administrativo de asignación del recurso, de manera que las soluciones encontradas se ajusten a la realidad del sistema hídrico. Esto ha supuesto el desarrollo de una metodología específica basada en la aplicación conjunta de un modelo de simulación de sistemas hídricos (SIMGES, Andreu et a., 1996) y de un modelo de optimización (WARGI, Sechi y Zuddas, 2002), cuyas características se describen a continuación. 


\section{V.2 SIM-CO}

El modelo SIM-CO realiza la evaluación del coste financiero del agua en un sistema hídrico y analiza la recuperación de costes asociada a la aplicación de una determinada política de precios. Se basa en el uso del modelo de simulación de la gestión SIMGES (Andreu et al., 1996), que proporciona resultados numéricos de flujo de agua en los distintos puntos de la cuenca y en el uso de un post-procesador que resuelve las ecuaciones de balance de coste para una red de flujo conservativa.

\section{V.2.1 Evaluación del coste de los servicios del agua en cada punto del sistema}

El método de cálculo pretende proporcionar una información objetiva del coste de los servicios del agua en cada punto de la cuenca en función únicamente del nivel de utilización de las infraestructuras presentes en el sistema. El problema de la evaluación del coste se resuelve mediante una metodología análoga al seguimiento de un trazador conservativo a lo largo de la cuenca: el coste de las infraestructuras se agrega al sistema en correspondencia de su elemento correspondiente $\mathrm{y}$, mediante ecuaciones de balance de coste en los nudos intermedios del sistema, se efectúa su seguimiento hasta los nudos de entrega. El resultado es una serie de coste del agua por $\mathrm{m}^{3}$ en cada punto del sistema y un flujo de coste en cada elemento de transporte del sistema. A efectos del cálculo es necesario:

- definir la red de flujo ordenada del modelo de simulación de la cuenca;

- disponer de los datos de asignación del recurso hídrico según la regla de gestión propia del sistema de explotación;

- definir el sistema de ecuaciones de balance de coste en cada nudo intermedio del sistema.

Los datos de asignación del recurso se obtienen mediante el modelo de simulación SIMGES (Andreu et al., 1996) en el que se define un esquema conceptual del sistema hídrico ordenado en una red de flujo. Los cálculos económicos se realizan mediante el post procesador SIMCO, que utiliza los archivos con los resultados de asignación del recurso generados por el SIMGES. 


\section{V.2.1.1 Caracterización económica de los elementos del sistema}

La utilización de modelos de simulación de cuenca para valorar sistemáticamente los costes de los servicios del agua presupone la necesidad de realizar estudios previos sobre los costes directos e indirectos relativos a la gestión de la cuenca y en particular de recopilar toda la información disponible acerca del coste de las infraestructuras presentes en el sistema y del organismo gestor. El objetivo prioritario es conseguir una racionalización de los costes de los servicios del agua que permita resumir el coste de una infraestructura en tres categorías:

- Coste unitario: partida de costes variables según el caudal circulante por la infraestructura (explotación, energía etc.);

- Coste anual: coste asignado anualmente a la infraestructura sin dependencia del caudal fluyente (mantenimiento, explotación, amortización);

- Coste total: coste de inversión asociado a la vida útil de una infraestructura;

\section{V.2.1.2 Coste básico unitario}

El coste básico unitario (CBU) corresponde al coste asignado a una infraestructura en un determinado periodo de tiempo. Se calcula a partir del estudio de caracterización económica del sistema y de los resultados de la simulación de la asignación de los recursos hídricos dividendo el coste de la infraestructura por el flujo circulante en cada intervalo de tiempo. El CBU se introduce al flujo circulante en un elemento del sistema en cada paso de la simulación (mensual) y permite fraccionar el coste de una infraestructura hidráulica a lo largo de un periodo de tiempo en función de su real nivel de utilización.

$$
\begin{aligned}
& \mathrm{CB}(\mathrm{i}, \mathrm{t})=\mathrm{CU}(\mathrm{i})+\mathrm{CA}(\mathrm{i}) / \mathrm{QA}(\mathrm{i}, \mathrm{t})+\mathrm{CT}(\mathrm{i}) / \mathrm{QT}(\mathrm{i}) \\
& \mathrm{CB}(\mathrm{i}, \mathrm{t})=\text { coste básico del elemento ' } \mathrm{i} \text { ' en el } \mathrm{anno}^{\prime} \mathrm{t} \text { ' }\left(€ / \mathrm{m}^{3}\right) \\
& \left.\mathrm{CU}(\mathrm{i})=\text { coste unitario (dato de entrada } € / \mathrm{m}^{3}\right) \\
& \mathrm{CA}(\mathrm{i})=\text { coste anual (dato de entrada } \mathrm{M} € / \mathrm{año}) \\
& \mathrm{QA}(\mathrm{i}, \mathrm{t})=\text { caudal circulante por el elemento ' } \mathrm{i} \text { ' en el año ' } \mathrm{t} \text { ' }\left(\mathrm{hm}^{3}\right) \\
& \mathrm{CT}(\mathrm{i})=\text { coste total (dato de entrada } \mathrm{M} €) \\
& \mathrm{QT}(\mathrm{i})=\text { caudal circulante por el elemento ' } \mathrm{i} \text { ' durante el periodo de simulación }
\end{aligned}
$$




\section{V.2.1.3 Definición de la red de flujo}

El programa SIMGES (Andreu et al., 1996) permite modelizar las características físicas de la cuenca mediante un conjunto de elementos ordenados en una red de flujo. Según los principios de la teoría de grafos una red de flujo puede interpretarse como un grafo orientado (dígrafo) constituido por una serie de conexiones (arcos) y nudos, al cual es posible asociar una matriz de adyacencia (o estructural) de tipo disperso, como se muestra en la Figura 9.

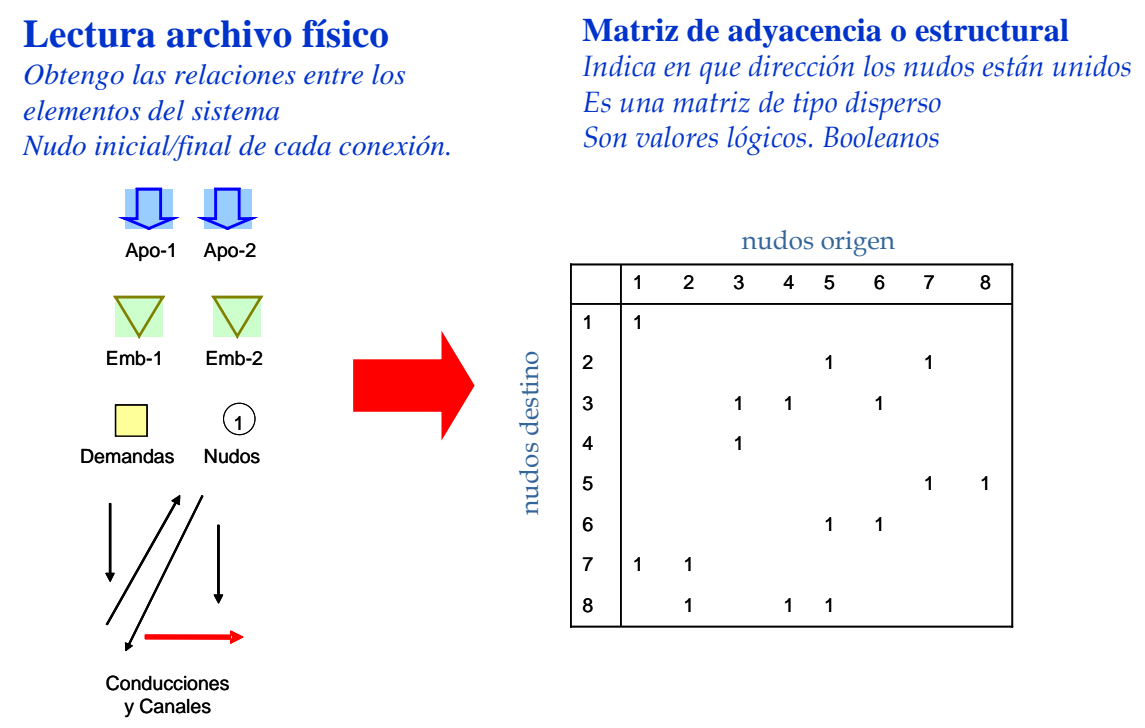

Figura 9: SIMCO, generación de la matriz estructural.

El proceso de ordenación de la red de flujo coincide con la triangularización de la matriz estructural y se describe en la Figura 10.
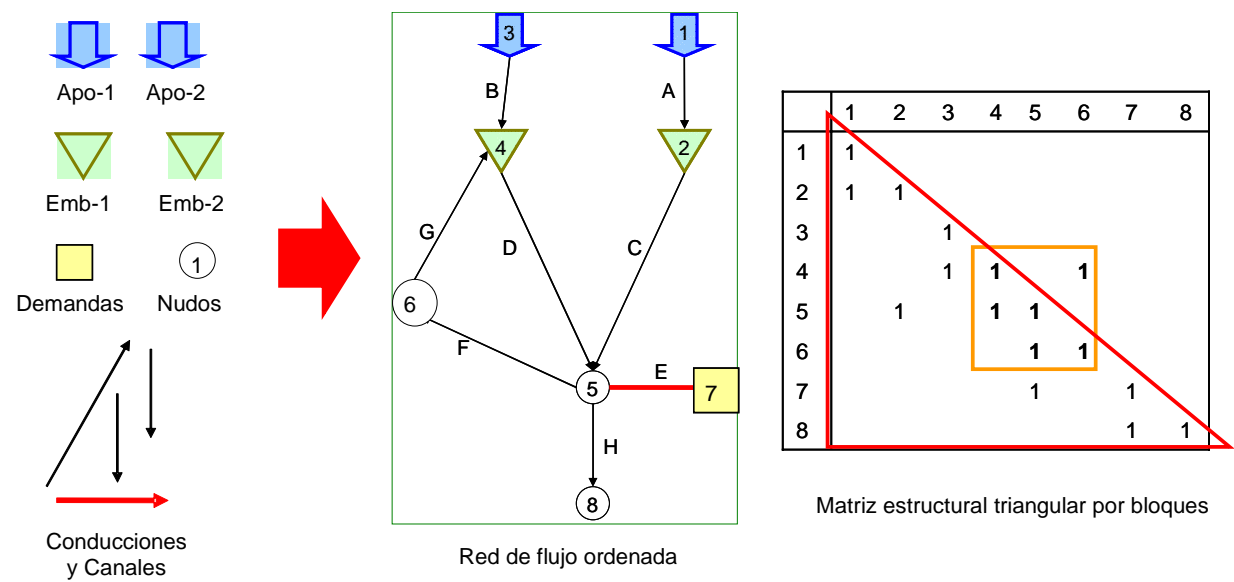

Figura 10: SIMCO, ordenación de la red de flujo. 
La reducción de la red de flujo en forma matricial permite la utilización de diferentes algoritmos de cálculo para la triangularización de matrices de tipo disperso, lo que facilita la implementación del proceso de ordenación en un lenguaje de programación de alto nivel. En este trabajo se ha seleccionado una elaboración del algoritmo de Tarjan (Tarjan, 1972) desarrollada por (Duff y Reid, 1978) debido a su facilidad de implementación en el lenguaje de programación Fortran y a su elevada eficiencia en el proceso de triangularización de matrices dispersas.

V.2.1.4 Definición del sistema de ecuaciones asociado a la red de flujo

El paso siguiente consiste en la definición de las ecuaciones de balance de coste para el cálculo del coste unitario del agua en cada elemento de la red de flujo. Se pretende calcular el coste unitario del agua resultante en cada nudo del sistema en función del coste unitario asociado al flujo de agua entrante en el mismo nudo y, en los casos correspondientes, el coste asociado al agua almacenada en los elemento de regulación (acuíferos, embalses).

$$
C_{v}=\frac{\sum_{I=1}^{N}\left(C_{i}+K_{I}\right) \cdot Q_{I}}{\sum Q_{I}}
$$

Ecuación de balance de coste en un nudo, donde:

$$
\begin{aligned}
& \mathrm{i} \text { = nudo inicial del arco “I” } \\
& \mathrm{v}=\text { nudo final } \\
& \mathrm{C}_{\mathrm{v}}=\text { coste unitario asociado al nudo final }\left(€ / \mathrm{m}^{3}\right) \\
& \mathrm{C}_{\mathrm{i}}=\text { coste unitario asociado al nudo inicial “ } \mathrm{i} \text { ” }\left(€ / \mathrm{m}^{3}\right) \\
& \mathrm{K}_{\mathrm{i}}=\mathrm{CBU} \text { asociado al arco " } \mathrm{I} \text { " }\left(€ / \mathrm{m}^{3}\right) \\
& \mathrm{Q}_{\mathrm{I}}=\text { caudal fluyente por el arco “I” }\left(\mathrm{hm}^{3}\right)
\end{aligned}
$$

En presencia de elementos de regulación el balance de coste se contabiliza incluyendo en la ecuación de balance el coste asociado al volumen almacenado en el periodo anterior. El efecto de la evaporación se modela suponiendo la concentración del coste en el volumen remanente en el embalse. Las pérdidas por filtración de un embalse o de un río se pueden representar permitiendo la transmisión del coste al acuífero (en este caso se produce una transferencia del 
coste a través de las filtraciones desde el sistema superficial al sistema subterráneo) o bien neutralizando sus efectos económicos (en este caso el coste se concentra en el agua que permanece en el sistema superficial). A continuación se muestra un esquema del balance de costes en un embalse, seguido por la ecuación correspondiente.

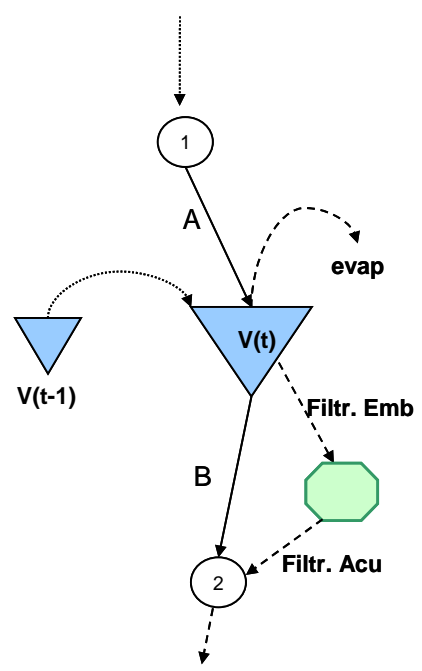

Figura 11: SIMCO, flujo de costes en un embalse.

$$
C_{v}(t)=\frac{\sum_{I=1}^{N}\left(C_{i}+K_{I}\right) \cdot Q_{I}+C_{v}(t-1) \cdot Q_{v}(t-1)}{\sum Q_{I}+Q_{v}(t-1)-Q_{\text {eva }}-Q_{\mathrm{inf}}}
$$

Ecuación de balance de coste en un elemento de regulación, donde:

$\mathrm{i}=$ nudo inicial del arco " $\mathrm{I}$ " $\mathrm{V}=$ nudo final del arco " $\mathrm{I}$ "

$\mathrm{C}_{\mathrm{v}}(\mathrm{t})=$ coste unitario asociado al nudo final en el periodo " $\mathrm{t}$ " $\left(€ / \mathrm{m}^{3}\right)$

$\mathrm{C}_{\mathrm{i}}=$ coste unitario asociado al nudo inicial “ $\mathrm{i}$ ” $\left(€ / \mathrm{m}^{3}\right)$

$\mathrm{K}_{\mathrm{I}}=\mathrm{CBU}$ asociado al arco “ $\mathrm{I}^{\prime \prime}\left(€ / \mathrm{m}^{3}\right)$

$\mathrm{Q}_{\mathrm{I}}=$ caudal fluyente por el arco “I" $\left(\mathrm{hm}^{3}\right)$

$\mathrm{Q}_{\mathrm{v}}(\mathrm{t}-1)=$ volumen almacenado en el elemento $\mathrm{v}$ en el periodo $(\mathrm{t}-1)\left(\mathrm{hm}^{3}\right)$

$\mathrm{Q}_{\mathrm{eva}}=$ volumen evaporado en el intervalo de simulación $\left(\mathrm{hm}^{3}\right)$

$Q_{\text {inf }}=$ volumen infiltrado en el intervalo de simulación $\left(\mathrm{hm}^{3}\right)$ 
El resultado del proceso es un sistema de ecuaciones de balance de coste lógicamente ordenadas desde aguas arriba hacia aguas abajo (Figura 12) cuya solución se obtiene resolviendo de forma secuencial la serie de ecuaciones en el mismo orden definido por la red de flujo.

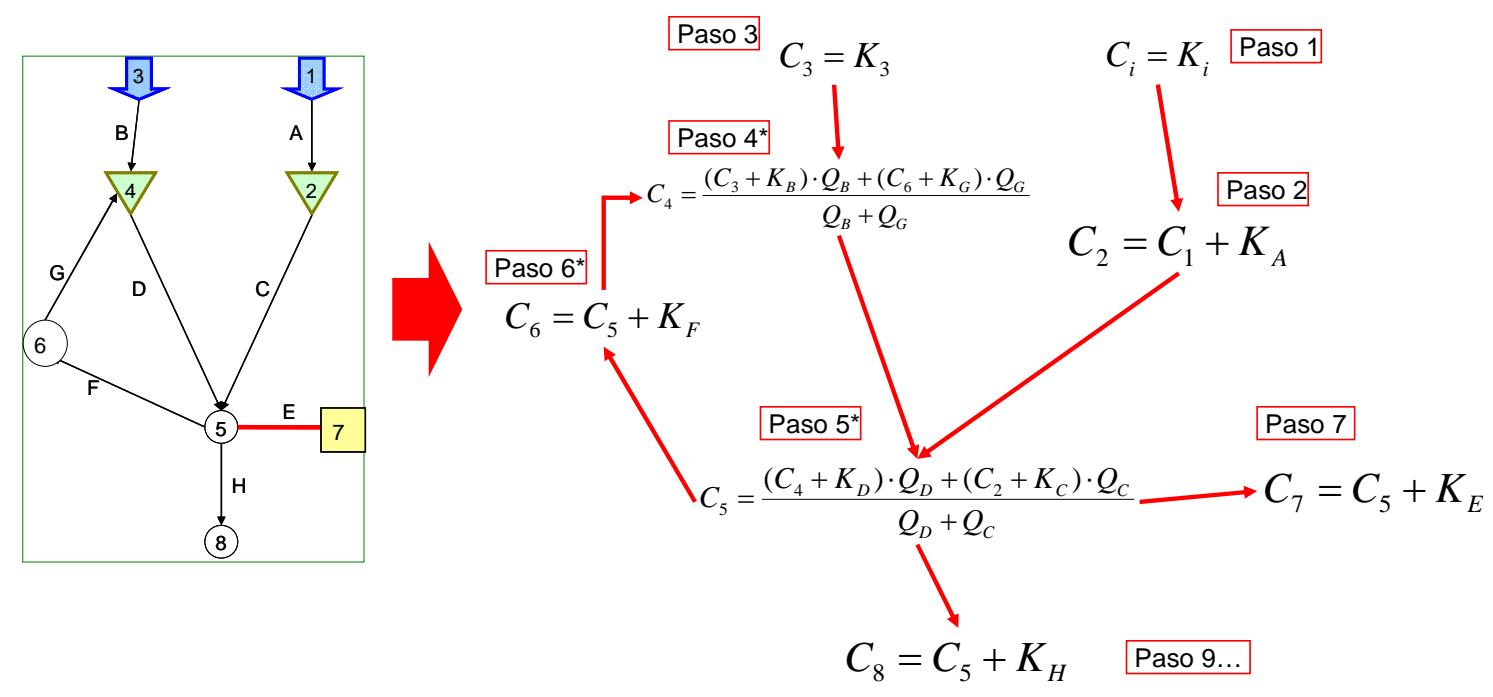

Figura 12: SIMCO, sistema de ecuaciones asociado a la red de flujo.

\section{V.2.1.5 Resultados del proceso de evaluación de costes}

La evaluación del coste de los servicios del agua se obtiene aplicando al sistema de ecuaciones descrito anteriormente los valores correspondientes de flujo en cada elemento y el CBU en cada infraestructura del sistema. La simulación de la asignación de los recursos hídricos se efectúa a escala mensual, lo que supone una variación de los parámetros del modelo en cada mes de simulación durante toda la serie histórica. El resultado de la simulación está constituido por los valores de coste unitario del agua en cada punto de la cuenca y los flujos de costes en cada conexión del sistema, obtenidos multiplicando el caudal fluyente en una conexión por el coste unitario del agua en el nudo de inicio de la conexión.

A continuación se muestran unos ejemplos de los resultados obtenidos mediante el modelo SIMCO: en la Figura 13 se puede observar el gráfico correspondiente al coste medio de los servicios, calculado a lo largo de la red de flujo; en la Figura 14 se ven las series históricas del coste unitario obtenidas para distintos puntos de la cuenca. 


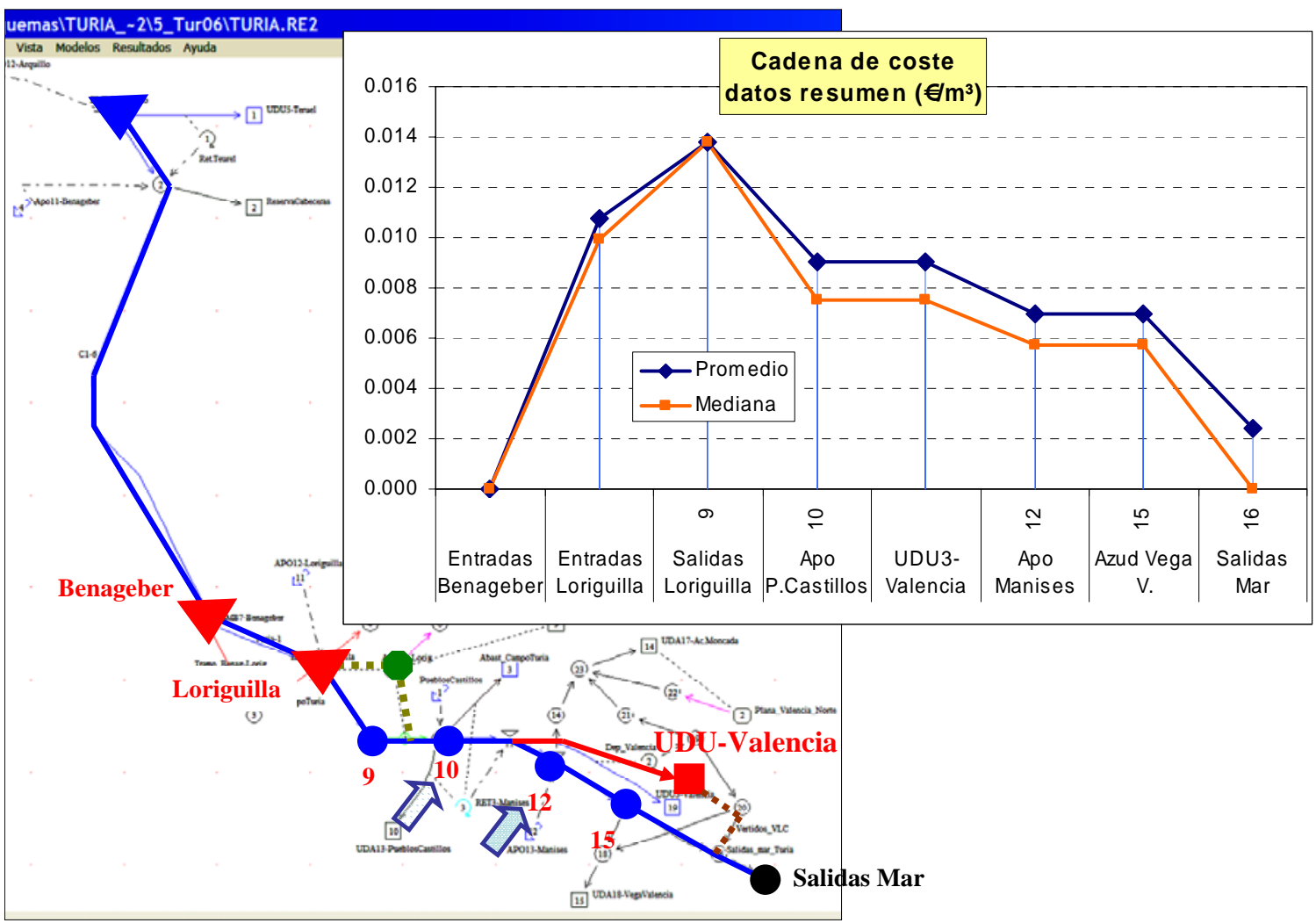

Figura 13: Resultados SIMCO, cadena de costes.
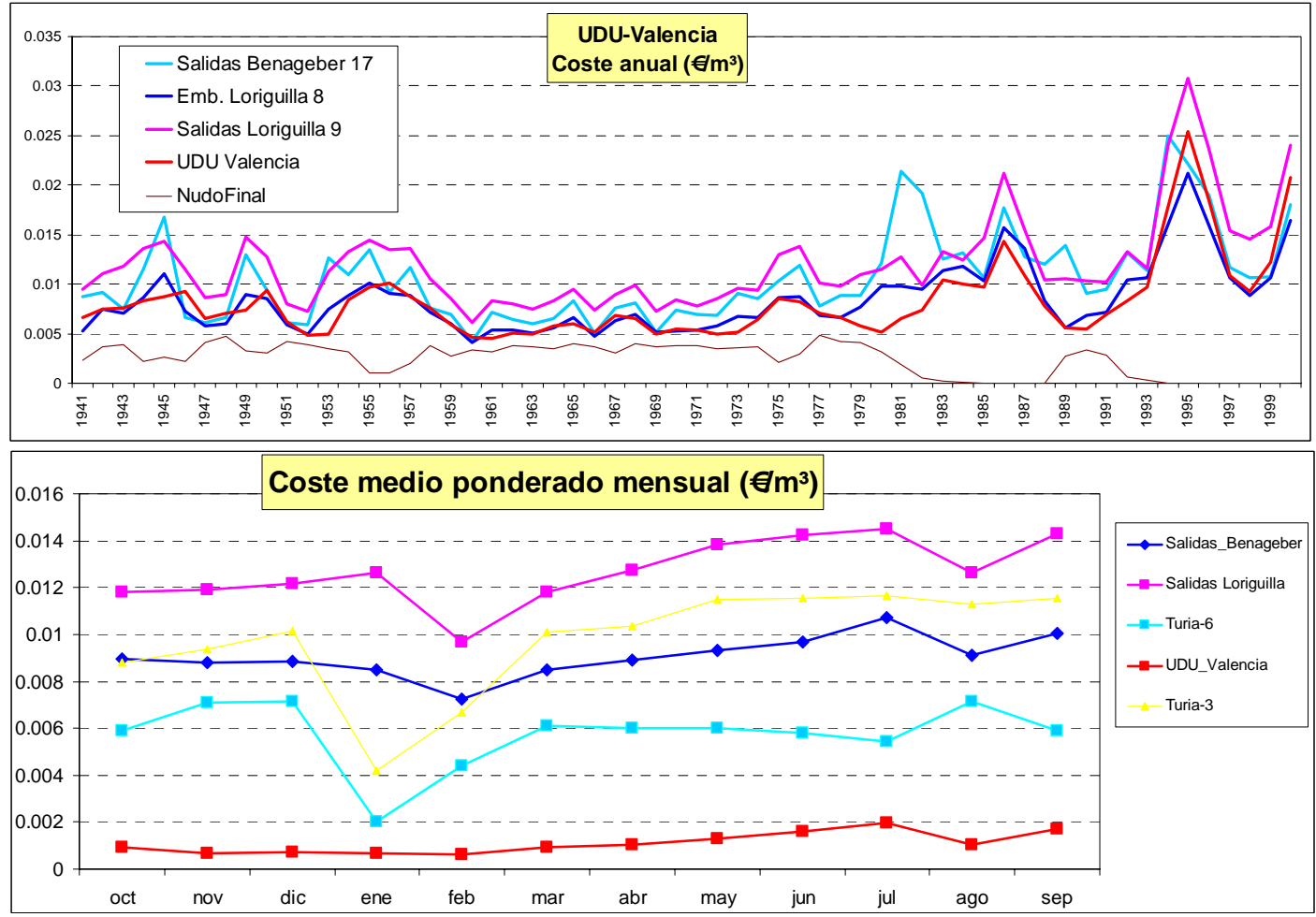

Figura 14: Resultados SIMCO, series de costes. 


\section{V.2.2 Definición de las tarifas y recuperación de costes}

El estudio de recuperación de costes se basa en la simulación de la aplicación de unas propuestas de tarifas a los usuarios del sistema. Para obtener el porcentaje de recuperación de costes se comparan los resultados del cálculo del coste de los servicios del agua con la tarifa aplicada a cada usuario del sistema, en función del suministro de agua asignado a cada demanda.

\section{V.2.3 Discusión}

El modelo SIMCO utiliza las potencialidades ofrecidas por los modelos de simulación para calcular la difusión del coste de una infraestructura a lo largo del sistema y finalmente su acumulación en los centros de demanda en función de los volúmenes consumidos y de su procedencia.

El método de asignación de costes permite analizar los costes financieros del sistema con un elevado nivel de detalle y obtener series de costes unitarios respectando la discretización temporal y espacial del sistema. Sin embargo, responde a un criterio de reparto de tipo esencialmente volumétrico, que no incorpora los aspectos de equidad y aceptabilidad enunciados en los capítulos anteriores. De allí la necesidad de avanzar en la investigación sobre la aplicación de la teoría de juegos cooperativos como una herramienta para contribuir a la definición de unos precios justos del agua de cara a la recuperación de los costes de los servicios.

\section{V.3 SIMGES}

SIMGES es un modelo general para la simulación de la gestión de cuencas hidrográficas, o sistemas de recursos hidráulicos complejos, en los que se dispone de elementos de regulación o almacenamiento tanto superficiales como subterráneos, de captación, de transporte, de utilización y/o consumo, y de dispositivos de recarga artificial. El modelo ha sido desarrollado por el Departamento de Ingeniería Hidráulica y Medio Ambiente de la Universidad Politécnica de Valencia (Andreu et al., 1996) y está incluido en el conjunto de aplicaciones que forman parte del sistema de soporte a la decisión para la gestión de sistemas de recursos hídricos Aquatool (www.upv.aquatool.es) desarrollado por los mismos autores. 


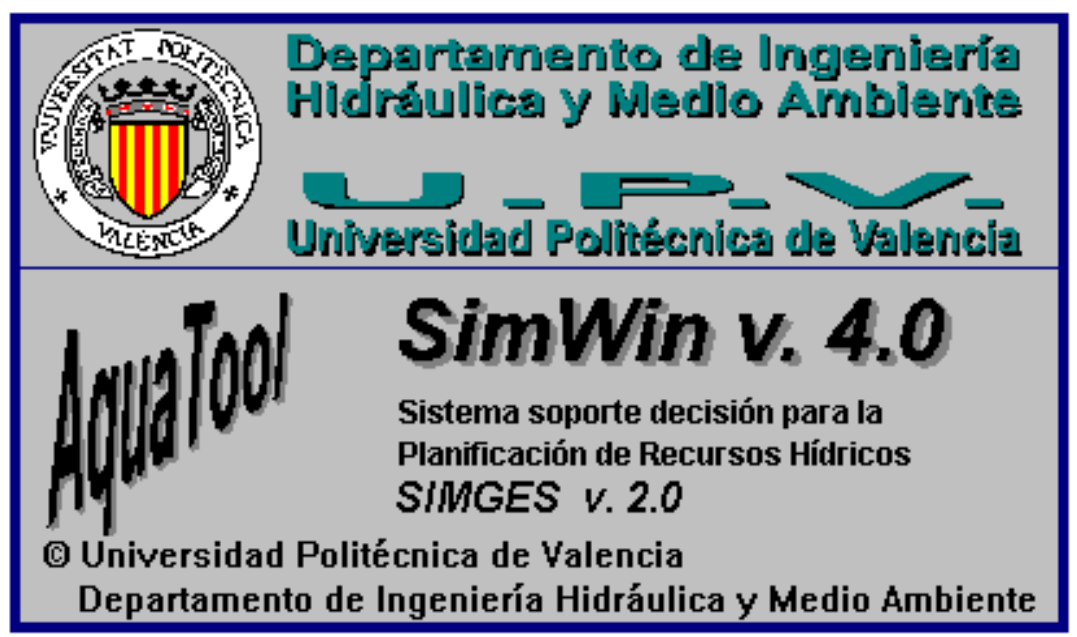

Figura 15: SIMGES, portada.

El SIMGES permite modelizar con extrema flexibilidad el SRH y realiza la simulación del flujo de agua a nivel mensual mediante el uso de un algoritmo de optimización de redes de flujo conservativo. Dicho algoritmo se encarga de determinar el flujo en el sistema tratando de satisfacer al máximo los objetivos múltiples de minimización del déficit, y de máxima adaptación a las curvas de volúmenes objetivo de embalse y objetivos de producción hidroeléctrica. Para los subsistemas superficiales el flujo es calculado simplemente por continuidad o balance, mientras que para los subsistemas subterráneos o acuíferos el flujo es simulado mediante modelos de celda, uni o pluricelulares, según convenga, o incluso, mediante modelos distribuidos de flujo lineal. Se tiene asimismo en cuenta en la simulación las pérdidas por evaporación y filtración en embalses y cauces, así como las relaciones entre aguas superficiales y aguas subterráneas.

\section{V.3.1 Elementos considerados}

Los elementos considerados por el modelo son:

- Embalses;

- Acuíferos;

- Conducciones;

- Demandas consuntivas;

- Elementos de retorno;

- Demandas no consuntivas (centrales hidroeléctricas); 
- Recargas artificiales;

- Bombeos adicionales;

- Aportaciones.

El modelo está dotado de una interfaz gráfica SIMWIN que permite agregar los elementos del sistema y definir sus propiedades en un entorno amigable para el usuario. Para la utilización del modelo es necesario confeccionar un esquema del SRH que incluya los elementos del sistema conectados racionalmente entre sí y definir un conjunto de reglas de operación.

En la Figura 16 y en la Figura 17 se muestran los menús de entrada de los datos relativos a los embalses y a las demandas, mientras en la Figura 18 se ve un ejemplo de esquema conceptual elaborado mediante SIMGES.

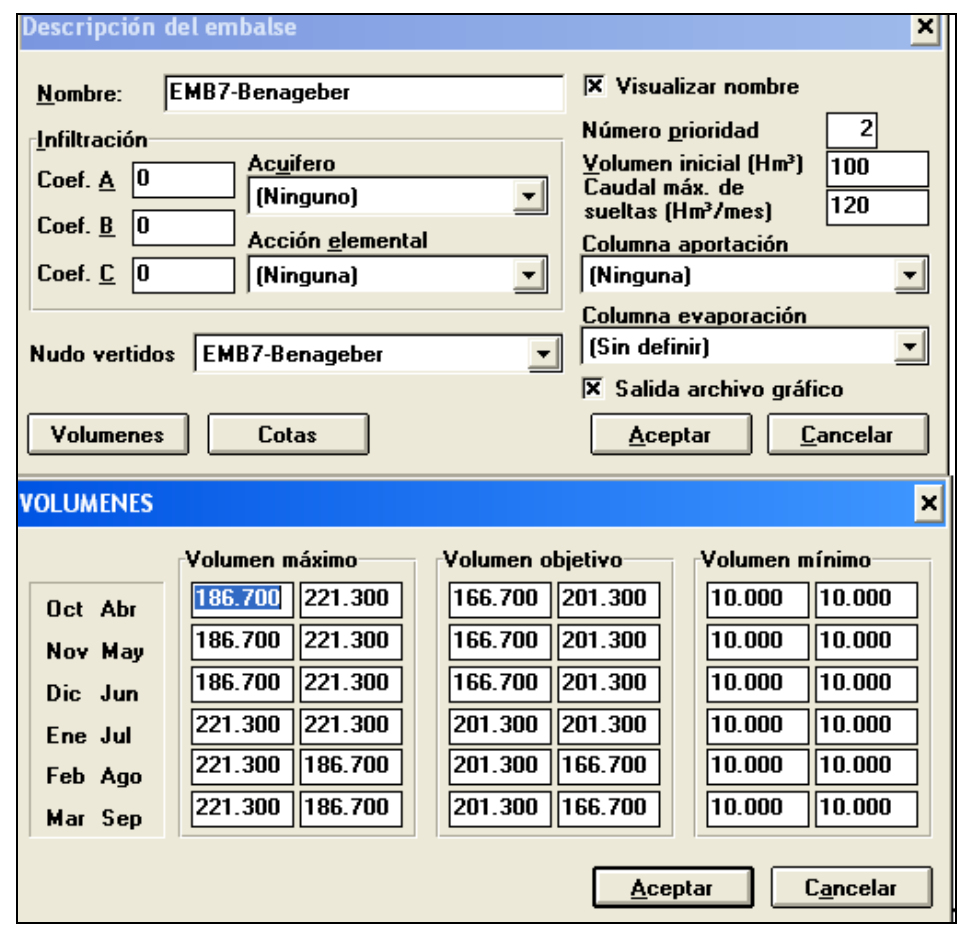

Figura 16: SIMGES, menú embalses. 


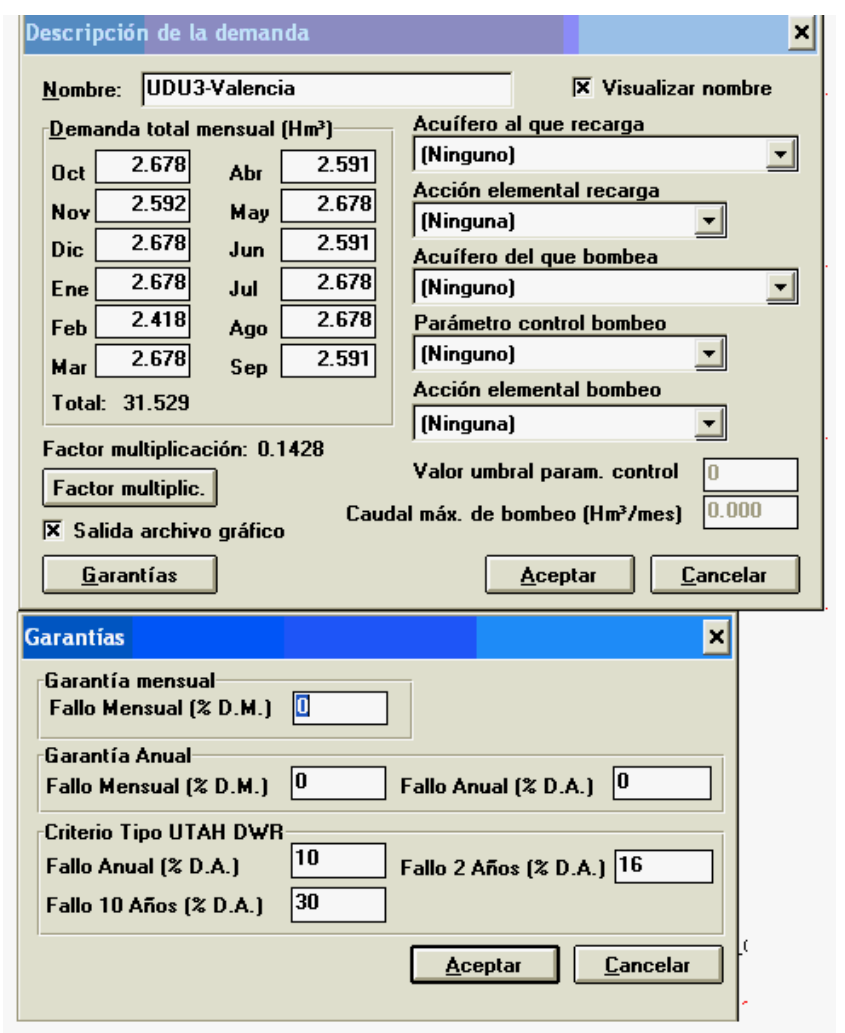

Figura 17: SIMGES, menú demandas.

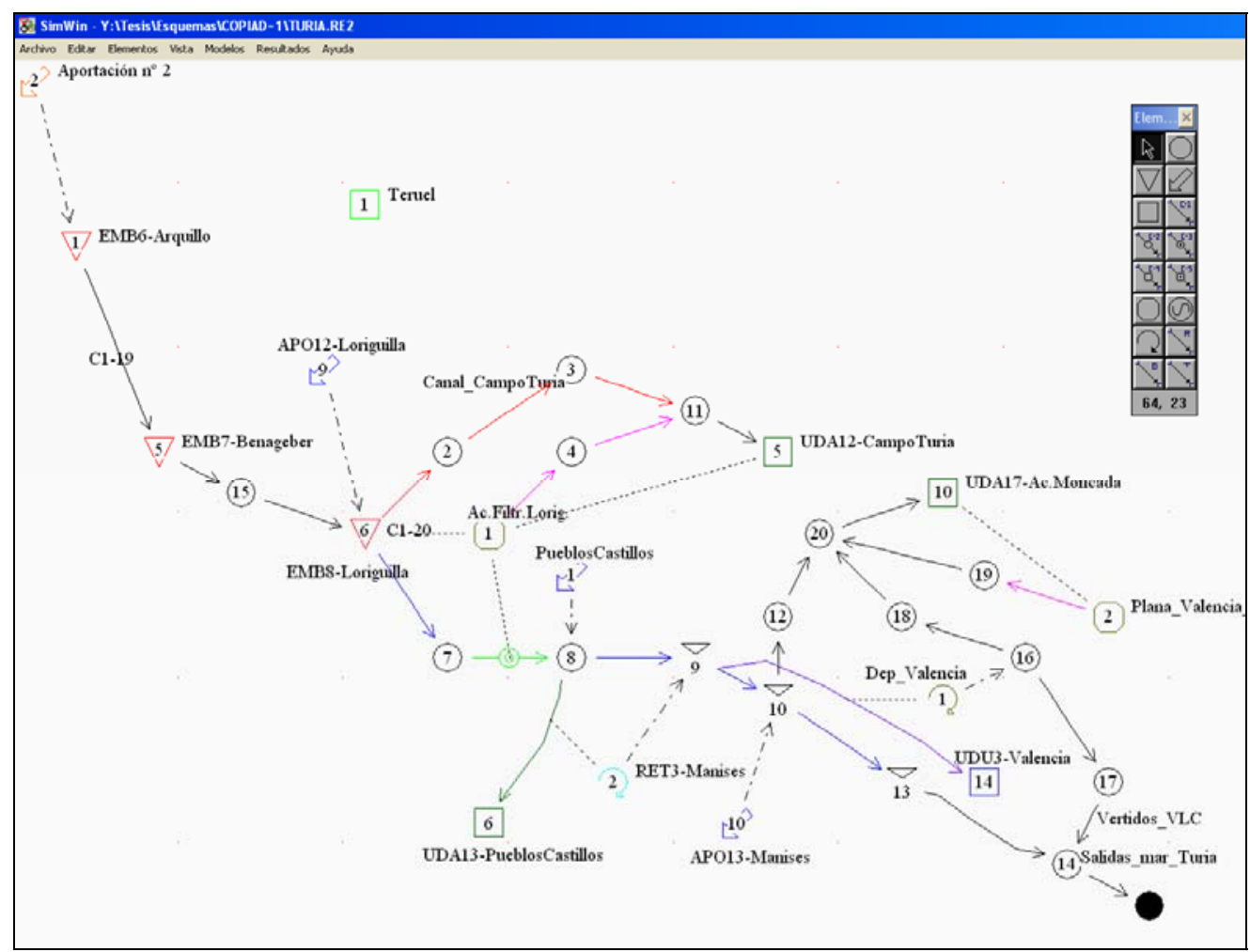

Figura 18: Esquema de un SRH elaborado mediante SIMGES. 


\section{V.3.2 Reglas de operación admitidas por el modelo}

La gestión de los recursos hidráulicos se efectúa mediante un conjunto de reglas de operación, definidas por el usuario, que permiten reproducir las distintas normas de explotación del sistema, entre ellas:

- Curvas de zonado de embalse: se definen los volúmenes objetivo y un número de prioridad de almacenamiento para cada embalse.

- Prioridades entre las demandas: reflejan las prioridades en los derechos del agua existentes en las normas de explotación de la cuenca;

- Indicadores de alarma y restricciones: actúan como restricciones en el suministro de agua hacia determinados usuarios y están relacionados con el volumen de agua almacenado en los embalses de la cuenca;

- Caudal ecológico: se impone un determinado caudal, variable mensualmente, en un determinado tramo de río.

\section{V.3.3 Explicación del funcionamiento del modelo}

Como se ha comentado anteriormente, la simulación y gestión del SRH se van a resolver simultáneamente mediante el uso de un algoritmo de optimización de redes de flujo conservativo.

A partir del esquema confeccionado por el usuario el modelo genera (internamente) una red de flujo conservativa y procede a su resolución para cada mes con los valores de aportaciones, demandas, y parámetros de gestión correspondientes. En caso de no linealidades o interacciones río-acuífero se procede mediante cálculos iterativos. Finalmente, una vez terminado el periodo de simulación, se procede a la confección de estadísticas, y cálculos de garantías.

Al resolver la optimización de la red de flujo, el modelo utiliza en cada mes una función objetivo sujeta a las restricciones de conservación de masa (continuidad) y a las de los límites físicos de transporte de conducciones y capacidades de embalses y otros elementos. La expresión matemática de la función objetivo y la definición de los archivos de salida supera las finalidades de esta breve explicación, ulteriores informaciones se pueden encontrar en el Manual del Usuario de SIMGES (Andreu et al. 2003). 


\section{V.3.4 Utilidad del modelo SIMGES}

Los resultados del modelo incluyen la evolución de todas las variables de flujo y de almacenamiento a nivel mensual, a nivel anual, así como los valores medios del período de simulación y las garantías. Todo ello permite que el modelo pueda ser utilizado, entre otras finalidades para:

- determinar las garantías que se obtienen para distintas hipótesis de infraestructura y de evolución de demandas, así como para distintas reglas de explotación de la cuenca;

- establecer las reglas de explotación más adecuadas para unos niveles exigidos de garantías;

- estimar los beneficios o perjuicios derivados de la alteración de prioridades de usos del agua y de las distintas alternativas de gestión;

- analizar el comportamiento del sistema hídrico bajo distintos escenarios hidrológicos.

Al tratarse de un modelo de simulación de tipo causa-efecto, la búsqueda de las soluciones más eficientes se realiza mediante ensayos de prueba y error, en los que se valoran las distintas propuestas de gestión según unos escenarios hidrológicos determinados. 


\section{V.4 WARGI}

WARGI (Water Resources Sistem Optimization Aided by Graphical Interface) es un modelo de optimización de uso general para la planificación y la gestión de los sistemas de recursos hídricos desarrollado por el CRIFOR (Centro di Ricerca e Formazione delle Reti) de la Universidad de Cagliari. Una descripción detallada del modelo está disponible en los trabajos de (Sechi y Zuddas, 2002; Sechi et al., 2004 ).

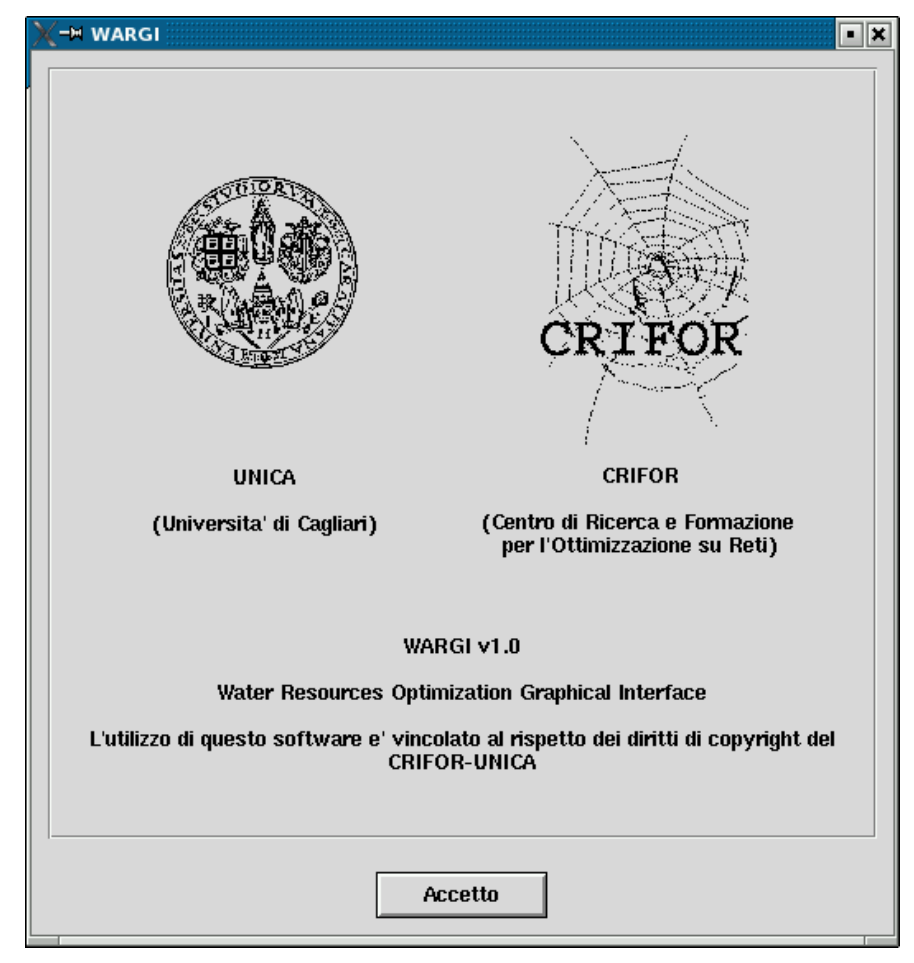

Figura 19: WARGI, portada.

La creación y el desarrollo de WARGI nace de la exigencia de disponer de una herramienta de trabajo capaz de resolver problemas complejos, cuya configuración permita adaptarse fácilmente a los cambios y a las nuevas necesidades que vayan surgiendo en el campo de la planificación y gestión de recursos hídricos.

El programa resuelve problemas de optimización mediante programación lineal (en adelante PL) a través del solver CPLEX, aunque permite implementar cualquier resolutor de problemas de PL disponible en el mercado. 
Para la codificación de los problemas de PL el programa utiliza el estándar MPS (Mathematical Programming Standard), desarrollado por IBM en 1960, de amplia difusión en programación matemática.

En la realización del modelo se ha tenido en cuenta cuidadosamente la flexibilidad y facilidad de adaptación a las nuevas exigencias de la gestión de servicios hídricos, lo que ha llevado a un desarrollo del software de tipo modular, mediante elementos transparentes e intercambiables.

Los principales módulos incluidos en el programa son:

- Caracterización de los elementos del sistema;

- Conexiones tipológicas y restricciones de flujo;

- Enlace a los archivos de datos hidrológicos y de demanda;

- Definición del horizonte de modelación y de los escenarios hidrológicos;

- Definición de las reglas de operación;

- Introducción de los datos de coste y beneficio;

- Búsqueda de la solución óptima;

- Salida de resultados.

Se describen a continuación las fases de utilización del WARGI:

1. Construcción del sistema;

2. Introducción de los datos correspondiente a cada elemento;

3. Generación del archivo MPS;

4. Resolución del problema de optimización;

5. Visualización de los resultados.

\section{V.4.1 Representación del sistema físico}

El sistema de recursos hídricos se representa en WARGI mediante un grafo compuesto por nudos y arcos, cada uno con sus características hidráulicas y económicas. El modelo permite representar los siguientes elementos mediante la paleta descrita en la Figura 20: 
- Tramos de río;

- Embalses y elementos de almacenamientos;

- Demandas civiles, industriales, agrícolas;

- Centrales hidroeléctricas;

- Acuíferos;

- Estaciones de bombeo, impulsiones;

- Plantas desalinizadoras;

- Depuradoras;

- Potabilizadoras.

Se definen también los siguientes elementos en forma de arcos y nudos ficticios:

- Recarga artificial de acuíferos;

- Infiltración en el sistema subterráneo;

- Evaporación de embalse;

- Vertidos de embalse;

- Nudo mar.

En cada nudo del sistema es posible agregar unas entradas/salidas hidrológicas en forma de flujo constante o de serie histórica. Una interfaz gráfica permite al usuario definir el esquema conceptual y acceder a distintos paneles para la configuración de los elementos del sistema hídrico.

La longitud del periodo de optimización está definida por el usuario, así como el paso de la optimización (mensual, anual o fracciones de un año). 


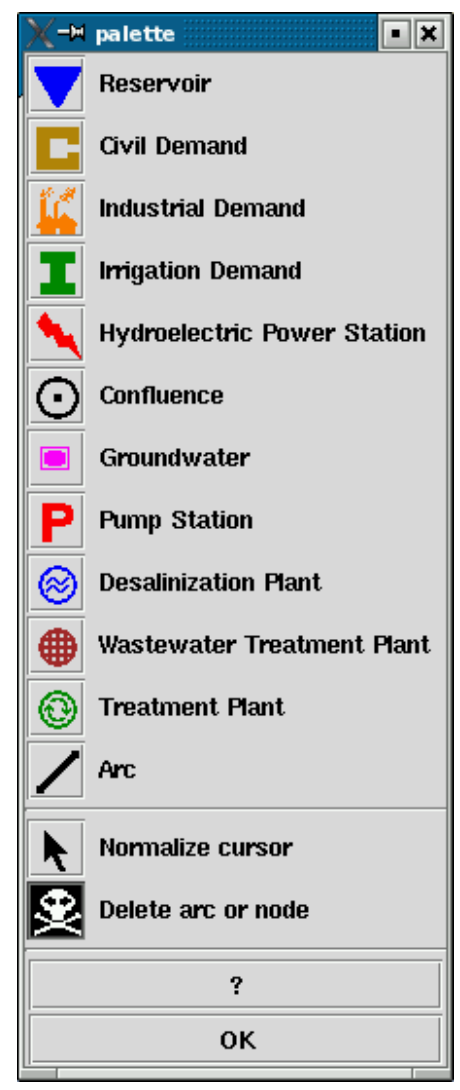

Figura 20: WARGI, menú elementos.

A continuación se muestran los menús para la caracterización de las demandas del sistema (Figura 21), de un elemento de regulación (Figura 22) y finalmente el esquema conceptual de un SRH modelado mediante WARGI (Figura 23).

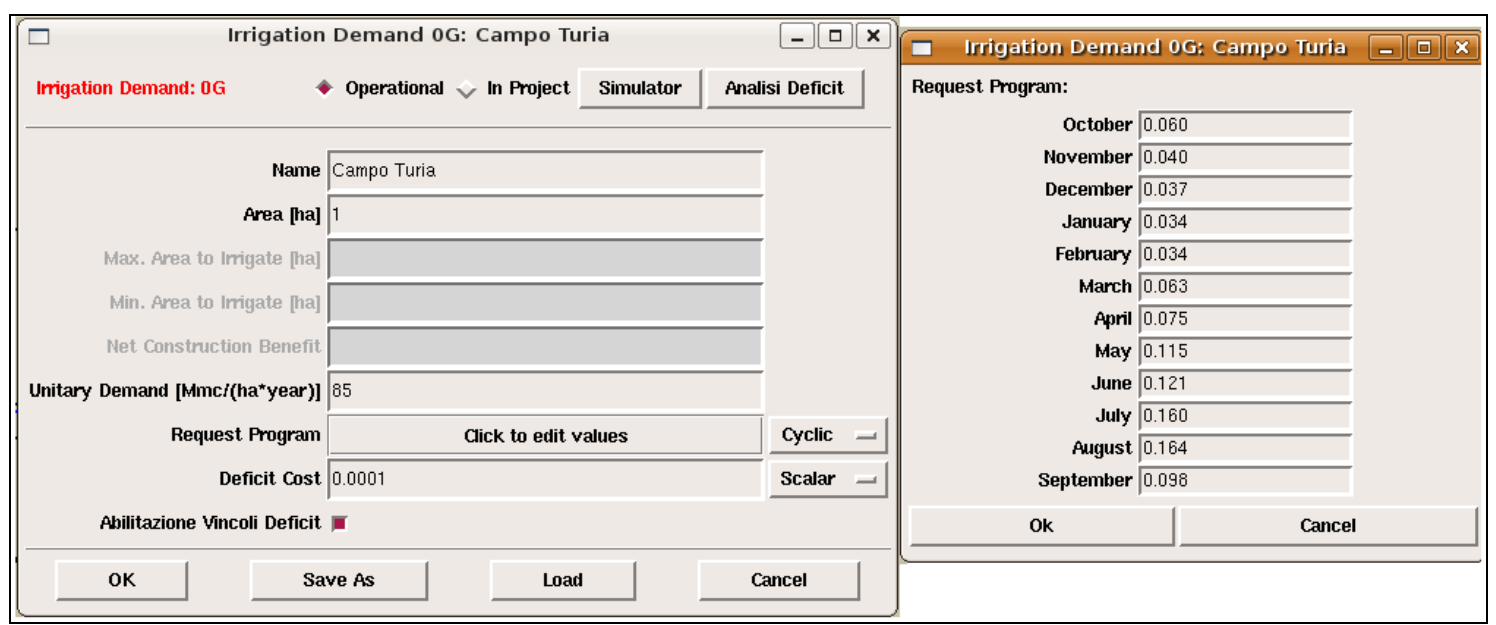

Figura 21: WARGI, menu demanda. 


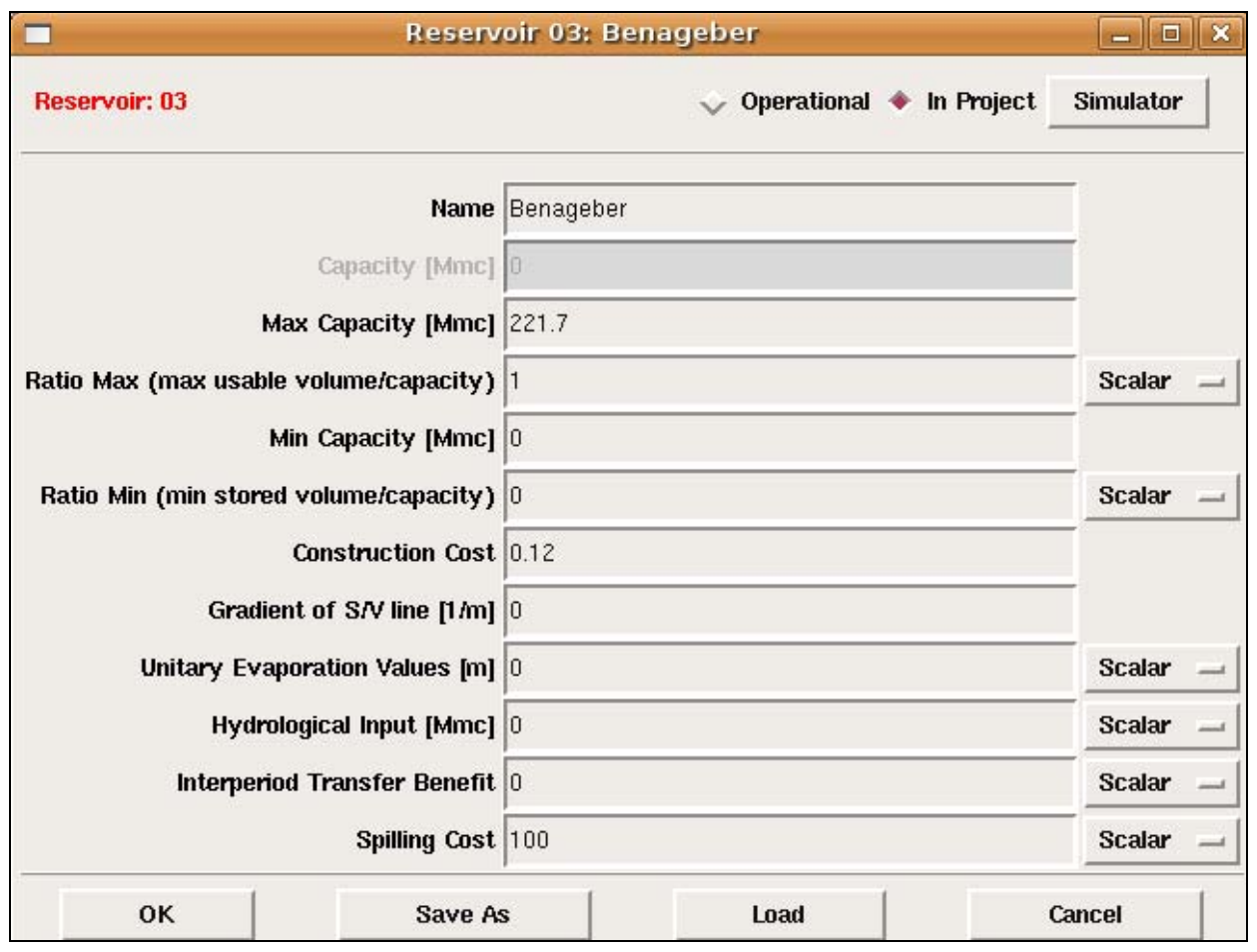

Figura 22: WARGI, menu embalse.

\section{Mnome/sulis/Fumendosa/Definitivo/SchemaProva.idr}

File View Configure Run

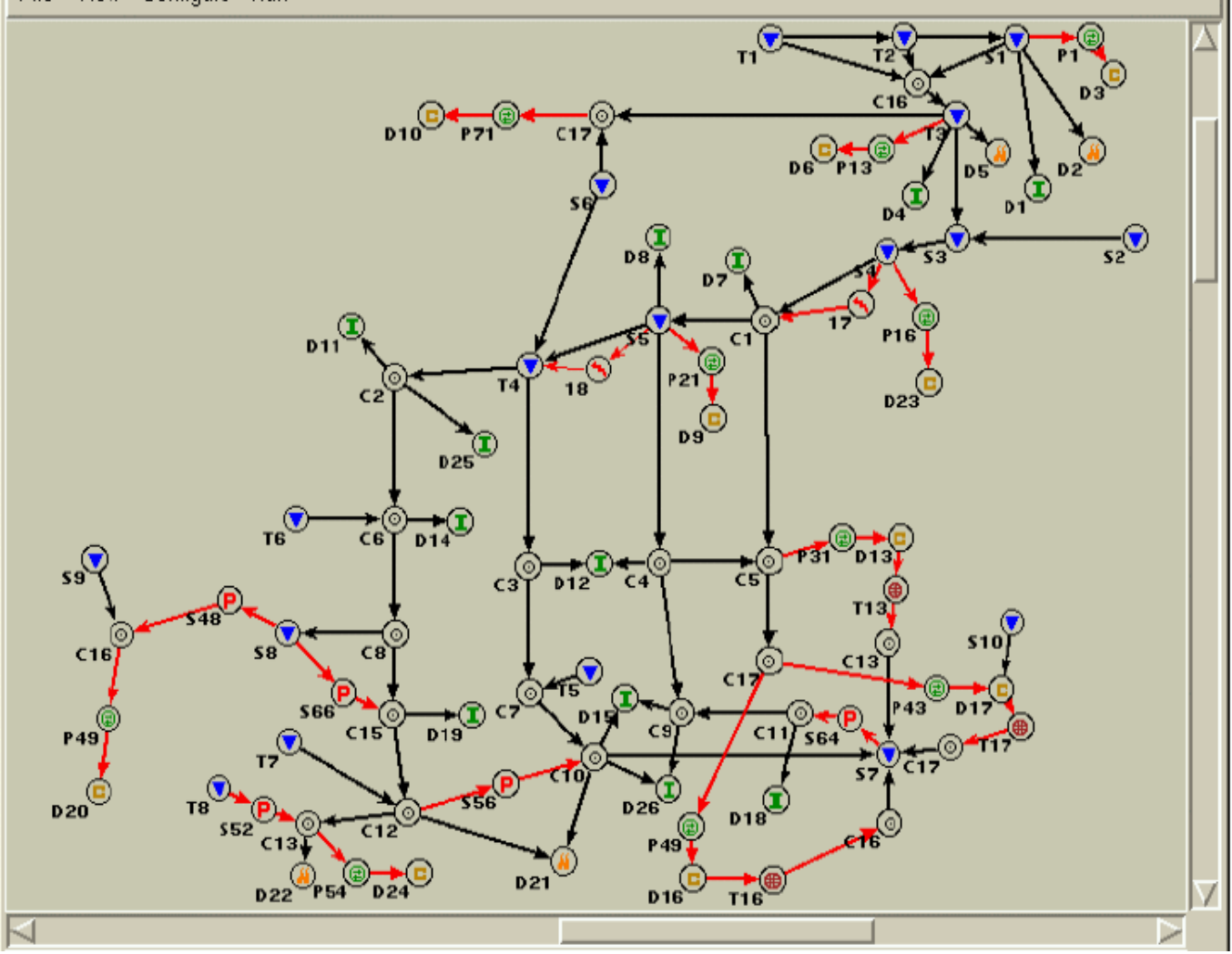

Figura 23: WARGI, esquema conceptual de un sistema hídrico. 


\section{V.4.2 Aspectos económicos}

Conforme con los objetivos de la tesis se ha procedido a la definición de una formulación general de los datos económicos a través de unas funciones de coste. A tal fin se han identificados las siguientes clases de coste:

- Coste de operación (operation cost): partida de costes variables según el caudal circulante por la infraestructura en fase de operación de la misma. Se introducen en el elemento correspondiente para contabilizar los gastos correspondientes al uso de la infraestructura.

- Coste de inversión (project cost): partida de costes relacionados con el tamaño y la configuración de la infraestructura. Corresponden a los costes de construcción de la misma y no están vinculados directamente con los caudales circulantes, sino con los caudales o volúmenes de proyecto.

El modelo permite introducir la información económica en forma de:

- Coste unitario constante en todo el período de optimización;

- Coste unitario variable cíclicamente a lo largo del año;

- Coste unitario definido como escalar mediante un vector que representa la variación histórica del coste unitario.

- Función de coste de tipo lineal;

Además de la información relativa a los costes del sistema el modelo de optimización incorpora un conjunto de datos económicos relacionados con las variables tradicionales de la gestión

- Coste del déficit, definido como constante, como variable cíclica o como escalar, penaliza las restricciones en el suministro a las demandas consuntivas;

- Beneficio en las demandas;

- Coste de vertido de embalse, penaliza los vertidos al mar;

- Beneficio de regulación interanual, incentiva la regulación en los embalses o acuíferos. 


\section{V.4.3 El proceso de optimización}

El modelo utiliza el formato universal MPS para la codificación del problema de programación lineal, cuya formulación se presenta a continuación:

$$
\begin{aligned}
& Z=c_{1} x_{1}+c_{2} x_{2}+\ldots+c_{m+n} x_{m+n}+c_{0} \\
& x_{1}=a_{11} x_{m+1}+a_{12} x_{m+2}+\ldots+a_{1 n} x_{m+n} \\
& x_{2}=a_{21} x_{m+1}+a_{22} x_{m+2}+\ldots+a_{2 n} x_{m+n} \\
& \ldots \\
& x_{m}=a_{m 1} x_{m+1}+a_{m 2} x_{m+2}+\ldots+a_{m n} x_{m+n} \\
& l_{1} \leq x_{1} \leq u_{1} \\
& l_{2} \leq x_{1} \leq u_{2} \\
& \ldots \ldots \ldots \ldots \ldots \\
& l_{m+n} \leq x_{m+n} \leq u_{m+n}
\end{aligned}
$$

donde:

$\mathrm{Z}$ es la función objetivo (en adelante $\mathrm{FO}$ )

$\mathrm{x}_{1} \ldots \mathrm{x}_{\mathrm{m}}$ representan las variables auxiliarías;

$\mathrm{x}_{\mathrm{m}+1} \ldots \mathrm{x}_{\mathrm{m}+\mathrm{n}}$ representan las variables estructurales;

$\mathrm{c}_{1} \ldots \mathrm{c}_{\mathrm{m}+\mathrm{n}}$ son los coeficientes de la FO;

$\mathrm{c}_{0}$ es el término constante de la FO;

$\mathrm{x}_{1} \ldots \mathrm{x}_{\mathrm{m}+\mathrm{n}}$ son los coeficientes de los vínculos;

$1_{1} \ldots 1_{\mathrm{m}+\mathrm{n}}$ son los límites inferiores de las variables;

$\mathrm{u}_{1} \ldots \mathrm{u}_{\mathrm{m}+\mathrm{n}}$ son los límites superiores de las variables.

El modelo de optimización se basa en la reproducción de un esquema conceptual del sistema hídrico en el que estén representadas:

- las demandas de los usuarios;

- las características hidrológico-hidráulicas de la cuenca; 
- los recursos disponibles en el sistema en forma de series de aportaciones mensuales de longitud definida;

- las actuaciones hidráulicas presentes y/o propuestas y las respectivas funciones de coste;

- los vínculos de suministro representados en forma de niveles de garantía mínimos a las demandas.

El problema matemático consiste en minimizar el valor de la función objetivo sujeta a una serie de restricciones que definen la región factible de las soluciones y que se detallan a continuación:

- ecuación de continuidad en los nudos/confluencias;

- ecuación de balance en los embalses;

- caudal mínimo/máximo en los arcos funcionales del sistema (río, tuberías, canales, desalinizadoras, depuradoras, bombeos);

- déficit máximo calculado según los indicadores de garantía;

La implementación de este último conjunto de restricciones, calculadas a partir de los criterios de garantía ha supuesto una modificación del modelo de cálculo y de la formulación de la función objetivo. En el apartado siguiente se describen en detalle las modificaciones aportadas al programa.

El modelo utiliza la herramienta CPLEX (http://www.ilog.com/products/cplex/) para la resolución del problema de optimización. El software CPLEX fue desarrollado en origen por R.E. Bixby, que en 1997 cedió los derechos de autor a la empresa ILOG, actual detentora de la patente sobre el programa. El ámbito de aplicación del programa se extiende los problemas de PL de gran escala, problemas de flujos de redes, programación cuadrática y programación entera mixta.

\section{V.4.4 Modificaciones aportadas al programa WARGI}

La metodología desarrollada en esta tesis se basa en la implementación de los criterios de garantía establecidos por la Instrucción de planificación hidrológica (MMARM, 2008) como restricciones en el proceso de optimización. Los criterios de garantía consideran la magnitud del déficit admitido por las demandas del sistema en un determinado intervalo de tiempo y están convenientemente descritos en el capítulo V.5. 
Se ha procedido, de acuerdo con los autores del programa, a una modificación del mismo para incluir los criterios de garantías entre el conjunto de restricciones. El trabajo ha consistido en la modificación de la función objetivo y en la actualización de la interfaz gráfica con el fin de agregar los comandos necesarios para la introducción de los datos relativos a los criterios de garantía.

Los vínculos basados en los indicadores de garantía tienen la siguiente formulación:

$$
\sum_{j=1}^{n} x_{i j} \leq \alpha_{i} \bar{D}_{i}
$$

donde:

$\mathrm{X}_{\mathrm{ij}}$ : flujo entrante en el arco ficticio de déficit hacia el nudo de demanda " $i$ " en el periodo " $j$ ", corresponde al déficit asignado a la demanda durante el intervalo temporal considerado por el indicador de garantía;

n: número de meses comprendidos en el intervalo temporal del indicador de garantía (ejemplo: 1 mes, $n=1 ; 1$ año, $n=12 ; 10$ años, $n=120$ );

$\alpha_{\mathrm{i}}$ : magnitud del déficit admitido, calculado como un porcentaje sobre la demanda media anual;

$\bar{D}_{i}$ : demanda media anual del nudo " $i$ ", calculada como sigue:

$$
\bar{D}_{i}=\frac{\sum_{i=1}^{n} R_{i}}{n} \cdot 12
$$

$R_{i}$ : demanda anual del nudo " $i$ ";

El cálculo de la demanda media anual en el intervalo temporal objeto del análisis se justifica con la necesidad de permitir también la aplicación de los indicadores de garantía a nudos cuyos valores de demandas son anualmente variables. El déficit máximo puede ser calculado en intervalos de tiempo mensuales o múltiples de un mes, anuales o interanuales. 


\section{V.5 INDICADORES DE EFICIENCIA EN LA GESTIÓN DE LOS SERVICIOS DEL AGUA}

El uso de modelos para la gestión de recursos hídricos conlleva la generación de una ingente cantidad de información. Los datos de salida incluyen series históricas mensuales de flujos de agua en las conexiones, déficit en las demandas y niveles de almacenamiento en los embalses, entre los cuales puede resultar difícil seleccionar y analizar la información útil para los objetivos de gestión. Se procede por lo tanto individuando un conjunto de indicadores que permitan la comparación entre los niveles de servicio de los usuarios. Un indicador corresponde a una medida cuantitativa que puede usarse como guía para controlar y valorar la calidad de los niveles de servicio. Los indicadores se construyen a partir de la experiencia y del conocimiento sobre la gestión, respetando ciertas recomendaciones:

- Deben ser siempre fáciles de capturar;

- Deben enunciarse con objetividad y de la forma más sencilla posible;

- Deben resultar relevantes para la toma de decisiones;

- No deben implicar un elevado grado de dificultad en su interpretación;

- Deben abarcar un amplio número de posibilidades. Hay que tener en cuenta que al poner en práctica un indicador se observa, en la práctica, que este podría mejorar al modificar las condiciones de gestión pero que otros aspectos no recogidos por los indicadores podrían empeorar.

Mediante el uso de indicadores se pretende evaluar la influencia de unas medidas en los niveles de servicio de los usuarios del agua, así como estimar las posibles afecciones a terceros.

\section{V.5.1 Criterios prácticos de garantía}

En la fase de explotación de un sistema hídrico pueden darse inevitablemente situaciones en las que no sea posible suministrar de forma satisfactoria los usos establecidos. Se suele llamar fallo al estado de no satisfacción de una demanda. En (Estrada Lorenzo, 1994) se define la garantía de suministro como la probabilidad de que el sistema se halle en una situación satisfactoria, entendiendo por tal aquella en la que el suministro es superior a la demanda de agua solicitada. En la literatura se han propuesto numerosos índices para precisar lo que se entiende por situación satisfactoria, considerando los distintos 
factores que afectan al valor de la garantía, la mayoría de los cuales atienden a tres características básicas: ocurrencia, duración y severidad de los fallos.

Los criterios de garantía representan, mediante un valor numérico sintético, aspectos como la eficiencia en la gestión del sistema hídrico y el nivel de satisfacción de las demandas. El uso de los criterios de garantía está particularmente desarrollado en asociación con los modelos de gestión de sistemas hídricos, en cuanto permiten resumir los resultados del modelo y comparar de forma sintética la eficacia de distintas alternativas para cada uno de los usuarios o agrupaciones de ellos. En la bibliografía científica y en las normativas nacionales se han desarrollado diversos criterios de garantía (Estrada Lorenzo, 1994):

\section{El comportamiento frente a una posible contingencia}

Se considera contingencia una determinada situación crítica, en general una sequía, ante la cual el sistema debe responder de forma adecuada. La sequía de cálculo puede coincidir con una sequía histórica registrada o un evento correspondiente a un determinado periodo de retorno, obtenido a partir de la función de distribución de la serie histórica de aportaciones. En el noreste de EE.UU. es práctica habitual dimensionar los embalses para una sequía de periodo de retorno de 20 años y añadir al volumen de regulación calculado una reserva adicional del 25\% (Hudson y Hazen, 1964). Este criterio está afectado por la arbitrariedad en la elección de la sequía de cálculo y por la imposibilidad de apreciar la capacidad de recuperación del sistema después de un fallo.

\section{La frecuencia de fallos}

Se define como la probabilidad de satisfacer la demanda de agua en un determinado periodo de tiempo. El Soil Conservation Service de EE.UU. ha dimensionado tradicionalmente los embalses de modo que sea satisfecha la demanda de riego en el $80 \%$ de los años. Este criterio no permite cuantificar la entidad del fallo al no considerar la diferencia entre leves reducciones de suministro o fallos de carácter catastrófico.

\section{La repercusión del fallo}

Requieren un conocimiento de los daños o pérdidas provocados por el déficit de suministro, usualmente representados a través de una función de pérdidas. A partir del análisis de la repercusión de los fallos es posible efectuar un análisis comparativo entre las pérdidas estimadas por falta de suministro y el coste de las obras necesarias para reducir el número y la entidad de los fallos. La Organización de las Naciones Unidas para la Agricultura y la Alimentación 
(FAO) plantea un análisis de las garantías de acuerdo con la disminución del rendimiento de las cosechas y propone una curva de riesgo aceptable en la que se establecen los niveles tolerables de descenso de los rendimientos relativos anuales de los cultivos (Carr y Underhill, 1974). En un contexto de recuperación de costes y ausencia de subvenciones el concepto de riesgo aceptable carece de sentido en cuanto la propia sostenibilidad financiera de la inversión justifica el gasto que supone la nueva infraestructura.

\section{La severidad del fallo}

Basados en la evaluación del déficit registrado durante un determinado periodo de tiempo. Estos criterios, oportunamente modificados, son los más utilizados por los organismos encargados de la planificación y gestión de los sistemas hídricos, ya sea a la hora de diseñar nuevas infraestructuras, como para evaluar y comparar la eficiencia de la gestión del sistema. Entre ellos cabe destacar el criterio empleado por el Utah Department of Water Resources (Lall y Miller, 1988) que define los niveles de déficit permisibles especificados en los contratos de suministro de agua para usos agrarios de la siguiente forma:

a) El déficit en un año no puede exceder el 50\% de la demanda anual;

b) El déficit en dos años consecutivo no puede exceder el $75 \%$ de la demanda anual;

c) El déficit en 10 años consecutivos no puede exceder el 100\% de la demanda anual.

\section{V.5.2 Criterios utilizados en España}

En España se han utilizado varios de los criterios expuestos en los apartados anteriores, entre ellos los índices clásicos como las garantías anual, mensual y volumétrica (Cabezas, 1987). Con el fin de establecer los criterios técnicos para la homogeneización y sistematización de los trabajos de elaboración de los planes hidrológicos de cuenca el Ministerio del Medio Ambiente y Medio Rural y Marino ha definido en la Instrucción de planificación hidrológica (MMARM, 2008) los objetivos previstos para el desarrollo de las actuaciones en materia de obras hidráulicas.

Según la Instrucción, a efectos de la asignación y reserva de recursos se considerará satisfecha la demanda urbana cuando:

a) El déficit en un mes no sea superior al $10 \%$ de la correspondiente demanda mensual. 
b) En diez años consecutivos, la suma del déficit no sea superior al $8 \%$ de la demanda anual.

La demanda agraria se considerará satisfecha cuando:

a) El déficit en un año no sea superior al $50 \%$ de la correspondiente demanda anual.

b) En dos años consecutivos, la suma del déficit no sea superior al 75\% de la demanda anual.

c) En diez años consecutivos, la suma del déficit no sea superior al 100\% de la demanda anual.

En este trabajo se propone un avance en el uso de los criterios de garantía, que dejan de ser un indicador a posteriori de la eficiencia en la explotación del sistema y se consideran como una parte activa en el proceso de cálculo de la función característica, configurándose como una ulterior restricción en el proceso de optimización. El modelo de optimización desarrollado opera dimensionando las actuaciones necesarias en términos de infraestructuras con el objetivo de asegurar unos niveles de garantía mínimos predefinidos para determinadas demandas sin afectar los niveles de garantía de los demás usuarios, de acuerdo con el principio de no afección a terceros. 


\section{CAPÍTULO VI DESCRIPCIÓN DE LA METODOLOGÍA}

En el presente capítulo se describe la metodología de asignación de costes de los servicios del agua basada en la aplicación conjunta de modelos de gestión de sistemas hídricos y de la TJC.

Como enuncia el Art. 2 de la Directiva Marco de Aguas, la definición de servicios del agua es amplia y se puede extender a todos los servicios en beneficio de los hogares, las instituciones públicas, la agricultura o cualquier actividad económica, incluyendo: la protección frente a las avenidas, la extracción, la regulación, el depósito, el tratamiento y la distribución de aguas superficiales o subterráneas y también la recogida y depuración de aguas residuales, que se viertan posteriormente en las aguas superficiales.

De forma resumida, la metodología desarrollada consiste en los siguientes pasos:

1. Análisis del sistema hídrico: desglose de las necesidades del sistema y definición del conjunto de alternativas de gestión para alcanzar los niveles de servicio requeridos por los usuarios;

2. Definición del juego cooperativo: identificación de los agentes independientes y formación de las coaliciones;

3. Cálculo de la función característica: uso de herramientas de optimización de sistemas hídricos para seleccionar las alternativas de gestión de menor coste para cada coalición;

4. Solución del juego: aplicación de los algoritmos de TJC. 
A continuación, en la Figura 24, se muestra el esquema del proceso de aplicación de la metodología.

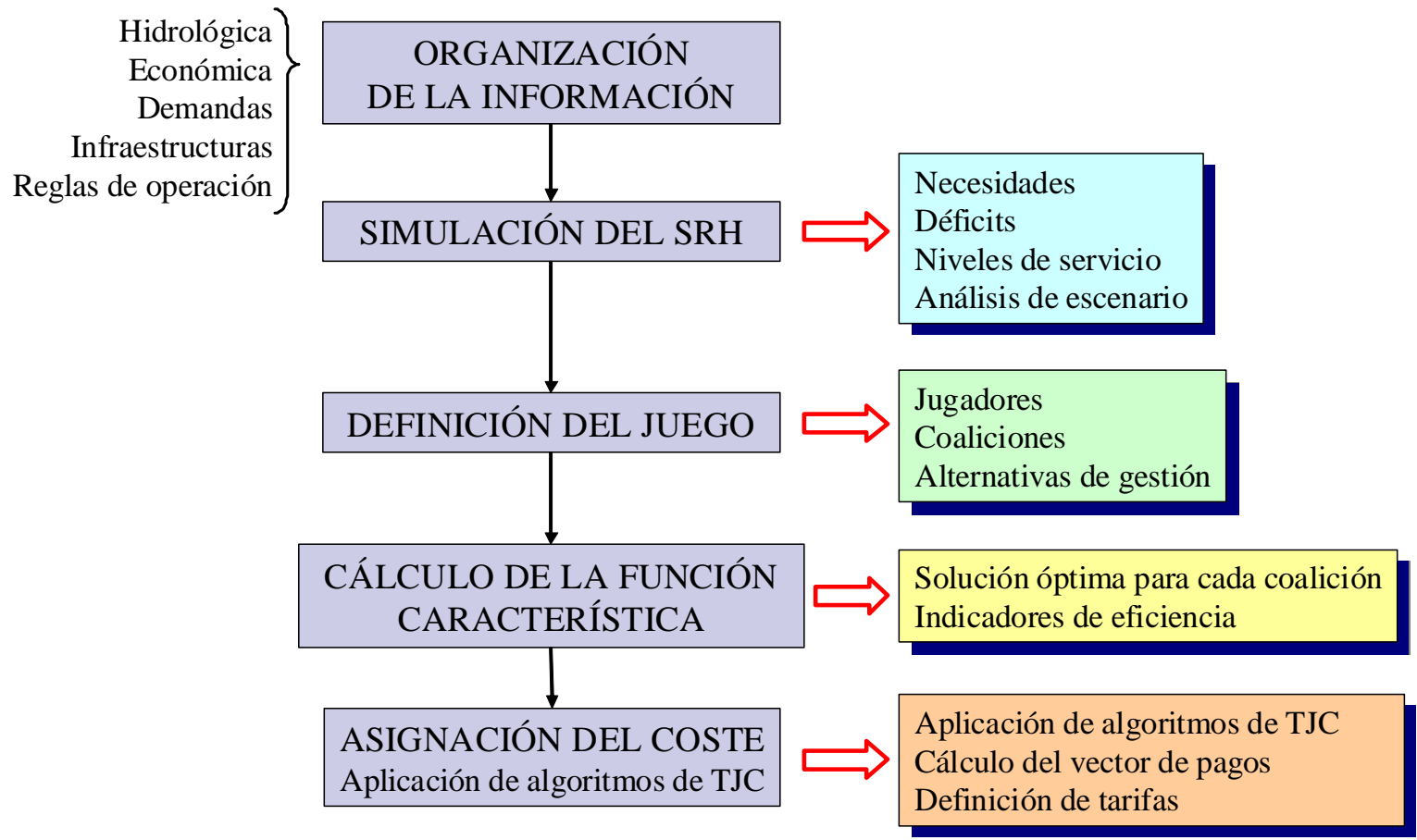

Figura 24: Esquema de aplicación de la metodología.

\section{VI.1 ANÁLISIS DEL SISTEMA HÍDRICO}

El proceso de análisis del sistema hídrico tiene como finalidad la identificación de los niveles de servicio de base del sistema y la definición de las actuaciones que concurren a realizar el servicio hídrico. El alcance del problema puede limitarse a una obra singular con múltiples beneficiarios, como por ejemplo la construcción de una estación de depuración mancomunada, o extenderse al conjunto de elementos que constituyen un sistema de recursos hídricos, como es el caso de la definición de las tarifas para la distribución del agua en alta.

El estudio de sistemas hídricos complejos plantea la necesidad de manejar un gran volumen de información:

- Datos hidrológicos acerca de la disponibilidad espacial y temporal de recursos hídricos;

- Niveles de embalses y acuíferos; 
- Recargas y escorrentía subterráneas;

- Usos del agua: consuntivos, no consuntivos y ambientales;

- Caudales de avenida y riesgo de inundaciones;

- Reglas de operación del sistema;

- Infraestructuras presentes en el sistema, datos de diseño y de operación;

- Costes fijos y variables, operativos y de inversión de las infraestructuras;

- Niveles de eficiencia del sistema, calidad de los servicios del agua.

Los modelos de simulación de sistemas hídricos permiten organizar toda esta información, analizar las relaciones entre elementos del sistema y efectuar predicciones sobre el comportamiento del mismo bajo oportunas hipótesis de gestión.

En esta tesis se ha utilizado el modelo de simulación SIMGES para la modelización del sistema hídrico. El modelo SIMGES, descrito en el apartado V.3, permite obtener una representación detallada del sistema hídrico, incluyendo los datos relativos al sistema físico, las infraestructuras, las demandas, la hidrología y las reglas de gestión de la cuenca. La extensa experiencia madurada en el uso del modelo, tanto en ámbito académico como profesional, ha llevado al desarrollo de esquemas de recursos hídricos completos de distintas cuencas hidrográficas, entre ellos el sistema del río Turia que será el caso de estudio presentado en esta tesis. La apuesta por la herramienta SIMGES presenta por lo tanto la ulterior ventaja de garantizar una completa compatibilidad de la metodología desarrollada en esta tesis con los modelos de gestión actualmente en uso en numerosas cuencas españolas y mediterráneas.

Mediante el modelo SIMGES se calculan las garantías de suministro de base y se plantean las actuaciones con el fin de mejorar los niveles de servicio de los usuarios, cuyo coste será objeto de análisis mediante la teoría de juegos cooperativos, de acuerdo con la Figura 25 que se muestra a continuación. 


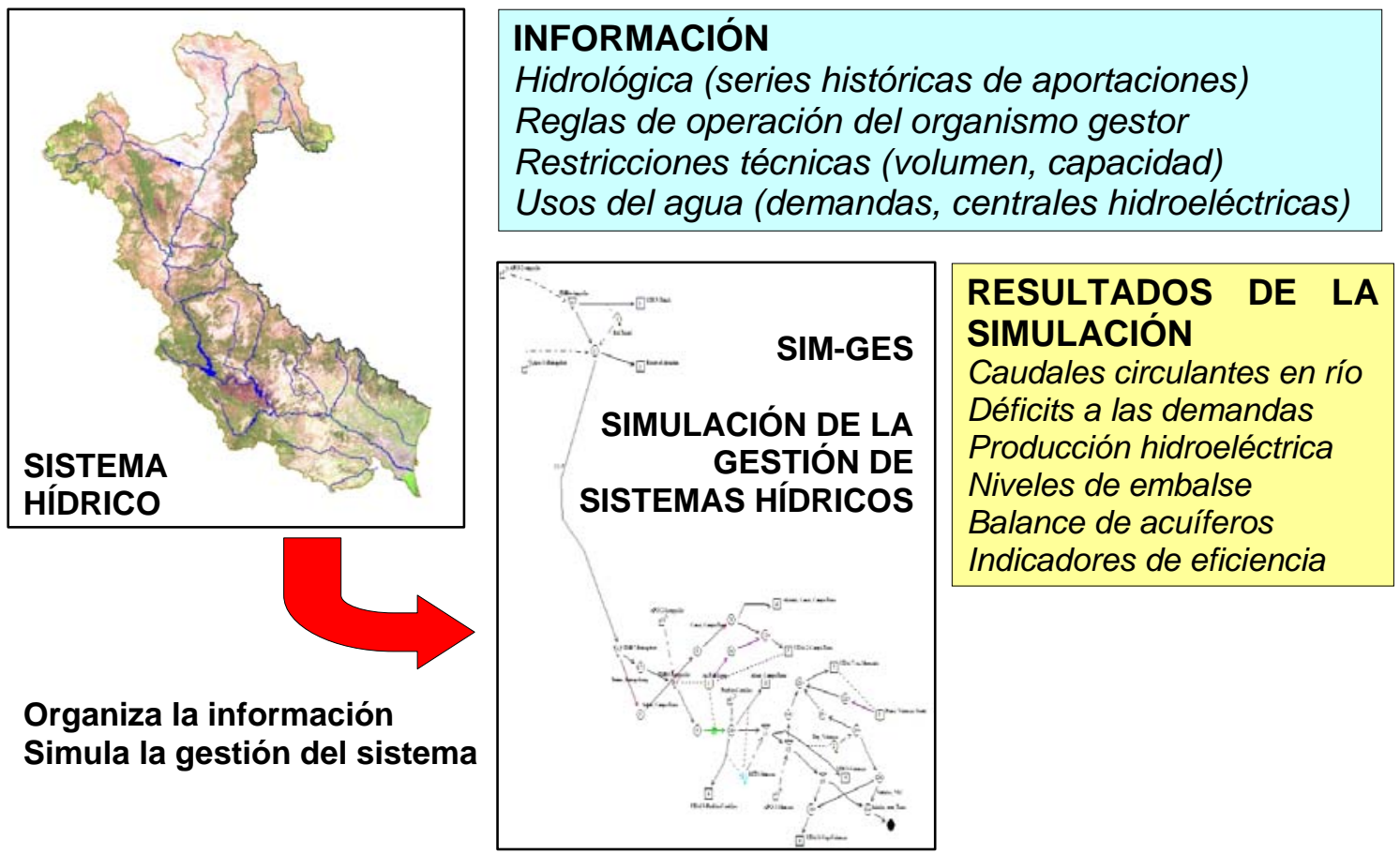

Figura 25: Aplicación de la herramienta SIMGES.

\section{VI.2 DEFINICIÓN DEL JUEGO COOPERATIVO}

Una vez definido el contexto del análisis se determinan los usuarios interesados por los servicios, cuyo número dependerá del tipo de agentes y de sus objetivos. En el caso de los usos hídricos el número de agentes podría multiplicarse a medida que aumente el nivel de detalle del análisis hasta llegar a considerar al abonado particular como último beneficiario de los servicios. Sin embargo, la elección de un nivel mayor de discretización conlleva complejidades en términos de economías de cálculo y posterior análisis de los resultados que a menudo no están compensadas por un mayor detalle de escala.

Se considera, por lo tanto, una tarea fundamental en el proceso de definición del juego la identificación de los agentes independientes, que consiste en agrupar racionalmente a los usuarios del sistema en función de algunas características comunes, como por ejemplo:

- la existencia de infraestructuras de uso compartido;

- la localización geográfica; 
- los niveles de servicio requeridos (en términos de garantías de suministro, prioridades en el uso del agua, calidad del recurso, protección frente a avenidas, etc.);

- los patrones de consumo de los usuarios (demanda mensual y anual);

- las afecciones al sistema hídrico según la tipología de vertido;

- la actividad económica asociada al uso del agua;

Se considera que los usuarios, una vez agrupados en la figura de un jugador (o agente independiente), comparten las mismas expectativas y son portadores de idénticos intereses en el juego.

La definición de un agente independiente está vinculada a la escala y al contexto del juego: en el caso de la gestión de una potabilizadora mancomunada se pueden consideran actores independientes los distintos municipios que participan en el proyecto, sin embargo los mismos municipios podrían actuar como un único jugador en competencia con otras mancomunidades o comunidades de regantes a la hora de reclamar el agua al organismo gestor.

Una vez identificados los $\mathrm{N}$-jugadores es posible definir el sistema de $2^{\mathrm{N}}-1$ coaliciones. Los agentes que forman parte de una coalición conservan sus objetivos particulares pero buscan en la coalición la posibilidad de satisfacerlos a través de un proyecto común que les permita ahorrar parte de los costes de una actuación individual.

\section{VI.3 CÁLCULO DE LA FUNCIÓN CARACTERÍSTICA}

La función característica representa el conjunto de soluciones de menor coste calculadas para cada coalición, independientemente de las actuaciones realizadas por los jugadores que no pertenecen a la coalición. Al estar los usuarios interconectados y al beneficiarse de un bien público, se plantea la necesidad de determinar unos criterios para evaluar los niveles de servicios obtenidos por los jugadores pertenecientes a una coalición y al mismo tiempo controlar las posibles afecciones sobre los usuarios que no pertenecen a ella. 


\section{VI.3.1 Responsabilidad de los usuarios en el uso del sistema}

Se define la responsabilidad de un jugador en el uso de los servicios como los requerimientos en términos de diseño, tamaño, tecnología y finalmente coste de los servicios que plantea cada agente con el fin de satisfacer sus necesidades.

El modelo de optimización, a diferencia del modelo de simulación, no incorpora las prioridades en el suministro a las demandas en cuanto que pretende evaluar el coste de los servicios en condiciones de igualdad de acceso a las infraestructuras hidráulicas para todos los usuarios del sistema.

Las diferencias legales existentes entre los usuarios quedan reflejadas en la primera fase del análisis, al calcular los niveles de garantía de base mediante el modelo de simulación que sí incorpora las prioridades de las demandas sobre el uso de los caudales en régimen natural. En la fase de optimización se postula que los recursos adicionales obtenidos por medio de obras hidráulicas sean de titularidad exclusiva de los promotores de las inversiones. El coste de los servicios se calcula por lo tanto a partir de los niveles de garantía de base en función de las infraestructuras necesarias para alcanzar los objetivos de suministro que plantea cada usuario al sistema.

Este planteamiento se fundamenta en la necesidad de determinar una contribución adecuada de cada uso del agua en función de los costes de los servicios requeridos por cada uno, de acuerdo con los principios enunciados en la DMA. A título de ejemplo se puede afirmar que en condiciones de escasez de agua no es indiferente por parte de una demanda lograr un nivel de suministro del 100\% en lugar de admitir un déficit del 50\%, lo que puede llevar a un consistente ahorro en infraestructuras o en medidas de emergencia para hacer frente a la sequía. Aún más evidente resulta el caso del proyecto de un canal, cuyo diseño puede variar notablemente en función de los picos de consumo de los usuarios, aunque el consumo medio se mantenga constante.

En la presente metodología se han considerado los indicadores de garantía descritos en el apartado V.5.1 como la herramienta más adecuada para describir y comparar los niveles de servicio asociados a la explotación de un sistema hídrico. Se asume finalmente el criterio citado en la Instrucción de planificación hidrológica (MMARM, 2008) como objetivo a conseguir en el desarrollo de las actuaciones en materia de obras hidráulicas. Los valores de referencia se describen en la Tabla 8 para los usos urbano y en la Tabla 9 para las demandas agrarias. 


\begin{tabular}{|c|l|}
\hline \multicolumn{2}{|c|}{ Demandas urbanas } \\
\hline Periodo & Déficit máximo \\
\hline 1 mes & $10 \%$ sobre la demanda mensual \\
\hline 10 años & $\mathbf{8 \%}$ sobre la demanda anual \\
\hline
\end{tabular}

Tabla 8: Nivel de garantía para demandas urbanas (MMARM, 2008)

\begin{tabular}{|c|l|}
\hline \multicolumn{2}{|c|}{ Demandas agrarias } \\
\hline Periodo & Déficit máximo \\
\hline 1 año & $\mathbf{5 0 \%}$ sobre la demanda anual \\
\hline 2 años & $75 \%$ sobre la demanda anual \\
\hline 10 años & $\mathbf{1 0 0 \%}$ sobre la demanda anual \\
\hline
\end{tabular}

Tabla 9: Nivel de garantía para demandas agrarias (MMARM, 2008)

Estos valores son susceptibles de modificación con el fin de aumentar o disminuir las garantías exigidas por parte de los usuarios. Cada modificación lleva a una alteración de las actuaciones necesarias para abastecer la demanda y a una consecuente repercusión en los costes asociados al mismo uso.

De esta manera, no solo es posible calcular los costes correspondientes a unos usuarios caracterizados por un igual nivel de garantía del servicio, sino también el incremento (o el ahorro) de costes que supondría para unos jugadores la mejora (o la relajación) de sus niveles de servicio.

\section{VI.3.2 Cálculo del coste para cada coalición}

El cálculo del coste que supone el alcance de un determinado nivel de garantía se efectúa mediante el modelo de optimización WARGI, descrito en el apartado V.4. La metodología de cálculo desarrollada se basa en la incorporación de los criterios de garantía entre las restricciones del sistema, de manera que el modelo busque la configuración óptima de las infraestructuras con el fin de alcanzar un nivel de garantía establecido por parte de un usuario o conjunto de usuarios. Es posible además vincular las garantías de las demandas de manera que se les asegure un suministro mínimo independientemente de las actuaciones de los demás usuarios del sistema.

La razón de este planteamiento responde a dos necesidades: 
a) Impedir que algunos usuarios se beneficien de inversiones de las cuales no son promotores. Se pretenden evitar casos en los que algunos usuarios se benefician indirectamente de las obras de regulación sin participar en la gestión y financiación de las mismas.

b) Evitar que unas coaliciones mejoren sus niveles de suministro a costa de las garantías de otros usuarios. En ausencia de límites inferiores al suministro de las demandas la solución más económica para aumentar la garantía de algunos jugadores consistiría en una simple transferencia de los caudales destinados en origen a otros usuarios.

El proceso de formación de coaliciones responde al criterio tradicionalmente empleado por los organismos de cuenca para la asignación de nuevas concesiones, según el cual toda concesión para el uso privativo del agua se entenderá hecha sin perjuicio a terceros (TRLA, Art. 61). Este planteamiento ha marcado el desarrollo de los nuevos planes de regadíos, cuya actuación supuso la realización de nuevas obras hidráulicas con el fin de no alterar las garantías de los usuarios tradicionales.

La condición de no afección a terceros se concreta mediante la definición de un escenario base del sistema hídrico, que representa el funcionamiento del sistema en ausencia de nuevas actuaciones. El escenario base constituye el punto de inicio del proceso de cálculo de la función característica, en el que se registran los niveles de garantía de partida para todos los usuarios.

En las sucesivas optimizaciones se incorporan las propuestas de medidas destinadas a la consecución de los niveles de garantía requeridos por los usuarios (o coaliciones de usuarios) interesados en las actuaciones, bajo la condición que los niveles de servicio de los usuarios que no participan en el proyecto queden vinculados a los valores de base predeterminados. De esta manera es posible calcular el coste del proyecto más eficaz asociado a una coalición sin que los demás usuarios se beneficien o sufran perjuicios indirectos. El proceso de optimización responde a un criterio de costo-eficacia, es decir en la búsqueda del conjunto de medidas de menor coste para lograr unos objetivos de gestión prefijados.

El número de optimizaciones necesario para el cálculo de la función característica está vinculado al número de coaliciones posibles $\left(2^{\mathrm{N}}-1\right)$ y aumenta de forma exponencial en razón del número de jugadores del sistema. En cada optimización se individua el conjunto de jugadores en coalición (activos), para los cuales se definen los objetivos de garantía de suministro y se calcula el conjunto de actuaciones. El resto de usuarios, no incluidos en la coalición (inactivos), no se beneficia de las actuaciones y está vinculado al mantenimiento de los niveles de servicio calculados en el escenario base. 
En éstos términos el cálculo de la función característica corresponde a la estimación de la responsabilidad de los usuarios en el uso del sistema, sean estos solos o agrupados en coaliciones.

En la Figura 26 se describe el proceso de cálculo de la función característica mediante el uso conjunto del modelo SIMGES y de la herramienta de optimización WARGI.

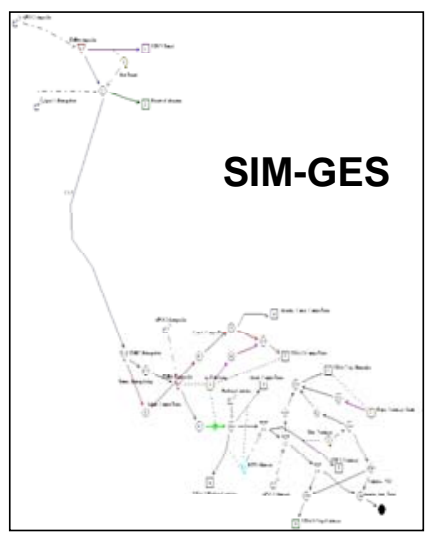

PLANTEAMIENTO DEL JUEGO Identificación de los jugadores Definición de las coaliciones Cálculo de los niveles de garantía

$2^{\mathrm{N}}-1$ coaliciones

$\mathrm{N}$-jugadores

A, B, C

$A B, A C, B C$,

$\{\mathrm{A}, \mathrm{B}, \mathrm{C} \ldots \mathrm{n}\}$ $\mathrm{ABC} .$.

...An...

...Bn...

ABC...n
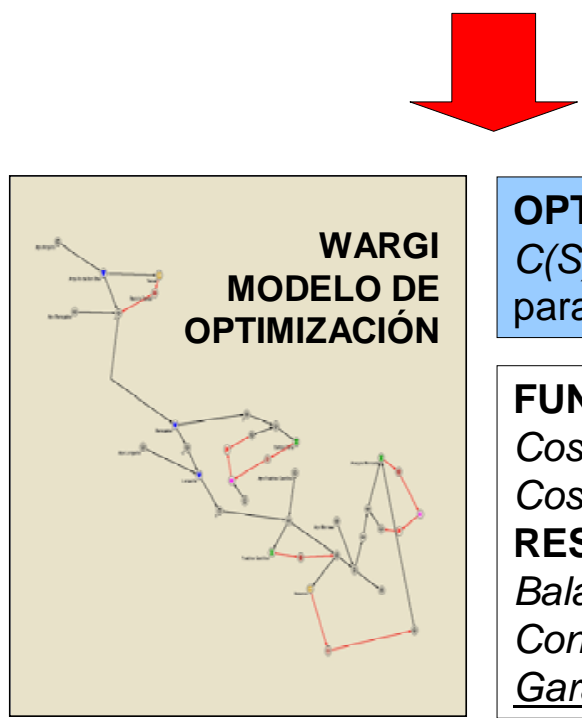

\section{OPTIMIZACIÓN:}

$C(S)$ : coste optimizado

para cada coalición

FUNCION OBJETIVO

Costes de los servicios

Coste de déficit

RESTRICCIONES

Balance en embalses

Continuidad en nudos

Garantías

\section{FUNCIÓN CARACTERÍSTICA}

Coste mínimo asociado a cada coalición para un determinado nivel de servicio.

Figura 26: Cálculo de la función característica. 


\section{VI.4 SOLUCIÓN DEL JUEGO COOPERATIVO}

Una vez calculados los valores de la función característica, la solución del juego cooperativo se halla mediante la aplicación de los algoritmos descritos en el Capítulo IV.

El método de resolución adoptado en esta tesis es el valor de Shapley, que responde a la necesidad de garantizar una solución aceptable frente a características peculiares del sistema hídrico, como por ejemplo la incertidumbre en los costes finales del proyecto, la necesidad de proceder a la realización y financiación de proyecto por fases o la existencia de jugadores nulos. El valor de Shapley representa una forma directa y simple de encontrar una solución racional y eficiente para un juego cooperativo de estas características, con independencia del número de jugadores. Sin embargo, solo es posible asegurar que la configuración de pagos encontrada se encuentre en el núcleo en el caso de que la función característica sea cóncava. Esto implica que la función característica sea sometida a un análisis previo para comprobar la eficiencia de la gran coalición y la existencia de un núcleo de soluciones factibles.

El resultado de la aplicación del juego es un vector de pagos asociados a cada jugador presente en la gran coalición y relativo a la realización de las actuaciones contenidas en el proyecto de coalición más eficiente durante el periodo de tiempo considerado. Se hace necesario un análisis posterior para traducir el insumo de costes calculado para cada jugador en las tarifas asociadas al usuario singular según los criterios tradicionalmente empleados (cuota anual, has, volumen consumido) y en función de exigencias particulares de tipo organizativo u objetivos de ahorro y mejora en el uso del recurso.

\section{VI.5 ÁMBITOS DE APLICACIÓN DE LA METODOLOGÍA}

El ámbito de aplicación de la metodología se extiende tanto al reparto de los costes contables de las infraestructuras existentes en el sistema hídrico como a la expansión de las mismas por medio de nuevas actuaciones con el fin de mejorar los niveles de servicio de los usuarios.

En el primer caso, se considera el conjunto de infraestructuras y los niveles de garantía existentes como la gran coalición y se define una función característica a partir de un escenario base de gestión simulado en ausencia de infraestructuras hidráulicas. La simulación del escenario base permite obtener los valores de garantía de las demandas del sistema, a partir de los cuales se define, mediante herramientas de optimización, el conjunto de infraestructuras 
necesarias para alcanzar los niveles de servicio actuales para cada coalición de usuarios. Una vez obtenida la función característica del juego es posible calcular el reparto de costes de las infraestructuras existentes de acuerdo con los criterios de asignación definidos por la TJC.

En el segundo caso, el escenario base corresponde a la simulación de la situación existente en el sistema, a partir del cual se plantea un juego de reparto de costes de las futuras inversiones necesarias para la mejora de las garantías de suministro. Mediante herramientas de optimización se calcula la función característica y se define la solución de gestión más eficiente, cuyo coste se reparte entre los usuarios de acuerdo con los algoritmos de la TJC. 



\section{CAPÍTULO VII}

\section{APLICACIÓN DE LA METODOLOGÍA AL CASO DEL RÍO TURIA}

En este capítulo se resume la descripción del modelo utilizado para la asignación del coste de los servicios en el sistema de explotación del río Turia y se procede a la definición de un criterio de reparto de los costes de las infraestructuras existentes en la cuenca, basado en la estimación de la responsabilidad de cada usuario en el uso de las mismas.

A partir del estudio del esquema conceptual de la cuenca del río Turia se plantea el juego cooperativo mediante un proceso de racionalización y agrupación de usuarios y se define el modelo de optimización económica a partir del cual es posible calcular la función característica. Finalmente se procede al cálculo del valor de Shapley para obtener el vector de pagos y al análisis de los resultados.

El carácter experimental del estudio concede una cierta libertad a la hora de definir la información económica del modelo, que no pretende reflejar fielmente y de forma detallada la realidad del sistema, sino permitir una representación, lo más objetiva posible, del problema con el fin de ofrecer un ejemplo de aplicación de la metodología a un caso de estudio. Por lo tanto, se advierte el lector que muchos aspectos del sistema hídrico han sido objeto de simplificaciones e idealizaciones y que los resultados obtenidos no pretender ser una propuesta formal de tarifación. Para una aplicación práctica real, debería mejorarse la representación del sistema y estimarse con mayor precisión algunas características del mismo, entre ellas las funciones características.

\section{VII.1 EL SISTEMA HÍDRICO DEL RÍO TURIA}

La modelización del sistema es el primer paso para la aproximación al conocimiento del mismo, siendo éste el paso más largo y costoso debido a la cantidad de información a considerar. De hecho la definición de un esquema conceptual es un proceso que constituye un estudio por sí mismo. Siendo el 
sistema del río Turia muy estudiado y disponiendo de varios modelos dedicados, en el presente documento se propone una actualización del modelo previamente elaborado en el ámbito de un estudio de uso conjunto de aguas superficiales y subterráneas (MIMAM, 2002). El esquema de gestión está representado en la Figura 27 e incluye:

1. Las infraestructuras fundamentales (presas, canales, retornos, bombeos);

2. Las conexiones entre elementos puntuales (tramos de río, conducciones, canales, tomas);

3. Las demandas;

4. Las aportaciones hidrológicas;

5. Los acuíferos conectados hidráulicamente con el sistema superficial. 

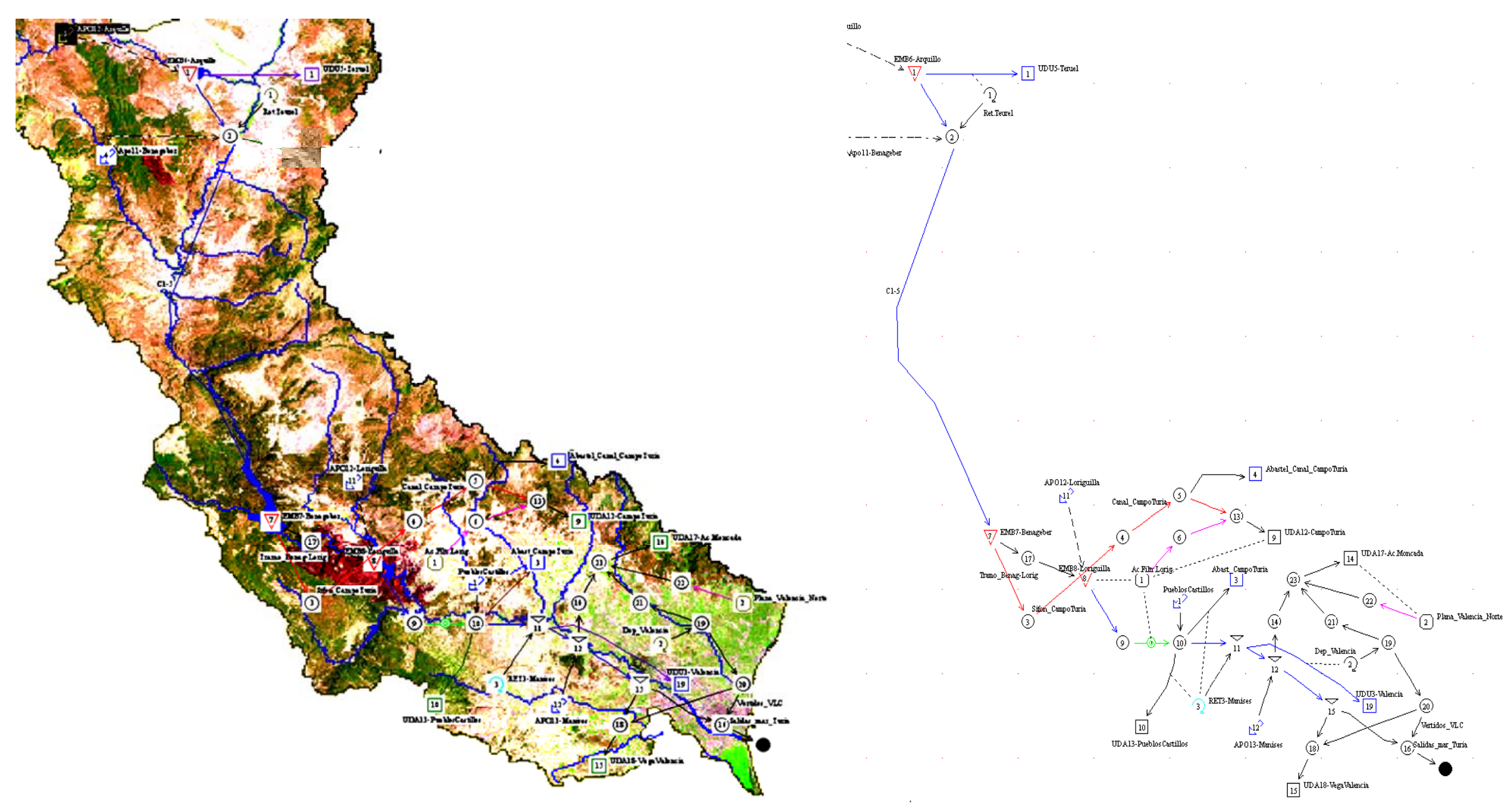

Figura 27: SIMGES, esquema de simulación del río Turia. 



\section{VII.1.1 Descripción general del sistema}

El sistema de explotación Turia está localizado en las provincias de Valencia y Teruel y comprende la cuenca del río Turia, el Barranco del Carraixet, el Barranco o Rambla del Poyo, y las subcuencas litorales comprendidas entre el límite norte del término municipal de Puzol y la Gola de El Saler. La superficie total del sistema es de $6.913 \mathrm{~km}^{2}$. Los recursos hídricos totales del sistema ascienden a $634 \mathrm{hm}^{3}$ de los que $473,5 \mathrm{hm}^{3}$ corresponden a aportes subterráneos, 83,7 a aportes por escorrentía superficial y 76,8 a bombeos netos. La demanda global del sistema alcanza actualmente un valor de $685 \mathrm{hm}^{3}$ anuales, que se destinan en su mayor parte a la agricultura $\left(466 \mathrm{hm}^{3}\right)$; al abastecimiento urbano (casi $200 \mathrm{hm}^{3}$ ) y el resto, unos $20 \mathrm{hm}^{3}$, al uso industrial.

En la cabecera del río se sitúa el embalse del Arquillo de San Blas, adonde llega la aportación superficial del río Guadalaviar, correspondiente a la cuenca aguas arriba del mismo. De este embalse toma el agua la demanda urbana de Teruel, la cual retorna sus aguas residuales aguas abajo. El modelo objeto del estudio presenta algunas simplificaciones respecto al sistema real, entre las cuales se desglosa la supresión de las demandas para usos agrícolas y piscicultura presentes en la cabecera del río Turia.

A continuación se sitúa el embalse de Benagéber al cual llegan las aportaciones superficiales correspondientes a las cuencas aguas arriba del mismo no incluidas en la aportación anterior. Desde el embalse de Benagéber empieza la conducción de tipo 1 (canal) que representa la derivación del Canal Campo del Turia hacia la demanda homónima. La demanda agraria del Canal Campo del Turia realiza un uso conjunto de las aguas superficiales suministradas por el canal y de las aguas subterráneas extraídas del acuífero subyacente.

El río Turia sigue desde el embalse de Benagéber hacia el embalse de Loriguilla, donde se incorpora la aportación homónima que representa la entrada hidrológica superficial de la intercuenca entre Benagéber y Loriguilla.

Aguas abajo del embalse de Loriguilla se sitúa la demanda de riego denominada de los Pueblos Castillos, que incluye los riegos tradicionales de las acequias de Benaguacil, Lorca y Villamarchante.

En el siguiente nudo se incorpora el retorno de las demandas agrarias situadas aguas arriba, mediante el elemento de retorno "Ret-Manises". A este nudo se conecta la toma de la demanda urbana de la ciudad de Valencia.

Aguas abajo, se dispone la toma de la demanda agraria de los Riegos tradicionales de la Acequia de Moncada y se incorpora la aportación del tramo 
final de la cuenca "APO - Manises". La unidad de demanda "Acequia de Moncada" dispone, además, del suministro subterráneo procedente del acuífero de la Plana Norte. En el tramo siguiente de río se sitúa la toma de los Riegos tradicionales de la Vega de Valencia.

En el tramo final del río se incorporan los vertidos no reutilizados de la depuradora de Valencia y finalmente se llega al estuario del río Turia que coincide con la salida del sistema.

\section{VII.1.2 Prioridades y reglas de gestión.}

Se describen a continuación, las reglas de gestión establecidas para el sistema de recursos hídricos del río Turia:

- En primer lugar, no se vulnerarán en la medida que sea posible los valores mínimos de embalses establecidos por motivos medioambientales.

- Se intentan mantener en lo posible los caudales mínimos ecológicos.

- Se procede al suministro de las demandas con el siguiente orden de prioridad: en primer lugar, se asegura el suministro para el abastecimiento urbano de Teruel y Valencia; en segundo lugar, se abastecen las demandas de los riegos tradicionales de La Vega de Valencia, de los Pueblos Castillo y de la Acequia de Moncada; y por último, se abastece la demanda de los riegos del Canal Campo del Turia.

- Una vez abastecidas todas las demandas del sistema y satisfechos los caudales ambientales, el agua sobrante se conserva en los embalses.

- Respecto al embalse de Arquillo de San Blas, la gestión prevista consiste en mantener el embalse con el máximo volumen posible, ya que es la única fuente de suministro para el abastecimiento urbano de la ciudad de Teruel.

- Se ha asignado al embalse de Benagéber un volumen objetivo próximo al volumen máximo, y al embalse de Loriguilla próximo al volumen mínimo, de manera que siempre se soltará agua en primer lugar del embalse de Loriguilla y en segundo lugar de Benagéber. 


\section{VII.1.3 Demandas del sistema}

Las demandas consuntivas consideradas en la modelización del sistema del río Turia son las siguientes:

Demandas urbanas:

- Abastecimiento de la ciudad de Teruel;

- Abastecimiento parcial de la ciudad de Valencia, y su área metropolitana.

Demandas agrícolas:

- Riegos Tradicionales de La Vega de Valencia;

- Riegos Tradicionales de la Acequia de Moncada;

- Riegos de los Pueblos Castillo (acequias de Benaguacil, Lorca y Villamarchante);

- Riegos del Canal Campo de Turia.

Los valores medios anuales y mensuales de las demandas consideradas en el modelo se resumen en las tablas siguientes.

\begin{tabular}{|c|c|c|c|c|}
\hline DEMANDA & $\begin{array}{c}\text { Demanda } \\
\left(\mathrm{hm}^{3} / \mathrm{año}\right)\end{array}$ & Tipo & Prioridad & $\begin{array}{c}\text { Coeficiente } \\
\text { de consumo }\end{array}$ \\
\hline Urbana Teruel & 3.17 & Urbana & 1 & 0.2 \\
\hline Urbana Valencia & 31.53 & Urbana & 1 & 1 \\
\hline Pueblos Castillo & 51.88 & Agrícola & 2 & 0.7 \\
\hline Acequia Moncada & 80.85 & Agrícola & 2 & 1 \\
\hline Tradicionales Turia & 80.15 & Agrícola & 2 & 1 \\
\hline Campo Turia & 85 & Agrícola & 3 & 0.7 \\
\hline Total & 332.6 & & & \\
\hline
\end{tabular}

Tabla 10. Demandas en el sistema Turia. 
CAPÍTULO VII: APLICACIÓN DE LA METODOLOGÍA AL CASO DEL RÍO TURIA

\begin{tabular}{|c|c|c|c|c|c|c|c|c|c|c|c|c|c|}
\hline $\begin{array}{c}\text { DISTRIBUCION } \\
\text { MENSUAL }\end{array}$ & oct & nov & dic & ene & feb & mar & abr & mayo & jun & jul & ago & sep & TOTAL \\
\hline $\begin{array}{c}\text { Teruel } \\
\text { hm3/mes }\end{array}$ & 0.27 & 0.26 & 0.27 & 0.27 & 0.24 & 0.27 & 0.26 & 0.27 & 0.26 & 0.27 & 0.27 & 0.26 & 3.17 \\
\hline $\begin{array}{c}\text { Valencia } \\
\mathrm{hm}^{3} / \text { mes }\end{array}$ & 2.678 & 2.592 & 2.678 & 2.678 & 2.418 & 2.678 & 2.591 & 2.678 & 2.591 & 2.678 & 2.678 & 2.591 & 31.53 \\
\hline $\begin{array}{c}\text { P. Castillo } \\
\mathrm{hm}^{3} / \text { mes }\end{array}$ & 4.02 & 2.49 & 2.81 & 2.59 & 2.61 & 4.88 & 3.93 & 5.29 & 5.14 & 5.97 & 6.24 & 5.91 & 51.88 \\
\hline $\begin{array}{c}\text { Ac. Moncada } \\
\mathrm{hm}^{3} / \text { mes }\end{array}$ & 3.54 & 2.02 & 3.54 & 3.14 & 3.16 & 7.11 & 7.69 & 8.65 & 9.21 & 11.24 & 11.24 & 10.31 & 80.85 \\
\hline $\begin{array}{c}\text { Campo Turia } \\
\mathrm{hm}^{3} / \text { mes }\end{array}$ & 3.02 & 0.74 & 1.66 & 1.34 & 2.54 & 5.62 & 6.17 & 9.72 & 13.46 & 17.18 & 13.4 & 5.29 & 80.15 \\
\hline Total \% & 6.04 & 3.98 & 3.68 & 3.40 & 3.39 & 6.28 & 7.47 & 11.47 & 12.12 & 15.96 & 16.39 & 9.81 & $100 \%$ \\
\hline
\end{tabular}

Tabla 11. Distribución mensual de la demanda.

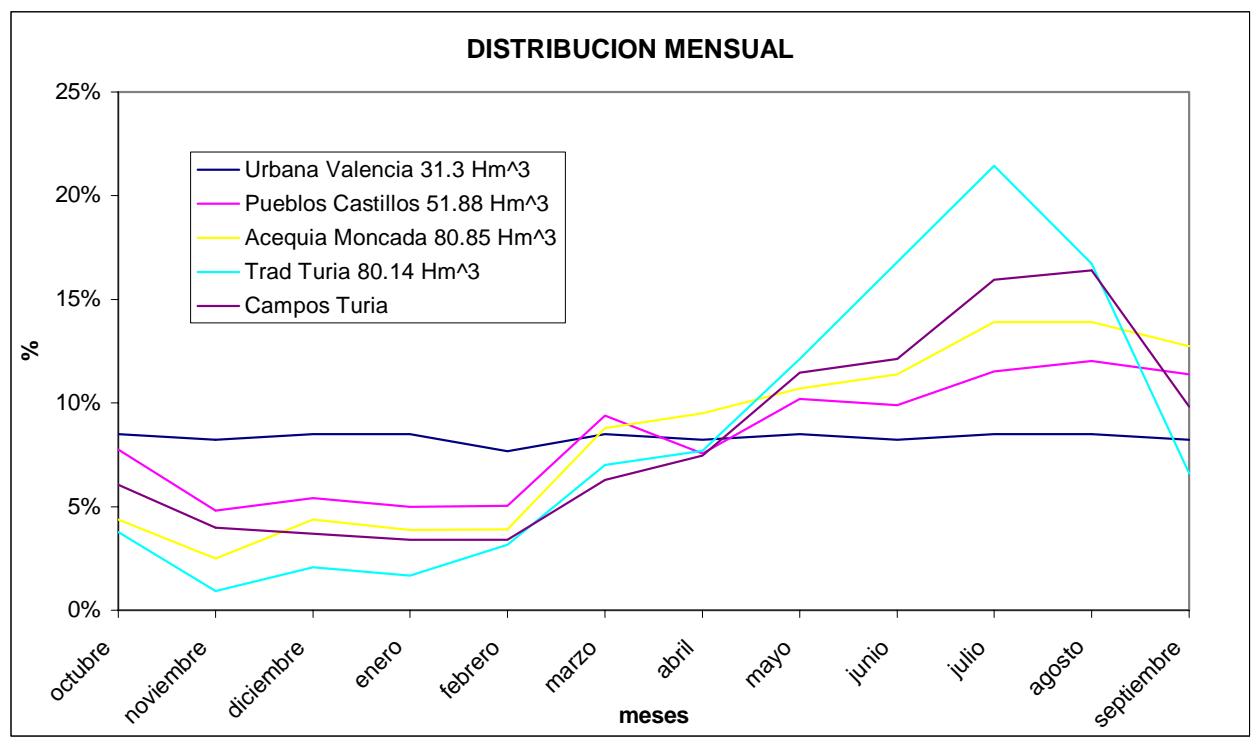

Figura 28: Curvas de la distribución porcentual mensual de las demandas.

\section{VII.1.3.1 Tomas fueras de comisión de desembalse}

Los usuarios citados en el apartado anterior están representados en la Comisión de Desembalse y en cada ejercicio hídrico están sujetos a sus disposiciones sobre el régimen de llenado y vaciado de los embalses en función de los distintos usos demandados. Existen sin embargo otros usuarios minoritarios en la cuenca que no están presentes en la comisión de desembalse pero tienen derecho a la toma de un cierto caudal circulante por el río. Estos usuarios no participan en la gestión y financiación de los embalses pero pueden beneficiarse 
indirectamente de la regulación al derivar parte de los caudales desembalsados para otros usuarios.

Uno de los objetivos del análisis es estimar el beneficio indirecto que obtienen, en términos de mejoras de las garantías, los usuarios cuyas tomas no están representadas en comisión de desembalse, y definir la asignación de costes correspondiente a su responsabilidad en el uso de las infraestructuras.

La demanda de las tomas fuera de comisión (TFC) es de difícil estimación, en cuanto que no está sometida a vínculos de volúmenes y no está controlada por medidores de caudal. Sin embargo, los balances hidrológicos sugieren una valoración del orden de $10 \mathrm{hm}^{3}$ anuales. En el modelo se han simulado las TFC como una unidad de demanda de $10 \mathrm{hm}^{3}$ anuales situada aguas abajo de los embalses principales de la cuenca, cuya distribución mensual coincide con los riegos tradicionales.

\section{VII.1.4 Infraestructuras presentes en el sistema}

Las obras hidráulicas presentes en el sistema y consideradas en el análisis cuentan con:

- 3 embalses con funciones de regulación y laminación de avenidas (Arquillo de San Blas, Benagéber y Loriguilla);

- 1 canal: Canal Campo del Turia;

- Los retornos de las aguas depuradas de Valencia y Teruel;

- Los sistemas de pozos del Canal Campo del Turia y de la Acequia de Moncada;

- Una red capilar de distribución en baja para los sistemas de riego.

\section{VII.1.5 Simulación de la asignación del recurso mediante SIMGES}

Los resultados de la simulación efectuada por el SIMGES según la configuración del esquema descrita anteriormente se pueden resumir en la presencia de unos periodos -inicial e intermedio- caracterizados por elevadas aportaciones, en los que no se detectan problemas de escasez del recurso. Durante el periodo final de la simulación (correspondiente a los años '80 y '90) el decremento de los niveles de aportación comporta la disminución de los 
volúmenes almacenados en los embalses principales y la activación de los indicadores de alarma del sistema con las consecuentes restricciones al suministro del agua de procedencia superficial y el aumento en proporción del uso de los recursos subterráneos.

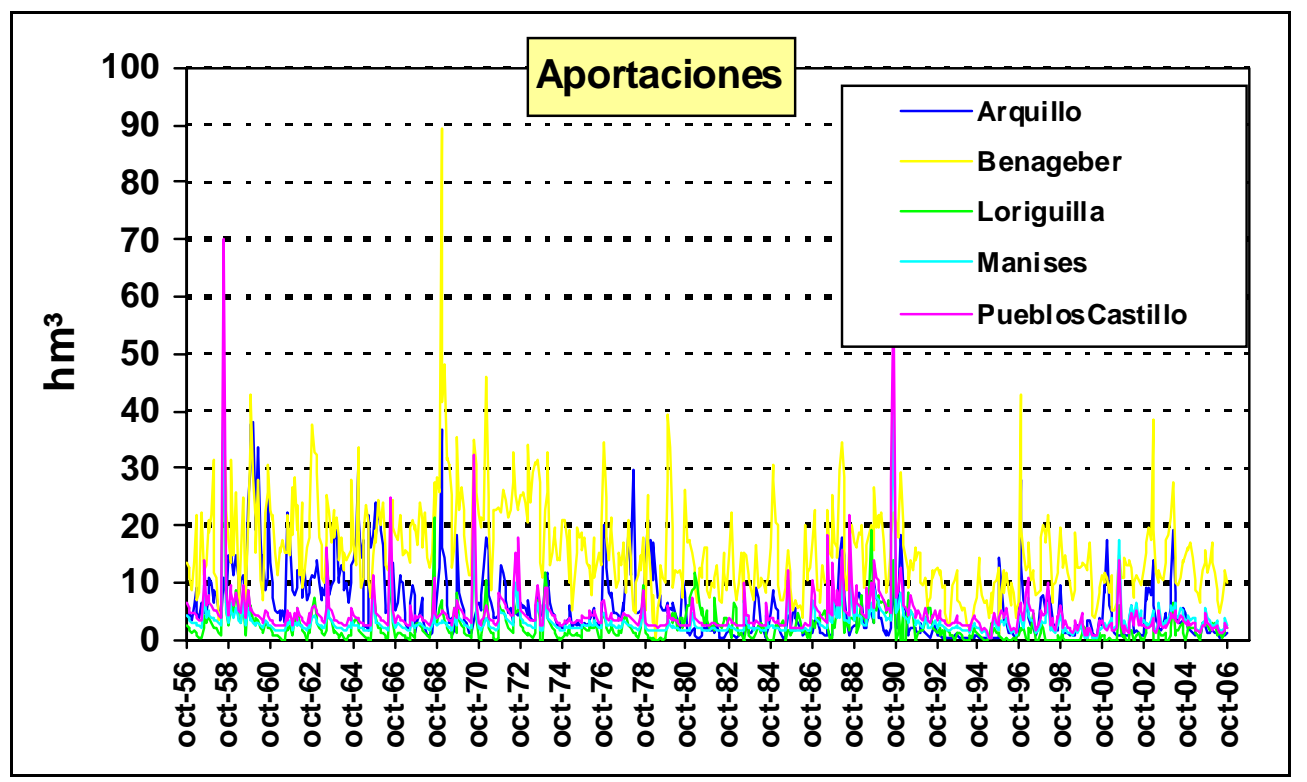

Figura 29: Simulación del sistema Turia, aportaciones.

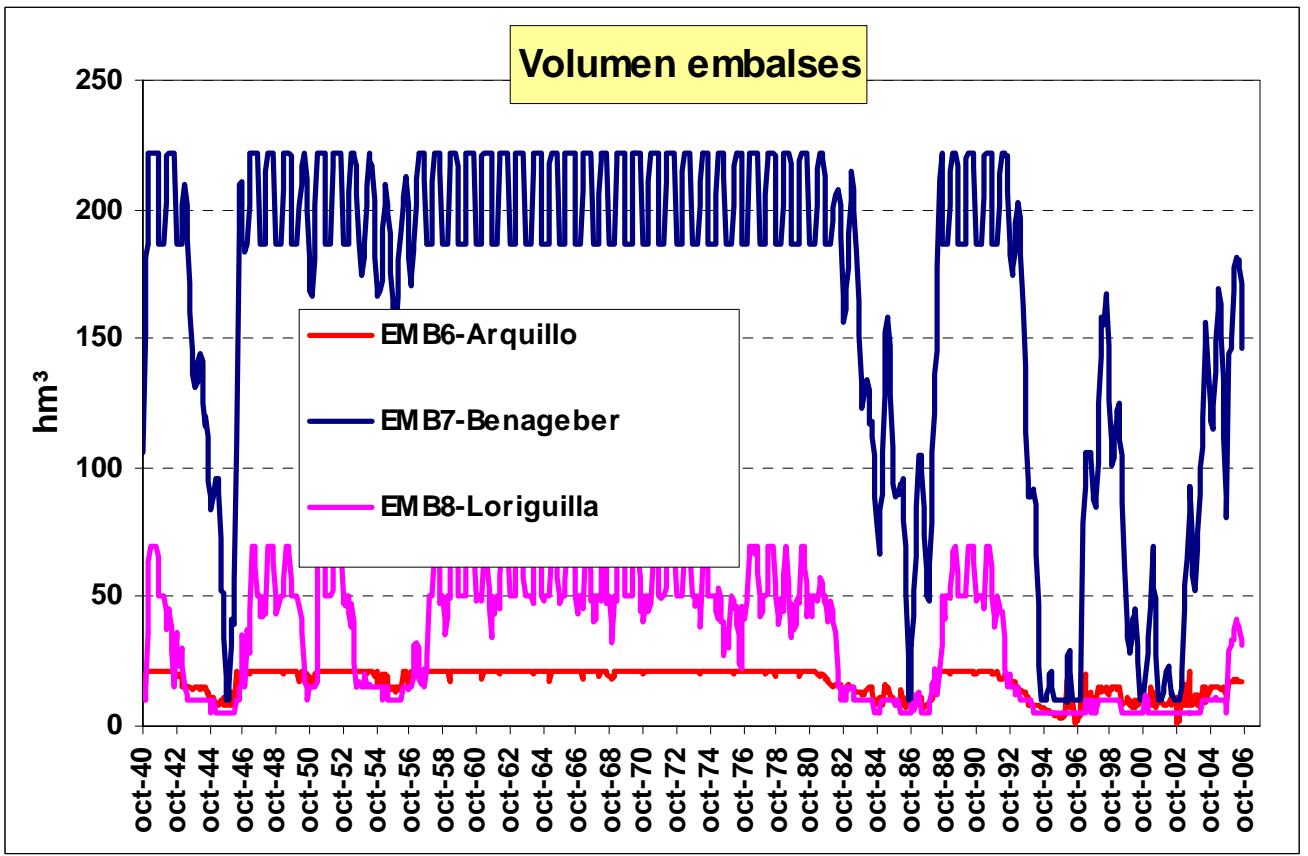

Figura 30: Simulación del sistema Turia, volúmenes almacenados. 


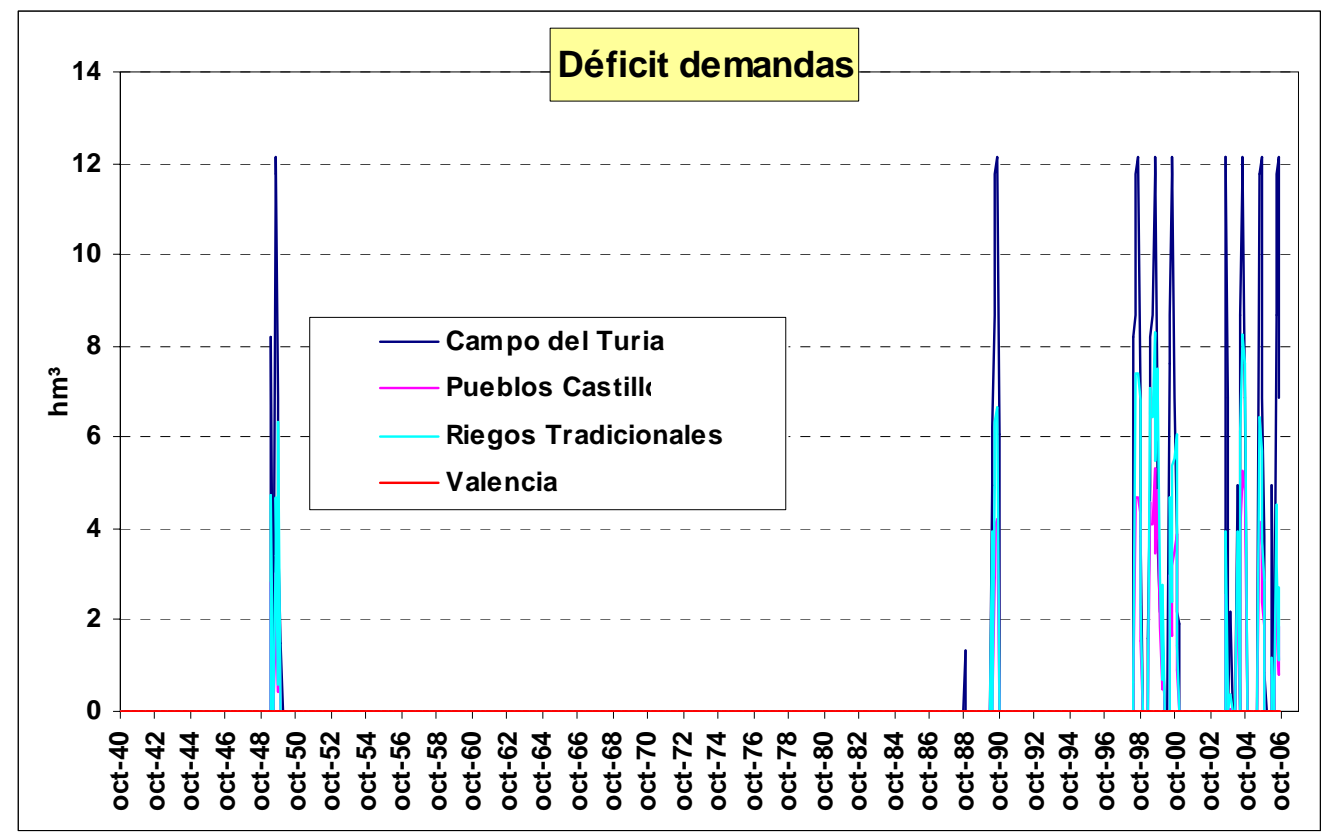

Figura 31: Simulación del sistema Turia, déficit anual a las demandas.

\section{VII.2 CARACTERIZACIÓN ECONÓMICA DE LA CUENCA}

En el presente apartado se recopila la información económica del sistema requerida por la nueva metodología de asignación de costes. El carácter experimental del estudio concede una cierta libertad a la hora de definir la información económica del modelo, que no pretende reflejar fielmente y de forma detallada la realidad económica del sistema, sino permitir una representación, lo más objetiva posible, del problema con el fin de ofrecer un ejemplo de aplicación de la metodología a un sistema hídrico real. No se tendrán en cuenta, por lo tanto, todas las infraestructuras presentes en el sistema y su coste efectivo. Se seleccionarán las infraestructuras consideradas más representativas y se definirá una función de coste de las obras según los criterios de valoración disponibles en la literatura científica.

El proceso de cálculo se basa en la definición y en el uso de las funciones de coste de las infraestructuras, que representan una relación directa entre los costes de inversión, mantenimiento y explotación de una inversión finalizada a la prestación de un servicio hídrico y los parámetros de diseño característicos de la misma. La definición de una función de coste requiere por lo tanto que se identifiquen los parámetros de diseño, que dependerán de la naturaleza y finalidad de la medida. A continuación, se procede a vincular los parámetros de diseño con las variables de decisión consideradas en el modelo de gestión del 
sistema hídrico con el fin de incorporar los aspectos económicos en la función objetivo.

El uso de funciones de costes constituye un avance en el proceso de planificación de los servicios del agua, en cuanto que permite al gestor efectuar previsiones a medio y largo plazo sobre los costes de las medidas y su eficiencia económica. Su aplicación se ha desarrollado en las últimas décadas en paralelo con el uso de modelos de simulación y de optimización de la gestión de los recursos hídricos, como demuestran los estudios realizados por el Ministerio de Medio Ambiente en el Plan Hidrológico Nacional (MIMAM, 2000) y los documentos publicados más recientemente por el CEDEX (2008).

Encontrándose el trabajo de definición de las funciones de costes fuera de los objetivos de esta tesis, y disponiendo de una amplia bibliografía al respecto producida por los organismos públicos españoles, se ha decidido utilizar la información existente como referencia para los procesos de cálculo del coste de las infraestructuras.

\section{VII.2.1 Cálculo de las funciones de coste}

\section{VII.2.1.1 Embalses}

El coste de las presas para la regulación y laminación de caudales fluviales suele depender de los parámetros de diseño de la misma y de su geometría, sin embargo los modelos de gestión del recurso consideran únicamente el volumen almacenado como variable de decisión. La definición de la función de coste de un embalse se realiza vinculando las características geométricas de la presa con la curva cota-volumen del embalse según el procedimiento que se expone a continuación:

1. Selección de la tipología de la presa y de sus componentes;

2. Análisis de la geometría de la obra (longitud, taludes y altura de coronación)

3. Cálculo de la curva de coste en función de la geometría de la obra y de la estimación del coste de las obras accesorias;

4. Cálculo de la relación cota-volumen de presa y definición de una nueva función de coste respecto al volumen almacenado. 
El resultado es una función coste-volumen, que en la presente tesis ha sido calculada a partir de las tablas presentadas en el Plan Hidrológico Nacional (MIMAM, 2000) y actualizadas recientemente por el CEDEX (2008).

Se considera una presa tipo de gravedad en hormigón vibrado, de la cual es necesario recopilar los siguientes parámetros de diseño:

- Talud de la presa aguas arriba;

- Talud de la presa aguas abajo;

- Talud cimiento presa;

- Anchura de coronación (m);

- Excavación de cimientos (m);

- Anchura del cauce (\% longitud de coronación).

Basándose de los parámetros de diseño de la presa es posible calcular las siguientes partidas de gastos:

- $m^{3}$ de hormigón;

- $\mathrm{m}^{2}$ de encofrados;

- $\mathrm{m}^{3}$ de excavación en cimientos.

A éstas partidas se suman los costes de algunas partidas difícilmente parametrizables, que se calculan como un porcentaje sobre el presupuesto de ejecución de la obra. 


\begin{tabular}{|l|c|}
\hline \multicolumn{2}{|c|}{$\begin{array}{c}\text { PARTIDAS VALORADAS EN TANTO POR CIENTO DEL } \\
\text { PRESUPUESTO DE EJECUCION MATERIAL }\end{array}$} \\
\hline $\begin{array}{l}\text { Otras unidades en cuerpo de presa además de hormigón, } \\
\text { encofrado y excavación (despeje y desbroce, camino de } \\
\text { coronación, etc) }\end{array}$ & $12 \%$ \\
\hline Galerías & $2 \%$ \\
\hline Desagüe de fondo y tomas & $5 \%$ \\
\hline Desvío de río & $1 \%$ \\
\hline $\begin{array}{l}\text { Accesos a la presa, variantes de carreteras y servicios } \\
\text { afectados }\end{array}$ & $10 \%$ \\
\hline Instalación eléctrica & $1 \%$ \\
\hline Auscultación & $1 \%$ \\
\hline Inyecciones & $3 \%$ \\
\hline Medidas correctoras del impacto ambiental & $2 \%$ \\
\hline Seguridad y salud laboral & $2 \%$ \\
\hline Otras partidas & $2 \%$ \\
\hline
\end{tabular}

Tabla 12: Presas, otras partidas de costes (MIMAM, 2000).

Para las obras de regulación se considera un coste anual de mantenimiento del 1,2\% sobre los costes de inversión y una vida útil de 50 años (CEDEX, 2008).

\section{VII.2.1.2 Canales}

El coste de los canales para el trasporte del agua depende en gran medida de las características del entorno en el que se emplaza la obra, siendo fundamental al respecto la orografía y la geología del terreno. A igualdad de condiciones existe sin embargo una relación directa entre los caudales de diseño y el coste de la obra, que refleja el encarecimiento de los trabajos de excavación e impermeabilización consecuente al aumento de la sección de paso del agua.

Otro aspecto peculiar responde a la necesidad de dimensionar la obra en función del caudal punta y no del caudal medio requerido aguas abajo, situación que puede llevar a diferencias sustanciales en la asignación de costes en caso de demandas caracterizadas por una elevada variabilidad en el consumo interanual. 
Se han considerado las funciones de costes definidas en (MIMAM, 2000) para un diseño tipo, distinguiéndose si el canal discurre por suelo o por roca y si la pendiente del terreno supera o no el 50\% (1:2). En el caso de pendiente moderada se plantea la ejecución de forma mecanizada tanto de la excavación como del revestimiento de hormigón, cuyo espesor se estima de $15 \mathrm{~cm}$. En el caso de terrenos con pendiente superior al $50 \%$ se supone que el canal discurre mayoritariamente en roca y que la ejecución se realice con escasa mecanización, mediante la realización de un revestimiento en hormigón armado y de un muro de contención para el camino de servicio.

Los parámetros de diseño que caracterizan las secciones se indican en las tablas siguientes:

\begin{tabular}{|l|c|c|c|}
\hline CANALES EN TIERRA & $0<\mathrm{q}<10 \mathrm{~m}^{3} / \mathrm{s}$ & $10<\mathrm{q}<20 \mathrm{~m}^{3} / \mathrm{s}$ & $20<\mathrm{q}<30 \mathrm{~m}^{3} / \mathrm{s}$ \\
\hline Pendiente canal & 0.0001 & 0.0001 & 0.0001 \\
\hline Anchura base canal & 2.5 & $2.5-3.5$ & 3.5 \\
\hline Espesor revestimiento $(\mathrm{m})$ & 0.15 & 0.15 & 0.15 \\
\hline Ancho camino de servicio & $4-6$ & 6 & 6 \\
\hline Ancho banqueta & 2 & $2-3$ & 3 \\
\hline Ancho cuneta $(\mathrm{m})$ & 2.5 & 2.5 & 2.5 \\
\hline Resguardo $(\mathrm{m})$ & $0.2-0.3$ & $0.3-0.5$ & $0.5-0.65$ \\
\hline Prof. Enterramiento $(\mathrm{m})$ & $0.5-1$ & $1-2$ & $2-3$ \\
\hline Pendiente ladera $(\%)$ & 30 & 30 & 30 \\
\hline Talud desmonte $(\mathrm{V} / \mathrm{H})$ & 1 & 1 & 1 \\
\hline Talud terraplen $(\mathrm{H} / \mathrm{V})$ & 1.5 & 1.5 & 1.5 \\
\hline
\end{tabular}

Tabla 13: Canales en tierra, parámetros de diseño (MIMAM, 2000) 


\begin{tabular}{|l|c|c|c|}
\hline CANALES EN ROCA & $0<\mathrm{q}<10 \mathrm{~m}^{3} / \mathrm{s}$ & $10<\mathrm{q}<20 \mathrm{~m}^{3} / \mathrm{s}$ & $20<\mathrm{q}<30 \mathrm{~m}^{3} / \mathrm{s}$ \\
\hline Pendiente canal & 0.0001 & 0.0001 & 0.0001 \\
\hline Anchura base canal & $2-2.6$ & $2.6-3.8$ & $3.8-5$ \\
\hline Espesor revestimiento (m) & 0.25 & $0.25-0.45$ & $0.45-0.65$ \\
\hline Ancho camino de servicio & 3 & $3-6$ & 6 \\
\hline Ancho banqueta & 1 & $1-2$ & 2 \\
\hline Ancho cuneta (m) & 1.5 & 1.5 & 1.5 \\
\hline Resguardo (m) & $0.2-0.3$ & $0.3-0.5$ & $0.5-0.65$ \\
\hline Prof. Enterramiento (m) & $1-1.6$ & $1.6-2.8$ & $2.8-4$ \\
\hline Pendiente ladera (\%) & 50 & 50 & 50 \\
\hline Talud desmonte (V/H) & 6 & 6 & 6 \\
\hline
\end{tabular}

Tabla 14: Canales en roca, parámetros de diseño (MIMAM, 2000)

La altura necesaria del canal está determinada por un modelo hidráulico, una vez asignados los parámetros anteriores, aplicando la fórmula de Manning con una rugosidad $n=0,0135$.

Una vez definida la sección tipo del canal se calcula el coste multiplicando las partidas de obras que componen la sección tipo por una base de precios por unidades de obra:

- Movimiento tierra: $\mathrm{m}^{3}$ de excavación y de terraplén;

- Sección tipo: $\mathrm{m}^{3}$ hormigón, $\mathrm{m}^{2}$ de encofrado, $\mathrm{kg}$ de acero para armaduras;

- Camino de servicio $\left(\mathrm{m}^{2}\right)$;

- Dren longitudinal y cuneta revestida de hormigón (m).

Las partidas de costes difícilmente parametrizables se valoran como un porcentaje sobre el presupuesto de ejecución de la obra, según las cantidades expuestas a continuación: 


\begin{tabular}{|l|c|}
\hline \multicolumn{2}{|c|}{$\begin{array}{c}\text { PARTIDAS VALORADAS EN TANTO POR CIENTO DEL } \\
\text { PRESUPUESTO DE EJECUCION MATERIAL }\end{array}$} \\
\hline $\begin{array}{l}\text { Otras unidades de la partida movimiento tierra que no sean } \\
\text { excavación y terraplén (despeje y desbroce, etc.) }\end{array}$ & $4 \%$ \\
\hline $\begin{array}{l}\text { Otras unidades de la partida sección tipo que no sean } \\
\text { encofrados y acero (juntas, etc.) }\end{array}$ & $6 \%$ \\
\hline $\begin{array}{l}\text { Otras unidades de la partida camino de servicio que no sean el } \\
\text { propio camino (barreras de seguridad, señalización, etc.) }\end{array}$ & $4 \%$ \\
\hline $\begin{array}{l}\text { Otras unidades de la partida drenaje longitudinal que no sean } \\
\text { el dren o la cuneta (refino, etc) }\end{array}$ & $4 \%$ \\
\hline Drenaje Transversal & $5 \%$ \\
\hline Estructuras del canal (almenaras, aliviaderos, etc.) & $6 \%$ \\
\hline Accesos y servicios afectados & $5 \%$ \\
\hline Medidas correctoras del impacto ambiental & $2 \%$ \\
\hline Seguridad y salud laboral & $2 \%$ \\
\hline Otras partidas & $2 \%$ \\
\hline
\end{tabular}

Tabla 15: Canales, otras partidas de costes (MIMAM, 2000)

Los costes de explotación y mantenimiento se estiman en una cuantía fija anual del 1,2\% sobre el coste de inversión (CEDEX 2008).

La vida útil para las obras civiles se estima en 50 años.

\section{VII.2.1.3 Bombeos}

El coste de bombeo se compone en general de las siguientes partidas:

- costes fijos atribuidos a la amortización de los costes de sondeo, de las obras civiles y de los equipos electro-mecánicos;

- costes anuales de mantenimiento de la instalación;

- costes variables atribuibles a la energía consumida en el proceso de elevación.

En general el análisis de las explotaciones existentes evidencia el predominio de la componente energética, cuya magnitud está relacionada con la profundidad 
del bombeo y el caudal bombeado, sobre los costes de inversión y mantenimiento. A pesar de ello se ha evidenciado, en el caso de los pozos de sequía o de las medidas de emergencia, que la influencia de los costes de inversión aumenta hasta situarse por encima de los costes de explotación.

En las siguientes gráficas (MIMAM, 2000) se expone una propuesta de parametrización del coste de las obras civiles y de los equipos electromecánicos en función de la potencia instalada.

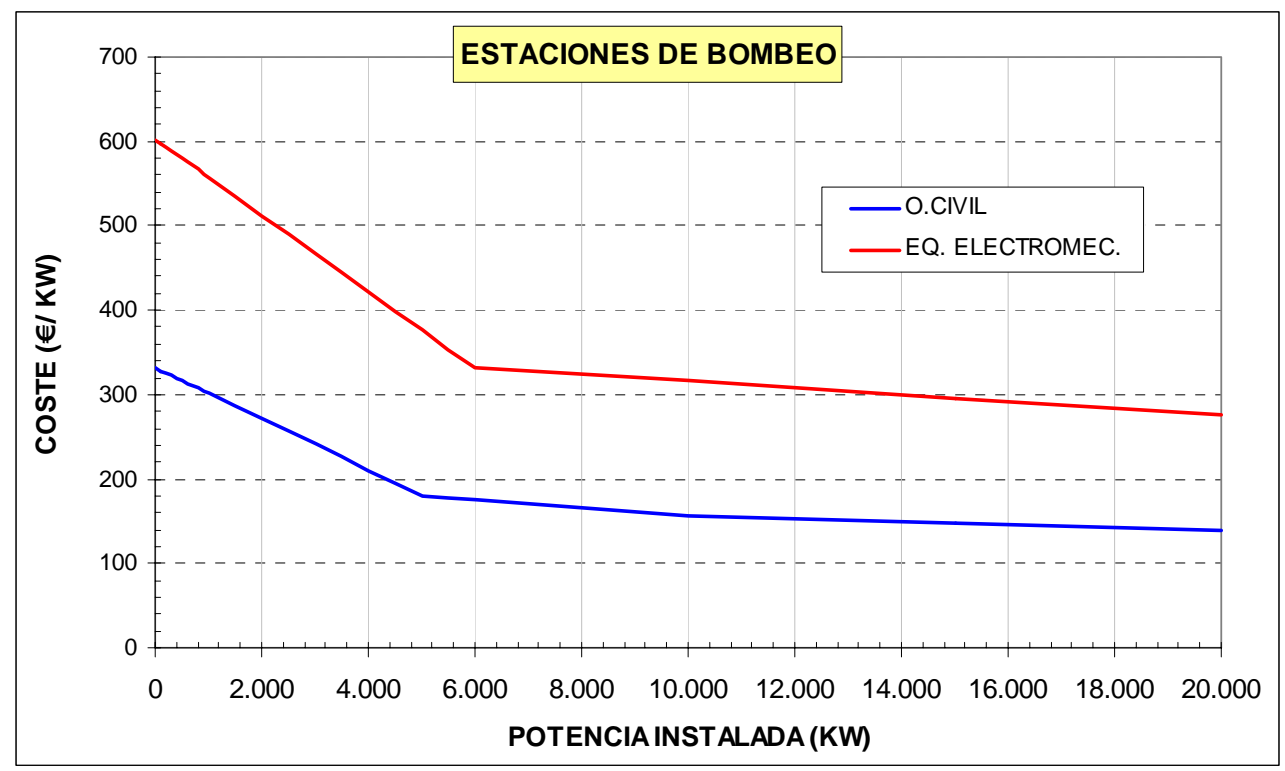

Figura 32: Bombeos, parametrización de costes (MIMAM, 2000).

Las restantes partidas de coste se calculan en porcentaje respecto al presupuesto de ejecución de la obra.

\begin{tabular}{|l|c|}
\hline \multicolumn{2}{|c|}{$\begin{array}{c}\text { PARTIDAS VALORADAS EN TANTO POR CIENTO DEL } \\
\text { PRESUPUESTO DE EJECUCION MATERIAL }\end{array}$} \\
\hline Instalaciones de mando y control & $3 \%$ \\
\hline Instalaciones eléctricas & $20 \%$ \\
\hline Accesos y servicios afectados & $2 \%$ \\
\hline Medidas correctoras del impacto ambiental & $2 \%$ \\
\hline Seguridad y salud laboral & $2 \%$ \\
\hline Otras partidas & $2 \%$ \\
\hline
\end{tabular}

Tabla 16: Bombeos, otras partidas de costes (MIMAM, 2000). 
El coste de mantenimiento se estima, como en los casos anteriores, como una cantidad anual del orden de 1,2\% respecto a los costes de inversión. Los costes de explotación están asociados mayoritariamente a la tarifa eléctrica, cuya estimación depende en parte de las circunstancias contingentes del mercado eléctrico. Una estimación razonable puede encontrarse entre 0,07 y 0,09€/kwh (CEDEX, 2008). La vida útil de la instalación se suele estimar en 50 años para las obras civiles y 25 años para los equipos electromecánicos. Sin embargo, teniendo en cuenta que estos últimos son los elementos caracterizantes de la instalación, se puede optar por asignar una vida útil de 25 años al conjunto de la inversión.

\section{VII.2.1.4 Reutilización.}

La reutilización de aguas residuales para usos agrícolas representa una alternativa eficaz para aumentar los recursos disponibles.

Se consideran tres tipos de tratamientos en función de los requisitos establecidos en el RD 1620/2007 por el que se establece el régimen jurídico de la reutilización de las aguas depuradas. El parámetro en función del cual se ha definido el rango de aplicación de cada tratamiento es el valor máximo admisible de Escherichia coli: ausencia, menor o igual que $1000 / \mathrm{mL}$ o mayor que $1000 / \mathrm{mL}$. También se considera un cuarto tratamiento de desalinización en aquellas poblaciones cercanas a la costa, debido a las infiltraciones de agua marina en la red de alcantarillado. Los costes de impulsión, donde los haya, determinan el alcance territorial de estas medidas, en cuanto su magnitud aumenta al aumentar la longitud de la red de trasporte y la cota de entrega del recurso regenerado.

Se ha supuesto la implantación de un tratamiento de regeneración adicional a una instalación de depuración pre-existente con tratamiento de tipo secundario. En caso contrario se podría estudiar la realización de un diseño conjunto depuración-reutilización que optimizaría el coste de ambos procesos.

Los datos de coste de inversión reportados a continuación se han obtenido a partir de documentación sobre actuaciones reales (CEDEX, 2008), teniendo en cuenta los efectos de economías de escala. Los costes de explotación y mantenimiento engloban los debidos al consumo de energía y recreativos, a la reposición de elementos fungibles y al personal. También hay que considerar los costes de las operaciones de muestreo y control de calidad de obligado cumplimiento, que en plantas pequeñas pueden suponer una fracción significativa de los costes de explotación.

La vida útil de una estación de regeneración de aguas residuales puede estimarse en 15 años. Este valor común trata de incluir elementos como las 
obras civiles, cuya vida útil resulta más elevada, o algunos equipos, entre los cuales se encuentran las membranas, que alcanzan una vida útil inferior a los 5 años.

\section{Tratamiento de tipo 1}

Este tratamiento garantiza la ausencia de contaminación por Escherichia coli en el agua, cuyo uso está permitido para:

- riego de jardines privados y descarga de aparatos sanitarios;

- Torres de refrigeración industriales;

- Recarga de acuíferos por inyección directa.

La línea propuesta se compone de 3 etapas:

- Decantación;

- Filtración;

- Ultrafiltración por membranas;

- Desinfección de mantenimiento.

El coste de inversión queda acotado entre 198 y $424 € /\left(\mathrm{m}^{3} /\right.$ día), mientras los costes de explotación y mantenimiento se sitúan entre 0,17 y 0,24 €/ $\mathrm{m}^{3}$ producido, y se detallan a continuación:

\begin{tabular}{|c|c|c|}
\hline Etapa & $\begin{array}{c}\text { Coste inversión } \\
€ /\left(\mathrm{m}^{3} / \text { día }\right)\end{array}$ & $\begin{array}{c}\text { Coste expl. y mant. } \\
€ / \mathrm{m}^{3} \text { producido }\end{array}$ \\
\hline Decantación & $21-29$ & $0.032-0.038$ \\
\hline Filtración & $6-13$ & $0.055-0.075$ \\
\hline Membranas & $167-375$ & $0.07-0.11$ \\
\hline Desinfección & $1-2$ & $0.001-0.002$ \\
\hline Total & $198-424$ & $0.17-0.24$ \\
\hline
\end{tabular}

Tabla 17: Coste regeneración tratamiento tipo 1 (CEDEX, 2008). 


\section{Tratamiento de tipo 2}

Este tratamiento permite reducir los valores de Escherichia coli por debajo de 100UFC/100mL pero no garantiza su ausencia. Se recomienda este tratamiento para los usos que admitan un valor máximo de $1000 \mathrm{UCF} / 100 \mathrm{~mL}$ y no precisen una etapa de desalinización. Los usos permitidos son:

- Riego de zonas verdes, baldeo de calles, sistemas antiincendio y lavado industrial de vehículos;

- Procesos de limpieza industriales;

- Riego de campos de golf;

- Recarga de acuíferos por percolación localizada a través del terreno;

- Riego de cultivos para consumo humano, pastos y acuicultura.

El tratamiento se compone de las siguientes etapas:

- Decantación;

- Filtración;

- Desinfección mediante rayos ultravioleta;

- Desinfección de mantenimiento.

Los coses se detallan a continuación

\begin{tabular}{|c|c|c|}
\hline Etapa & $\begin{array}{c}\text { Coste inversión } \\
€ /\left(\mathrm{m}^{3} / \text { día }\right)\end{array}$ & $\begin{array}{c}\text { Coste expl. y mant. } \\
€ / \mathrm{m}^{3} \text { producido }\end{array}$ \\
\hline Decantación & $21-29$ & $0.032-0.038$ \\
\hline Filtración & $6-13$ & $0.055-0.075$ \\
\hline Ultravioleta & $4-11$ & $0.0018-0.0029$ \\
\hline Desinfección & $1-2$ & $0.001-0.0029$ \\
\hline Total & $33-56$ & $0.09-0.12$ \\
\hline
\end{tabular}

Tabla 18: Coste regeneración tratamiento tipo 2 (CEDEX, 2008). 


\section{Tratamiento de tipo 3}

El objetivo del tratamiento de tipo 3 es obtener un agua regenerada de adecuada calidad $(\mathbf{1 0 0 0}<\mathrm{UCF} / \mathbf{1 0 0 m L}<\mathbf{1 0 0 0 0})$ para los siguientes usos:

- Riego localizado de cultivos leñosos que impida el contacto del agua con los frutos consumidos;

- Riego de cultivos ornamentales y no alimentarios;

- Riego de bosques o estanques no accesibles al público;

- Usos industriales no alimentarios.

La línea de tratamiento se compone de una única etapa consistente en la desinfección por rayos ultravioletas. Los costes de inversión estimados se sitúan entre 5 y $13 € /\left(\mathrm{m}^{3} /\right.$ día), mientras los costes de explotación entre 0,0028 y 0,0049 $€ / \mathrm{m}^{3}$ producido.

\section{Tratamiento de tipo 4}

Este tratamiento es aplicable con el fin de reducir el contenido de sales del agua regenerada. Se plantean dos posibles líneas de tratamiento en función de la tecnología de desalinización empleada: electrodiálisis reversible (EDR) u ósmosis inversa (OI). El factor determinante en la elección del proceso de desalinización es la calidad del efluente de la depuradora: las membranas de OI presentan costes de inversión sensiblemente inferiores pero presentan problemas de funcionamiento relacionados con la presencia de materia orgánica disuelta en el agua residual.

Los costes de los distintos tratamientos se detallan en las siguientes tablas:

\begin{tabular}{|c|c|c|}
\hline Etapa & $\begin{array}{c}\text { Coste inversión } \\
€ /\left(\mathrm{m}^{3} / \text { día }\right)\end{array}$ & $\begin{array}{c}\text { Coste expl. y mant. } \\
€ / \mathrm{m}^{3} \text { producido }\end{array}$ \\
\hline Decantación & $21-29$ & $0.032-0.038$ \\
\hline Filtración & $6-13$ & $0.055-0.075$ \\
\hline Ultrafiltración & $167-375$ & $0.07-0.011$ \\
\hline Desalinización EDR & $200-350$ & $0.23-0.33$ \\
\hline Total & $440-863$ & $0.43-0.61$ \\
\hline
\end{tabular}

Tabla 19: Coste regeneración tratamiento tipo 4 EDR (CEDEX, 2008). 


\begin{tabular}{|c|c|c|}
\hline Etapa & $\begin{array}{c}\text { Coste inversión } \\
€ /\left(\mathrm{m}^{3} / \text { día }\right)\end{array}$ & $\begin{array}{c}\text { Coste expl. y mant. } \\
€ / \mathrm{m}^{3} \text { producido }\end{array}$ \\
\hline Decantación & $21-29$ & $0.032-0.038$ \\
\hline Filtración & $6-13$ & $0.055-0.075$ \\
\hline Microfiltración & $100-200$ & $0.07-0.011$ \\
\hline Desalinización OI & $125-188$ & $0.15-0.30$ \\
\hline Total & $311-540$ & $0.39-0.64$ \\
\hline
\end{tabular}

Tabla 20: Coste regeneración tratamiento tipo 4 OI (CEDEX, 2008).

\section{VII.2.1.5 Desalinización}

Los costes de desalinización dependen fundamentalmente de la tecnología empleada para la separación de los sales y de los costes de impulsión necesarios para la distribución del agua en el entorno urbano.

En la desalinización se puede separar el agua de las sales ó viceversa. Por lo tanto la primera clasificación de los métodos de desalinización atiende a la forma de separación de sales y agua. Las siguientes clasificaciones se hacen según el tipo de energía utilizada para el proceso, y finalmente por el proceso físico de la desalinización. La Tabla 21 muestra la clasificación de los métodos existentes.

\begin{tabular}{|c|c|c|c|}
\hline Separación & Energia & Proceso & Método \\
\hline \multirow[t]{8}{*}{ Agua de sales } & \multirow[t]{6}{*}{ Térmica } & \multirow[t]{4}{*}{ Evaporación } & Destilación súbita (flash) \\
\hline & & & Destilación multiefecto \\
\hline & & & Termocompresión de vapor \\
\hline & & & Destilación solar \\
\hline & & \multirow{2}{*}{$\begin{array}{l}\text { Cristalización } \\
\text { Filtración y evaporación }\end{array}$} & Congelación \\
\hline & & & Formación de hidratos \\
\hline & \multirow[t]{2}{*}{ Mecánica } & Evaporación & Compresión mecánica de vapor \\
\hline & & Filtración & Ósmosis inversa \\
\hline \multirow[t]{2}{*}{ Sales de agua } & Eléctrica & Filtración selectiva & Electrodiálisis \\
\hline & Química & Intercambio & Intercambio iónico \\
\hline
\end{tabular}

Tabla 21: Métodos de desalinización (Valero et al., 2001) 
No entra en los objetivos de esta tesis la descripción detallada de todos los métodos de desalinización existente. El alcance del estudio se limitará a los métodos mayoritariamente utilizados para la producción de agua desalinizada destinada al consumo humano o agrícola.

En la literatura científica se han individuado actualmente tan sólo unos pocos procesos tecnológicamente viables a escala industrial: evaporación súbita por efecto flash (MSF), destilación múltiple efecto (MED), termocompresión de vapor $(\mathrm{TVC})$ y compresión de vapor mecánica $(\mathrm{CV})$, ósmosis inversa $(\mathrm{OI})$ y electrodiálisis (ED). A modo de recopilación es conveniente realizar un análisis comparativo de las ventajas e inconvenientes de cada uno de estos métodos tecnológicamente avanzados para la producción de agua desalinizada. La Tabla 22 muestra la valoración de todos los métodos comentados anteriormente frente a ciertas características exigibles a una tecnología de desalinización.

\begin{tabular}{|l|c|c|c|c|c|}
\hline Tecnología & MSF & MED-TVC & CV & OI & ED \\
\hline Tipo energía & térmica & térmica & eléctrica & eléctrica & eléctrica \\
\hline $\begin{array}{l}\text { Consumo energético } \\
(\mathrm{KJ} / \mathrm{kg})\end{array}$ & alto & Medio/alto & Medio & Bajo & Bajo \\
\hline Coste instalaciones & Alto & Medio/alto & Alto & Medio & Medio \\
\hline $\begin{array}{l}\text { Capacidad } \\
\text { producción }\left(\mathrm{m}^{3} / \text { día }\right)\end{array}$ & $\begin{array}{c}\text { Alta } \\
(>50000)\end{array}$ & $\begin{array}{c}\text { Media } \\
(<20000)\end{array}$ & $\begin{array}{c}\text { Baja } \\
(<5000)\end{array}$ & $\begin{array}{c}\text { Alta } \\
(>50000)\end{array}$ & $\begin{array}{c}\text { Media } \\
(<30000)\end{array}$ \\
\hline $\begin{array}{l}\text { Posibilidad de } \\
\text { ampliación }\end{array}$ & Difícil & Difícil & Difícil & Fácil & Fácil \\
\hline Fiabilidad & Alta & Media & Baja & Alta & Alta \\
\hline $\begin{array}{l}\text { Desalinización de } \\
\text { agua de mar }\end{array}$ & Sí & Sí & Sí & Sí & No \\
\hline $\begin{array}{l}\text { Calidad de producto } \\
\text { (ppm })\end{array}$ & Alta $(<50)$ & Alta $(<50)$ & Alta $(<50)$ & Media (300- \\
$500)$ & $\begin{array}{c}\text { Media } \\
(<300)\end{array}$ \\
\hline $\begin{array}{l}\text { Superficie requerida } \\
\text { por la instalación }\end{array}$ & Amplia & Media & Reducida & Reducida & Reducida \\
\hline
\end{tabular}

Tabla 22: Características deseables de los métodos de desalinización (Valero et al., 2001).

El tratamiento de OI se ha afirmado como la tecnología más favorable para la producción de agua desalinizada para consumo humano y agrícola. Las razones del éxito residen esencialmente en la capacidad de producir grandes cantidades de agua de un nivel de calidad adecuado (<1000ppm) y con un consumo energético reducido en comparación con otros métodos.

Para el tratamiento de los costes de la desalinización de agua de mar con OI hay que tener en cuenta la infinidad de variables que afectan de forma considerable 
al coste final del agua desalinizada: tamaño de la instalación, condiciones físicas y geográficas de la captación del agua marina, calidad del producto requerido, sistema de recuperación de energía utilizado, etc. El análisis presentado a continuación trata de incluir todo los factores que concurren a formar una horquilla de valores para el precio final del agua desalinizada procedente del mar.

Coste de la energía eléctrica.

En este análisis, hay que tener en cuenta dos factores: el consumo eléctrico específico de la planta y de todos sus equipos $\left(\mathrm{kWh} / \mathrm{m}^{3}\right)$ y el precio a pagar por el kWh eléctrico consumido.

Desde las primeras instalaciones, con un consumo específico que rondaba los 7 $\mathrm{kWh} / \mathrm{m}^{3}$ (Torres y Medina, 1999), el consumo de las bombas de la instalación ha ido bajando continuamente. La aparición de los sistemas de recuperación de energía ha contribuido significativamente a ello, al igual que la instalación de bombas de alta presión más eficientes y de mayor tamaño. Por lo tanto, es posible considerar que el consumo específico actualmente varía entre los 3 y 4,5 $\mathbf{k W h} / \mathbf{m}^{3}$, aunque en este caso el mínimo consumo puede obtenerse en plantas de pequeño tamaño con sistemas de recuperación de energía de última generación (los últimos avances hablan de $2,4 \mathrm{kWh} / \mathrm{m} 3$ ), como los intercambiadores de presión (Wesson, 2000). En algunas instalaciones se suele contabilizar el consumo eléctrico derivado del bombeo hasta el sistema de distribución de alta presión, que puede suponer una cota de elevación de más de 100 metros y un consumo específico adicional de hasta $1 \mathrm{kWh} / \mathrm{m}^{3}$.

Como dato orientativo, el consumo específico proyectado en la estación desalinizadora de agua de mar (en adelante EDAM) de Carboneras ( 2 unidades con $60.000 \mathrm{~m}^{3} /$ día de capacidad, y $42 \mathrm{hm}^{3}$ /año de producción) totaliza 4,26 $\mathrm{kWh} / \mathrm{m}^{3}$, de los cuales 2,93 corresponden al bombeo de alta presión, 0,4 al bombeo de agua de mar, 0,34 al de producto y 0,59 al resto de consumos auxiliares. El estudio previo Solución Alicante para la generación de $25 \mathrm{hm}^{3}$ de agua desalinizada presenta un coste de $3,3 \mathrm{kWh} / \mathrm{m}^{3}$ para el tratamiento de ósmosis y un coste adicional de bombeo valorado en $0,90 \mathrm{kWh} / \mathrm{m}^{3}$ (Lapuente, 2005).

En cuanto al segundo factor a tener en cuenta, una estimación razonable del coste de la energía eléctrica puede encontrarse entre 0,07 y 0,09 €/kwh (CEDEX, 2008). La Tabla 23 muestra el coste energético de la osmosis inversa de agua de mar teniendo en cuenta los condicionantes anteriormente citados. 


\begin{tabular}{|c|c|c|}
\hline $\begin{array}{c}\text { Consumo específico } \\
\left(\mathrm{kWh} / \mathrm{m}^{3}\right)\end{array}$ & $\begin{array}{c}\text { Precio electricidad } \\
(€ / \mathrm{kWh})\end{array}$ & $\begin{array}{c}\text { Coste energía } \\
(€ / \mathrm{m} 3)\end{array}$ \\
\hline $3-4,5$ & $0,07-0,09$ & $0,21-0,41$ \\
\hline
\end{tabular}

Tabla 23: Desalinización de agua de mar, coste energía.

Coste de la inversión.

El tipo y tamaño de la planta juegan un papel importantes a la hora de obtener el coste de la amortización necesaria para recuperar la inversión ejecutada. También las mejoras tecnológicas que surgen constantemente y la gran competencia existente entre los fabricantes de membranas y empresas adjudicatarias contribuyen a la rebaja de los costes de inversión. En la Figura 33 se muestra la inversión necesaria por $\mathrm{m}^{3} /$ día dependiendo de la capacidad de planta.

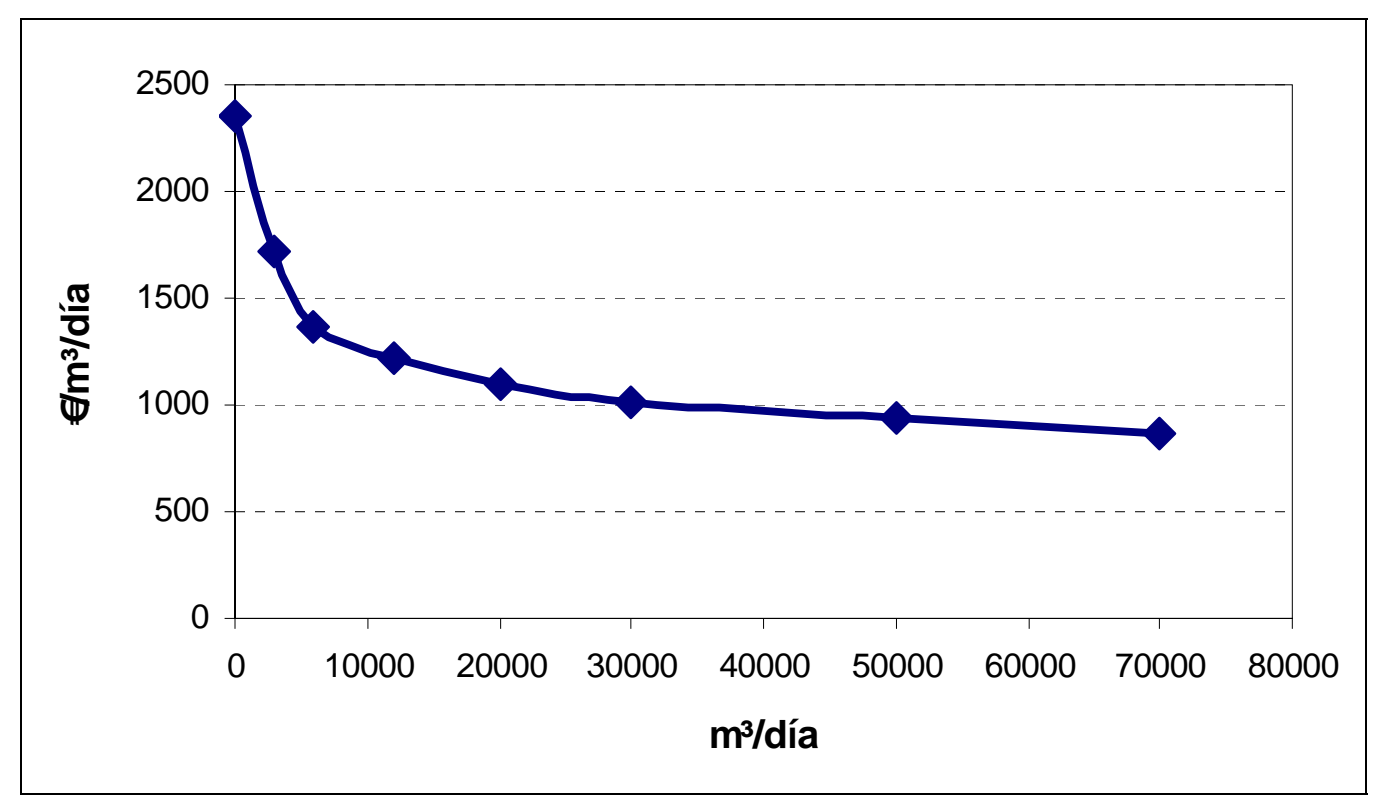

Figura 33: EDAM, coste de inversión en m³/día del agua desalinizada (Fariñas, 1999).

En la Tabla 24 se exponen de forma esquemática los porcentajes representativos de cada parte de la inversión y los períodos de amortización típicos para dichas partes. 


\begin{tabular}{|l|c|c|}
\hline & $\begin{array}{c}\% \text { de inversión } \\
\text { respecto al total }\end{array}$ & $\begin{array}{c}\text { Periodo de } \\
\text { amortización (años) }\end{array}$ \\
\hline Edificación y urbanización & $8-12$ & 20 \\
\hline Conducciones & $12-16$ & 15 \\
\hline Membranas (incluye limpieza) & $25-32$ & 8 \\
\hline Bombeo & $15-20$ & 12 \\
\hline Pretratamiento (filtros, aditivos) & $8-10$ & 15 \\
\hline Equipos eléctricos & $9-13$ & 15 \\
\hline Instrumentación y control & $2-4$ & 12 \\
\hline Otros (posttratamiento, repuestos) & $3-5$ & 15 \\
\hline
\end{tabular}

Tabla 24: Desalinización, porcentaje de inversión y periodo de amortización (Fariñas, 1999).

Coste del personal y mantenimiento.

Las pequeñas instalaciones de tipo turístico suelen funcionar sin apenas mantenimiento o con el mismo personal dedicado a otras actividades dentro del complejo turístico. Conforme la planta va adquiriendo capacidad, empieza a ser necesario mantener personal fijo en la instalación, con ayuda especializada en caso de situaciones de avería. Cuando la planta alcanza una capacidad considerable (> $30.000 \mathrm{~m}^{3}$ / día) es necesaria una plantilla mínima de 20 personas para su gestión y mantenimiento.

Teniendo en cuenta todos estos condicionantes, el coste medio asociado al personal y mantenimiento de la planta puede estimarse en $\mathbf{0 , 0 7 - 0 , 1 5} € / \mathrm{m}^{3}$.

Coste de aditivos químicos.

Los reactivos químicos utilizados en los diversos procesos realizados en una EDAM dependen fundamentalmente de la calidad del agua bruta a tratar, y también de la calidad del producto requerida.

El coste repercutible al agua desalinizada por este concepto se puede cifrar en torno a $\mathbf{0 , 0 3 - 0 , 0 9} € / \mathrm{m}^{3}$, teniendo en cuenta la gran influencia de la calidad del agua bruta aportada a este coste. 
Coste de reposición de membranas y arenas.

Suele ser muy variable, dependiendo de las frecuencias de lavado y del control de operación de la planta. Normalmente los fabricantes ofrecen una garantía de un porcentaje de reposición típico para una duración determinada; si el porcentaje de fallo es mayor del establecido, la reposición corre a cuenta del fabricante.

El coste de reposición de membranas, puede evaluarse entre $\mathbf{0 , 0 2}$ y $\mathbf{0 , 0 5} € / \mathbf{m}^{\mathbf{3}}$. También debe mencionarse la reposición de la arena de los filtros perdida con los lavados periódicos, aunque ésta tiene una periodicidad de 7 a 10 años.

\section{Coste total del agua}

Teniendo en cuenta que el coste final del agua desalinizada depende fuertemente del tamaño de la planta y de la calidad del agua tratada y recopilando los diversos conceptos de costes analizados en los apartados anteriores, es posible efectuar una evaluación del coste final del agua desalinizada. Escogiendo un periodo de amortización de 20 años y un tipo de interés del 5\%, estos costes varían entre 0,35 y 1,00 $€ / \mathrm{m}^{3}$ en una EDAM. La horquilla de precios calculada está conforme con los datos obtenidos en literatura sobre el coste de las actuaciones similares realizadas o en proyecto en España (Lapuente, 2005; Valero et al., 2001; Sanz, 2000).

\section{Coste de desalinización en aguas salobres}

Como se muestra en la Figura 34, la desalinización de aguas salobres soporta unos costes muy inferiores a los necesarios para desalar agua de mar, aunque comparta la tecnología de OI. 


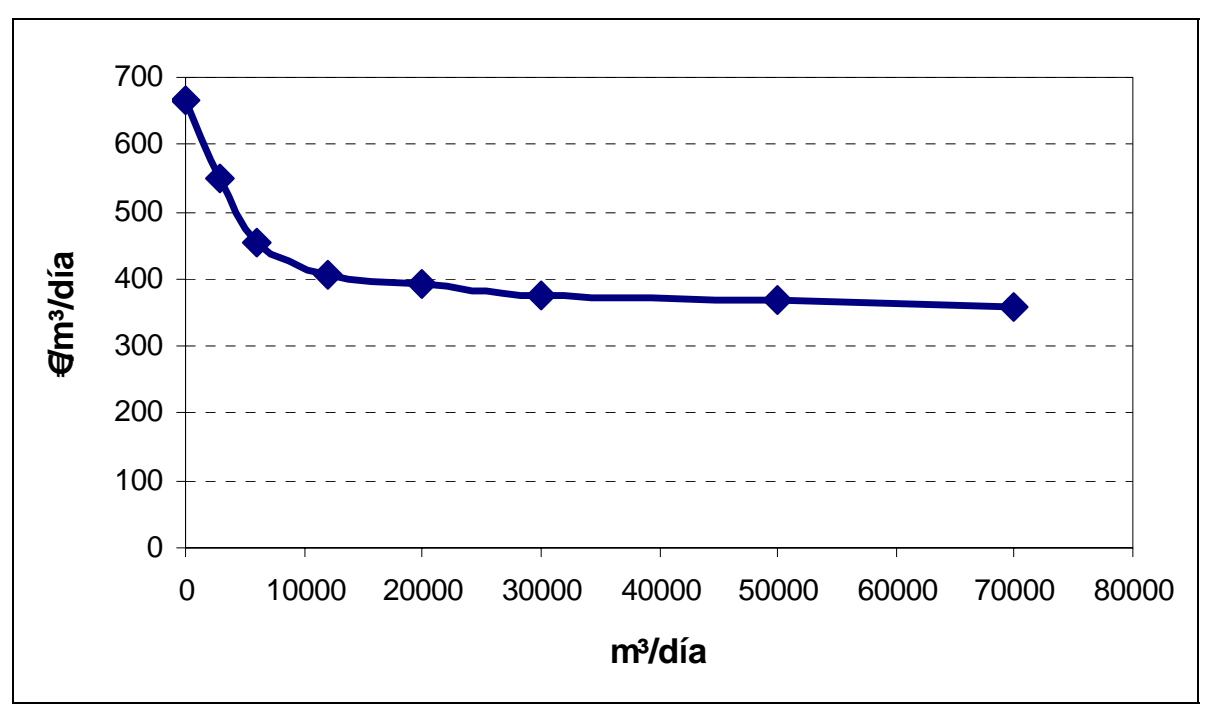

Figura 34: EDAS, coste de inversión en m³/día del agua desalinizada (Fariñas, 1999)

Los costes totales se estiman en una horquilla de $\mathbf{0 , 1 8}-\mathbf{0 , 4 5} € / \mathrm{m}^{3}$, dependiendo del tamaño de la planta y de las características químicas del agua a tratar (Valero et al., 2001).

\section{VII.2.2 Funciones de coste aplicadas en el caso de estudio}

A continuación se muestran las funciones de costes adaptadas a las infraestructuras presentes en el sistema, conforme con el procedimiento descrito en los apartados anteriores.

\section{VII.2.2.1 Embalse de Arquillo}

Los datos relativos a la presa de Arquillo de San Blas se han obtenido a partir del documento XYZT y de las Normas de Explotación (CHJ, 2002a,d). Se recogen a continuación las tablas relativas a la geometría de la presa y los datos necesarios para la determinación de la función coste-volumen. 


\begin{tabular}{|l|l|}
\hline \multicolumn{2}{|c|}{ Características de la Presa } \\
\hline Nivel Máximo Normal: & 974,21 m.s.n.m. \\
\hline Capacidad a N.M.N.: & $21,036 \mathrm{hm}^{3}$ \\
\hline Superficie de embalse a N.M.N.: & $142,63 \mathrm{Ha}$ \\
\hline Nivel Avenida de Proyecto: & $976,96 \mathrm{~m} . s . n . m$ \\
\hline Tipo & Gravedad \\
\hline Planta: & Recta \\
\hline Año de construcción: & 1962 \\
\hline Clasificación: & A (Fecha: 26-3-1.999) \\
\hline Cota de coronación: & $978,96 \mathrm{~m} . s . n . m$. \\
\hline Cota del cauce: & $932,96 \mathrm{~m}$ \\
\hline Cota de cimientos: & $924,96 \mathrm{~m}$ \\
\hline Altura sobre el cauce: & $46 \mathrm{~m}$ \\
\hline Altura sobre cimientos: & $54 \mathrm{~m}$ \\
\hline Longitud de coronación: & $167 \mathrm{~m}$ \\
\hline Ancho de coronación: & Variable 6,20-4,20 m \\
\hline Taludes en cuerpo de aliviadero: & $\begin{array}{l}\text { Aguas arriba: } 0,05 \\
\text { Aguas abajo: 0,745 }\end{array}$ \\
\hline Taludes en cuerpos laterales: & $\begin{array}{l}\text { Aguas arriba: 0,05 } \\
\text { Aguas abajo: 0,745 }\end{array}$ \\
\hline Galerías: & 3 \\
\hline
\end{tabular}

Tabla 25: Presa de Arquillo de San Blas, características.

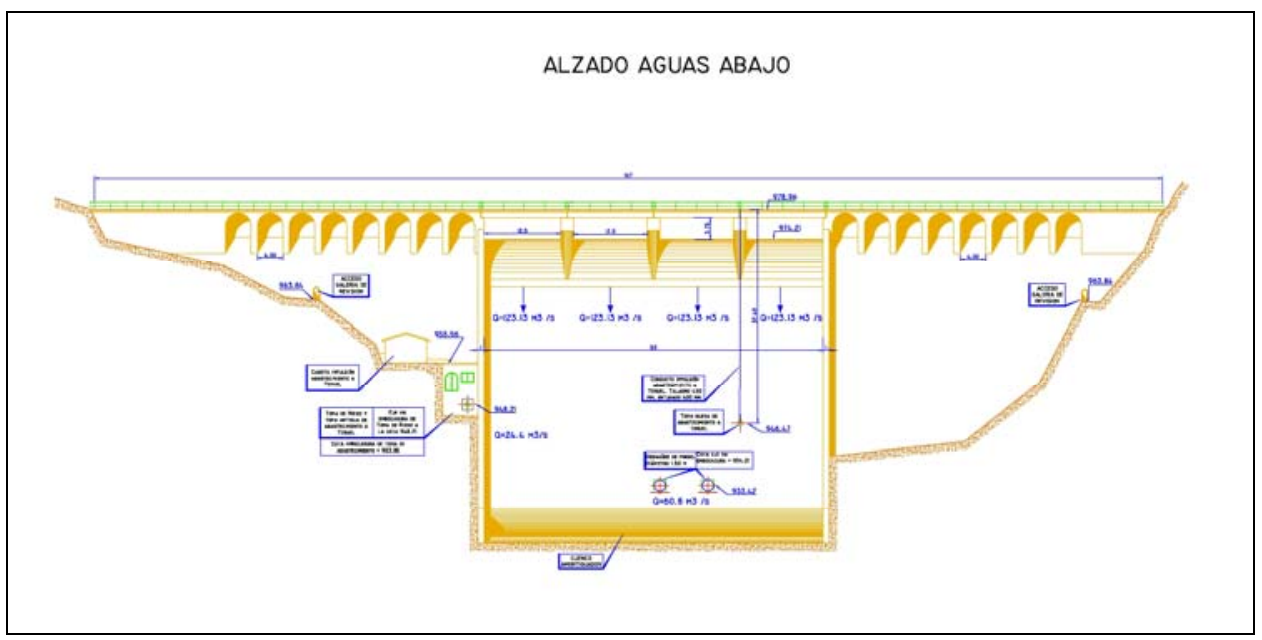

Figura 35: Presa de Arquillo, alzado aguas abajo. 


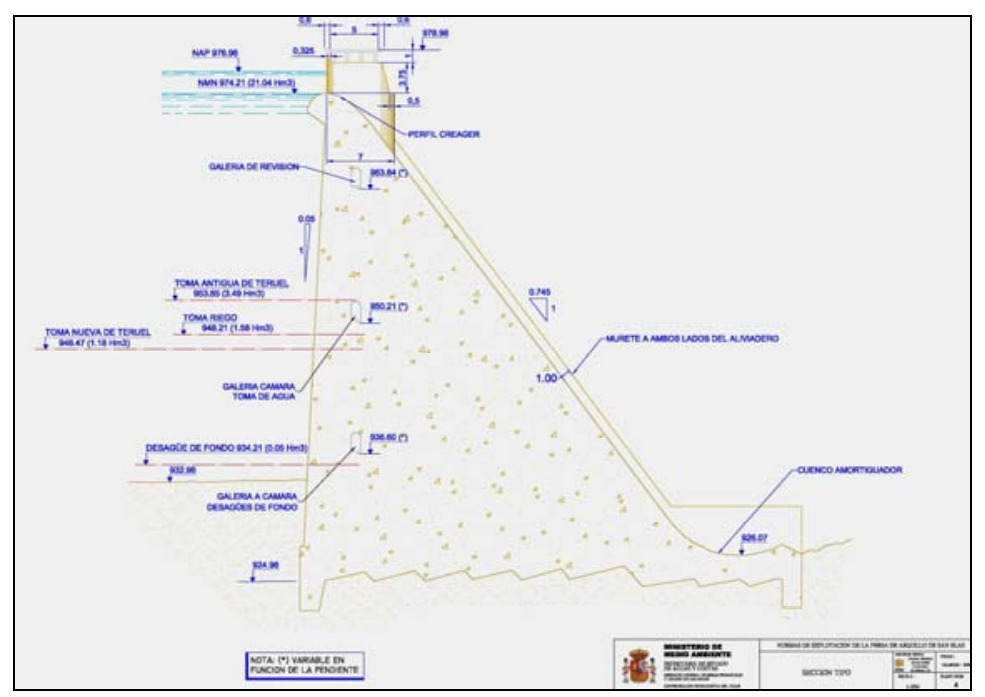

Figura 36: Presa de Arquillo, sección tipo.

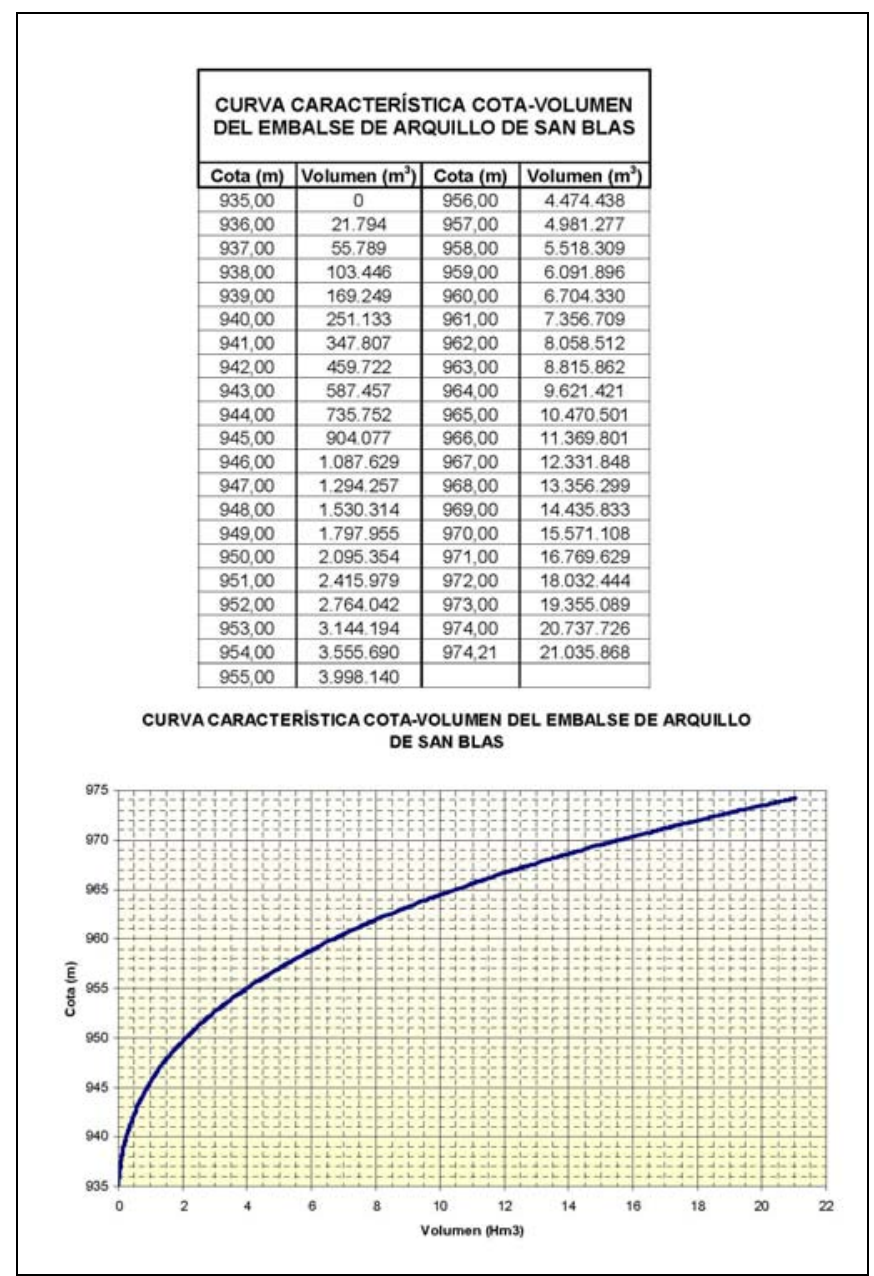

Figura 37: Presa de Arquillo, curva cota-volumen. 
A partir de los datos contenidos en el archivo técnico, se calculan las relaciones existentes entre las principales variables de la presa (Tabla 26) y, finalmente, la función coste-volumen (Figura 38):

\begin{tabular}{|c|c|c|c|}
\hline \multicolumn{4}{|c|}{ Arquillo } \\
\hline Altura $(\mathrm{m})$ & Longitud $(\mathrm{m})$ & Volumen $\left(\mathrm{Hm}^{3}\right)$ & Coste $(\mathrm{M} €)$ \\
\hline 11 & 60 & 0.021 & 0.75 \\
\hline 25 & 105 & 2.1 & 1.5 \\
\hline 39 & 145 & 9.6 & 3.5 \\
\hline 54 & 167 & 21 & 4.5 \\
\hline
\end{tabular}

Tabla 26: Presa de Arquillo, tabla altura-longitud-volumen-coste.

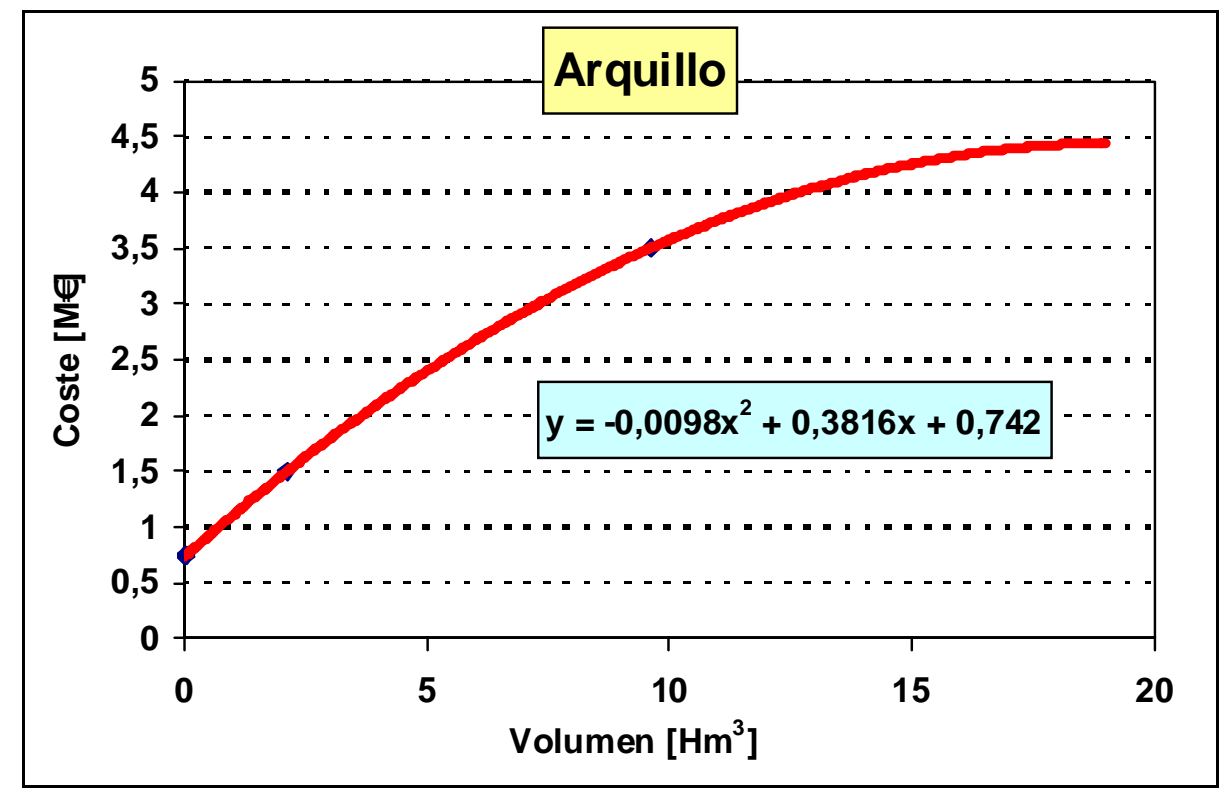

Figura 38: Presa de Arquillo, función de coste.

\section{VII.2.2.2 Embalse de Benagéber}

Los datos relativos a la presa de Benagéber se han obtenido a partir del documento XYZT y de las Normas de Explotación (CHJ, 2002b,d). Se recogen a continuación las tablas relativas a la geometría de la presa y los datos necesarios para la determinación de la función coste-volumen. 


\begin{tabular}{|l|l|}
\hline \multicolumn{2}{|c|}{ Características de la Presa } \\
\hline Nivel Máximo Normal: & 527,24 m.s.n.m. \\
\hline Capacidad a N.M.N.: & $221,34 \mathrm{hm}^{3}$ \\
\hline Superficie a N.M.N.: & $721,9 \mathrm{Ha}$ \\
\hline Nivel Avenida de Proyecto: & $529,5 \mathrm{~m}$. s.n.m \\
\hline Tipo: & Gravedad \\
\hline Planta: & Recta \\
\hline Año de finalización: & 1954 \\
\hline Clasificación: & A (Fecha: 21-7-2.000) \\
\hline Cota de coronación: & 530,00 m.s.n.m. \\
\hline Cota del cauce: & $440,00 \mathrm{~m}$ \\
\hline Cota de cimientos: & $420,00 \mathrm{~m}$ \\
\hline Altura sobre el cauce: & $90 \mathrm{~m}$ \\
\hline Altura sobre cimientos: & $110 \mathrm{~m}$ \\
\hline Longitud de coronación: & $227 \mathrm{~m}$ \\
\hline Ancho de coronación: & $10,50 \mathrm{~m}$ \\
\hline Taludes en cuerpo de presa: & $\begin{array}{l}\text { Aguas arriba: } 0,05 \\
\text { Aguas abajo: } 0,74\end{array}$ \\
\hline Galerías: & 4, desdobladas \\
\hline
\end{tabular}

Tabla 27: Presa de Benagéber, características.

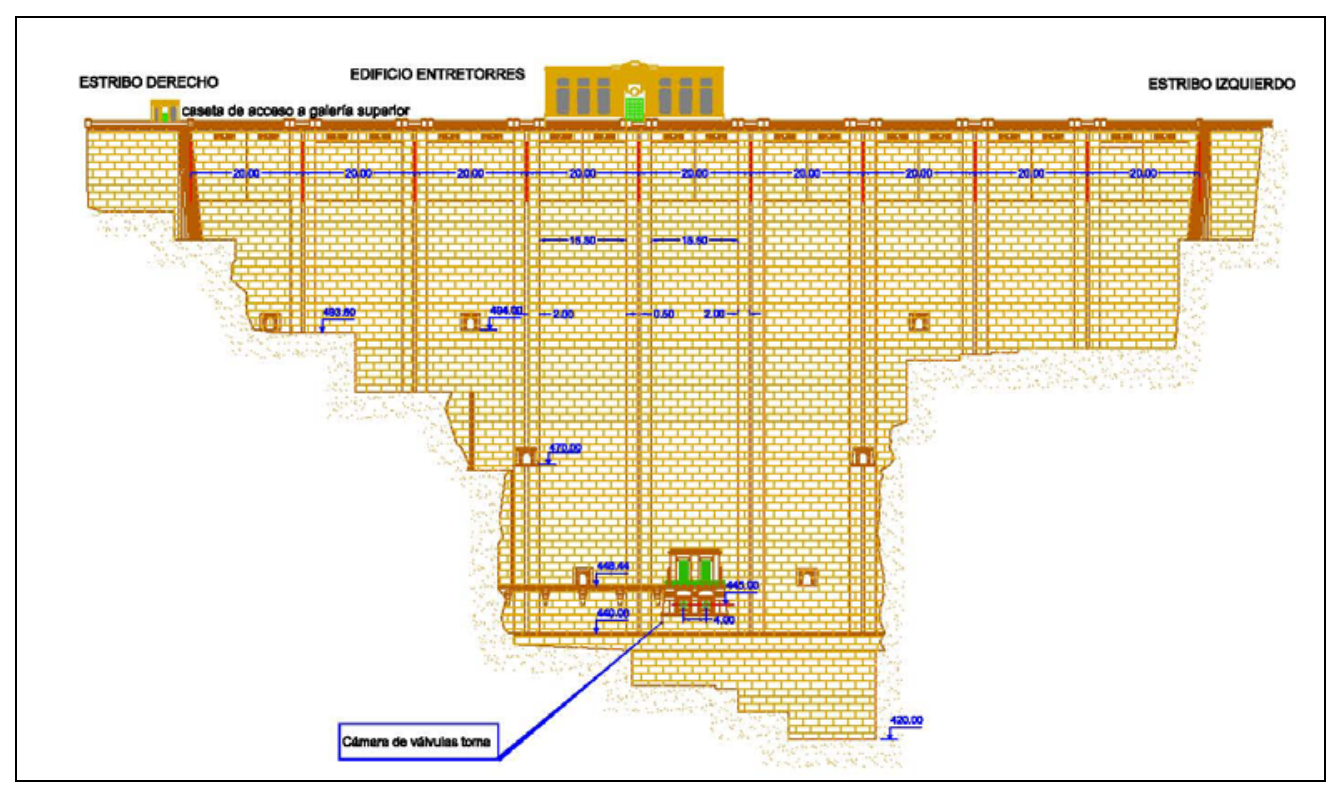

Figura 39: Presa de Benagéber, alzado aguas abajo. 


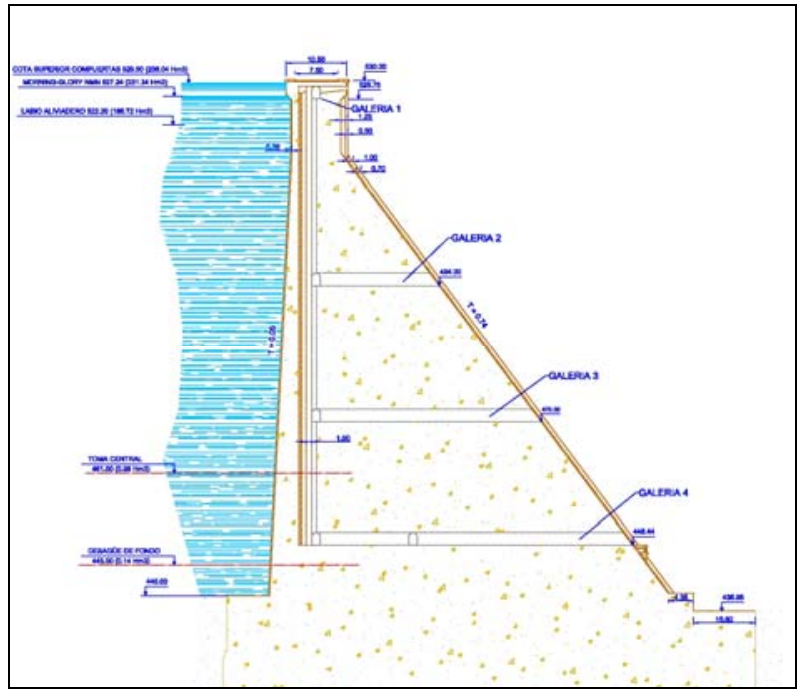

Figura 40: Presa de Benagéber, sección tipo.

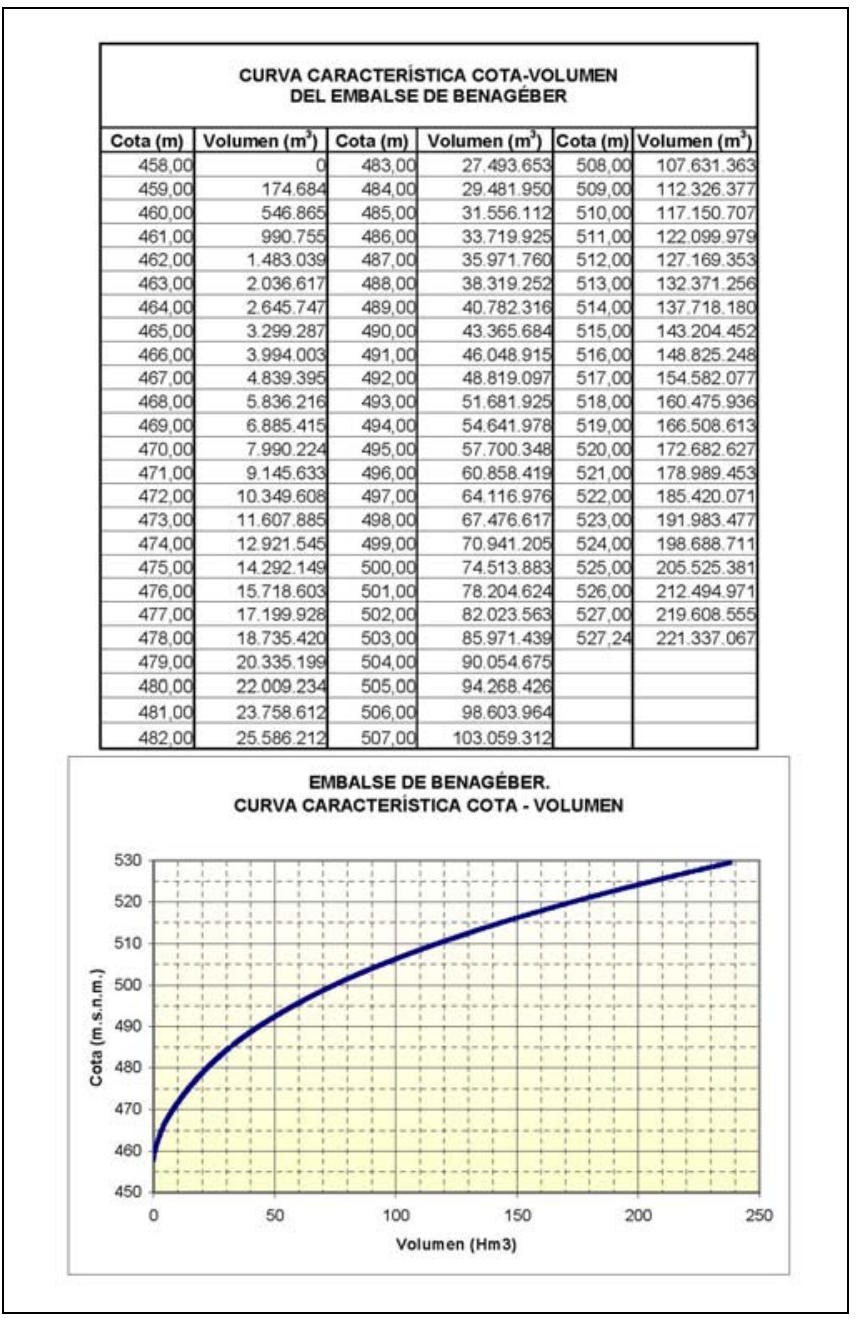

Figura 41: Presa de Benagéber, curva cota-volumen. 
En la Tabla 28 se definen las relaciones entre las variables de diseño y el coste de la presa y a continuación, en la Figura 42, se muestra la función costevolumen del embalse.

\begin{tabular}{|c|c|c|c|}
\hline \multicolumn{4}{|c|}{ Benagéber } \\
\hline Altura $(\mathrm{m})$ & Longitud $(\mathrm{m})$ & Volumen $\left(\mathrm{hm}^{3}\right)$ & Coste $(\mathrm{M} €)$ \\
\hline 0 & 20 & 0 & 5 \\
\hline 78 & 180 & 69 & 15,28 \\
\hline 84 & 180 & 92 & 17,59 \\
\hline 90 & 210 & 115 & 23,3 \\
\hline 94 & 210 & 138 & 25,32 \\
\hline 98 & 210 & 161 & 27,42 \\
\hline 102 & 210 & 184 & 29,61 \\
\hline 90 & 210 & 207 & 31,3 \\
\hline 110 & 227 & 238 & 36,93 \\
\hline
\end{tabular}

Tabla 28: Presa de Benagéber, tabla cota-longitud-volumen-coste.

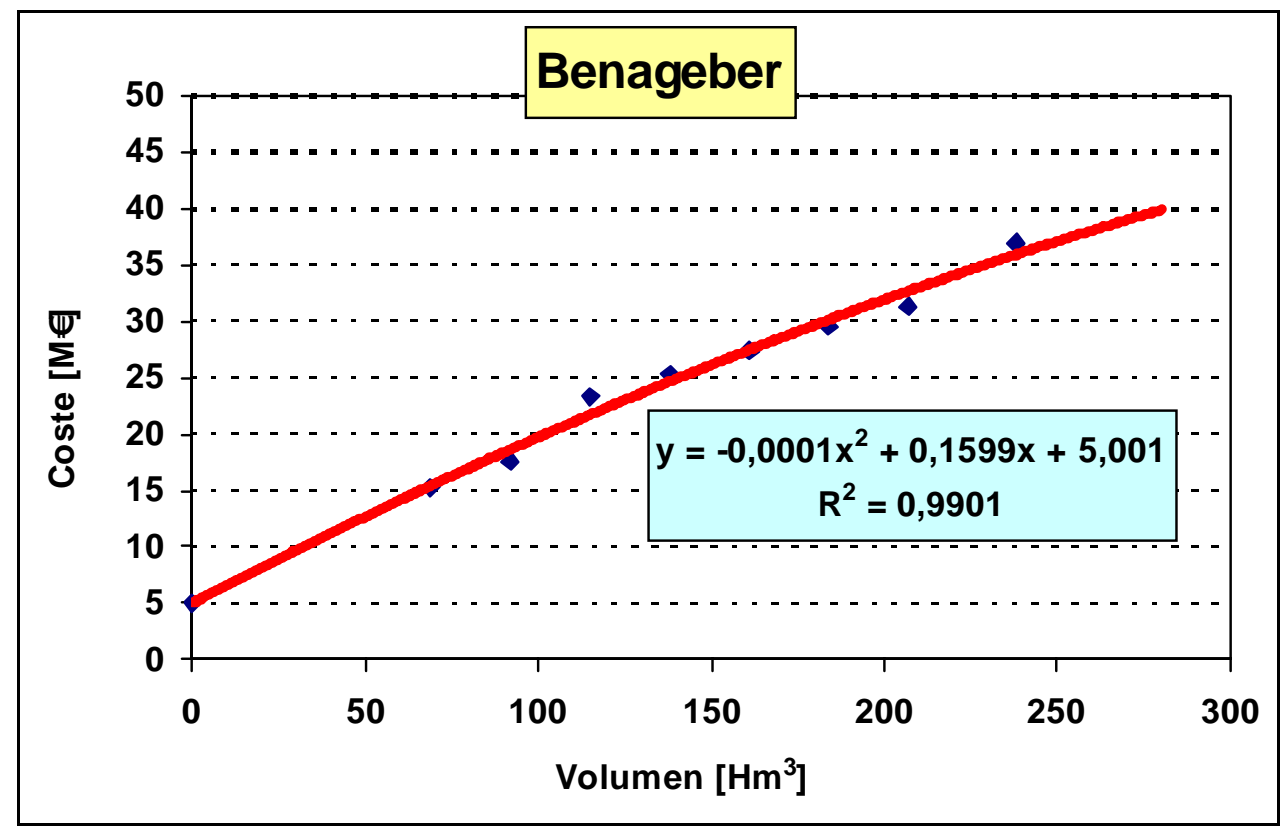

Figura 42: Presa de Benagéber, función de coste. 


\section{VII.2.2.3 Embalse de Loriguilla}

Los datos relativos a la presa de Loriguilla se han obtenido a partir del documento XYZT y de las Normas de Explotación (CHJ, 2002c,d). Se recogen a continuación las tablas relativas a la geometría de la presa y los datos necesarios para la determinación de la función coste-volumen.

\begin{tabular}{|l|l|}
\hline \multicolumn{2}{|c|}{ Características de la Presa } \\
\hline Nivel Máximo Normal: & $320,00 \mathrm{~m} . s . n . m$ \\
\hline Capacidad a N.M.N.: & $73,21 \mathrm{hm}^{3}$ \\
\hline Superficie a N.M.N.: & $364,21 \mathrm{Ha}$ \\
\hline Nivel Avenida de Proyecto: & $320,00 \mathrm{~m} . s . n . m$ \\
\hline Tipo: & Gravedad \\
\hline Planta: & Curva de $400 \mathrm{~m}$ de radio \\
\hline Año de finalización: & 1965 \\
\hline Clasificación: & A (Fecha: 25-3-1.999) \\
\hline Cota de coronación: & $322,50 \mathrm{~m} . s . n . m$. \\
\hline Cota del labio de aliviadero $\mathrm{n}^{\mathrm{o}} 1:$ & $313,00 \mathrm{~m} . s . n . m$. \\
\hline Cota del cauce: & $265,00 \mathrm{~m}$ \\
\hline Cota de cimientos: & $243,83 \mathrm{~m}$ \\
\hline Altura sobre el cauce: & $57,50 \mathrm{~m}$ \\
\hline Altura sobre cimientos: & $78,67 \mathrm{~m}$ \\
\hline Longitud de coronación: & $198 \mathrm{~m}$ \\
\hline Ancho de coronación: & $8 \mathrm{~m}$ \\
\hline Taludes en cuerpo de presa: & $\begin{array}{l}\text { Aguas arriba: 0,05 } \\
\text { Aguas abajo: 0,75 }\end{array}$ \\
\hline Galerías: & 3, desdoblada la inferior en dos \\
\hline
\end{tabular}

Tabla 29: Presa de Loriguilla, características técnicas. 


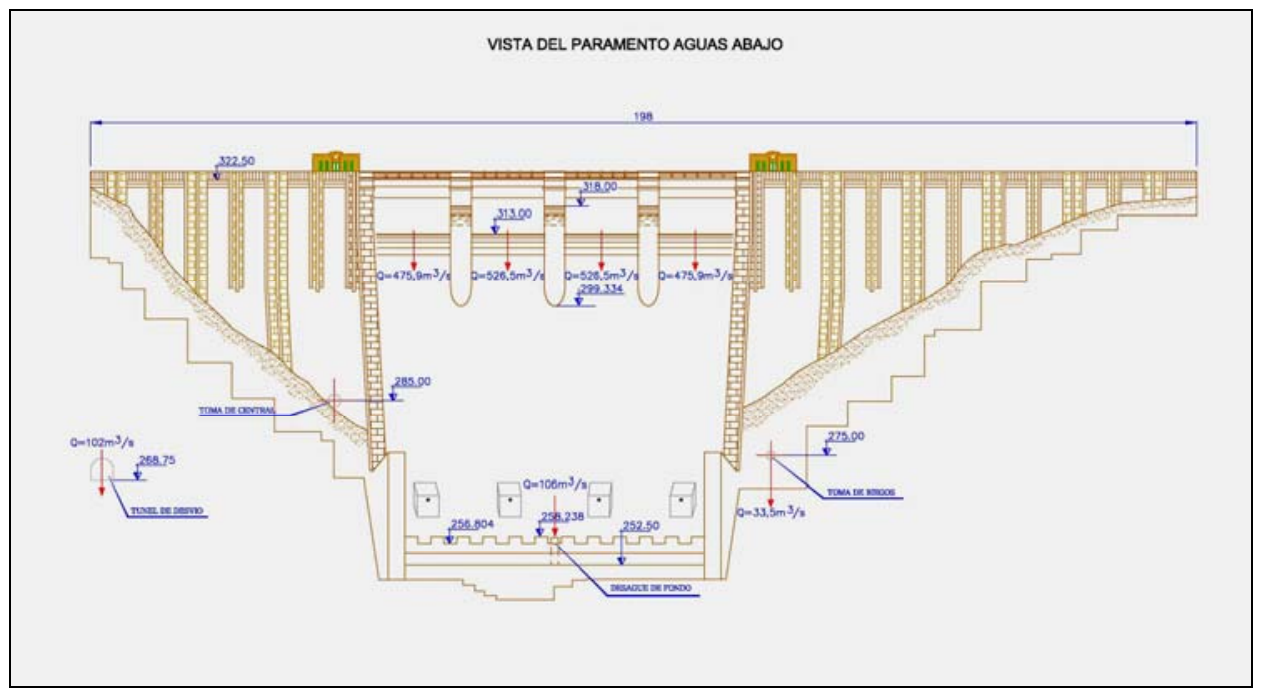

Figura 43: Presa de Loriguilla, alzado aguas abajo.

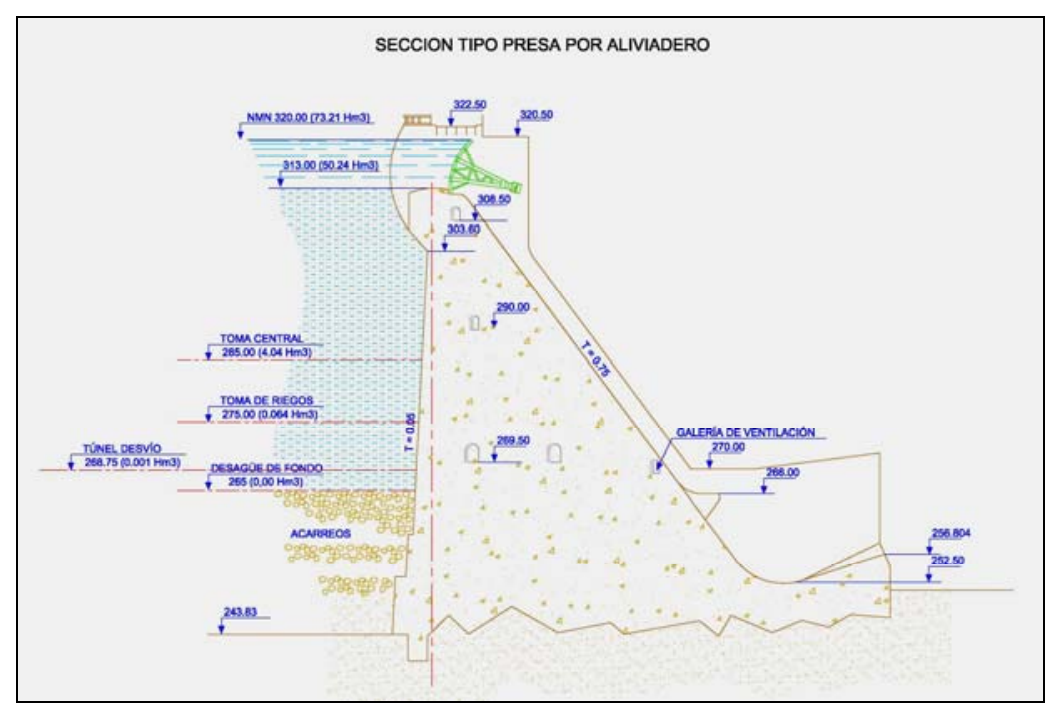

Figura 44: Presa de Loriguilla, sección tipo. 


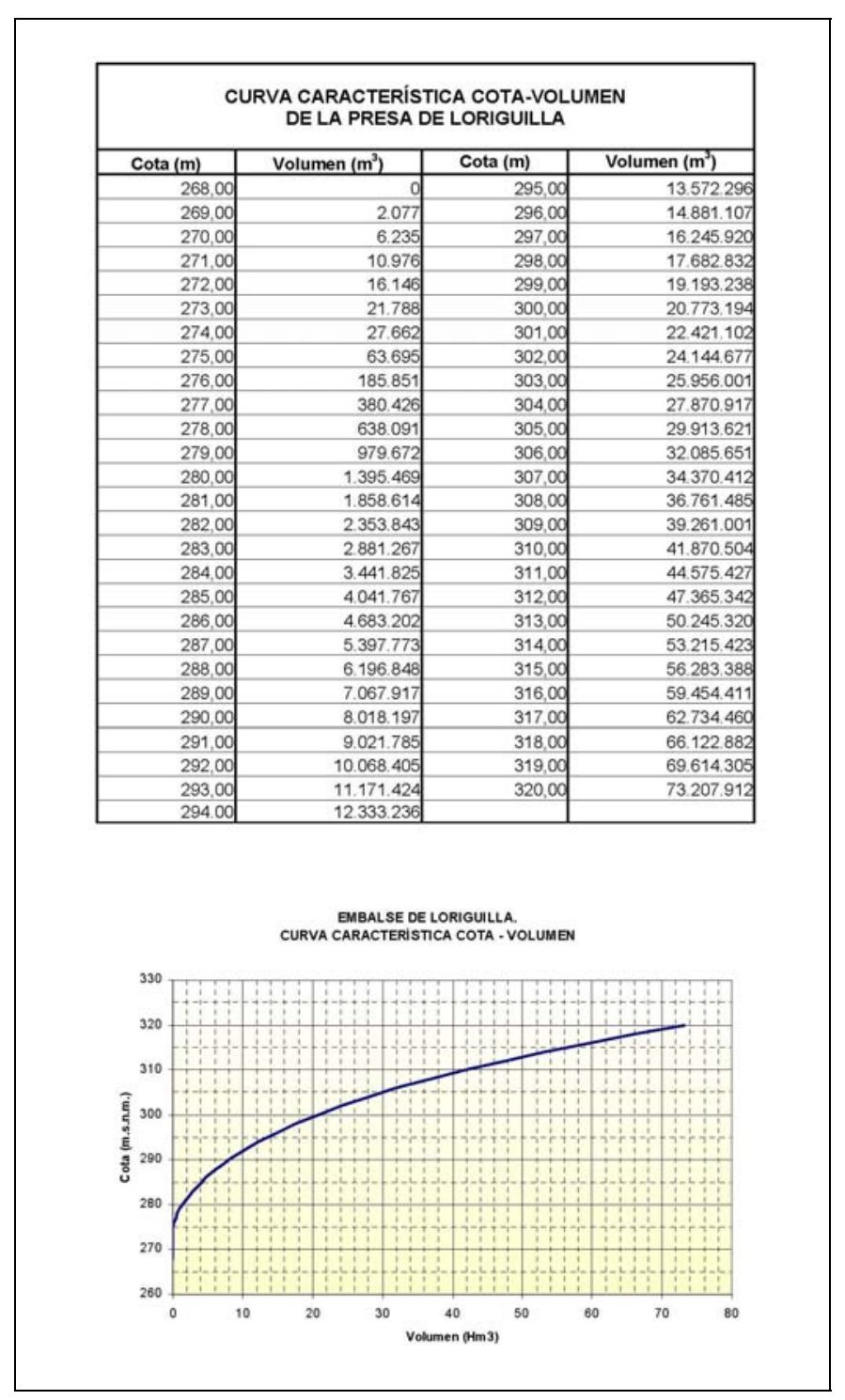

Figura 45: Presa de Loriguilla, curva cota-volumen.

En la Tabla 30 se definen las relaciones entre las variables de diseño y el coste de la presa y a continuación, en la Figura 46, se muestra la función costevolumen del embalse. 


\begin{tabular}{|c|c|c|c|}
\hline \multicolumn{4}{|c|}{ Loriguilla } \\
\hline Altura $(\mathrm{m})$ & Longitud $(\mathrm{m})$ & Volumen $\left(\mathrm{hm}^{3}\right)$ & Coste $(\mathrm{M} €)$ \\
\hline 0 & 60 & 0 & 3,06 \\
\hline 45 & 135 & 6 & 4,2 \\
\hline 59 & 157 & 24 & 7,94 \\
\hline 67 & 165 & 42 & 10,56 \\
\hline 71 & 180 & 54 & 12,91 \\
\hline 80 & 198 & 62 & 17,38 \\
\hline
\end{tabular}

Tabla 30: Presa de Loriguilla, tabla cota-longitud-volumen-coste.

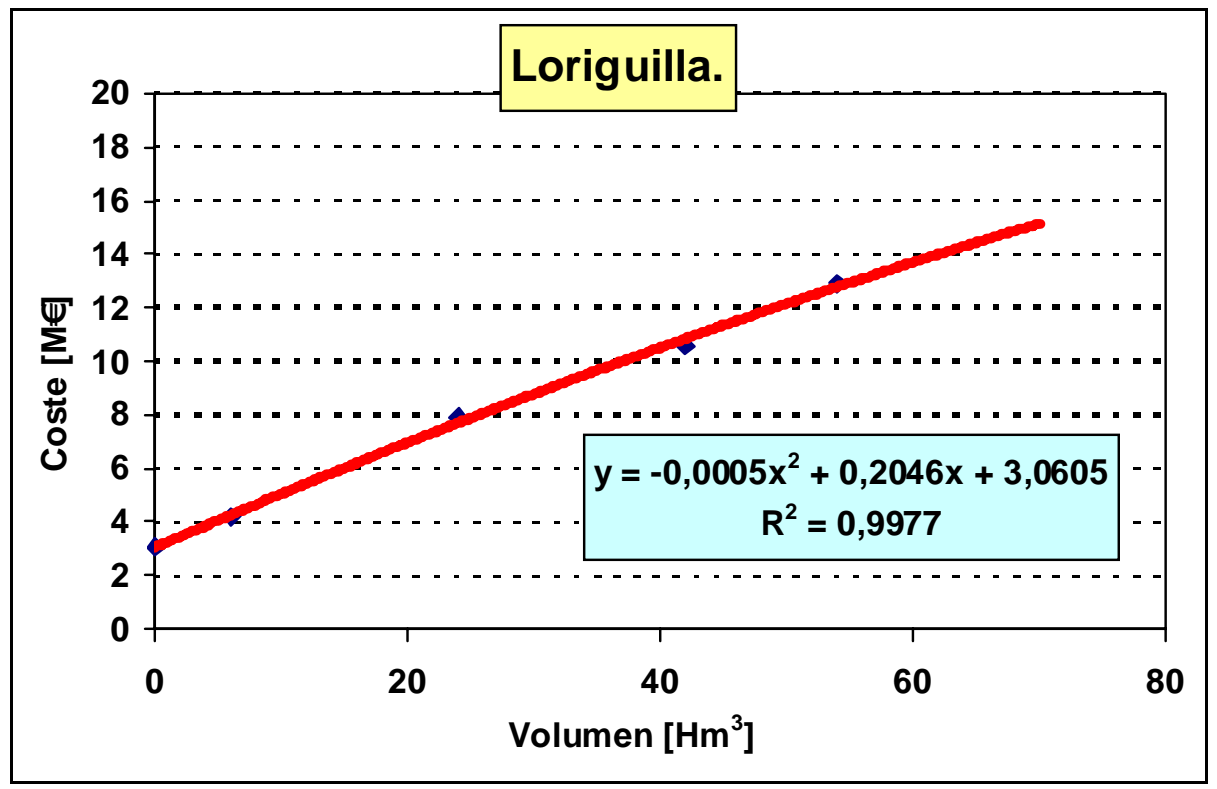

Figura 46: Presa de Loriguilla, función de coste.

\section{VII.2.2.4 Canales y obras de distribución}

Se ha considerado el Canal Campo del Turia desde la derivación del embalse de Benagéber hasta las demandas agrarias del Campo del Turia. La longitud total del canal es de $62 \mathrm{~km}$. En el caso de estudio no se han considerado los beneficios derivados de la producción hidroeléctrica de la central del salto de Domeño. En la Figura 47 se muestra el coste por metro lineal de obra, calculado en función del caudal de diseño, junto con el coste unitario por $\mathrm{m}^{3} / \mathrm{s}$. 


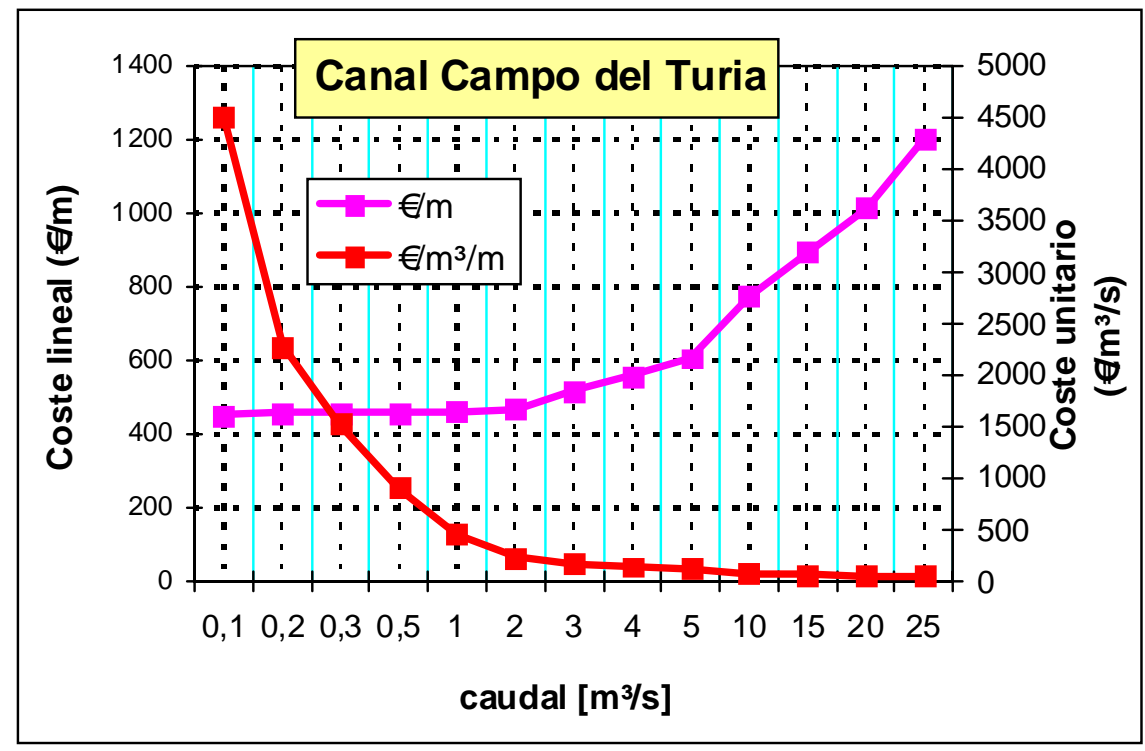

Figura 47: Canal Campo del Turia, función de coste.

\section{VII.2.2.5 Instalaciones de bombeo}

Los datos de coste de bombeo relativos a la cuenca del río Turia se han obtenido a partir de los datos elaborados por la $\mathrm{CHJ}$ en el Informe sobre la aplicación del Art. 5 de la DMA (CHJ, 2005). En las siguientes tablas se muestran los costes fijos y variables correspondientes a unas instalaciones tipo localizadas en el Campo del Turia y en la Plana de Valencia respectivamente.

\begin{tabular}{|l|c|}
\hline \multicolumn{2}{|c|}{ Bombeos Campo Turia } \\
\hline Datos de proyecto & 100 \\
Cota manométrica $[\mathrm{m}]$ & 95 \\
Profundidad de bombeo $[\mathrm{m}]$ & 0.015 \\
Caudal instalado $\left[\mathrm{m}^{3} / \mathrm{s}\right]$ & 8 \\
Horas diarias de funcionamiento & \\
Costes & 20000 \\
Obra civil y eq. electromecánicos $[€]$ & 19000 \\
Coste de sondeo $[€]$ & 130000 \\
Coste inversión unitario $\left[€ / \mathrm{m}^{3} / \mathrm{s}\right]$ & $\mathbf{0 . 1 0}$ \\
Explotación $\left[€ / \mathrm{m}^{3}\right]$ &
\end{tabular}

Tabla 31: Coste de bombeo Campo Turia 


\begin{tabular}{|l|c|}
\hline \multicolumn{2}{|c|}{ Bombeos Plana Valencia } \\
\hline Datos de proyecto & 20 \\
Cota manométrica $[\mathrm{m}]$ & 15 \\
Profundidad $[\mathrm{m}]$ & 0.025 \\
Caudal instalado $\left[\mathrm{m}^{3} / \mathrm{s}\right]$ & 8 \\
Horas diarias de funcionamiento & \\
Costes & 30000 \\
Obra civil y eq. electromecánicos $[€]$ & 3000 \\
Coste de sondeo $[€]$ & 150000 \\
Coste inversión unitario $\left[€ / \mathrm{m}^{3} / \mathrm{s}\right]$ & $\mathbf{0 . 0 6}$ \\
Explotación $\left[€ / \mathrm{m}^{3}\right]$ &
\end{tabular}

Tabla 32: Coste de bombeo Plana Valencia

Cabe destacar que el sistema de pozos definido en la Plana de Valencia no se corresponde con la capacidad de extracción realmente instalada en el territorio, sino que se incluye en el estudio para explorar la posibilidad de uso conjunto de aguas superficiales y subterráneas.

VII.2.2.6 Reutilización de las aguas residuales del área urbana de Valencia

Se considera la realización de una planta de tratamiento de tipo 2 para la reutilización de las aguas residuales de Valencia, destinadas al riego de los cultivos de los riegos tradicionales. El potencial de regeneración puede llegar al $70 \%$ de la demanda total de Valencia, que asciende a $120 \mathrm{hm}^{3} /$ año al sumarse los recursos procedentes de los sistemas Turia y Júcar.

A los efectos del análisis económico, se considera un coste de inversión de $40 € / \mathrm{m}^{3} /$ día y un coste de explotación de $0,12 € / \mathrm{m}^{3}$ producido.

El alcance del suministro del agua regenerada está vinculado con la capacidad de la red de distribución existente. La necesidad de realizar nuevas infraestructuras para la impulsión y el transporte de los volúmenes tratados puede suponer un incremento de coste que, a falta de ulterior información, se estima en $0,05 € / \mathrm{m}^{3}$ (Lapuente, 2005). 


\section{VII.2.2.7 Desalinización}

En la presente aplicación se ha considerado la realización de una planta de desalinización del agua de mar con tecnología de osmosis inversa de tipo modular, cuyo coste de construcción se calcula de acuerdo con la función descrita en la Figura 33 de la pág. 31.

Los costes de explotación para la demanda urbana de Valencia se han estimado en $0,45 € / \mathrm{m}^{3}$, con un incremento de $0,05 €$ en el caso de extender la distribución del agua desalinizada a las demandas agrarias situadas en el interior.

\section{VII.3 DEFINICIÓN DEL JUEGO Y FORMACIÓN DE LAS COALICIONES}

Una vez caracterizado el sistema desde el punto de vista físico, hidrológico y económico se procede con la definición del juego. El primer paso consiste en la identificación de los actores independientes.

\section{VII.3.1 Demandas consuntivas}

De acuerdo con los criterios expuestos en el apartado VI.2 se han definido 2 jugadores correspondientes a las demandas de agua para uso consuntivo:

Usos Urbanos: representados por las unidades de demanda urbana de Teruel y Valencia.

Usos agrícola: representados por las unidades de demanda del Canal Campo del Turia, Acequia de Moncada, Pueblos Castillos, Vega de Valencia.

Los jugadores coinciden con las dos clases de consumidores de agua mayoritarios de la cuenca y comparten:

- los patrones de consumo;

- la actividad económica asociada al uso del agua;

- los niveles de servicio requeridos.

Cabe destacar que la agrupación de las demandas en la figura de un jugador no comporta la pérdida de la discretización espacial del esquema, ya que las unidades de demanda siguen representadas en el modelo manteniendo su localización, sus patrones de consumo y las garantías. La agrupación se refiere 
únicamente a la optimización económica, que se efectúa conjuntamente para todos los usuarios pertenecientes a la figura de un jugador.

\section{VII.3.2 Laminación de avenidas}

Se pretende incluir en el juego un jugador que represente los intereses de los usuarios beneficiados por las obras de laminación. Los servicios de laminación de avenidas se configuran como restricciones en la gestión del sistema y corresponden a unas limitaciones del volumen máximo de los embalses con el fin de asegurar un volumen de laminación suficiente para hacer frente a una avenida de un determinado periodo de retorno.

No entra en los objetivos de esta tesis definir el periodo de retorno de las avenidas de proyecto ni calcular los volúmenes de laminación correspondientes. Para tal fin se ha utilizado la información contenida en el esquema de simulación redactado por (MS Ingenieros, 2002) y en las normas de explotación (CHJ, 2002d), y se han elaborados las curvas de embalse a escala mensual que representan el resguardo para la laminación de avenida determinado por el organismo gestor.

Las curvas de volúmenes autorizados para los embalses de Benagéber y loriguilla se muestran en la Figura 48 y en la Figura 49, respectivamente.

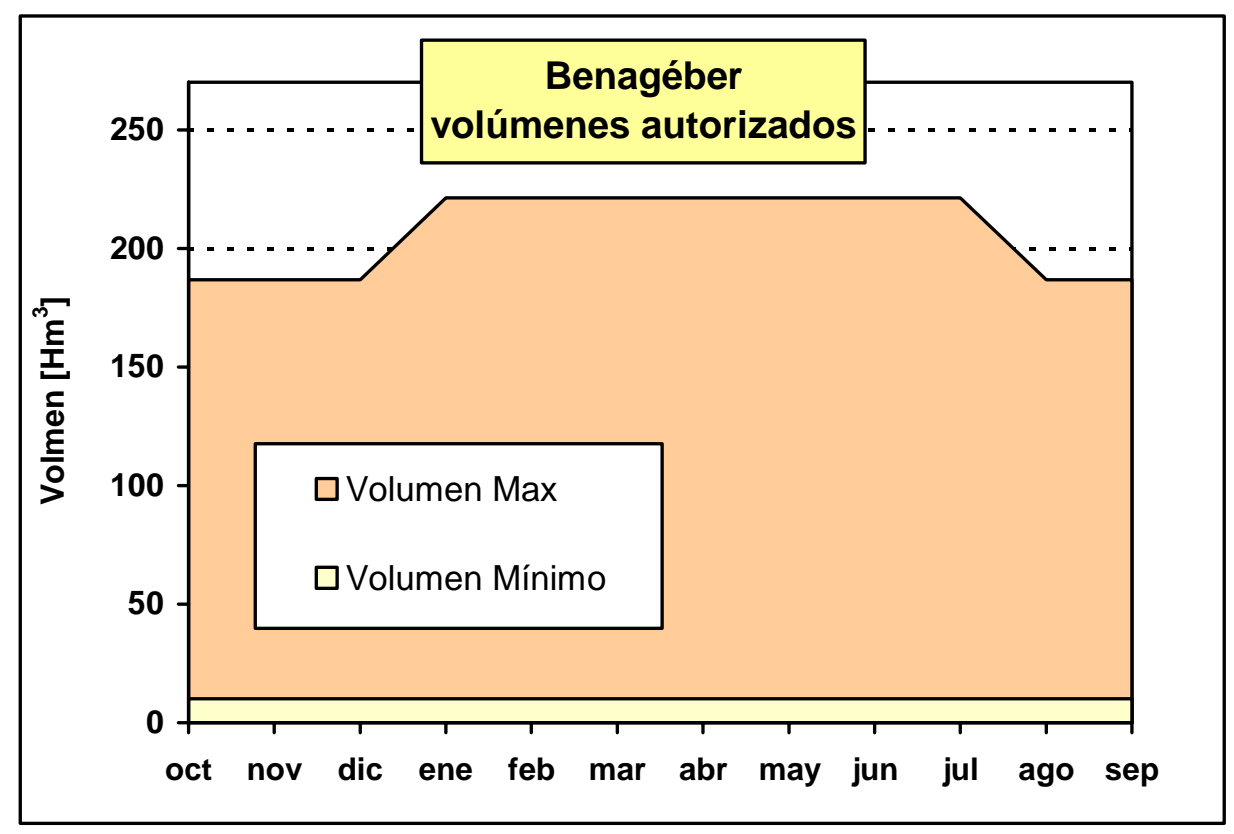

Figura 48: Benagéber, volúmenes autorizados. 


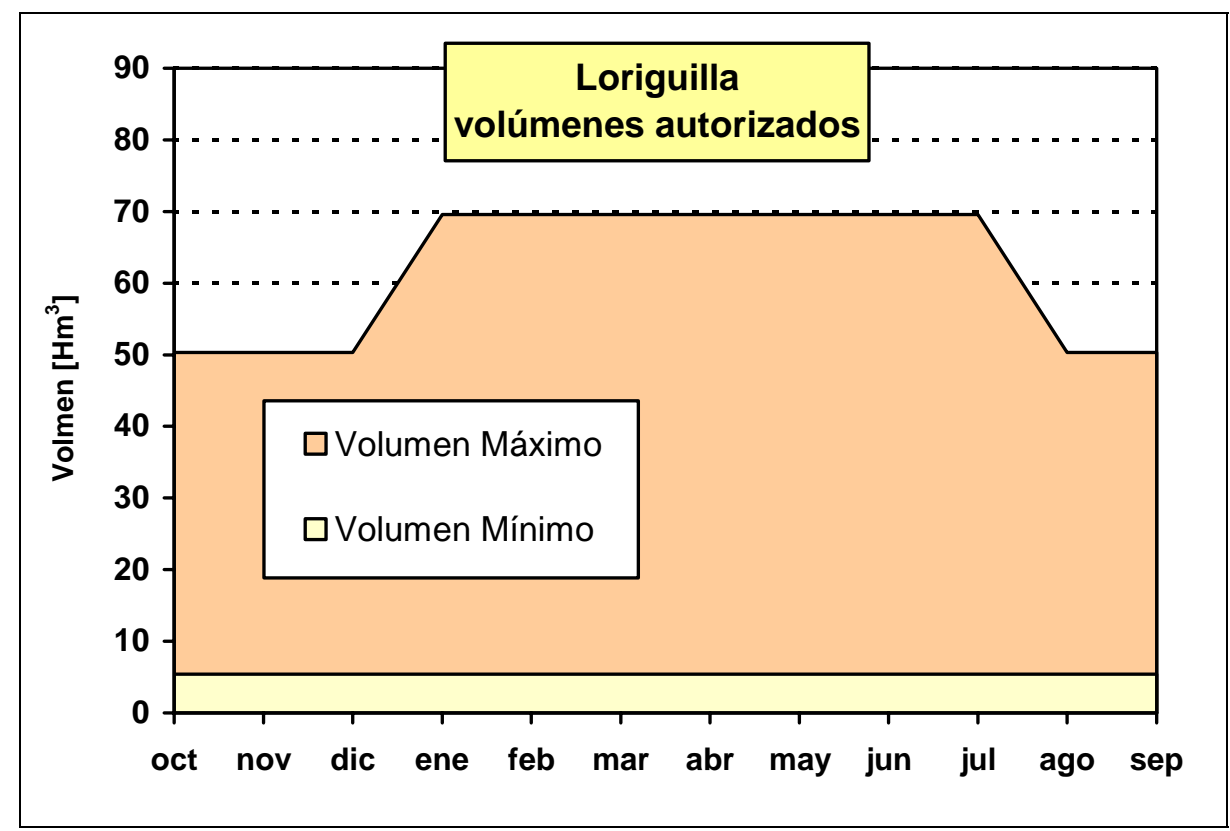

Figura 49: Loriguilla, volúmenes autorizados.

\section{VII.3.3 Tomas fuera de comisión}

El jugador identificado como tomas fuera de comisión (TFC) agrupa los usuarios que responden a las características descritas por en el apartado VII.1.3.1. La incorporación de las TFC tiene la finalidad de estimar la responsabilidad de las mismas en el uso de los embalses de regulación y estimar la asignación de coste correspondiente.

Se han simulado las TFC como una unidad de demanda de $\mathbf{1 0} \mathbf{~ h m}^{\mathbf{3}}$ anuales situada aguas abajo de los embalses principales de la cuenca, cuya distribución mensual coincide con los riegos tradicionales. El jugador se comporta como un usuario consuntivo con una garantía muy elevada ( $\approx 100 \%)$, que, al actuar en coalición con otros usuarios comporta un aumento del gasto en infraestructuras.

\section{VII.4 APLICACIÓN DEL MODELO DE OPTIMIZACIÓN}

A partir de la información disponible sobre el sistema se ha definido un esquema conceptual del sistema hídrico del río Turia mediante el programa WARGI. El esquema, descrito en la Figura 50, contiene además los parámetros relativos a las funciones de coste de las infraestructuras y los datos correspondientes a los niveles de servicio requeridos por los usuarios. 


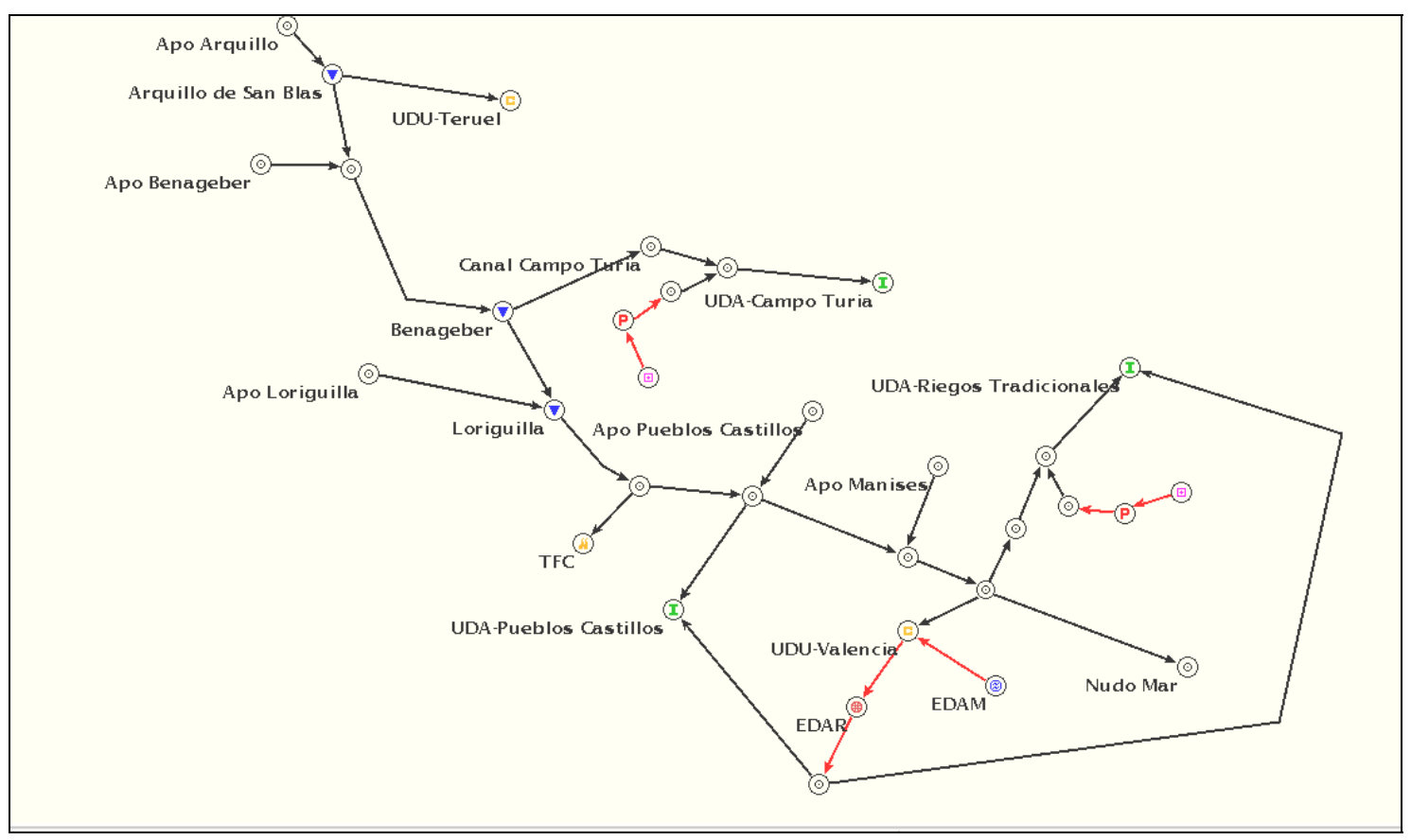

Figura 50: WARGI, esquema de simulación del río Turia.

\section{VII.4.1 Definición del caso base}

El caso base representa una condición de funcionamiento del sistema en ausencia de las infraestructuras y de los servicios que serán objeto del análisis. Mediante la simulación del caso base se pretende evidenciar los déficits de suministro a los que se enfrentarían las demandas del sistema al venir menos las infraestructuras de regulación, bombeo, transporte y laminación de avenidas.

La situación de partida coincide con un sistema hídrico en el que los usuarios pueden derivar los caudales fluyentes en régimen natural hasta los puntos de consumo según las prioridades establecidas en las reglas de operación. Los niveles de garantía que se muestran en la Tabla 33 corresponden a la suma del déficit de suministro a las demandas en un determinado intervalo de tiempo, calculado en un tanto por ciento respecto a la demanda anual. 


\begin{tabular}{|c|c|c|c|c|}
\hline \multicolumn{5}{|c|}{ Simulación del caso base } \\
\hline Déficit máximo & Mensual & $\mathbf{1}$ año & $\mathbf{2}$ años & $\mathbf{1 0}$ años \\
\hline Teruel & $100 \%$ & $80,13 \%$ & $129,34 \%$ & $290,22 \%$ \\
\hline Valencia & $100 \%$ & $51,76 \%$ & $96,52 \%$ & $252,99 \%$ \\
\hline Campo Turia & - & $57,69 \%$ & $111,35 \%$ & $376,72 \%$ \\
\hline Pueblos Castillos & - & $55,51 \%$ & $92,65 \%$ & $262,13 \%$ \\
\hline R. Tradicionales & - & $74,86 \%$ & $146,75 \%$ & $595,75 \%$ \\
\hline TFC & - & $39,50 \%$ & $72,65 \%$ & $161,55 \%$ \\
\hline
\end{tabular}

Tabla 33: Niveles de garantía calculados en el caso base.

\section{VII.4.2 Optimización de las coaliciones}

El paso siguiente consiste en la aplicación del modelo de optimización para cada una de las 15 coaliciones (24-1). En cada una de las optimizaciones los usuarios presentes en la coalición están vinculados al conseguimiento de los niveles de garantía de referencia definidos en el apartado V.5.2 y tienen a disposición todas las alternativas de suministro con sus respectivas funciones de coste. La elección del conjunto de alternativas de suministro más adecuado se realiza minimizando la función objetivo del sistema, que incluye las funciones de coste de las infraestructuras.

Los usuarios que no pertenecen a la coalición están vinculados al conseguimiento de los niveles de garantía de base calculados en el apartado anterior. Siendo el coste de déficit inferior al coste de las infraestructuras del sistema el modelo no está incentivado a disponer la realización de nuevas infraestructuras para elevar el nivel de garantía por encima del valor de base.

El intervalo temporal establecido en el análisis es de 50 años, que corresponde a la vida útil estimadas para las obras civiles. Las inversiones que presentan una vida útil inferior serán reemplazadas al caducar el período de amortización suponiendo un valor residual nulo.

A continuación se ofrece un resumen de los resultados calculados para cada coalición. Se puede observar en las distintas tablas el dimensionamiento de las infraestructuras y el coste mínimo asociado a cada coalición.

Con el fin de agilizar la identificación de las coaliciones se ha propuesto la siguiente notación para los jugadores del sistema: 
(A) Laminación de avenidas;

(B) Usos agrícolas;

(C) Usos urbanos;

(D) Tomas fuera de comisión.

\begin{tabular}{|c|c|c|c|c|c|}
\hline \multicolumn{5}{|c|}{ Coalición A: laminación de avenidas } \\
\hline \multirow{2}{*}{ Diseño } & Arquillo & Benagéber & Loriguilla & Bombeos & Canal \\
\cline { 2 - 6 } & 0,00 & 35,00 & 19,30 & 0,00 & 0,00 \\
\hline Costes $(\mathrm{M} €)$ & 0,00 & 10,48 & 6,82 & 0,00 & 0,00 \\
\hline Total $(\mathrm{M} €)$ & \multicolumn{5}{|c}{$\mathrm{hm}^{3} / \mathrm{mes}$} \\
\hline
\end{tabular}

Tabla 34: Coalición A.

\begin{tabular}{|c|c|c|c|c|c|}
\hline \multicolumn{5}{|c|}{ Coalición B: usos agrícolas } \\
\hline \multirow{2}{*}{ Diseño } & Arquillo & Benagéber & Loriguilla & Bombeos & Canal \\
\cline { 2 - 6 } & 0,00 & 221,70 & 0,00 & 8,30 & 10,04 \\
\hline Costes $(\mathrm{M} €)$ & 0,00 & 35,58 & 0,00 & 41,11 & 7,13 \\
\hline Total $(\mathrm{M} €)$ & \multicolumn{5}{|c|}{$\mathrm{hm}^{3}$} \\
\hline
\end{tabular}

Tabla 35: Coalición B.

\begin{tabular}{|c|c|c|c|c|c|}
\hline \multicolumn{6}{|c|}{ Coalición C: usos urbanos } \\
\hline & Arquillo & Benagéber & Loriguilla & Bombeos & Canal \\
\hline \multirow{2}{*}{ Diseño } & \multicolumn{3}{|c|}{$\mathrm{hm}^{3}$} & \multicolumn{2}{|c|}{$\mathrm{hm}^{3} / \mathrm{mes}$} \\
\hline & 10,68 & 0,00 & 0,00 & 0,00 & 0,00 \\
\hline Costes (M€) & 3,70 & 0,00 & 0,00 & 0,00 & 0,00 \\
\hline Total (M€) & \multicolumn{5}{|c|}{3,70} \\
\hline
\end{tabular}

Tabla 36: Coalición C. 
CAPÍTULO VII: APLICACIÓN DE LA METODOLOGÍA AL CASO DEL RÍO TURIA

\begin{tabular}{|c|c|c|c|c|c|}
\hline \multicolumn{5}{|c|}{ Coalición D: tomas fuera de comisión } \\
\hline \multirow{2}{*}{ Diseño } & Arquillo & Benagéber & Loriguilla & Bombeos & Canal \\
\cline { 2 - 6 } & 0,58 & 0,00 & 0,00 & 0,01 & 0,00 \\
\hline Costes $(\mathrm{M} €)$ & 0,96 & 0,00 & 0,00 & 0,03 & 0,00 \\
\hline Total $(\mathrm{M} €)$ & \multicolumn{5}{|c}{$\mathrm{hm}^{3} / \mathrm{mes}$} \\
\hline
\end{tabular}

Tabla 37: Coalición D.

\begin{tabular}{|c|c|c|c|c|c|}
\hline \multicolumn{5}{|c|}{ Coalición AB } \\
\hline \multirow{2}{*}{ Diseño } & Arquillo & Benagéber & Loriguilla & Bombeos & Canal \\
\cline { 2 - 6 } & 0,00 & 213,69 & 19,30 & 8,30 & 9,78 \\
\hline Costes $(\mathrm{M} €)$ & 0,00 & 34,59 & 6,82 & 39,73 & 6,94 \\
\hline Total $(\mathrm{M} €)$ & \multicolumn{5}{|c}{} \\
\hline
\end{tabular}

Tabla 38: Coalición AB.

\begin{tabular}{|c|c|c|c|c|c|}
\hline \multicolumn{5}{|c|}{ Coalición AC } \\
\hline \multirow{2}{*}{ Diseño } & Arquillo & Benagéber & Loriguilla & Bombeos & Canal \\
\cline { 2 - 6 } & 4,69 & 35,00 & 19,30 & 0,00 & 0,00 \\
\hline Costes $(\mathrm{M} €)$ & 2,32 & 10,48 & 6,82 & 0,00 & 0,00 \\
\hline Total $(\mathrm{M} €)$ & \multicolumn{5}{|c|}{$\mathrm{hm}^{3}$} \\
\hline
\end{tabular}

Tabla 39: Coalición AC.

\begin{tabular}{|c|c|c|c|c|c|}
\hline \multicolumn{5}{|c|}{ Coalición AD } \\
\hline \multirow{2}{*}{ Diseño } & Arquillo & Benagéber & Loriguilla & Bombeos & Canal \\
\cline { 2 - 6 } & 0,00 & 35,00 & 19,30 & 0,00 & 0,00 \\
\hline Costes $(\mathrm{M} €)$ & 0,00 & 10,48 & 6,82 & 0,00 & 0,00 \\
\hline Total $(\mathrm{M} €)$ & \multicolumn{5}{|c|}{$\mathrm{hm}^{3}$} \\
\hline
\end{tabular}

Tabla 40: Coalición AD. 
CAPÍTULO VII: APLICACIÓN DE LA METODOLOGÍA AL CASO DEL RÍO TURIA

\begin{tabular}{|c|c|c|c|c|c|}
\hline \multicolumn{5}{|c|}{ Coalición BC } \\
\hline \multirow{2}{*}{ Diseño } & Arquillo & Benagéber & Loriguilla & Bombeos & Canal \\
\cline { 2 - 6 } & 4,69 & 211,22 & 0,00 & 8,30 & 9,78 \\
\hline Costes $(\mathrm{M} €)$ & 2,32 & 34,30 & 0,00 & 41,42 & 6,94 \\
\hline Total $(\mathrm{M} €)$ & \multicolumn{5}{|c|}{$\mathrm{hm}^{3} / \mathrm{mes}$} \\
\hline
\end{tabular}

Tabla 41: Coalición BC.

\begin{tabular}{|c|c|c|c|c|c|}
\hline \multicolumn{5}{|c|}{ Coalición BD } \\
\hline \multirow{2}{*}{ Diseño } & Arquillo & Benagéber & Loriguilla & Bombeos & Canal \\
\cline { 2 - 6 } & 0,00 & 221,70 & 0,00 & $\mathrm{hm}^{3} / \mathrm{mes}$ \\
\hline Costes $(\mathrm{M} €)$ & 0,00 & 35,58 & 0,00 & 41,42 & 7,30 \\
\hline Total $(\mathrm{M} €)$ & \multicolumn{5}{|c}{} \\
\hline
\end{tabular}

Tabla 42: Coalición BD.

\begin{tabular}{|c|c|c|c|c|c|}
\hline \multicolumn{5}{|c|}{ Coalición CD } \\
\hline \multirow{2}{*}{ Diseño } & Arquillo & Benagéber & Loriguilla & Bombeos & Canal \\
\cline { 2 - 6 } & \multicolumn{5}{|c|}{$\mathrm{hm}^{3}$} \\
\hline \multirow{2}{*}{ Costes $(\mathrm{M} €)$} & 4,06 & 0,00 & 0,00 & 0,00 & 0,00 \\
\hline Total $(\mathrm{M} €)$ & 0,00 & 0,00 & 0,00 & 0,00 \\
\hline
\end{tabular}

Tabla 43: Coalición CD.

\begin{tabular}{|c|c|c|c|c|c|}
\hline \multicolumn{5}{|c|}{ Coalición ABC } \\
\hline \multirow{2}{*}{ Diseño } & Arquillo & Benagéber & Loriguilla & Bombeos & Canal \\
\cline { 2 - 6 } & 4,69 & 185,43 & 26,46 & 8,30 & 10,00 \\
\hline Costes $(\mathrm{M} €)$ & 2,32 & 31,20 & 7,76 & 40,43 & 7,10 \\
\hline Total $(\mathrm{M} €)$ & \multicolumn{5}{|c|}{$\mathrm{hm}^{3}$} \\
\hline
\end{tabular}

Tabla 44: Coalición ABC. 


\begin{tabular}{|c|c|c|c|c|c|}
\hline \multicolumn{5}{|c|}{ Coalición ABD } \\
\hline \multirow{2}{*}{ Diseño } & Arquillo & Benagéber & Loriguilla & Bombeos & Canal \\
\cline { 2 - 6 } & 0,00 & 206,89 & 26,46 & 8,30 & 9,78 \\
\hline Costes $(\mathrm{M} €)$ & 0,00 & 33,79 & 7,76 & 39,62 & 6,94 \\
\hline Total $(\mathrm{M} €)$ & \multicolumn{5}{|c}{} \\
\hline
\end{tabular}

Tabla 45: Coalición ABD.

\begin{tabular}{|c|c|c|c|c|c|}
\hline \multirow{2}{*}{} & Arquillo & Benagéber & Loriguilla & Bombeos & Canal \\
\hline \multirow{2}{*}{ Diseño } & \multicolumn{5}{|c|}{$\mathrm{hm}^{3}$} \\
\cline { 2 - 6 } & 4,69 & 35,00 & 19,30 & 0,00 & 0,00 \\
\hline Costes $(\mathrm{M} €)$ & 2,32 & 10,48 & 6,82 & 0,00 & 0,00 \\
\hline Total $(\mathrm{M} €)$ & \multicolumn{5}{|c|}{19,62} \\
\hline
\end{tabular}

Tabla 46: Coalición ACD.

\begin{tabular}{|c|c|c|c|c|c|}
\hline \multicolumn{5}{|c|}{ Coalición BCD } \\
\hline \multirow{2}{*}{ Diseño } & Arquillo & Benagéber & Loriguilla & Bombeos & Canal \\
\cline { 2 - 6 } & 4,69 & 221,70 & 0,00 & 8,09 & \multicolumn{2}{c|}{$\mathrm{hm}^{3} / \mathrm{mes}$} \\
\hline Costes $(\mathrm{M} €)$ & 2,32 & 35,58 & 0,00 & 40,52 & 6,94 \\
\hline Total $(\mathrm{M} €)$ & \multicolumn{5}{|c}{} \\
\hline
\end{tabular}

Tabla 47: Coalición BCD.

\section{VII.4.2.1 La gran coalición}

La gran coalición $(\mathrm{ABCD})$ está constituida por el programa de medidas que permite lograr los niveles objetivo de garantía y de laminación de avenida para todos los jugadores de forma conjunta. En la Tabla 48 se resumen los datos de diseño y el coste de las infraestructuras obtenidos mediante el proceso de optimización de la gran coalición. 


\begin{tabular}{|c|c|c|c|c|c|}
\hline \multicolumn{5}{|c|}{ Gran coalición (ABCD) } \\
\hline \multirow{2}{*}{ Diseño } & Arquillo & Benagéber & Loriguilla & Bombeos & Canal \\
\cline { 2 - 6 } & 4,69 & 221,49 & 24,46 & \multicolumn{2}{c|}{$\mathrm{hm}^{3} / \mathrm{mes}$} \\
\hline Costes $(\mathrm{M} €)$ & 2,32 & 35,52 & 6,95 & 37,32 & 7,15 \\
\hline Total $(\mathrm{M} €)$ & \multicolumn{5}{|c}{} \\
\hline
\end{tabular}

Tabla 48: Gran coalición , ABCD.

El análisis de las series de flujos calculadas por el optimizador permite estimar el volumen máximo de embalse y las capacidades de transporte y de bombeos necesarios para el cumplimiento de los niveles de servicio.

La Figura 51 muestra la serie histórica del volumen requerido por los embalses. El valor máximo de la serie corresponde al volumen de diseño del embalse calculado por el optimizador. A partir del dato de volumen de diseño se calcula el coste de la infraestructura mediante la función coste-volumen descrita en el apartado VII.2.1.1.

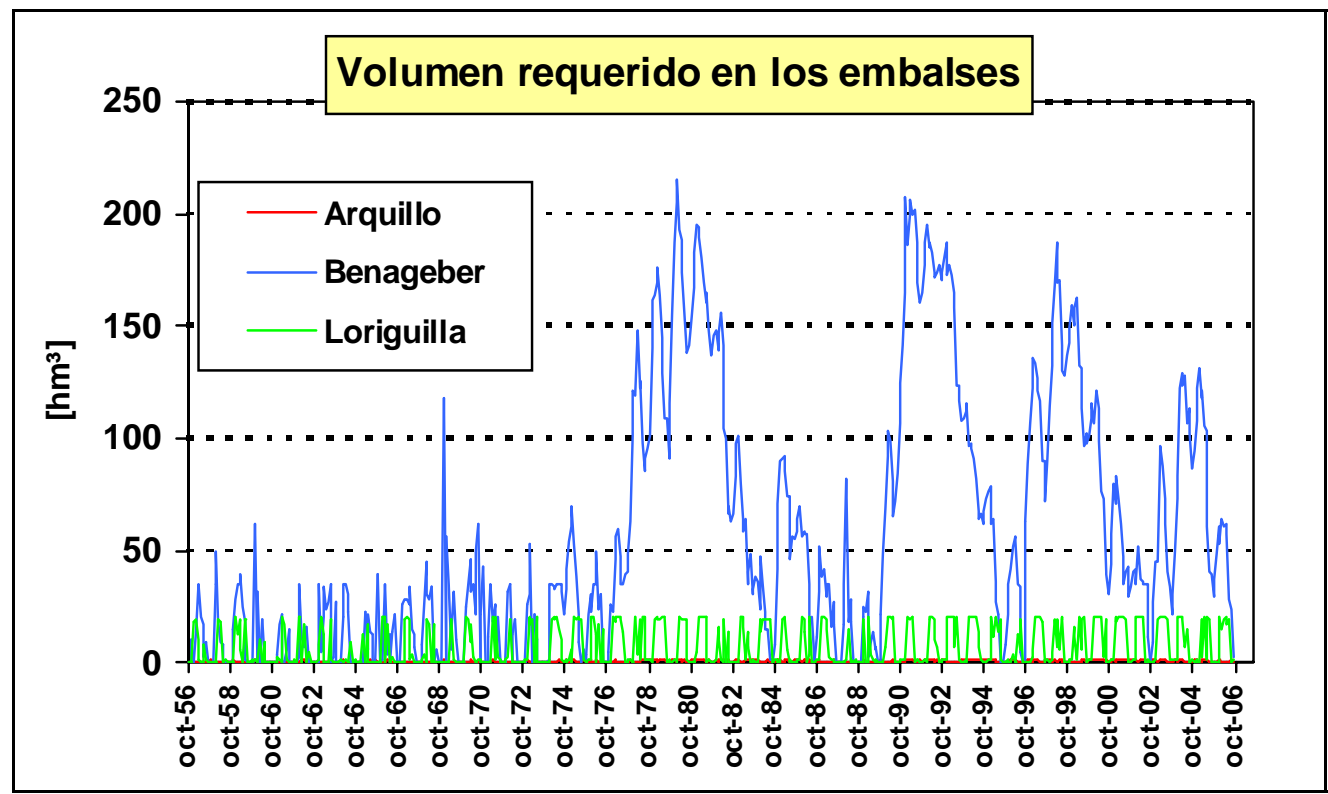

Figura 51: Gran coalición, volúmenes requeridos en los embalses. 
A continuación se muestran las series de caudales circulantes en el Canal Campo de Turia (Figura 52) y los volúmenes mensuales extraidos por las estaciones de bombeo (Figura 53).

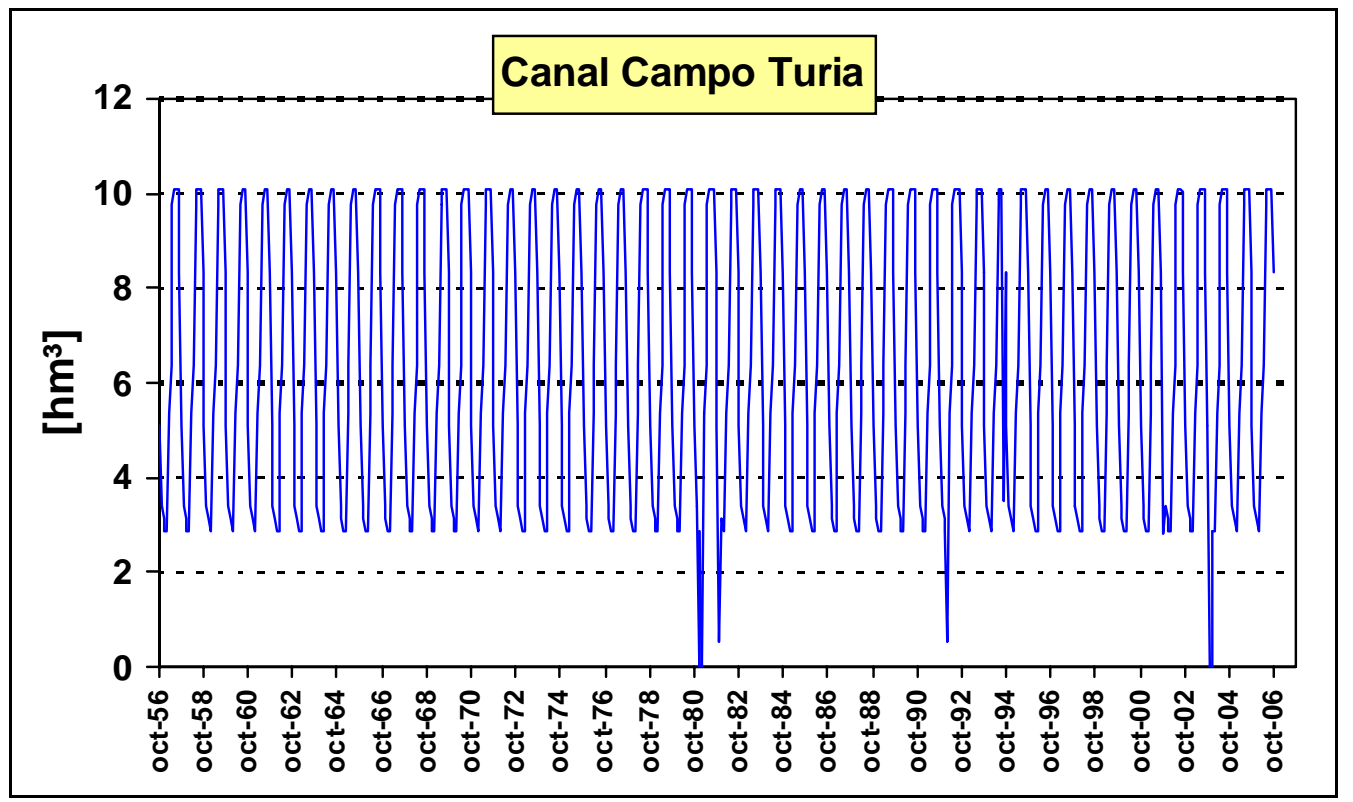

Figura 52: Gran coalición, canal Campo del Turia.

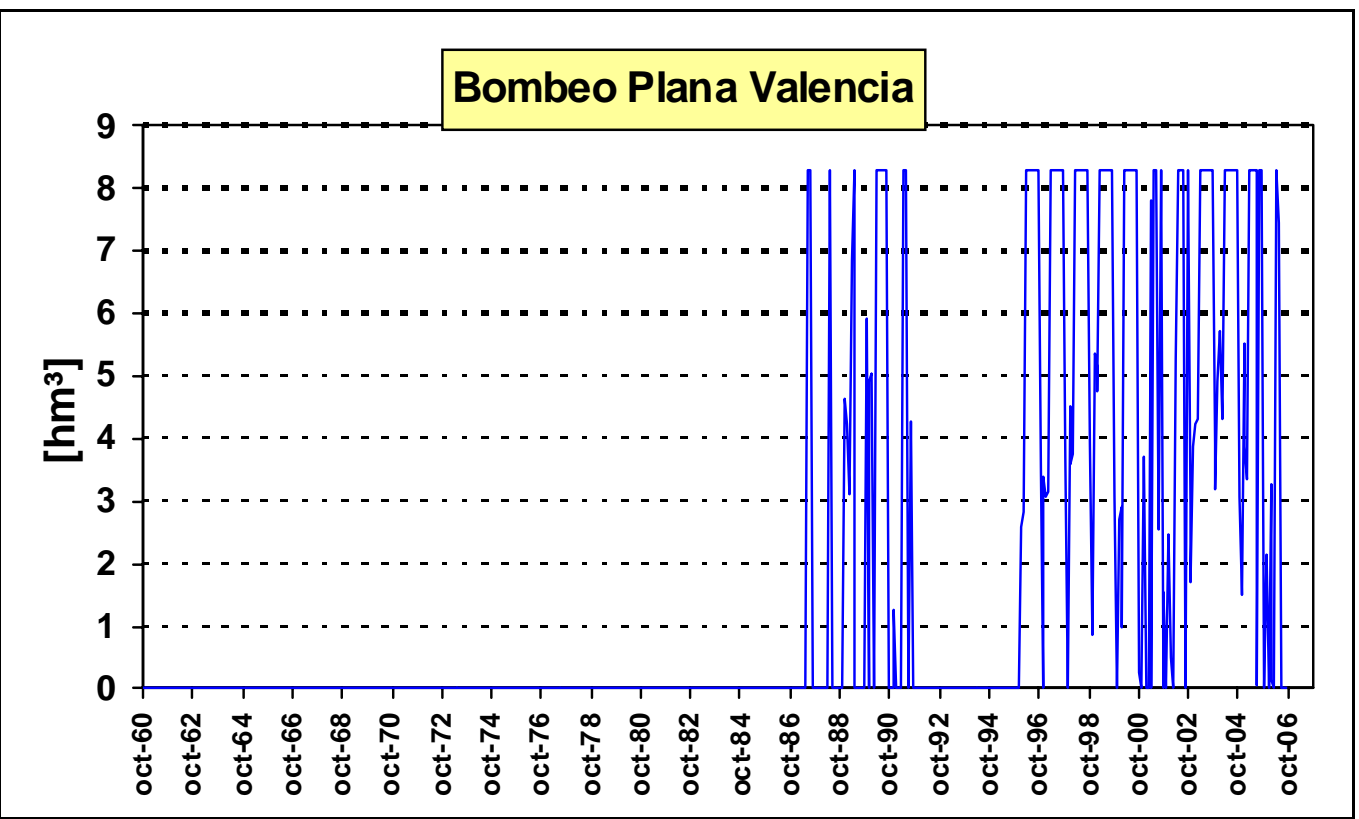

Figura 53: Gran coalición, bombeos. 
Las series de suministro a las demandas, descritas en la Figura 54 y en la Figura 55, muestran periodos en los que la demanda de agua resulta parcialmente insatisfecha. Pero la magnitud de los déficits en el suministro queda por debajo de los umbrales de garantía definidos por la Instrucción de planificación hidrológica.

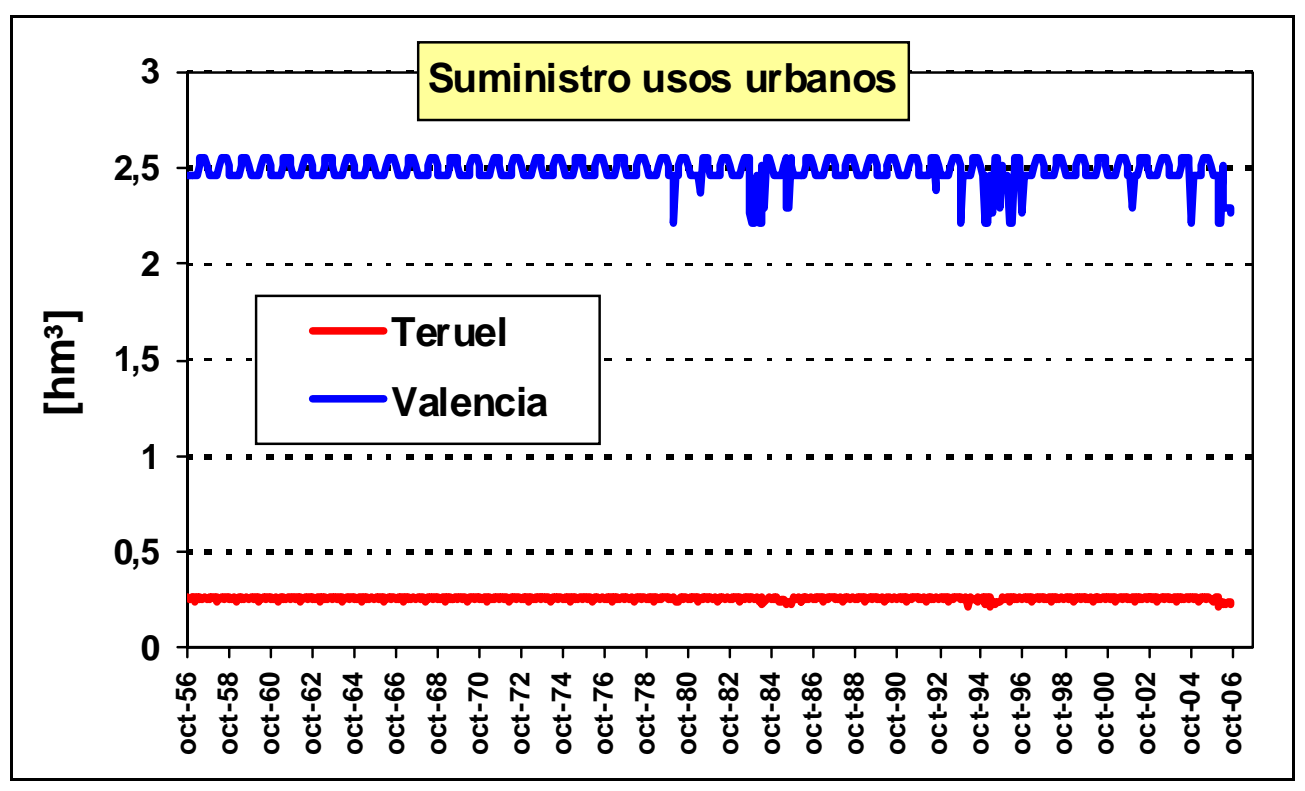

Figura 54: Gran coalición, suministro usos urbanos.

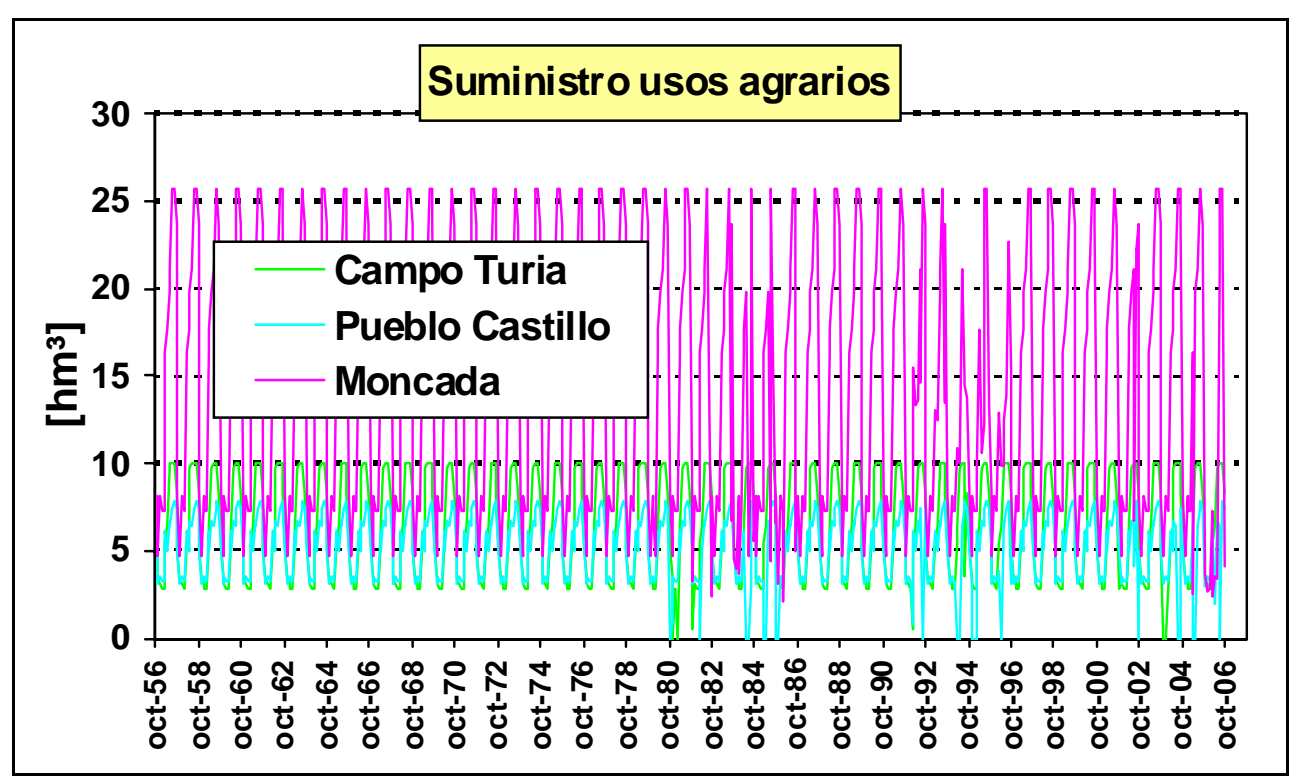

Figura 55: Gran coalición, suministro usos agrícolas. 
La Figura 56 y la Figura 57 muestran las series relativas al déficit de suministro a las demandas, que en el caso analizado se concentra en los intervalos 1982-84, 1992-96 y 2000-2004, en coincidencia con los periodos de sequía más graves registrados en la cuenca.

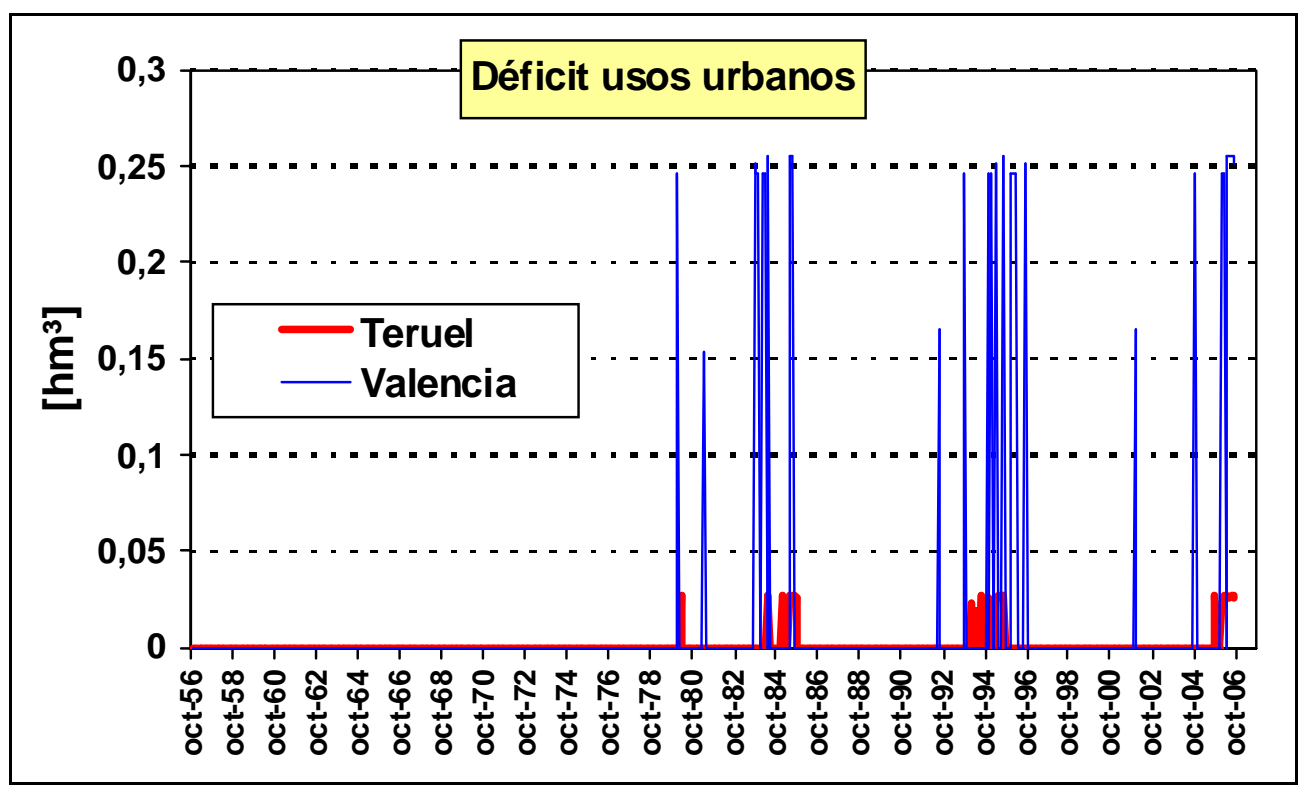

Figura 56: Gran coalición, déficit usos urbanos.

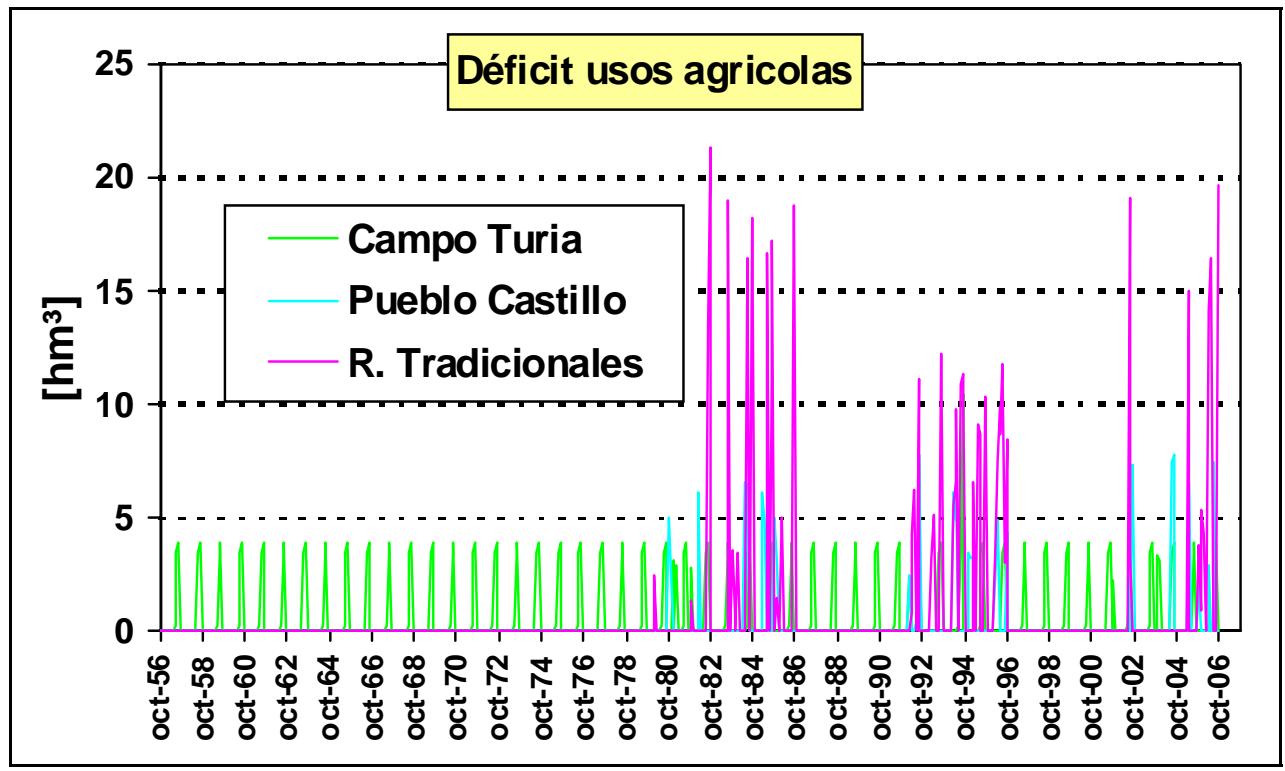

Figura 57: Gran coalición, déficit usos agrícolas. 
En el gráfico descrito en la Figura 58 se muestra la influencia de las distintas infraestructuras en la determinación del insumo de costes de los servicios para la gran coalición.

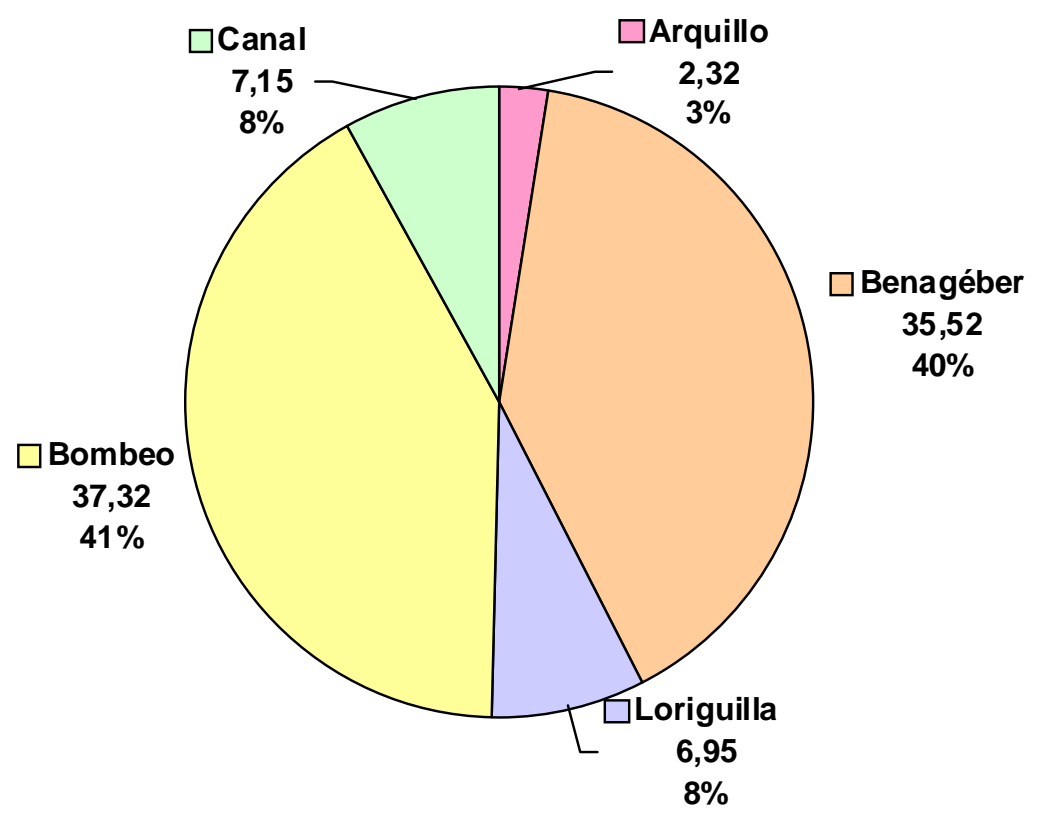

Figura 58: Gran coalición, reparto de coste de las infraestructuras.

El análisis del coste de las infraestructuras evidencia un peso determinante de las instalaciones de bombeo en el total de los costes de la gran coalición, como se muestra en la Figura 59.

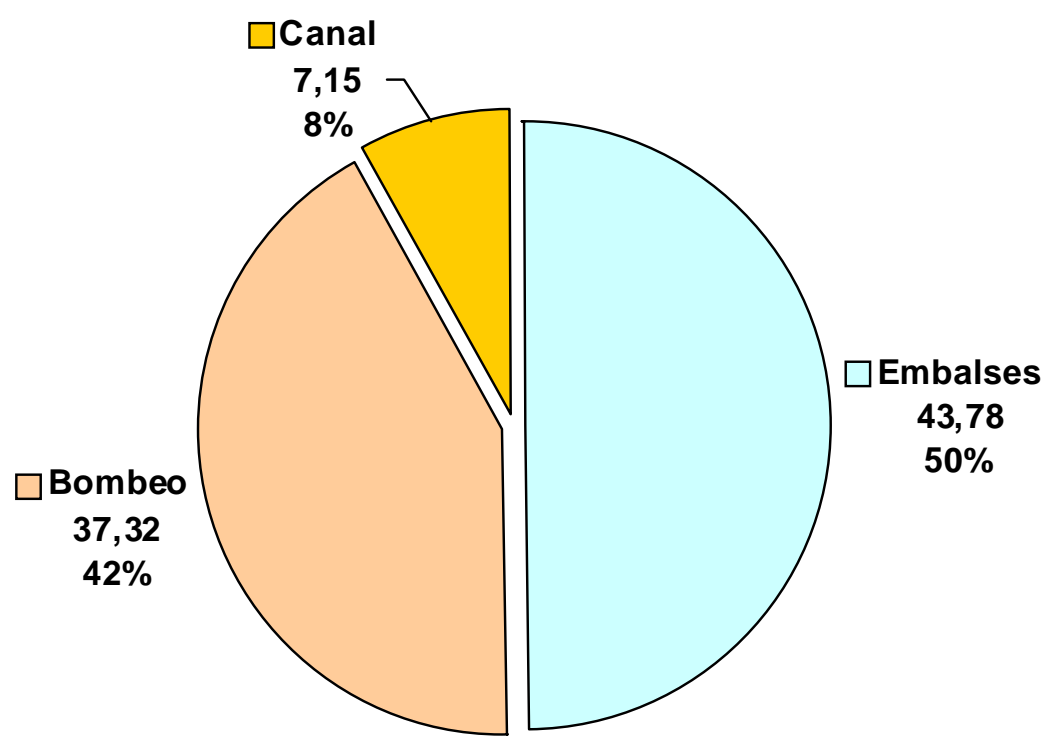

Figura 59: Gran coalición, reparto del coste según el tipo de infraestructura. 


\section{VII.4.2.2 La función característica}

A partir de los datos de coste obtenidos para cada coalición y descritos en los apartados anteriores es posible definir la función característica del juego.

En la Tabla 49 se resume el coste calculado para cada una de las coaliciones del juego y a continuación, en la Figura 60, se muestra el gráfico relativo a la función característica para el caso de estudio.

\begin{tabular}{|c|c|}
\hline \multicolumn{2}{|c|}{ Función característica } \\
\hline Coalición & Coste (M€) \\
\hline Laminación (A) & 17,30 \\
\hline Usos agrarios (B) & 83,82 \\
\hline Usos urbanos (C) & 3,70 \\
\hline Tomas fuera de comisión (D) & 0,99 \\
\hline AB & 88,08 \\
\hline AC & 19,62 \\
\hline AD & 17,33 \\
\hline BC & 84,98 \\
\hline BD & 84,31 \\
\hline CD & 4,06 \\
\hline ABC & 88,81 \\
\hline ABD & 88,11 \\
\hline ACD & 19,65 \\
\hline BCD & 85,36 \\
\hline Gran coalición (ABCD) & 89,26 \\
\hline
\end{tabular}

Tabla 49: Función característica. 


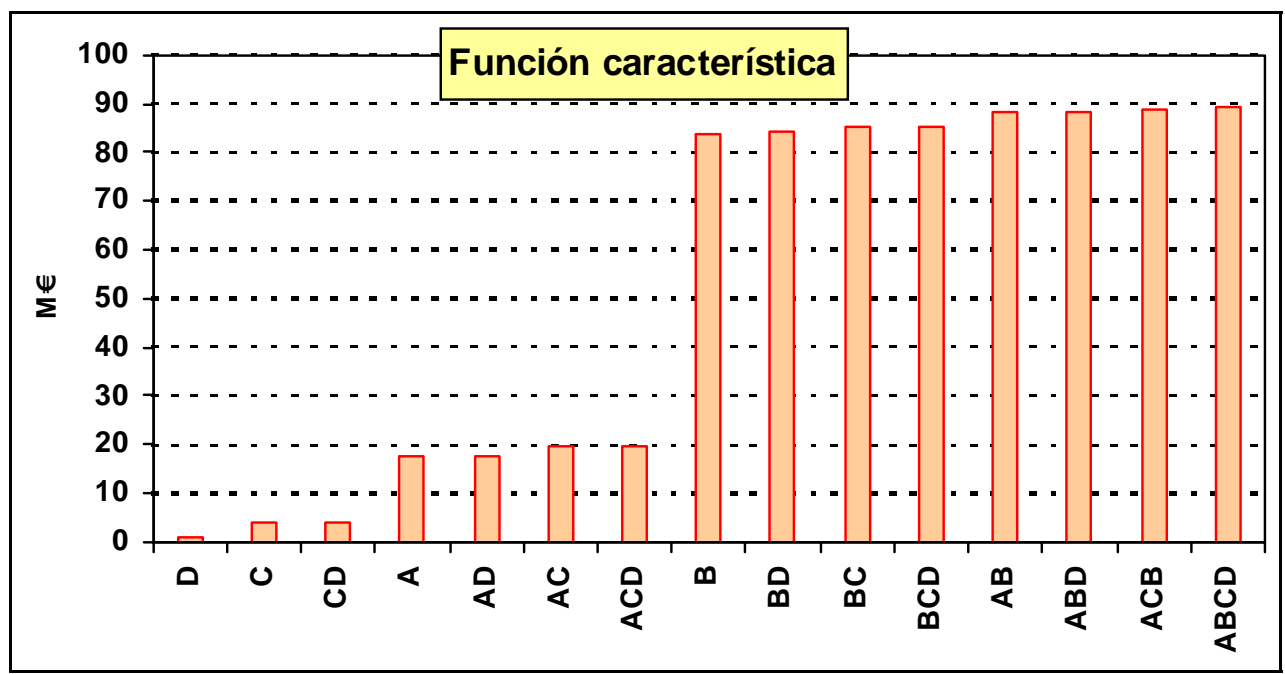

Figura 60: Función característica.

La comprobación de la condición de eficiencia demuestra que la gran coalición es también la solución más eficiente de todas las posibles combinaciones de actuaciones individuales. No existe alternativa de proyecto que permita alcanzar los objetivos de garantía y de laminación de avenidas a un coste inferior. En la Figura 61 es posible observar que la gran coalición asegura un ahorro de hasta $15 \mathrm{M} €$ con respecto a las actuaciones individuales.

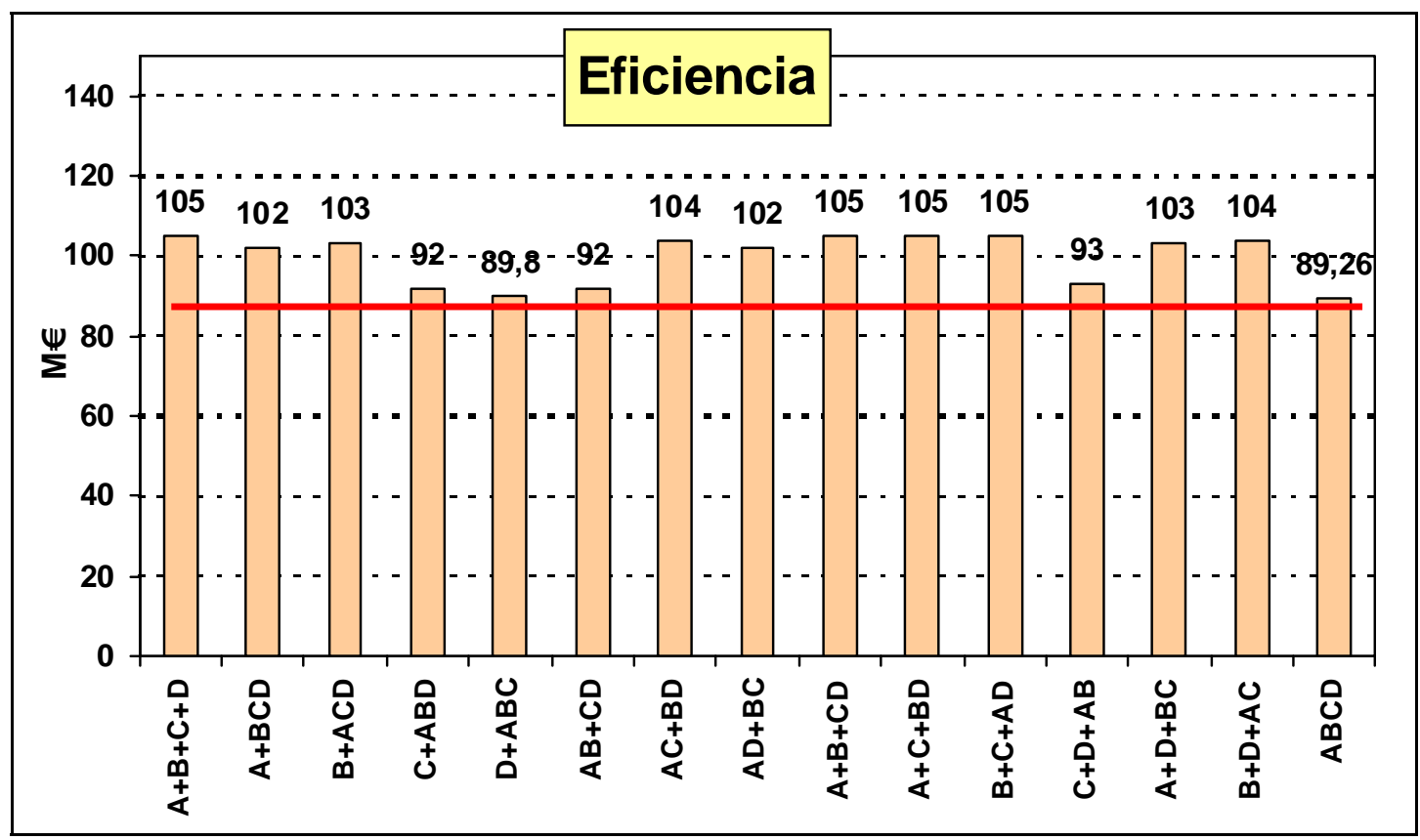

Figura 61: Condición de eficiencia de la gran coalición. 


\section{VII.4.3 Asignación de costes}

Una vez determinada la función característica del juego y comprobada la eficiencia de la gran coalición se procede a la asignación del coste de los servicios calculados mediante la aplicación del valor de Shapley.

$$
x_{i}(c)=\sum_{S \subseteq N-i} \frac{|S| !(|N-S|-1) !}{|N| !}[c(S+i)-c(S)]
$$

donde:

$\mathrm{x}_{\mathrm{i}}(\mathrm{c})$ : coste asignado al jugador $\mathrm{i}$;

S: cardinalidad de la coalición S;

$\mathrm{N}$ : componentes totales del proyecto, cardinalidad de la gran coalición;

$\mathrm{C}(\mathrm{S}+i)$ : función de costes asociada a la coalición $(\mathrm{S}+i)$;

$\mathrm{C}(\mathrm{S})$ : función de costes asociada a la coalición $\mathrm{S}$.

El algoritmo de Shapley asigna a cada jugador el promedio de sus contribuciones marginales a la coalición, considerando cada posible coalición equiprobable. Para determinar el valor de Shapley es necesario calcular las contribuciones marginales de cada jugador al incorporarse a cada una de las coaliciones según la fórmula descrita a continuación.

$$
C M(i, S)=[c(S+i)-c(S)]
$$

donde:

$C M(i, S)$ : contribución marginal del sujeto $i$ a la coalición $S$;

$c(S+i)$ : coste de la coalición $(\mathrm{S}+\mathrm{i})$;

$c(S)$ : coste de la coalición S.

Los valores de las contribuciones marginales se recogen en la Tabla 50. 


\begin{tabular}{|c|c|}
\hline Coalición S & $C M(i, S)$ en $M €$ \\
\hline A & 17,30 \\
\hline B & 83,82 \\
\hline $\mathrm{C}$ & 3,70 \\
\hline $\mathrm{D}$ & 0,99 \\
\hline AB-A & 4,26 \\
\hline $\mathrm{AB}-\mathrm{B}$ & 70,78 \\
\hline AC-A & 15,92 \\
\hline AC-C & 2,32 \\
\hline $\mathrm{AD}-\mathrm{A}$ & 16,34 \\
\hline AD-D & 0,03 \\
\hline BC-B & 81,28 \\
\hline BC-C & 1,16 \\
\hline BD-B & 83,32 \\
\hline BD-D & 0,49 \\
\hline CD-C & 3,07 \\
\hline CD-D & 0,36 \\
\hline ABC-A & 3,84 \\
\hline ABC-B & 69,20 \\
\hline ABC-C & 0,73 \\
\hline ABD-A & 3,80 \\
\hline ABD-B & 70,78 \\
\hline ABD-D & 0,03 \\
\hline ACD-A & 15,56 \\
\hline ACD-C & 2,29 \\
\hline ACD-D & 0,03 \\
\hline BCD-B & 81,30 \\
\hline BCD-C & 1,05 \\
\hline BCD-D & 0,38 \\
\hline ABCD-A & 3,90 \\
\hline ABCD-B & 69,64 \\
\hline ABCD-C & 1,15 \\
\hline ABCD-B & 0,44 \\
\hline
\end{tabular}

Tabla 50: Valor de Shapley, contribución marginal de los jugadores. 
Sigue el cálculo del componente factorial del algoritmo de Shapley, cuyos valores se recogen en la Tabla 51:

$$
\operatorname{fact}(S, N)=\frac{|S| !(|N-S|-1) !}{|N| !}
$$

donde:

$|\mathrm{S}|$ : número de miembros de la coalición;

$|\mathrm{N}|$ : número total de jugadores (4).

\begin{tabular}{|c|c|}
\hline$|\mathbf{S}|$ & fact $(S, 4)$ \\
\hline 0 & 0,250 \\
\hline 1 & 0,083 \\
\hline 2 & 0,083 \\
\hline 3 & 0,250 \\
\hline
\end{tabular}

Tabla 51: Valor de Shapley, componente factorial.

Finalmente se procede al cálculo del vector de pagos mediante el valor de Shapley, que corresponde a la asignación de los costes de la gran coalición entre los 4 jugadores.

En la Tabla 52 se muestran los valores de pago asociados a los jugadores individuados en el juego.

\begin{tabular}{|c|rr|}
\hline \multicolumn{2}{|c}{ Valor de Shapley } & M€ \\
\hline A & $11,52 \%$ & 10,28 \\
B & $85,61 \%$ & 76,41 \\
C & $2,35 \%$ & 2,10 \\
D & $0,52 \%$ & 0,47 \\
\hline \multicolumn{2}{r}{ total } & 89,26 \\
\hline
\end{tabular}

Tabla 52: Valor de Shapley, asignación de costes. 
La Figura 62 muestra el reparto de coste entre los jugadores, en el que se evidencia una asignación mayoritaria a los usos agrícolas (jugador B). La mayor contribución por parte de los usos agrícola se explica, en primer lugar, con las grandes diferencias en los volúmenes consumidos por parte de las demandas agrarias respecto a los demás usuarios del sistema, lo que comporta la construcción de obras hidráulicas de mayor envergadura. Otro factor tiene relación con el origen de los recursos utilizados para el riego, que al ser en parte de procedencia subterránea comportan un encarecimiento del coste final del agua para las demandas agrícolas. También el Canal Campo del Turia, de uso exclusivamente agrario, contribuye al aumento del diferencial de coste entre los usos agrícolas y los demás jugadores del sistema.

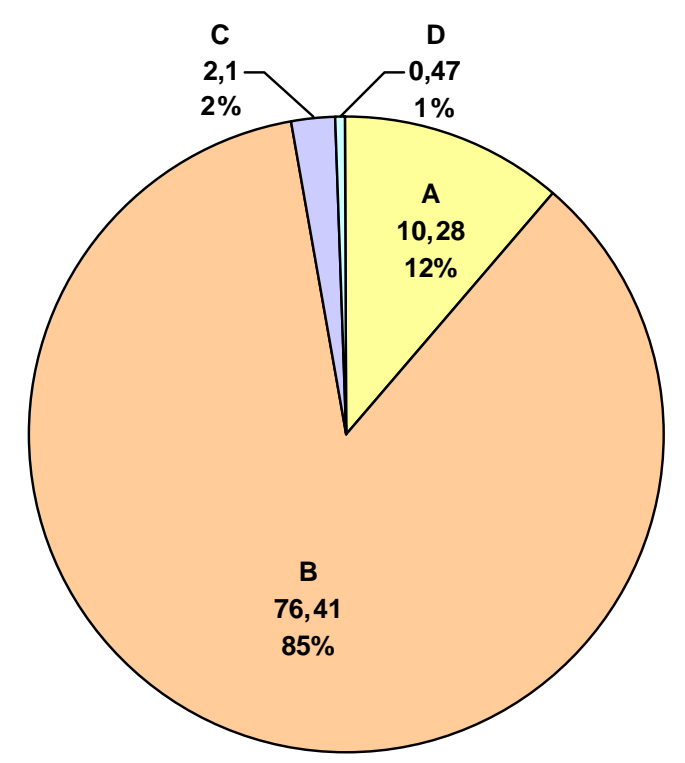

Figura 62: Valor de Shapley, asignación de costes (valores en M€).

\section{VII.4.3.1 Comparación con otras metodologías}

Se ha procedido a calcular la asignación de coste correspondiente a distintas metodologías detalladas en el capítulo III.3 con el fin de comparar los resultados obtenidos con los pagos calculados mediante el valor de Shapley.

En particular se han considerado: los repartos de costes de tipo volumétrico, igualitario, los criterios de costes separables con base volumétrica e igualitaria y el reparto de ahorros de tipo volumétrico e igualitario.

Para aplicar los criterios de tipo volumétrico se han considerados los volúmenes de suministro a las demandas (ver Tabla 53) calculados por el optimizador en la gran coalición durante los 50 años de simulación. 


\begin{tabular}{|l|c|c|}
\hline \multicolumn{3}{|c|}{ Volúmenes suministrados $\mathbf{( h m}^{\mathbf{3}} \mathbf{)}$} \\
\hline Agricolas & 15901 & $88,08 \%$ \\
\hline Urbanas & 1653 & $9,16 \%$ \\
\hline TFC & 499 & $2,77 \%$ \\
\hline Total & 18053 & \\
\hline
\end{tabular}

Tabla 53: Volúmenes suministrados a las demandas.

En la Tabla 54 se resumen los pagos calculados para cada jugador mediante las distintas metodologías de asignación de costes.

\begin{tabular}{|c|c|c|c|c|c|c|c|}
\hline \multicolumn{7}{|c|}{ Metodologías de asignación de costes } \\
\hline & Shapley & Volumétrico & Igualitario & $\begin{array}{c}\text { Coste separ. } \\
\text { volumétrico }\end{array}$ & $\begin{array}{c}\text { Coste sep. } \\
\text { igualitario }\end{array}$ & $\begin{array}{c}\text { Ahorros } \\
\text { volumétrico }\end{array}$ & $\begin{array}{c}\text { Ahorros } \\
\text { igualitario }\end{array}$ \\
\hline A & 10,28 & 17,85 & 22,31 & 6,73 & 7,44 & 13,99 & 13,16 \\
\hline B & 76,41 & 63,15 & 22,31 & 79,63 & 73,15 & 72,11 & 79,68 \\
\hline C & 2,10 & 6,33 & 22,31 & 2,15 & 4,69 & 2,52 & $-0,44$ \\
\hline D & 0,47 & 1,92 & 22,31 & 0,75 & 3,98 & 0,63 & $-3,15$ \\
\hline total & 89,26 & 89,26 & 89,26 & 89,26 & 89,26 & 89,26 & 89,26 \\
\hline
\end{tabular}

Tabla 54: Metodologías de asignación de costes, tabla comparativa.

Todas las metodologías propuestas cumplen el requisito de maximizar la eficiencia de la gestión en cuanto que están asociadas a la realización de la solución más eficiente. Además, todas respectan el principio de recuperación de costes, ya que asignan la totalidad de los costes del proyecto a los usuarios. Sin embargo, la comprobación de los principios de equidad y racionalidad muestra que no todos los criterios cumplen las propiedades de racionalidad individual y marginalidad. De hecho, el valor de Shapley es el único criterio que proporciona una asignación de costes en el núcleo.

En la Tabla 55 se ofrece una comparativa sobre el cumplimiento de la condición de pertenencia al núcleo por parte de las distintas soluciones de asignación de coste. Los valores en rojo o en naranja representan asignaciones que exceden los límites superiores o inferiores dictados por las propiedades de racionalidad y marginalidad. 


\begin{tabular}{|c|c|c|c|c|c|c|c|c|c|}
\hline \multicolumn{10}{|c|}{ Pertenencia al núcleo } \\
\hline $\mathrm{S}$ & \multicolumn{2}{|c|}{ Núcleo } & Shapley & Volum. & Igual. & $\begin{array}{c}\text { Coste sep. } \\
\text { volum. }\end{array}$ & $\begin{array}{l}\text { Coste sep. } \\
\text { igual. }\end{array}$ & $\begin{array}{c}\text { Ahorros } \\
\text { volum. }\end{array}$ & $\begin{array}{c}\text { Ahorros } \\
\text { igual. }\end{array}$ \\
\hline A & 3,90 & 17,30 & 10,28 & 17,85 & 22,31 & 6,73 & 7,44 & 13,99 & 13,16 \\
\hline B & 69,61 & 83,82 & 76,41 & 63,15 & 22,31 & 79,63 & 73,15 & 72,11 & 79,68 \\
\hline C & 1,15 & 3,70 & 2,10 & 6,33 & 22,31 & 2,15 & 4,69 & 2,52 & $-0,44$ \\
\hline D & 0,44 & 0,99 & 0,47 & 1,92 & 22,31 & 0,75 & 3,98 & 0,63 & $-3,15$ \\
\hline $\mathrm{AB}$ & 85,20 & 88,08 & 86,69 & 81,00 & 44,63 & 86,36 & 80,59 & 86,10 & 92,85 \\
\hline AC & 4,95 & 19,62 & 12,38 & 24,19 & 44,63 & 8,88 & 12,13 & 16,52 & 12,73 \\
\hline $\mathrm{AD}$ & 4,28 & 17,33 & 10,75 & 19,77 & 44,63 & 7,48 & 11,42 & 14,62 & 10,01 \\
\hline $\mathrm{BC}$ & 71,93 & 84,98 & 78,51 & 69,49 & 44,63 & 81,78 & 77,84 & 74,63 & 79,24 \\
\hline BD & 69,64 & 84,31 & 76,88 & 65,07 & 44,63 & 80,37 & 77,13 & 72,74 & 76,53 \\
\hline $\mathrm{CD}$ & 1,18 & 4,06 & 2,57 & 8,25 & 44,63 & 2,90 & 8,67 & 3,16 & $-3,59$ \\
\hline $\mathrm{ABC}$ & 88,27 & 88,81 & 88,79 & 86,69 & 86,69 & 86,69 & 86,69 & 86,69 & 86,69 \\
\hline $\mathrm{ABD}$ & 85,56 & 88,11 & 87,16 & 82,92 & 66,94 & 87,10 & 84,57 & 86,73 & 89,70 \\
\hline $\mathrm{ACD}$ & 5,44 & 19,65 & 12,85 & 26,11 & 66,94 & 9,63 & 16,11 & 17,15 & 9,57 \\
\hline $\mathrm{BCD}$ & 71,96 & 85,36 & 78,98 & 71,41 & 66,94 & 82,53 & 81,82 & 75,27 & 76,09 \\
\hline $\mathrm{ABCD}$ & 0,00 & 89,26 & 89,26 & 89,26 & 89,26 & 89,26 & 89,26 & 89,26 & 89,26 \\
\hline
\end{tabular}

Tabla 55: Comprobación de pertenencia al núcleo.

\section{VII.5 CONSIDERACIONES}

La aplicación de la metodología al caso de estudio muestra un escenario de gestión en el que los recursos son suficientes para abastecer a las demandas, con una integración de las aguas superficiales por parte de las reservas de agua subterráneas. No se evidencian déficits estructurales que comporten la realización de obras para la generación de recursos adicionales como plantas de desalinización o reutilización de aguas residuales.

\section{VII.5.1 Núcleo y asignación de costes}

En un contexto de cuatro jugadores, es posible definir el reparto de costes mediante un tetraedro regular, cuyos vértices corresponden a soluciones en la que los costes del proyecto están asignados integralmente a un solo usuario. Cada una de las caras del tetraedro representa el conjunto de soluciones de coste nulo para el usuario situado en el vértice opuesto, mientras las fronteras de los costes máximos/mínimos que corresponden a los principios de racionalidad individual y de marginalidad están definidas por unos planos paralelos a cada cara. El espacio tridimensional contenido entre estos planos constituye el núcleo del problema de asignación de costes. 
En la Figura 63 se muestra una representación gráfica del reparto de costes calculado para el caso de estudio, en la que se observa el tetraedro de asignación de costes y, en su interior, el espacio correspondiente al núcleo de soluciones. Destaca el desplazamiento del núcleo hacia el vértice $B$, lo que indica una mayor responsabilidad de las demandas agrícolas (jugador B) en el uso de las infraestructuras.

En el ejemplo propuesto, el valor de Shapley coincide con el baricentro del núcleo.

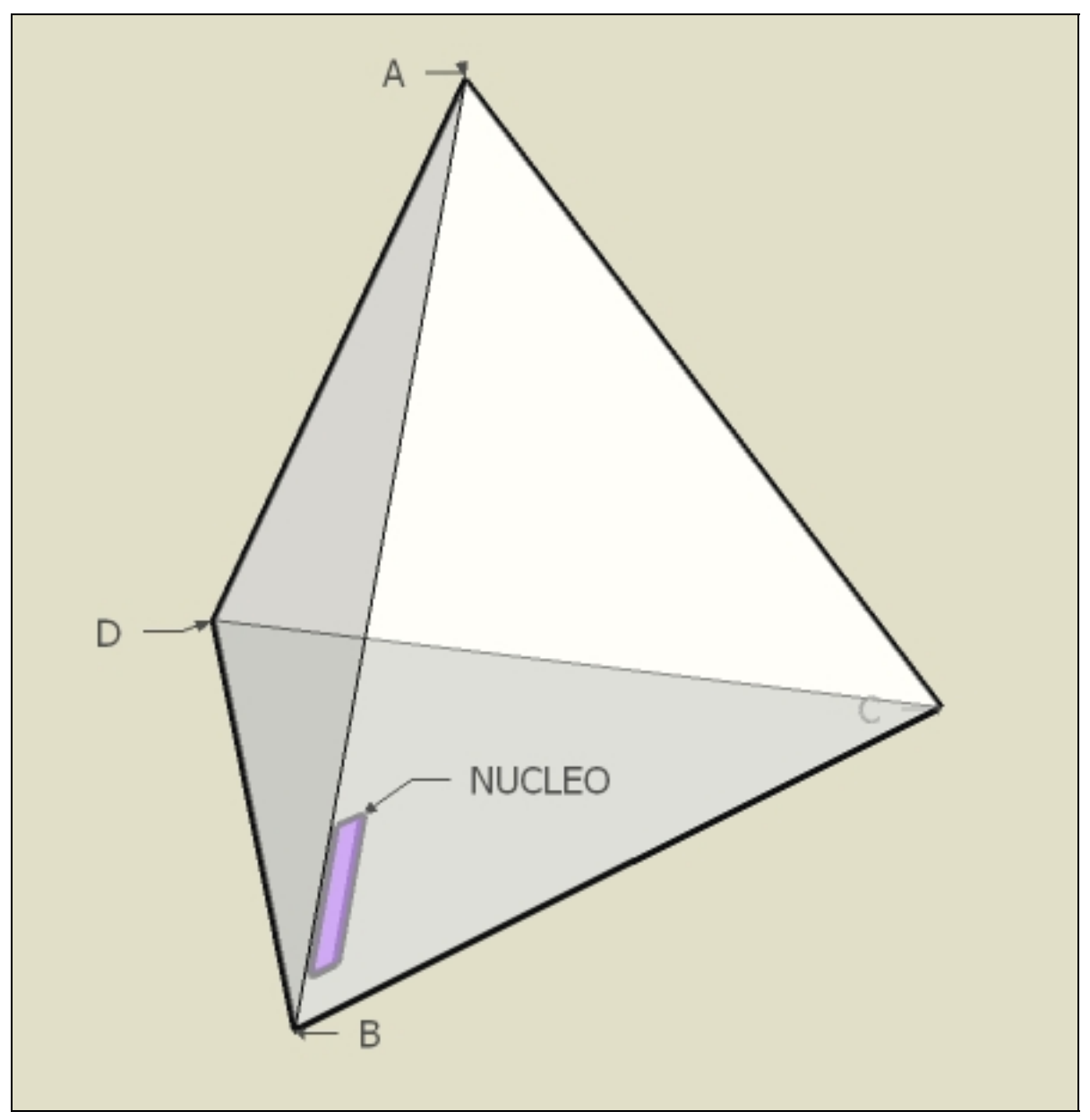

Figura 63: Asignación de costes, tetraedro.

La forma esbelta del núcleo refleja las diferencias en la magnitud de los costes asignados a los jugadores. Con referencia a los valores del núcleo descritos en la Tabla 55, para jugador $C$ (usos urbanos) se considera aceptable una asignación de coste comprendida entre 1,15 y 3,70 M€, mientras para el jugador D (TFC) es aceptable un coste comprendido entre 0,44 y 0,99 M€. Estos valores son de un orden de magnitud inferior respecto a los jugadores A (laminación, entre 3,90 y $17,30 \mathrm{M} €$ ) y B (usos agrarios 69,61 y 83,82) y explican porqué el núcleo tiene la 
forma de un paralelepípedo cuyas caras orientadas hacia los vértices $C$ y $D$ son más cortas respecto a las caras orientadas hacia los vértices A y B.

Con respecto al criterio de asignación del coste cabe destacar que el ejemplo analizado se presenta como un caso típico de juego con núcleo estrecho, caracterizado por un conjunto reducido de soluciones factibles. La comparación efectuada evidencia la dificultad de alcanzar una solución estable mediante los sistemas tradicionales de reparto de costes y el valor de Shapley se propone como el único concepto de solución en el núcleo.

A raíz de los resultados satisfactorios alcanzados mediante la aplicación del valor de Shapley y del número limitado de soluciones factibles, se ha desestimado la aplicación de otras metodologías inspiradas en la TJC para el cálculo del vector de pagos. El cálculo del nucleolo o de algoritmos equivalentes comportaría un importante esfuerzo computacional que, en el caso examinado, no estaría compensado por la mejora sustancial de los resultados de asignación de costes.

\section{VII.5.2 El uso de los recursos subterráneos}

El análisis del uso de los recursos subterráneos muestra una solución óptima de gestión caracterizada por el incremento del volumen bombeado en la Acequia de Moncada respecto a los riegos del Campo del Turia. Esta configuración corresponde a una optimización de la gestión del sistema en la que el coste de bombeo en el acuífero de la Plana de Valencia es inferior al coste de bombeo del acuífero del Campo del Turia.

En la realidad, la capacidad de bombeo instalada en el Campo del Turia es superior a la capacidad instalada en la Acequia de Moncada, donde las concesiones para el uso de aguas superficial tienen una prioridad elevada y solamente se utilizan los recursos subterráneos como medida extraordinaria para la mitigación de la sequía.

Se ha calculado la solución sub-óptima correspondiente a un uso limitado a 2 $\mathrm{hm}^{3} /$ mes para los bombeos de la Plana de Valencia y a un incremento de las extracciones en el Canal Campo del Turia, que presenta un coste de 118,29 M€ y muestra un aumento de los costes generales de los servicios de 29,03 M€.

En la Figura 64 se muestra la serie de volúmenes extraídos, correspondiente al caso de gestión modificado, en la que es posible observar el caudal limitado a 2 $\mathrm{hm}^{3} /$ mes para los bombeos de la Plana. 


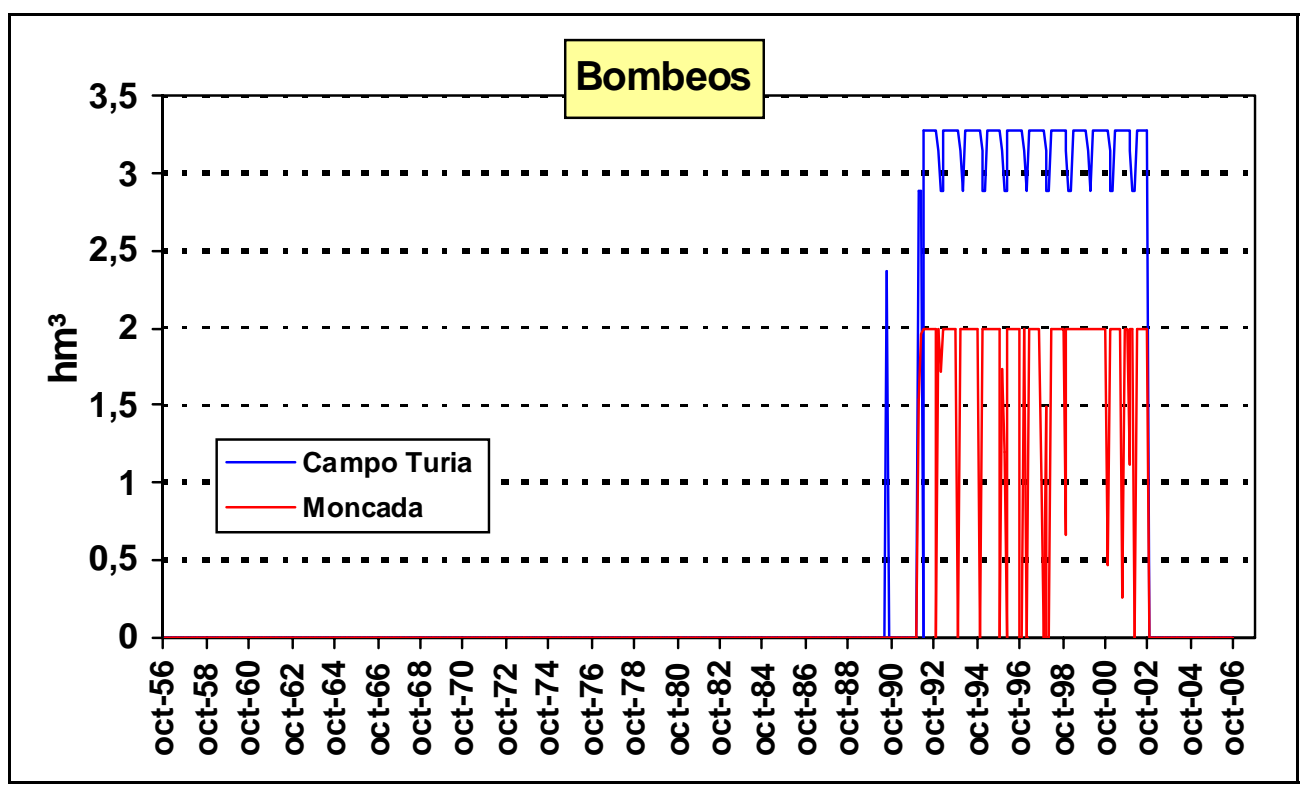

Figura 64: Incremento de las extracciones en el Campo del Turia.

En un contexto ideal de mayor liberalización del uso del agua y en ausencia de posibles problemas relacionados con la sobreexplotación de los acuíferos, se podría plantear un intercambio de derechos entre los usuarios del Campo del Turia y de la Acequia de Moncada. Los usuarios situados aguas arriba podrían utilizar recursos superficiales cedidos por los regantes de la Plana de Valencia con el fin de reducir sus extracciones. Los usuarios de la Plana podrían ceder parte de sus recursos superficiales a cambio del pago de los costes de bombeo y de un adecuado incentivo para la cooperación.

El reparto de los ahorros conseguidos y la definición de un incentivo justo y razonable para la cooperación representan otro interesante ejemplo de juego cooperativo a escala local.

\section{VII.5.3 Reparto de costes entre usos}

Los resultados de la aplicación del valor de Shapley muestran una responsabilidad predominante de los usos agrarios sobre los demás usos del sistema, con un consecuente incremento del pago correspondiente a los usuarios agrícolas. La explicación de la elevada asignación de costes se encuentra en el origen del recurso utilizado por las demandas agrícolas, que se abastecen en parte mediante aguas subterráneas a un coste mayor respecto al coste de los recursos superficiales. La demanda del Campo del Turia utiliza, además, un canal para la derivación de los caudales fluviales, cuyo coste recae integralmente sobre los usos agrarios. 
Se ha efectuado un análisis del reparto del coste correspondiente a las obras de regulación, excluyendo del cómputo general los costes de bombeo y del canal Campo del Turia. Los resultados muestran un aumento de la contribución a la financiación de los servicios por parte de las demandas urbanas, como se muestra en la Figura 65.

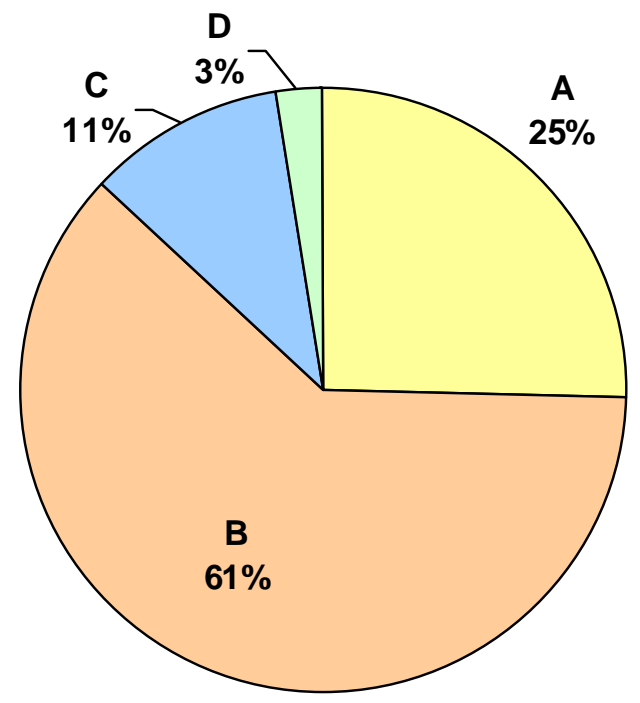

Figura 65: Valor de Shapley sin costes de bombeo y canal (valores en M€).

Los valores obtenidos ponen en evidencia que, independientemente de los volúmenes requeridos, las mayores exigencias en términos de garantías por parte de las demandas urbanas suponen un incremento relativo del uso de obras de regulación con respecto a las demandas agrícolas. La metodología desarrollada permite cuantificar el incremento de coste que supone para una demanda el cumplimiento de unos niveles de garantía más restrictivos.

\section{VII.5.4 Laminación de avenidas y regulación de caudales}

El servicio de laminación de avenida tiene un coste estimado de 17,30 M€ y está configurado mediante la introducción de unos embalses en el modelo de optimización, cuya capacidad corresponde al resguardo máximo para laminación definido en el archivo técnico de las presas. Sin embargo, debido a la variabilidad mensual de la curva de embalse es posible destinar, en determinados periodos del año, parte de los volúmenes liberados para la regulación, y obtener significativas eficiencias en la gestión.

En la Tabla 56 se ha calculado la diferencia entre el coste de unas actuaciones disjuntas para regulación y laminación y el coste relativo a una coalición en la que se comparten las obras de regulación y de laminación. La agregación de un 
uso consuntivo del agua a una coalición constituida por el solo jugador "laminación de avenidas" (A) comporta un ahorro de coste considerable respecto a la realización de unas obras de regulación individuales. El ahorro conseguido es el resultado de la acción combinada de las economías de escala (costes medios decrecientes de las infraestructuras) y de ámbito (posibilidad de utilizar la misma infraestructura para dos propósitos distintos.

\begin{tabular}{|c|c|c|}
\hline \multicolumn{3}{|c|}{ Eficiencia del uso conjunto laminación-regulación $(\mathbf{M} €)$} \\
\hline$(\mathrm{A}+\mathrm{B})-\mathrm{AB}$ & 13,04 & 70,78 \\
\hline (A+C)- AC & 1,38 & 2,32 \\
\hline (A+D)- AD & 0,99 & 0,03 \\
\hline
\end{tabular}

Tabla 56: Uso conjunto de embalses de laminación y regulación.

El análisis detallado de la estructura de costes del sistema permite evidenciar la influencia de las economías de escala y de ámbito en el desarrollo de proyectos hidráulicos, lo que comporta una mejora en el conocimiento del sistema y una ayuda en la búsqueda de las soluciones más eficientes para los servicios del agua.

\section{VII.5.5 El coste de la energía}

El coste de la energía representa un factor de incertidumbre en la planificación de los servicios del agua. Las variaciones a corto y largo plazo del coste de la energía, o de otros factores de producción, pueden influir en la configuración de costes del sistema e intervenir en el proceso de selección de las alternativas de gestión.

Se ha considerado un escenario caracterizado por el aumento del $25 \%$ del coste de la energía, que conlleva un incremento del coste de bombeo y de todas las alternativas de proyecto que comportan un elevado consumo energético, como la reutilización de aguas residuales y la desalinización. El modelo de optimización reacciona al aumento de los costes variables vinculados al consumo energético con un incremento generalizado de los costes de gestión, asociado a una mayor utilización de las obras de regulación y a una reducción de los volúmenes bombeados. La función característica, recogida en la Tabla 57, evidencia el incremento de los costes de gestión, que se manifiesta prevalentemente en las coaliciones que incluyen los usos agrarios. 


\begin{tabular}{|c|c|}
\hline \multicolumn{2}{|c|}{ Función característica } \\
\hline Coalición & Coste (M€) \\
\hline Laminación (A) & 17,30 \\
\hline Usos agrarios (B) & 92,27 \\
\hline Usos urbanos (C) & 3,70 \\
\hline Tomas fuera de comisión (D) & 0,99 \\
\hline AB & 96,10 \\
\hline AC & 19,62 \\
\hline AD & 17,30 \\
\hline BC & 93,42 \\
\hline BD & 92,84 \\
\hline CD & 4,06 \\
\hline ABC & 97,05 \\
\hline ABD & 96,10 \\
\hline ACD & 19,62 \\
\hline BCD & 93,57 \\
\hline Gran coalición (ABCD) & 97,23 \\
\hline
\end{tabular}

Tabla 57: Aumento del coste de la energía, función característica. 
El la Figura 66 se muestra el cumplimiento de la condición de eficiencia por parte de la gran coalición en condiciones de incremento del coste de la energía.

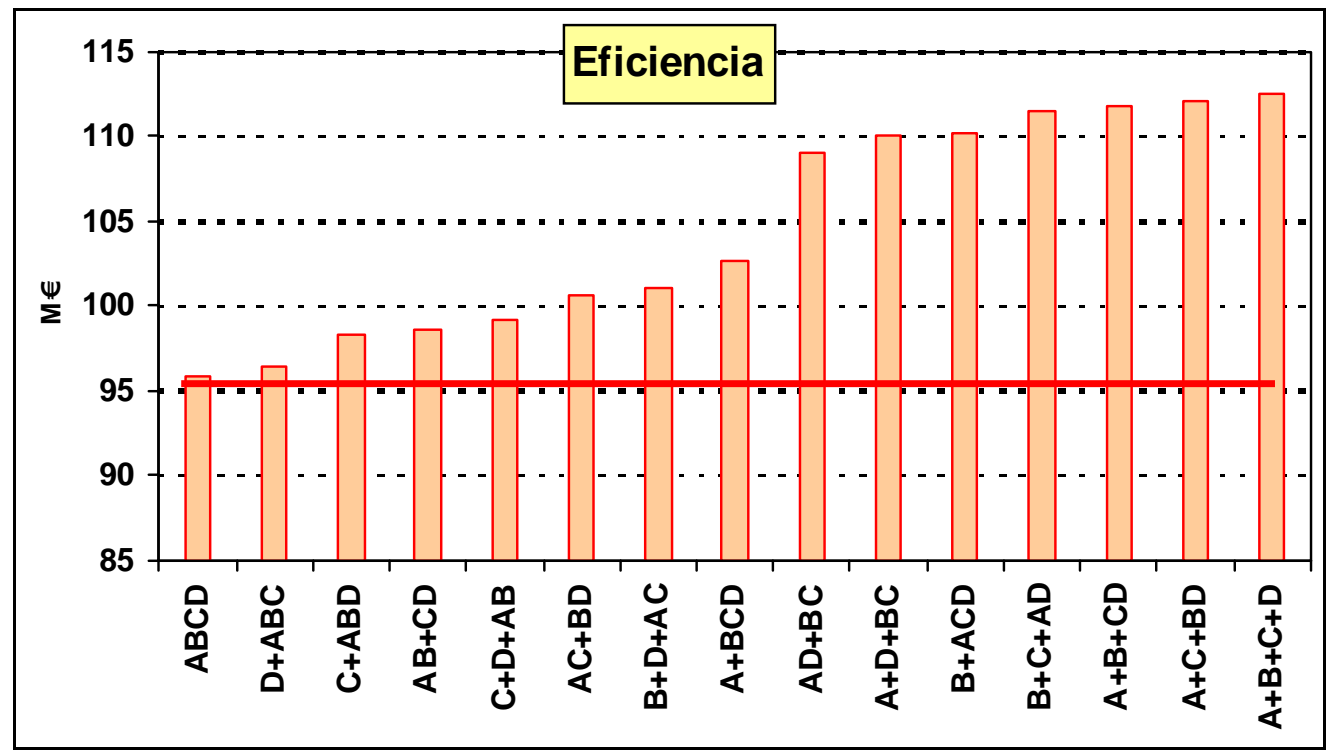

Figura 66: Aumento del coste de la energía, eficiencia de la gran coalición. 
El reparto de costes, calculado mediante el valor de Shapley y representado en la Figura 67, muestra un aumento de la contribución por parte de todos los jugadores. Sin embargo, refleja la responsabilidad de los usos agrarios (B) en el consumo de energía a través de una mayor contribución de este jugador en la financiación de los servicios. Se muestra, además, como el valor de Shapley, que goza de la propiedad de monotonía en costes, permite alcanzar una solución en la que todos los jugadores participan, aunque sea de forma menor, al aumento del coste del proyecto cooperativo. Ningún jugador consigue un beneficio en la asignación de costes a causa del aumento del coste total del proyecto. La metodología de cálculo ofrece por lo tanto una válida herramienta a la hora de definir acuerdos de cooperación que incluyan el reparto de costes en caso de incertidumbre sobre el coste final del proyecto.

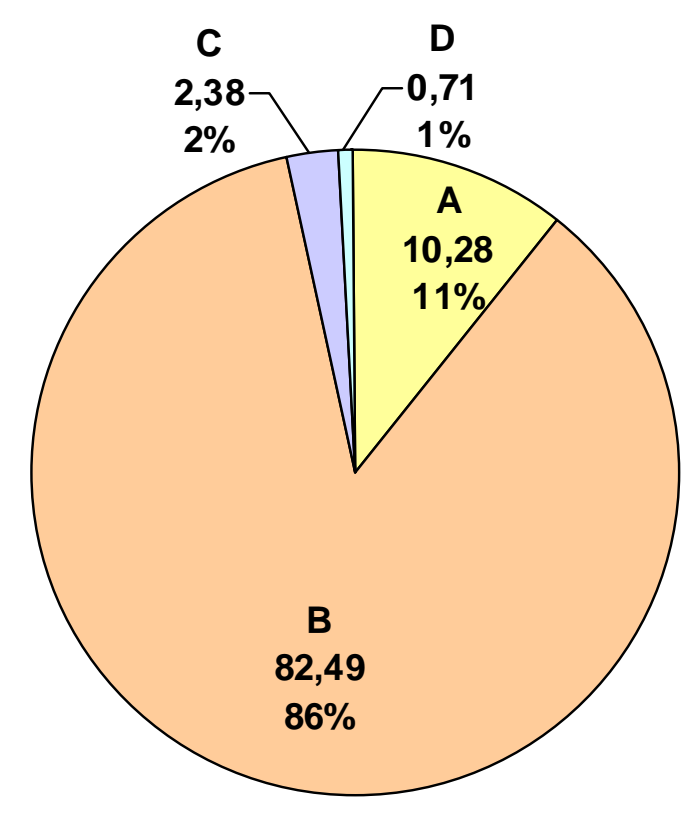

Figura 67: Aumento del coste de la energía, reparto de costes (valores en M€). 
En la Figura 68 es posible comprobar la existencia del núcleo de soluciones, cuyo espacio resulta más estrecho respecto al caso base, debido al aumento de las disparidades entre usuarios a causa del incremento del coste de bombeo. La reducción del espacio contenido en el núcleo limita el abanico de soluciones factible, y acota el margen de negociación disponible para los agentes interesados en el proyecto. Es posible suponer que un ulterior aumento del coste de la energía (o de otros servicios) pueda llevar a soluciones inestables y al abandono de la gran coalición por parte de algunos jugadores.

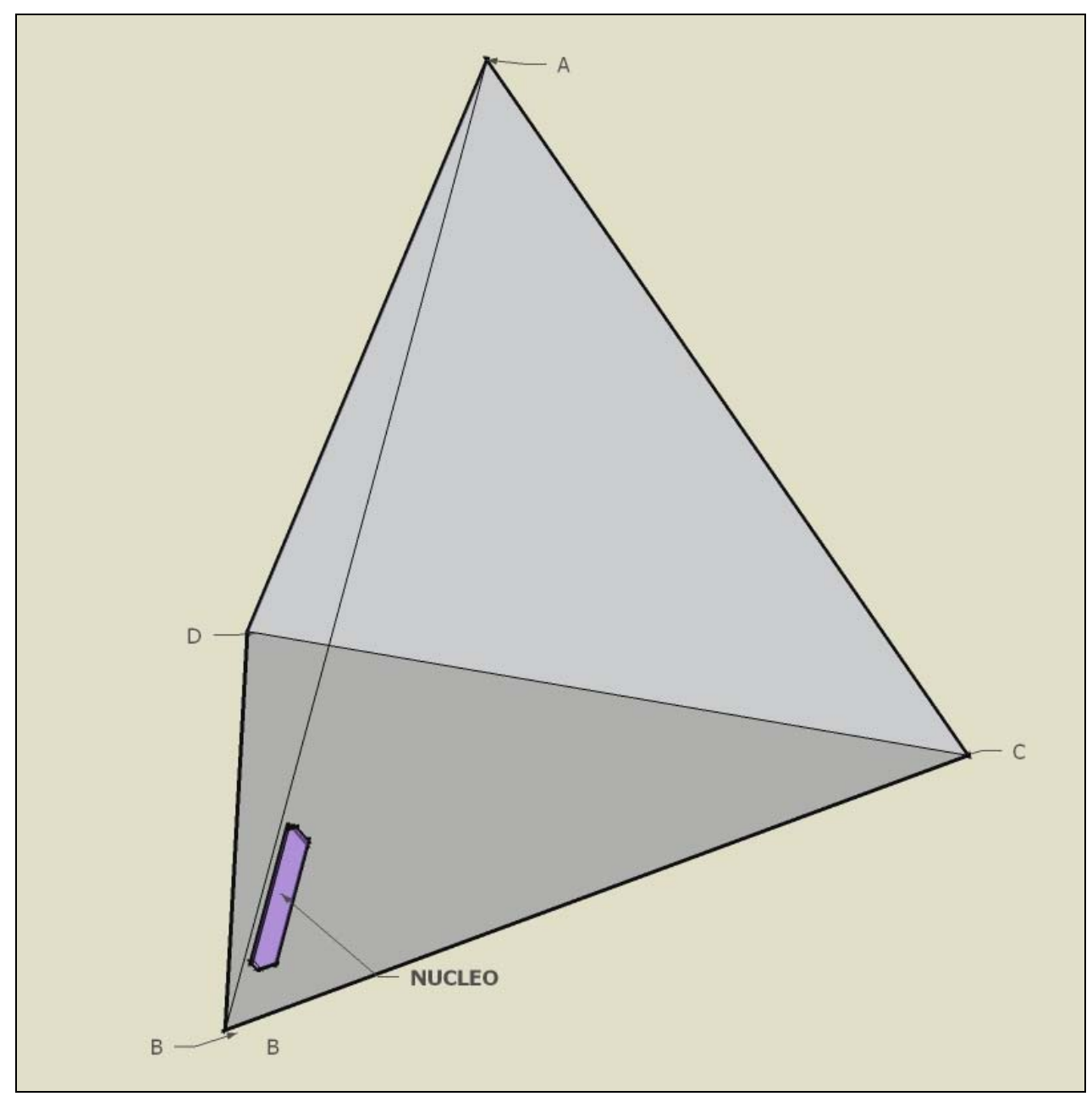

Figura 68: Aumento del coste de la energía, tetraedro. 


\section{CAPÍTULO VIII}

\section{ASIGNACIÓN DEL COSTE DE NUEVAS ACTUACIONES}

La aplicación desarrollada en el capítulo anterior tiene como finalidad la definición de un criterio de asignación de costes de los servicios actualmente en uso en la cuenca. Otra posible aplicación de la metodología responde a la necesidad de analizar los costes relativos a un escenario de expansión de los servicios, en el que se supone la realización de nuevas inversiones para hacer frente a unas hipótesis de gestión caracterizadas por la limitación de los recursos disponibles en el sistema, conjuntamente al aumento de la demanda de agua. Concretamente se pretende calcular la asignación de costes del sistema hídrico del río Turia considerando el siguiente escenario de gestión:

- De acuerdo con las especificaciones presentes en la Instrucción de planificación hidrológica (MMARM, 2008) y recogidas en la Tabla 58, se propone una disminución de las aportaciones naturales del sistema del $9 \%$. La reducción tiene el objetivo de incorporar el efecto del cambio climático a largo plazo, en el horizonte temporal del año 2027.

\begin{tabular}{lc}
\hline $\begin{array}{l}\text { Demarcación } \\
\text { hidrográfica }\end{array}$ & $\begin{array}{c}\text { Porcentaje de } \\
\text { disminución }\end{array}$ \\
\hline Miño-Sil & 3 \\
Cantábrico & 2 \\
Duero & 6 \\
Tajo & 7 \\
Guadiana & 11 \\
Guadalquivir & 8 \\
Segura & 11 \\
Júcar & 9 \\
Ebro & 5 \\
\hline
\end{tabular}

Tabla 58: Disminución de las aportaciones por efecto del cambio climático (MMARM, 2008).

- Con el objetivo de reducir el riesgo de sobreexplotación del acuífero se limita el volumen máximo de bombeo anual a los siguientes valores:

Campo del Turia: $5 \mathrm{hm}^{3} /$ mes.

Acequia de Moncada: $2 \mathrm{hm}^{3} /$ mes. 
- Se propone un aumento de la demanda anual de la ciudad de Valencia hasta un volumen total de $70 \mathrm{hm}^{3} /$ año como resultado de la reducción de los volúmenes trasvasados desde la cuenca del Júcar mediante el canal Júcar-Turia.

Las modificaciones aportadas en el sistema comportan un aumento de la presión sobre los recursos superficiales que no será compensada por un aumento de la utilización de aguas subterráneas.

A efecto de los cálculos se han mantenido invariados los demás elementos y variables del sistema hídrico del río Turia descrito en el Capítulo VII. En la Tabla 59 se muestra el resultado de la simulación del nuevo escenario con las infraestructuras actualmente en uso, que evidencia un empeoramiento de los niveles de garantía. Se plantea por lo tanto la necesidad de realizar nuevas inversiones con el fin de alcanzar los niveles de garantía definidos por la instrucción de planificación (MMARM, 2008). Los valores descritos a continuación representan los déficits registrados en distintos intervalos de tiempo, calculados como un porcentaje respecto a la demanda anual, y constituyen los niveles de garantía de referencia para los usuarios que no pertenecen a una coalición.

\begin{tabular}{|c|c|c|c|c|}
\hline Déficit máximo & Mensual & $\mathbf{1}$ año & $\mathbf{2}$ años & $\mathbf{1 0}$ años \\
\hline Teruel & $80,7 \%$ & $58,52 \%$ & $72,56 \%$ & $90,44 \%$ \\
\hline Valencia & $92,2 \%$ & $42,89 \%$ & $62,34 \%$ & $140,05 \%$ \\
\hline Campo Turia & - & $49,92 \%$ & $89,21 \%$ & $194,99 \%$ \\
\hline Pueblos Castillos & - & $47,06 \%$ & $89,36 \%$ & $242,52 \%$ \\
\hline R. Tradicionales & - & $97,48 \%$ & $186,69 \%$ & $702,49 \%$ \\
\hline
\end{tabular}

Tabla 59: Nuevas actuaciones, déficit de suministro a las demandas. 


\section{VIII.1 DEFINICIÓN DEL JUEGO Y FORMACIÓN DE COALICIONES}

Para la resolución del problema de asignación de costes se procede, de acuerdo con la metodología, a la definición del juego cooperativo y a la optimización de las coaliciones. Se ha considerado el caso base caracterizado por la presencia de todas las actuaciones ya existentes en la cuenca, a las cuales se sumarán posteriormente las nuevas inversiones que serán objeto del reparto de costes.

A continuación se describen las modificaciones aportadas en el conjunto de jugadores:

- Se ha eliminado el jugador laminación de avenidas en cuanto el servicio de laminación no comporta la realización de nuevas actuaciones;

- Se ha eliminado el jugador tomas fuera de comisión al suponer que estos usuarios no participan al desarrollo de nuevas actuaciones;

- Se han distinguido tres jugadores que corresponden a distintos usuarios agrícolas, con el fin de ofrecer un mayor nivel de detalle en la determinación de los pagos.

Los nuevos jugadores del sistema coinciden por lo tanto con las siguientes demandas de uso consuntivo:

(A) Usos Urbanos: representados por las unidades de demanda urbana de Teruel $\left(3,17 \mathrm{hm}^{3} /\right.$ año) y Valencia, esta ultima con una demanda anual de $70 \mathrm{hm}^{3}$

(B) Riegos del campo del Turia: $85 \mathrm{hm}^{3} /$ año.

(C) Riegos tradicionales de los Pueblos Castillos: $51,88 \mathrm{hm}^{3} /$ año;

(D) Riegos tradicionales de la plana de Valencia: $160 \mathrm{hm}^{3} /$ año;

\section{VIII.2 CÁLCULO DE LA FUNCIÓN CARACTERÍSTICA}

Los resultados de la optimización relativos a la gran coalición muestran que el sistema logra satisfacer a las demandas mediante la realización de una planta para la reutilización de las aguas residuales de la ciudad de Valencia y la construcción de una planta desalinizadora de reducida capacidad (1,17 $\left.\mathrm{hm}^{3} / \mathrm{mes}\right)$. 
En la Figura 69 se muestran las series relativas a los volúmenes almacenados en los embalses, en la Figura 70 los caudales mensuales proporcionados por las plantas de reutilización y en la Figura 71 la serie relativa a los volúmenes generados mediante desalinización.

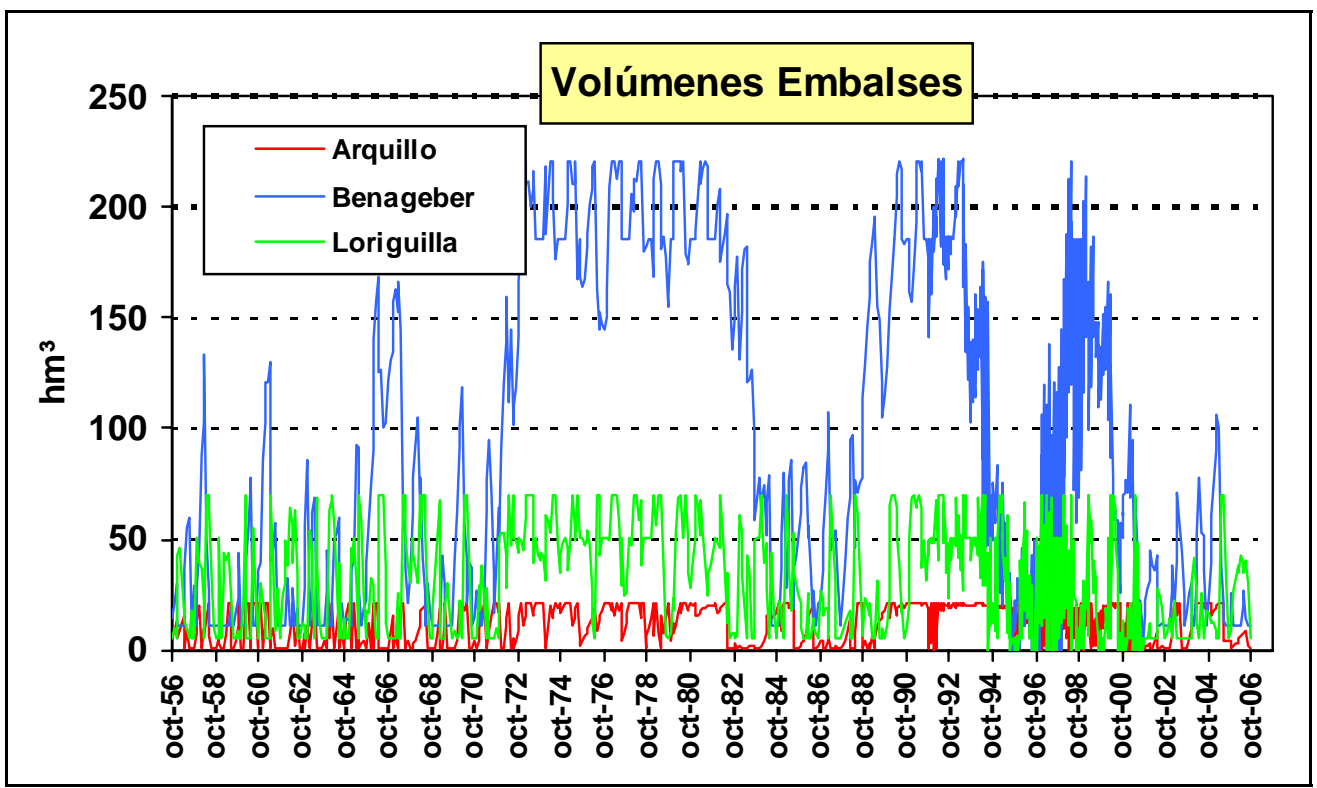

Figura 69: Nuevas actuaciones, volúmenes de los embalses.

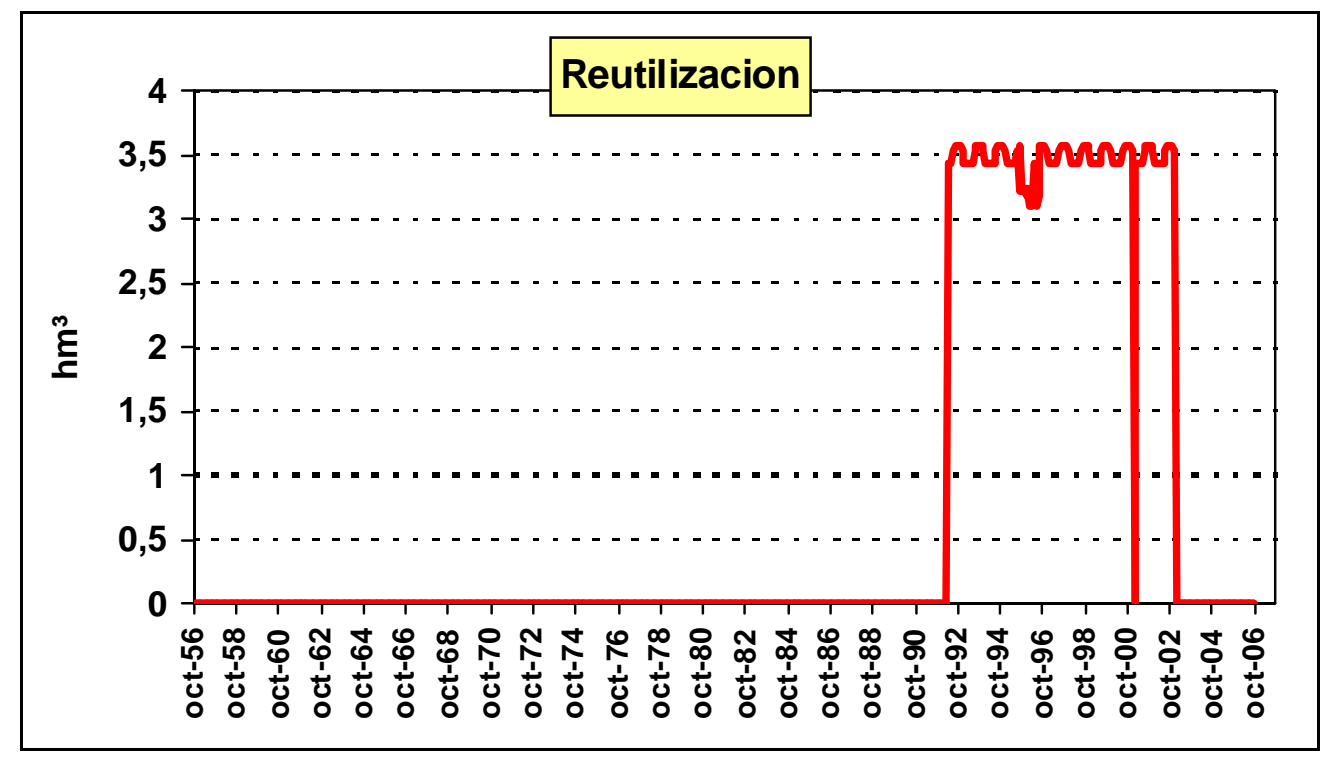

Figura 70: Nuevas actuaciones, reutilización. 


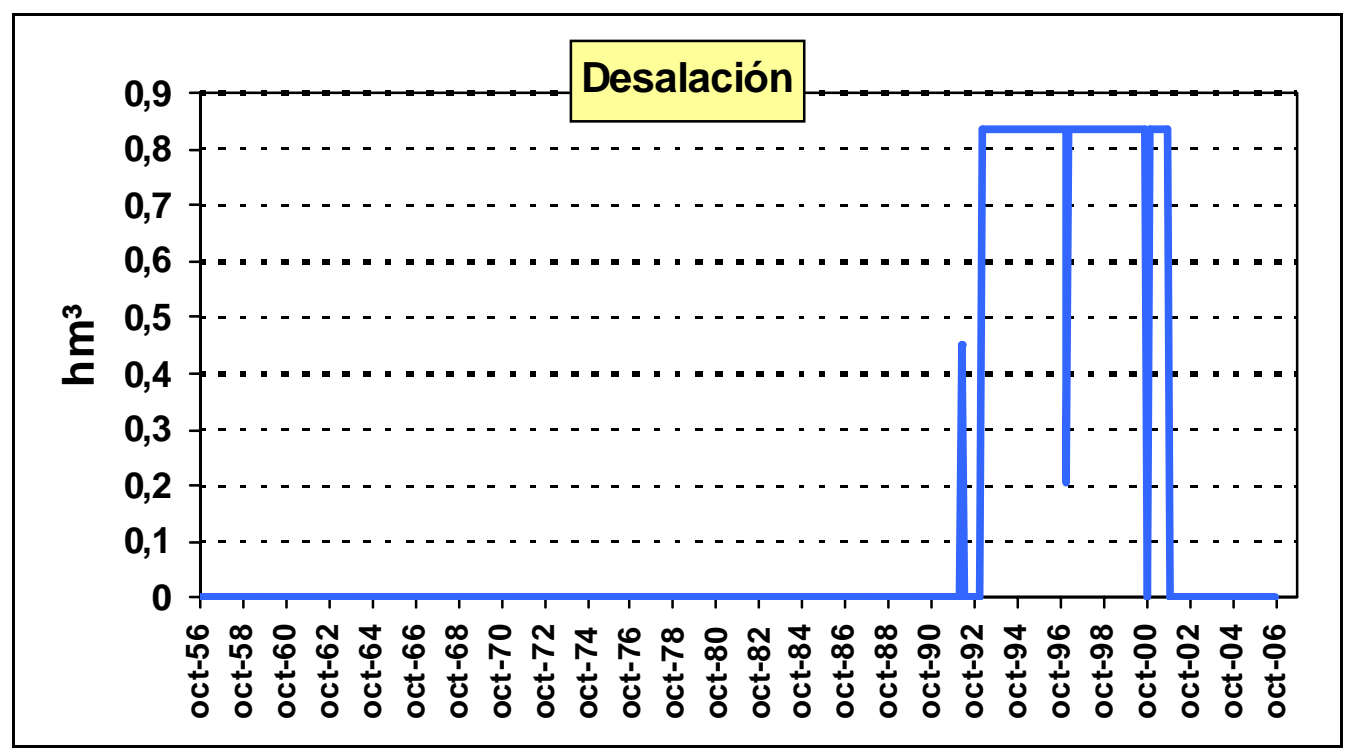

Figura 71: Nuevas actuaciones, desalinización.

La consecución de los niveles de servicios requeridos comporta un aumento substancial del coste de los servicios, en particular de los costes de explotación. En la Tabla 60 se muestra un resumen de los volúmenes obtenidos mediante regeneración y desalinización y se detalla el coste correspondiente a dichas obras. Cabe destacar que los riegos de los Pueblos Castillos tienen acceso a las aguas regeneradas a un coste superior de $0,05 €$ respecto a los usuarios de la plana de Valencia debido a los gastos de las obras de impulsión hasta las redes de distribución secundarias.

\begin{tabular}{|c|c|c|c|}
\hline & \multicolumn{2}{|c|}{ Reutilización } & \multirow{2}{*}{$\frac{\text { Desalinización }}{\text { Valencia }}$} \\
\hline & $\begin{array}{l}\text { Pueblos } \\
\text { castillos }\end{array}$ & $\begin{array}{c}\text { Riegos } \\
\text { tradicionales }\end{array}$ & \\
\hline Volumen total $\left(\mathrm{hm}^{3}\right)$ & 7,85 & 437,02 & 87,15 \\
\hline Coste explotación $\left(€ / \mathrm{m}^{3}\right)$ & 0,17 & 0,12 & 0,45 \\
\hline Coste total explotación (M€) & 1,33 & 52,44 & 39,21 \\
\hline Volumen máx. (hm³/mes) & \multicolumn{2}{|c|}{3,57} & 0,83 \\
\hline Coste inversión (M€/hm³/mes) & \multicolumn{2}{|c|}{1,3} & 2 \\
\hline Coste total inversión $(\mathrm{M} €)$ & \multicolumn{2}{|c|}{4,64} & 1,67 \\
\hline Coste total (M€) & \multicolumn{2}{|c|}{58,41} & 40,87 \\
\hline
\end{tabular}

Tabla 60: Nuevas actuaciones, costes de regeneración y desalinización. 
En la Tabla 61 se recogen los resultados de las optimizaciones calculadas para las distintas coaliciones de jugadores. Sigue en la Tabla 62 el resumen de los costes correspondientes a la gran coalición y en la Figura 72 la función característica.

\begin{tabular}{|c|c|}
\hline \multicolumn{2}{|c|}{ Función característica } \\
\hline Coalición & Coste $(\mathbf{M} €)$ \\
\hline A & 24,70 \\
\hline B & 20,40 \\
\hline C & 11,80 \\
\hline D & 124,60 \\
\hline AB & 43,80 \\
\hline AC & 39,70 \\
\hline AD & 173,53 \\
\hline BC & 31,40 \\
\hline BD & 160,07 \\
\hline CD & 141,66 \\
\hline ABC & 67,40 \\
\hline ABD & 213,04 \\
\hline ACD & 191,66 \\
\hline BCD & 181,78 \\
\hline ABCD & 237,69 \\
\hline
\end{tabular}

Tabla 61: Nuevas actuaciones, función característica.

\begin{tabular}{|c|c|c|c|c|}
\hline \multicolumn{5}{|c|}{ Gran coalición (ABCD) } \\
\hline & $\begin{array}{c}\text { Bombeos } \\
\text { Campo del Turia }\end{array}$ & $\begin{array}{c}\text { Bombeos } \\
\text { Plana de Valencia }\end{array}$ & Reutilización & Desalinización \\
\hline $\begin{array}{c}\text { Diseño } \\
\left(\mathrm{hm}^{3} / \mathrm{mes}\right)\end{array}$ & 5,00 & 2,00 & 3,57 & 0,83 \\
\hline Costes $(\mathrm{M} €)$ & 104,22 & 34,19 & 58,41 & 40,87 \\
\hline Total $(\mathbf{M})$ & \multicolumn{4}{|c|}{$\mathbf{2 3 7 , 6 9}$} \\
\hline
\end{tabular}

Tabla 62: Nuevas actuaciones, gran coalición. 


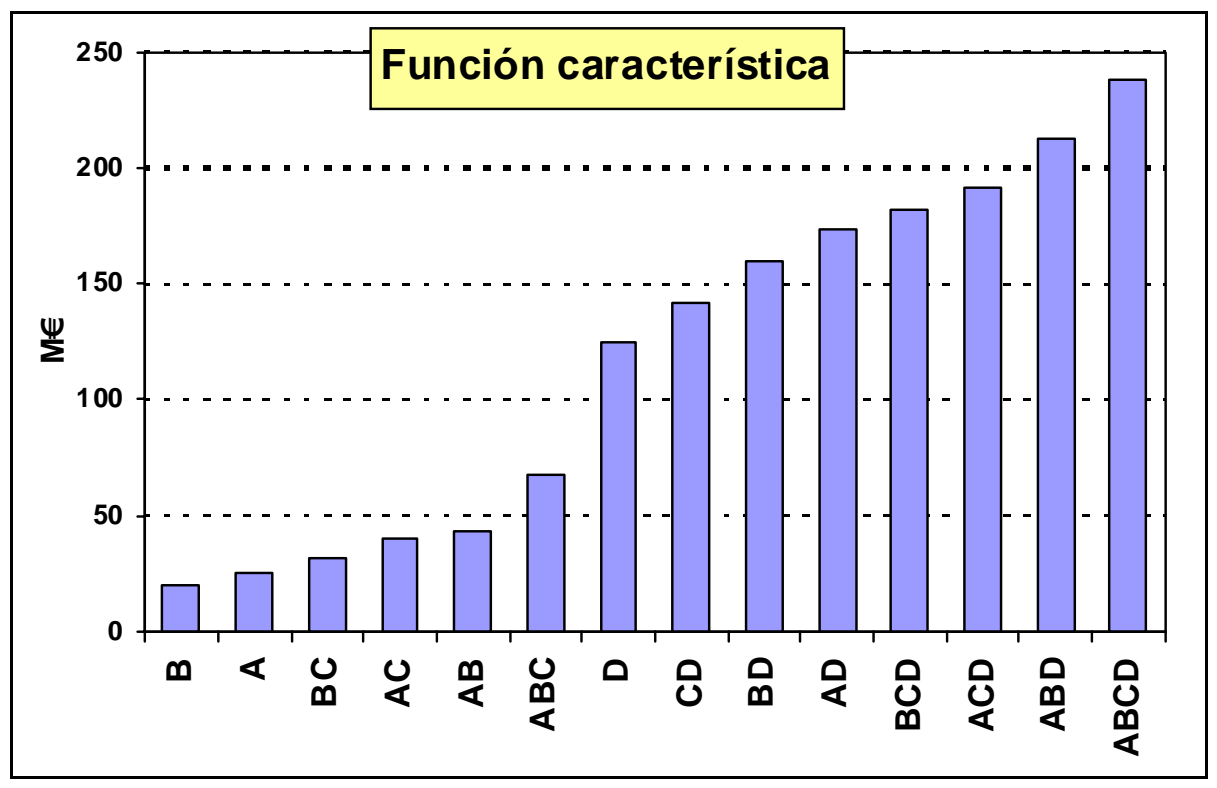

Figura 72: Nuevas actuaciones, función característica.

La comprobación de la condición de eficiencia (ver Figura 73) evidencia que la gran coalición tiene un coste superior respecto a la suma de los costes de las actuaciones individuales. Este resultado tiene su fundamento en la mutación de la estructura de costes del problema, desde una condición de subaditividad hacia una condición de superaditividad, en la que la introducción de un nuevo usuario en la gestión comporta la búsqueda de nuevas fuentes de suministro de mayor coste, con el consecuente aumento de los costes medios del sistema y la pérdida de las economías de escala.

La razón de este cambio se debe al agotamiento de los recursos renovables del sistema, constituidos en gran medida por los caudales fluyentes en los ríos, cuyas obras de captación, almacenamiento y distribución están caracterizadas por importantes costes de inversión que comportan elevadas economías de escala. Las nuevas infraestructuras requeridas para paliar el déficit de suministro, como las estaciones de desalinización y de reutilización, se caracterizan por un mayor peso de los gastos de explotación en el coste total de los servicios, lo que conlleva a una minimización de las economías de escala. 


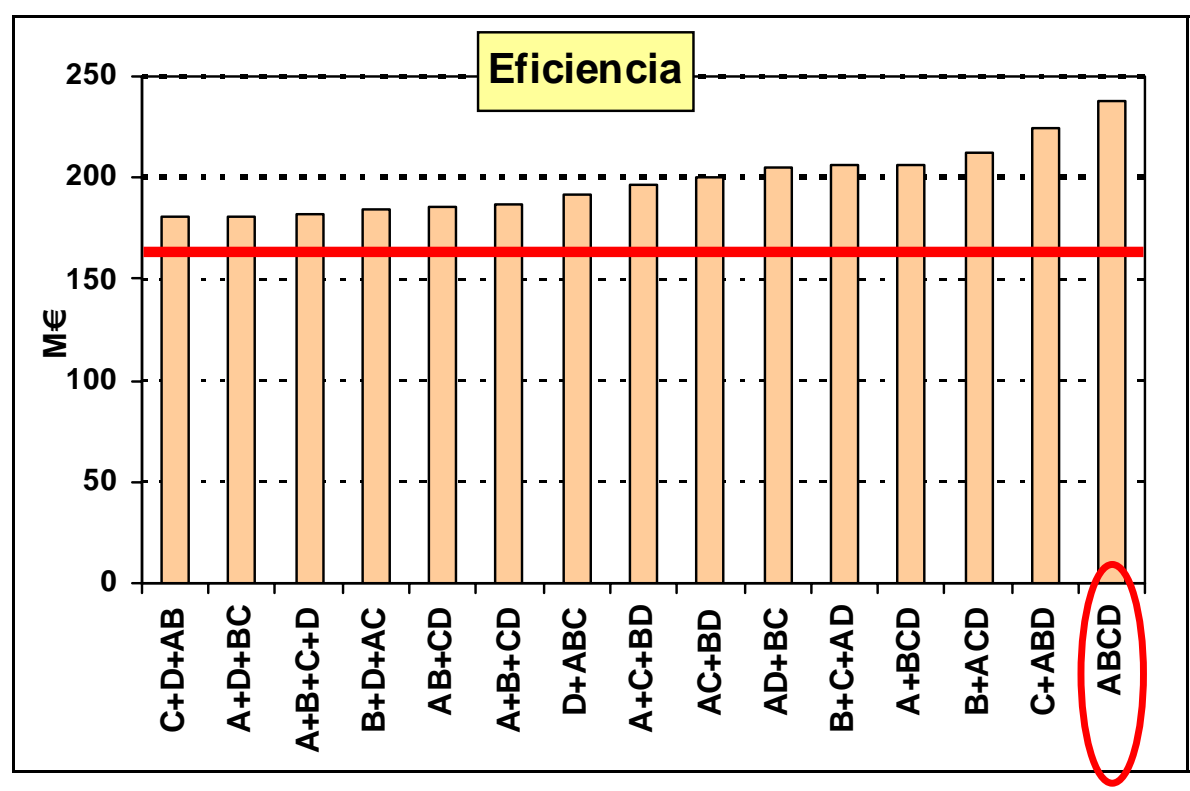

Figura 73: Nuevas actuaciones, condición de eficiencia.

Si la solución mancomunada resulta ineficiente respecto a las soluciones individuales no se generan incentivos adecuados para que los sujetos realicen acuerdos de cooperación. Se entra, por lo tanto, en un escenario de gestión competitivo en el que las soluciones a los problemas de suministro se alcanzan de forma autónoma a un coste inferior respecto a la gran coalición.

Los escenarios competitivos conllevan sin embargo problemas relacionados con las posibles afecciones a terceros y las externalidades a largo plazo, lo que puede llevar la administración a definir medidas específicas con el fin de incentivar la cooperación o penalizar la realización de soluciones individuales.

\section{VIII.3 PROPUESTA DE SOLUCIÓN MEDIANTE SUBVENCIONES PÚBLICAS}

Una propuesta de solución de los problemas de asignación de costes en caso de soluciones cooperativas no-eficientes se basa en la aplicación de subvenciones económicas que actúen como incentivos económicos a la cooperación.

En el caso examinado es necesario lograr una reducción del coste de la gran coalición de al menos 58M€ para asegurar el cumplimiento de la condición de eficiencia. La aplicación de una subvención para la reutilización de aguas residuales podría generar los ahorros suficientes para lograr una gestión de tipo consensuado. El coste de estas medidas sería a cargo de la colectividad y contribuiría a la mejora del medio ambiente, limitando las extracciones del 
sistema superficial y subterráneo con el fin de prevenir posibles externalidades no controladas.

\section{VIII.4 MODIFICACIÓN DEL CRITERIO DE FORMACIÓN DE COALICIONES.}

Otra propuesta de solución al problema de la ineficiencia de las actuaciones conjuntas se define a partir del análisis del proceso de formación de coaliciones.

Como se ha comentado en el Capítulo VI.3.2, el criterio de formación de coaliciones aplicado en esta tesis impone que los nuevos usos del agua tengan que abastecerse mediante actuaciones alternativas sin perjuicio para los usuarios preexistentes. En estas condiciones los jugadores individuales, actuando singularmente, pueden mejorar sus garantías utilizando los recursos de menor coste, bajo la condición de no afectar a las garantías de los demás usuarios del sistema; mientras las coaliciones de usuarios, que necesitan mayores cantidades de recursos, pagan un coste medio superior debido a la ausencia de economías de escala. El resultado es que los jugadores prefieren actuar singularmente para aprovechar los escasos recursos disponibles a bajo coste.

Una posible solución, que no comporta la aplicación de subvenciones públicas, consiste en la modificación del criterio que está a la base del desarrollo de nuevas actuaciones:

1. Se concede la prioridad en la utilización de los recurso adicionales a los usuarios asociados en coalición;

2. Los usuarios que no pertenezcan a una coalición están obligados a abastecerse mediante los recursos que no han sido aprovechados por las coaliciones de usuarios.

Bajo estas condiciones, en presencia de una estructura de costes de tipo superaditivo, los usuarios que pertenecen a una coalición tienen la prioridad sobre el uso de los recursos, mientras los usuarios que actúan individualmente utilizan recursos marginales de mayor coste. Cabe destacar que, en condiciones de subaditividad, en las que los costes medios son decrecientes, los usuarios individuales podrían beneficiarse de los recursos marginales de menor coste.

En la Tabla 63 se recogen los valores correspondientes al coste de cada coalición y en la Figura 74 se muestra la función característica asociada al nuevo criterio de formación de coaliciones. 


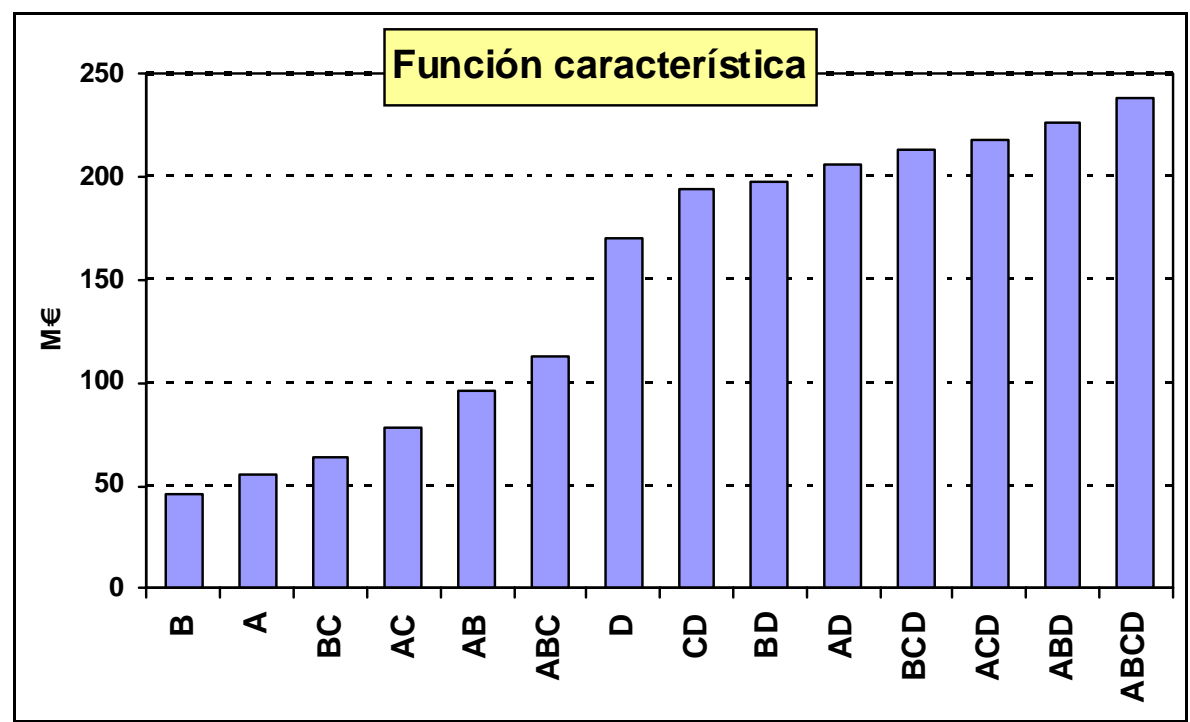

Figura 74: Nuevas actuaciones, caso modificado, función característica.

\begin{tabular}{|c|c|}
\hline \multicolumn{2}{|c|}{ Función característica } \\
\hline Coalición & Coste (M€) \\
\hline A & 55,91 \\
\hline B & 46,03 \\
\hline C & 24,65 \\
\hline D & 170,29 \\
\hline AB & 96,03 \\
\hline AC & 77,62 \\
\hline AD & 206,29 \\
\hline BC & 64,16 \\
\hline BD & 197,99 \\
\hline CD & 193,89 \\
\hline ABC & 113,09 \\
\hline ABD & 225,89 \\
\hline ACD & 217,29 \\
\hline BCD & 212,99 \\
\hline ABCD & 237,69 \\
\hline
\end{tabular}

Tabla 63: Nuevas actuaciones, caso modificado, función característica. 
En la Figura 75 es posible observar que el coste del proyecto mancomunado resulta inferior respecto a todas las actuaciones alternativas. El nuevo criterio de formación de coaliciones asegura, por lo tanto, el cumplimiento de la condición de eficiencia para la gran coalición sin necesidad de aportar subvenciones económicas y manteniendo invariado el coste final del proyecto.

La modificación en el criterio de formación de coaliciones actúa, de hecho, como un desincentivo legal a la realización de actuaciones individuales, que al poder utilizar únicamente los recursos marginales del sistema están sujetas al pago de un coste medio mayor con respecto a las coaliciones de usuarios.

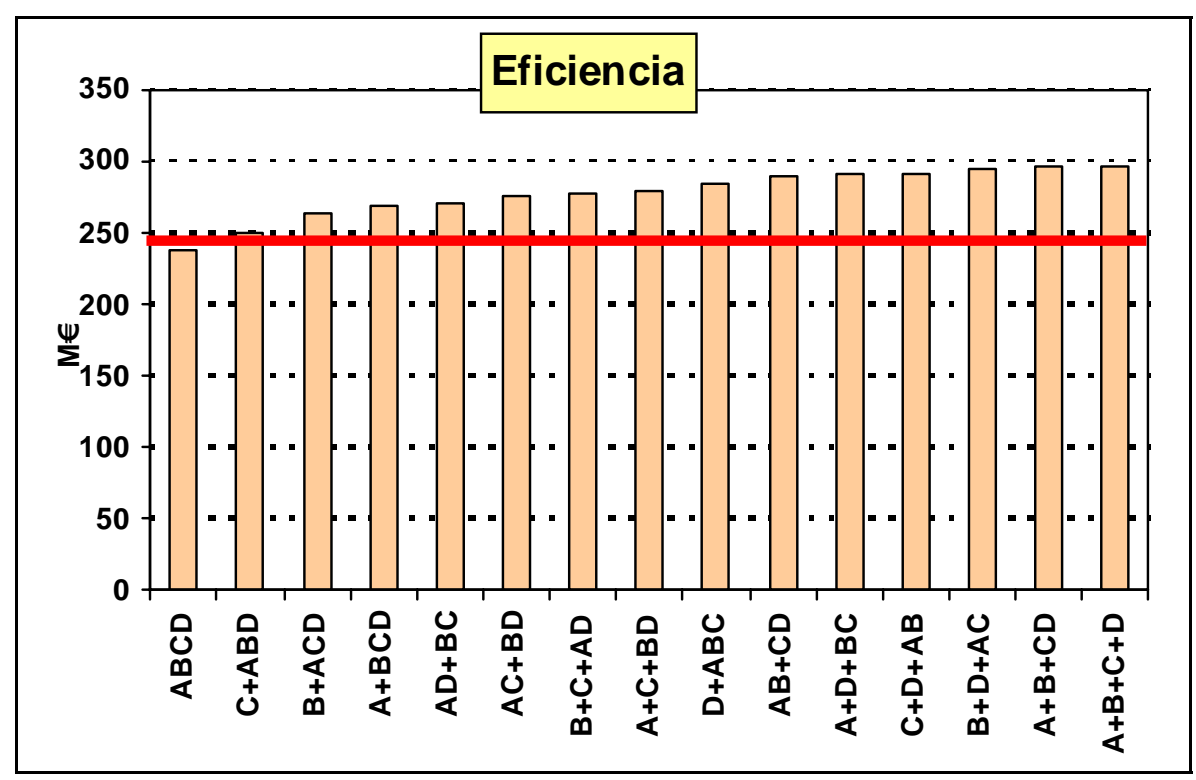

Figura 75: Nuevas actuaciones, caso modificado, condición de eficiencia.

A continuación se ha procedido al reparto de costes mediante el procedimiento descrito en los capítulos anteriores. En la Tabla 64 se recogen los resultados del cálculo del valor de Shapley y de la aplicación de algunas metodologías alternativas: reparto volumétrico, igualitario, costes separables volumétrico e igualitario. 


\begin{tabular}{|c|c|c|c|c|c|}
\hline \multicolumn{7}{|c|}{ Asignación de costes (M€) } \\
\hline & Shapley & Volumétrico & Igualitario & CS volum. & CS igual. \\
\hline A & 40,09 & 46,98 & 59,42 & 35,81 & 38,75 \\
B & 31,73 & 54,58 & 59,42 & 33,30 & 34,45 \\
C & 17,99 & 33,39 & 59,42 & 19,69 & 25,85 \\
D & 147,88 & 102,74 & 59,42 & 148,89 & 138,65 \\
\hline total & 237,69 & 237,69 & 237,69 & 237,69 & 237,69 \\
\hline
\end{tabular}

Tabla 64: Nuevas actuaciones, caso modificado, asignación de costes.

En la Tabla 65 se puede comprobar que existe un núcleo de soluciones y que el valor de Shapley proporciona una solución en el núcleo. Cabe destacar que, en este ejemplo, es posible determinar una asignación de costes en el núcleo mediante metodologías alternativas al valor de Shapley, como el método de los costes separables con reparto de tipo volumétrico.

\begin{tabular}{|c|c|c|c|c|c|c|c|}
\hline \multicolumn{8}{|c|}{ Pertenencia al Núcleo (M€) } \\
\hline \multirow[b]{2}{*}{ S } & \multicolumn{2}{|c|}{ Núcleo } & \multirow[b]{2}{*}{ Shapley } & \multirow[b]{2}{*}{ Volumétrico } & \multirow[b]{2}{*}{ Igualitario } & \multirow{2}{*}{$\begin{array}{l}\text { Costes } \\
\text { sep. vol. }\end{array}$} & \multirow{2}{*}{$\begin{array}{l}\text { Costes } \\
\text { sep. ig. }\end{array}$} \\
\hline & $x(S)>$ & $x(S)<$ & & & & & \\
\hline A & 24,70 & 55,91 & 40,09 & 46,98 & 59,42 & 35,81 & 38,75 \\
\hline B & 20,40 & 46,03 & 31,73 & 54,58 & 59,42 & 33,30 & 34,45 \\
\hline $\mathrm{C}$ & 11,80 & 24,65 & 17,99 & 33,39 & 59,42 & 19,69 & 25,85 \\
\hline $\mathrm{D}$ & 124,60 & 170,29 & 147,88 & 102,74 & 59,42 & 148,89 & 138,65 \\
\hline $\mathrm{AB}$ & 43,80 & 96,03 & 71,82 & 101,56 & 118,85 & 69,11 & 73,20 \\
\hline $\mathrm{AC}$ & 39,70 & 77,62 & 58,07 & 80,37 & 118,85 & 55,50 & 64,60 \\
\hline $\mathrm{AD}$ & 173,53 & 206,29 & 187,97 & 149,72 & 118,85 & 184,69 & 177,40 \\
\hline $\mathrm{BC}$ & 31,40 & 64,16 & 49,72 & 87,97 & 118,85 & 53,00 & 60,30 \\
\hline $\mathrm{BD}$ & 160,07 & 197,99 & 179,62 & 157,32 & 118,85 & 182,19 & 173,10 \\
\hline $\mathrm{CD}$ & 141,66 & 193,89 & 165,87 & 136,13 & 118,85 & 168,58 & 164,50 \\
\hline $\mathrm{ABC}$ & 67,40 & 113,09 & 89,81 & 71,82 & 178,27 & 71,82 & 71,82 \\
\hline $\mathrm{ABD}$ & 213,04 & 225,89 & 219,70 & 204,30 & 178,27 & 218,00 & 211,84 \\
\hline $\mathrm{ACD}$ & 191,66 & 217,29 & 205,96 & 183,11 & 178,27 & 204,39 & 203,24 \\
\hline $\mathrm{BCD}$ & 181,78 & 212,99 & 197,60 & 190,71 & 178,27 & 201,88 & 198,94 \\
\hline $\mathrm{ABCD}$ & 0,00 & 237,69 & 237,69 & 237,69 & 237,69 & 237,69 & 237,69 \\
\hline
\end{tabular}

Tabla 65: Nuevas actuaciones, caso modificado, pertenencia al núcleo. 
En la Figura 76 se muestra la representación gráfica del núcleo de soluciones en el que es posible individuar el punto correspondiente al valor de Shapley.

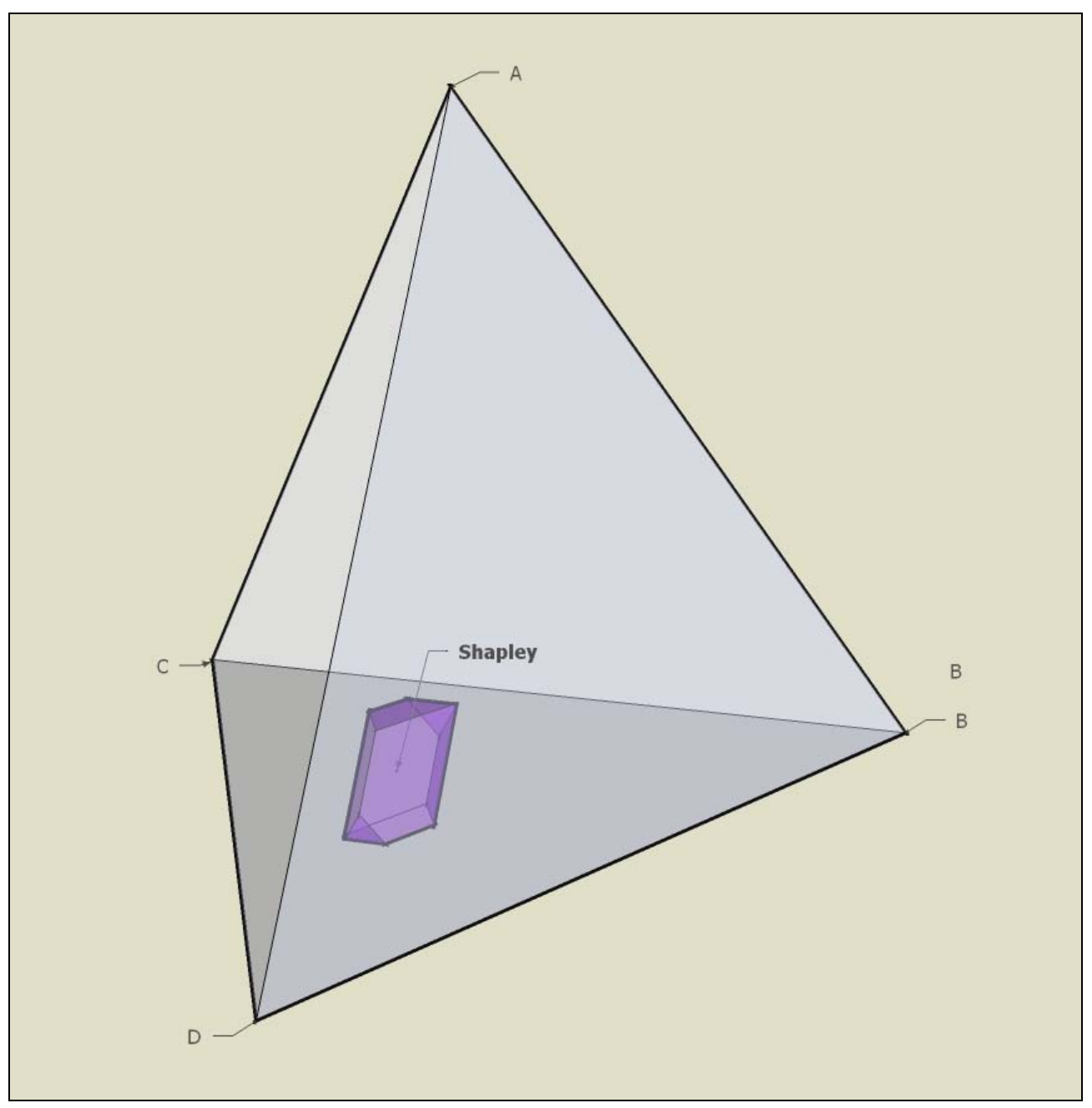

Figura 76: Nuevas actuaciones, caso modificado, tetraedro.

Se observa como, en este caso, el núcleo está constituido por un espacio amplio de soluciones, lo que da lugar a una mayor capacidad de negociación por parte de los jugadores. Es posible, por lo tanto, alcanzar acuerdos sobre el reparto de costes alternativos al valor de Shapley que incorporen distintas variables de decisión $\mathrm{y}$, sin embargo, respecten los principios de racionalidad $\mathrm{y}$ marginalidad. 



\section{CAPÍTULO IX CONCLUSIONES Y LÍNEAS FUTURAS}

En esta tesis doctoral se ha abordado el problema de la asignación de los costes de los servicios del agua según criterios de eficiencia, racionalidad y equidad, de acuerdo con los principios enunciados en la Directiva Marco de Aguas (DMA). El propósito del estudio ha sido, por un lado, descubrir cuales son las pautas que definen el proceso de asignación de costes de los servicios entre los usuarios del agua en función de su responsabilidad en el uso de las infraestructuras; y por otro lado, investigar la aplicación de la teoría de juegos cooperativos (TJC) al problema del reparto de costes de los servicios en un sistema hídrico complejo.

Para la consecución de los objetivos se ha desarrollado una metodología basada en la aplicación de la teoría de juegos cooperativos mediante el uso combinado de modelos de simulación (SIMGES, Andreu et al., 1996) y optimización (WARGI, Sechi y Zuddas, 2002) de la gestión de recursos hídricos a escala de cuenca. La metodología propuesta trata de analizar el problema de asignación de costes como un juego cooperativo, en el que los usuarios del agua actúan como jugadores individuales o en coalición en la búsqueda del máximo beneficio (o del mínimo coste). El uso de modelos de gestión de sistemas hídricos permite obtener el coste de las coaliciones y definir la función característica, cuyos valores se calculan para cada coalición mediante un modelo de optimización, y representan el conjunto mínimo de infraestructuras capaces de cumplir los objetivos de garantía definidos para cada usuario. Una vez determinada la función característica, es posible proceder a la asignación de costes entre los jugadores del sistema mediante la aplicación del valor de Shapley, $\mathrm{u}$ otros algoritmos de repartos de costes.

En el ejemplo de aplicación a la cuenca del río Turia se ha procedido a la asignación de los costes de los servicios existentes entre los distintos usos del agua, incluyendo en el reparto los usos agrarios, urbanos, la laminación de avenidas y los usuarios que no están representados en la comisión de desembalse. Se ha propuesto, además, una aplicación de la metodología para la asignación de los costes de expansión del sistema de acuerdo con un escenario de gestión futuro. 
A continuación se presentan las conclusiones más relevantes a las que se ha llegado durante el desarrollo de esta tesis. Se han definido tres grupos de conclusiones: el primero referente a los resultados de la aplicación de la teoría de juegos cooperativos al problema de asignación de costes de los servicios del agua; el segundo relativo a la estructura y al desarrollo de la metodología; y el tercero relativo a la aplicación de la TJC a los casos de estudio.

Aplicación de la TJC al problema de asignación de costes de los servicios del agua

- La TJC modifica el punto de vista en el proceso de asignación de costes incorporando una visión estratégica de los proyectos hidráulicos. El enfoque de TJ permite adelantarse a los procesos de negociación, acotando a priori el conjunto de soluciones disponibles y evidenciando las alternativas más beneficiosas para todos y cada uno de los jugadores.

- En la base de la aplicación de la TJ está un proceso de axiomatización de los conceptos de eficiencia, equidad y racionalidad, lo que permite la implantación de los mismos mediante modelos matemáticos aplicados a la gestión de recursos hídricos.

- Se ha identificado el núcleo como una herramienta eficaz para delinear los márgenes de negociación y determinar un conjunto de soluciones factibles y razonables, bajo el punto de vista de la contribución financiera, entre las cuales es posible negociar una política tarifaria que sea consensuada y que tenga en cuenta todos los condicionantes no-económicos del modelo.

- El valor de Shapley ha demostrado ser un algoritmo de solución válido para el reparto de costes de los servicios del agua por su simplicidad computacional y por la capacidad de encontrar soluciones equilibradas en contextos de núcleos estrechos y escasos márgenes de negociación.

- La TJC proporciona un mecanismo de asignación de coste transparente, eficaz, racional y equitativo, en el pleno cumplimiento de los principios enunciados por la Directiva Marco de Agua.

\section{Desarrollo de la metodología de asignación de costes}

- La principal limitación a la aplicación de la TJC ha sido tradicionalmente la dificultad que comporta el cálculo de la función característica para sistemas complejos y fuertemente interconectados. Esta aproximación al problema de asignación de costes ha permitido proceder en la aplicación de la teoría de juego a través de una modelización suficientemente detallada de la realidad del sistema hídrico, manteniendo los criterios 
actuales de gestión y una adecuada discretización espacial y temporal de las variables del sistema.

- Los modelos utilizados permiten considerar de forma conjunta las variables técnicas, hidrológicas y económicas del sistema hídrico, incluyendo además las restricciones de tipo legal y administrativo.

- La metodología desarrollada resulta totalmente compatible con, y continuadora de, los modelos realizados previamente en las cuencas españolas y mediterráneas para objetivos de planificación y gestión. Además, la extensa experiencia madurada en el uso de las herramientas de gestión de sistemas hídricos ha llevado al desarrollo de modelos completos de distintas cuencas hidrográficas, entre ellos el sistema del río Turia, que se ha presentado como caso de estudio en esta tesis.

- La integración de los criterios de garantía en el conjunto de restricciones del modelo de optimización se ha demostrado particularmente eficaz en la tarea de limitar las afecciones a terceros y vincular el uso de las infraestructuras únicamente a los sujetos interesados.

- Se define un criterio, basado en la optimización de la gestión vinculada al cumplimiento de los criterios de garantía determinados por la Instrucción de planificación hidrológica, para determinar la responsabilidad de los usuarios en el uso de los servicios del agua.

- Se ofrece una herramienta para determinar el coste de los servicios en función de la responsabilidad de cada usuario en el uso de las infraestructuras. Los resultados de la aplicación muestran que, desde el punto de vista de los usuarios, los costes de los servicios del sistema están vinculados a un conjunto de factores cuya interacción determina el coste a asignar para cada usuario, entre ellos:

- El volumen total demandado;

- La relación entre los picos de consumo y consumo medio anual;

- El nivel de garantía requerido;

- La disponibilidad de recursos alternativos;

A raíz de los resultados obtenidos, se confirma que los criterios de reparto de costes basados en una única variable de decisión (como el volumen suministrado) no permiten alcanzar el nivel de complejidad y heterogeneidad de un sistema hídrico, y pueden llevar a soluciones de asignación de costes inaceptables e ineficientes. 


\section{Aplicación de la metodología a los casos de estudio}

- El caso de estudio relativo a la asignación de costes de las infraestructuras existentes en la cuenca del río Turia (Capítulo VII) muestra una situación caracterizada por la existencia de un núcleo estrecho, y evidencia una gran disparidad en el uso de los servicios por parte de los jugadores del sistema. Los usos agrarios representan las demandas que más responsabilidad tienen en el uso de las infraestructuras, por efecto de los mayores volúmenes consumidos, y por la utilización de fuentes de suministro de mayor coste, como las aguas subterráneas.

- El análisis de los resultados ha evidenciado la existencia de economías de escala y de ámbito, relacionadas en gran medida con el uso conjunto de obras de regulación y de laminación de avenidas.

- La existencia de restricciones en el uso de los recursos subterráneos por parte de determinadas demandas ha dado lugar a soluciones de gestión sub-óptimas. El intercambio de derechos de uso del agua subterránea permitiría aprovechar las diferencias existentes en el coste de bombeo entre distintas regiones de la cuenca con el fin de mejorar la eficiencia de la gestión. El reparto de los ahorros conseguidos, y la definición de un incentivo justo y razonable para la cooperación, representan otro interesante ejemplo de juego cooperativo a escala local.

- Se ha analizado la influencia del coste de la energía con el fin de comprobar la robustez de la metodología frente a la variación de algún parámetro de coste. El aumento del $25 \%$ del coste de la energía ha llevado a un aumento generalizado de los costes de los servicios, lo que ha comportado un aumento de la asignación de costes para todos los jugadores y en mayor medida para los usos agrarios.

- El escenario relativo al cambio climático ha evidenciado la necesidad de generar recursos adicionales en el sistema mediante reutilización de aguas residuales y desalinización de agua de mar. El juego de asignación de coste de las nuevas actuaciones está caracterizado por una estructura de costes superaditiva y presenta una solución cooperativa claramente ineficiente. Se han propuesto dos soluciones al problema de la ruptura de la gran coalición, basadas en la aplicación de subvenciones públicas y en la modificación del criterio de formación de coaliciones.

- La imposición de un criterio de formación de coaliciones que asigne la prioridad en el uso de los recursos a los usuarios en coalición permitiría alcanzar una solución cooperativa eficiente en ausencia de subvenciones públicas. 


\section{IX.1 CONTRIBUCIONES ORIGINALES}

La principal novedad propuesta en esta tesis consiste es el desarrollo de una metodología para la implementación de los conceptos y métodos característicos de la teoría de juegos cooperativos en los modelos de gestión de sistemas hídricos.

Se detallan a continuación las contribuciones originales aportadas en este trabajo:

- Integración del modelo de simulación SIMGES y del modelo de optimización WARGI para el análisis económico de los servicios del agua a escala de cuenca;

- Desarrollo del modelo SIM-CO para la evaluación del coste financiero del agua en un sistema hídrico y el análisis de la recuperación de costes asociada a la aplicación de una determinada política de precios;

- Desarrollo de una metodología para el cálculo de la función característica de un juego de asignación de costes en un sistema hídrico complejo;

- Integración de los criterios de garantía establecidos por la Instrucción de Planificación Hidrológica (MMARM, 2008) en las restricciones del proceso de optimización de la gestión de sistemas de recursos hídricos;

- Asignación de los costes de los servicios del agua en un sistema hídrico complejo entre los usuarios en función de la responsabilidad de los mismos en el uso de las infraestructuras;

- Cálculo de la contribución adecuada por parte de cada uso del sistema (agrario, urbano, laminación de avenidas) en la financiación de los servicios del agua;

- Definición de un reparto justo de costes de los embalses multipropósito entre los beneficiarios de los servicios de regulación y de laminación de avenidas;

- Estimación del beneficio indirecto que obtienen en términos de mejoras de las garantías los usuarios que no están representados en comisión de desembalse y definición de la asignación de costes correspondiente a su responsabilidad en el uso de las infraestructuras. 


\section{IX.2 LINNEAS FUTURAS DE INVESTIGACIÓN}

De acuerdo con los resultados obtenidos, y con las limitaciones encontradas en el desarrollo de esta tesis, pueden definirse las siguientes líneas futuras de investigación:

- Desarrollar la herramienta de optimización con el fin de agilizar el cálculo de la función característica del juego, concretamente automatizar el proceso de formación y evaluación del coste de las coaliciones;

- Profundizar en el conocimiento de las funciones de coste de las infraestructuras hidráulicas para robustecer los parámetros económicos a introducir en el modelo;

- Extender la aplicación de la metodología a nuevos y más complejos casos de estudio, caracterizados por la presencia de un mayor número de usuarios, o por la inclusión de nuevos usos, como la producción hidroeléctrica o los usos recreativos.

- Explorar las posibilidades de aplicación de la teoría de juegos a sistemas hídricos con recursos insuficientes, o caracterizados por soluciones cooperativas económicamente ineficientes e inestables. Se propone al respecto el estudio de los problemas de bancarrota (Fragnelli et al. 2008) que han demostrado su utilidad en la aplicación a situaciones de asignación de recursos insuficientes o escasos. 


\section{CAPÍTULO $\mathrm{X}$ CONCLUSIONI E LINEE FUTURE}

In questa tesi di dottorato si é affrontato il problema della assegnazione dei costi dei servzi idrici secondo criteri de efficienza, razionalitá e equitá, in osservanza dei principi enunciati nella Direttiva Quadro Europea sulle acque 2000/60. L'obiettivo della ricerca é stato, da una parte, individuare i fattori che condizionano il processo di assegnazione dei costi dei servizi idrici in funzione della responsabilitá degli utenti nell'uso delle infrastrutture; dall'altra parte, sviluppare una proposta di applicazione della teoria dei giochi cooperativi (TGC) al problema del reparto dei costi dei servizi in un sistema idrico complesso.

Il raggiungimento degli obiettivi proposti ha comportato lo sviluppo di una metodología, basata nella applicazione della teoria dei giochi cooperativi mediante l'uso combinato di modelli di simulazione (SIMGES, Andreu et al. 1996) e di ottimizzazione (WARGI, Sechi G.M. y Zuddas P., 2002) della gestione delle risorse idriche a scala di bacino. La metodologia proposta permette di analizzare il problema della assegnazione dei costi come un gioco cooperativo, nel quale gli utenti dell'acqua agiscono come giocatori individuali $\mathrm{e}$ in coalizione per il raggiungimento del massimo beneficio individuale (o del minimo costo). L'uso dei modelli di gestione dei sistemi idrici é finalizzato al calcolo del costo delle distinte coalizioni e alla definizione della funzione caratteristica, i cui valori sono il risultato di un processo di ottimizzazione condotto per ogni coalizione e rappresentano il mínimo sistema di infrastrutture capace raggiungere gli obiettivi di efficienza definiti per ogni utente. Una volta determinata la funzione caratteristica, si procede a la assegnazione dei costi fra i giocatori del sistema mediante la applicazione del valore di Shapley o di altri algoritmi di teoria dei giochi.

Nell'esempio di applicazione al bacino del fiume Turia si é calcolata l'assegnazione dei costi dei servizi idrici fra i distinti utenti dell'acqua, includendo nel reparto gli usi agricoli, idropotabili, la laminazione delle piene e gli utenti non inclusi nella commissione di gestione degli invasi.

Si presentano a seguire le conclusioni piú rilevanti raggiunte durante lo svolgimento della ricerca, suddivise in tre categorie: la prima riguardante i 
risultati della applicazione della TGC al problema della assegnazione dei costi dei servizi idrici; la seconda riguardante la struttura e lo sviluppo della metodología basata nell'approccio simulazione-ottimizzazione al problema dell'analisi dei costi dei sistemi idrici complessi: la terza relativa ai risultati della applicazione della metodologia al caso del bacino del fiume Turia.

Applicazione della teoria dei giochi cooperativi al problema dell'assegnazione dei costi dei servizi idrici

- Si modifica il punto di vista del processo di assegnazione dei costi incorporando una visione strategica dei progetti idraulici. La TGC permette di anticipare i processi di negoziazione, individuando a priori l'insieme di soluzioni fattibili e evidenziando le alternative piú vantaggiose per il sistema nel suo complesso e per ogni utente particolare.

- Alla base della applicazione della TGC vi é un processo di assiomatizzazione dei concetti di efficienza, equitá e razionalitá, che ne permette la implementazione nei principali modelli matematici applicati alla gestione delle risorse idriche.

- É stato individuato il nucleo di un gioco cooperativo come uno strumento efficace per definire i margini della negoziazione e per isolare l'insieme di soluzioni fattibili dal punto di vista della equitá e della sostenibilitá finanziaria, entro le quali é possibile definire una politica tariffaria consensuata che includa anche le variabili non-economiche del sistema.

- Il valore di Shapley si é dimostrato un algoritmo di soluzione valido per l'assegnazione dei costi dei servizi idrici, in virtú della sua semplicitá computazionale e per la capacitá di individuare soluzioni equilibrate nei casi di giochi dal nucleo ristretto, caratterizzati da un ridotto margine di negoziazione.

- La TGC propone un meccanismo di assegnazione dei costi fondato su criteri di trasparenza, efficienza, equitá, razionalitá, nel pieno compimento dei principi enunciati dalla Direttiva Quadro Europea sulle acque.

\section{Sviluppo della metodología di assegnazione dei costi}

- La tradizionale limitazione nella applicazione della TGC é stata la difficoltá che comporta il calcolo della funzione caratteristica nei sistemi complessi e fortemente interconnessi, come sono i bacini idrografici. La metodologia proposta ha permesso di procedere nella applicazione della TGC mediante la modellazione della realtá del sistema idrico, 
conservando gli attuali criteri di gestione e una adeguata discretizzazione temporale e spaziale delle variabili del sistema.

- I modelli di gestione utilizzati permettono di considerare congiuntamente le variabili tecniche, idrologiche e economiche del sistema idrico, includendo le condizionanti di tipo legale e amministrativo.

- La metodologia proposta risulta totalmente compatibile e continuatrice dei modelli precedentemente realizzati nei bacini spagnoli e mediterranei per obiettivi di pianificazione e gestione delle risorse idriche. Inoltre, la esperienza maturata nell'uso degli strumenti di gestione ha portato alla costruzione di modelli completi di distinti bacini idrografici, fra i quali si include in bacino del fiume Turia, presentato in questa tesi.

- La integrazione dei criteri di efficienza nell'insieme delle restrizioni del modello di ottimizzazione si é dimostrato uno strumento particolarmente efficace per la individuazione e il contenimento delle esternalitá e per vincolare l'uso delle infrastrutture ai soli soggetti promotori.

- Si definisce un criterio, basato nella ottimizzazione della gestione vincolata ai soddisfacimento dei criteri di efficienza definiti dalla Istruzione di pianificazione idrologica (MMARM, 2008), per determinar la responsabilitá degli utenti nell'uso dei servizi idrici.

- Viene presentata una tecnica che permette di determinare il coste dei servizi idrici in funzione della responsabilitá di ogni utente nell'uso delle infrastrutture del sistema. I risultati della applicazione mostrano che i costi del servizio sono condizionati dai seguenti fattori, la cui interazione determina il costo finale assegnato agli utenti:

- Il volume totale d'acqua richiesto;

- La relazione esistente fra i picchi di consumo e il consumo medio annuale;

- Il livello di garanzia richiesto nell'approvvigionamento;

- La disponibilitá di risorse idriche alternative.

Alla luce dei risultati ottenuti si conferma che i criteri di assegnazione dei costi basati su una sola variable decisionale (come il volume erogato) non permettono di cogliere la complessitá e eterogeneitá del sistema idrico e possono portare a soluzioni di assegnazione dei costi inaccettabili e inefficienti. 
- I risultati della applicazione della metodologia al bacino del fiume Turia mostrano una situazione caratterizzata per la presenza di un nucleo ristretto di soluzioni e evidenziano una grande disparitá nella assegnazione dei costi agli utenti. La maggiore responsabilitá nell'uso dei servizi idrici ricade sugli usi agricoli, a causa dei maggiori volumi consumati e dell'uso di fonti di approvvigionamento di maggior costo, come le acque sotterranee.

- L'analisi dei risultati ha evidenziato l'esistenza di economíe di scala e di ambito relazionate principalmente con l'utilizzo combinato di infrastrutture per la regolazione fluviale e per la laminazione delle piene.

- La presenza di restrizioni nell'uso delle risorse sotterranee da parte di alcune domande ha portato alla determinazione di soluzioni di gestione sub-ottime. La possibilitá di permutare i diritti sull'uso dell'acqua permetterebbe di trarre beneficio delle differenze esistenti nel costo di estrazione fra le distinte regioni del bacino per migliorare l'efficienza della gestione e ottenere indubbi vantaggi económici. Il reparto dei risparmi raggiunti e la definizione di un giusto incentivo per la cooperazione costituisce un interessante esempio di gioco cooperativo a scala locale.

- É stata analizzata l'influenza del costo della energía al fine di verificare la robustezza della metodologia nel caso di una variazione dei parametri di costo. L'aumento del $20 \%$ del costo della energia ha portato a un incremento generalizzato dei costi del sistema e a un aumento della assegnazione dei costi per tutti i giocatori, specialmente per gli usi agrari.

- Lo scenario relativo al cambio climatico ha evidenziato la necessitá di generare risorse addizionali nel sistema mediante il riutilizzo dei reflui e la dissalazione. Il gioco di assegnazione dei costi dei nuovi investimenti ha manifestato una struttura dei costi superadditiva e presenta una soluzione cooperativa chiaramente inefficiente. Sono state proposte due ipotesi di soluzione, basate sull'intervento di sovvenzioni pubbliche e sulla modifica del criterio di formazione delle coalizioni.

- La imposizione di un nuovo criterio di formazione delle coalizioni, che assegni la prioritá nell'uso delle risorse addizionali agli utenti in coalizione, ha portato al raggiungimento di una soluzione cooperativa efficiente in assenza di sovvenzioni pubbliche. 


\section{X.1 CONTRIBUTI ORIGINALI}

La principale novitá proposta in questa tesi risiede nello sviluppo di una metodologia per la implementazione dei concetti e metodi caratteristici della teoria dei giochi nei modelli di gestione dei sistemi idrici attualmente in uso.

I contributi originali apportati in questa ricerca si riassumono nei seguenti punti:

- Integrazione del modello di simulazione SIMGES e del modello di ottimizazione WARGI per l'analisi economica dei servizi idrici a scala di bacino;

- Sviluppo di una metodologia per il calcolo della funzione caratteristica di un gioco di assegnazione dei costi in un sistema idrico complesso.

- Integrazione dei criteri di efficienza stabiliti dalla Istruzione di Pianificazione Idrologica (MMARM, 2008) nell'insieme dei vincoli del processo di ottimizzazione della gestione dei sistemi idrici;

- Definizione di una metodologia per l'assegnazione dei costi dei servizi idrici in funzione della responsabilitá degli utenti nell'uso delle infrastrutture, basata sul calcolo degli investimenti necessari per il raggiungimento di determinati livelli di servizio;

- Calcolo del contributo adeguato per il finanziamento dei servizi idrici da parte dei diversi usi del sistema: agricoltura, idropotabile, laminazione delle piene;

- Definizione di un criterio per il reparto giusto dei costi delle infrastrutture multi-utente e multi-proposito, come gli invasi di regolazione e laminazione piene;

- Stima del beneficio indiretto ottenuto dagli utenti che non sono rappresentati negli organismi di gestione degli invasi e definizione della assegnazione dei costi corrispondente. 


\section{X.2 LINEE FUTURE DI RICERCA}

Alla luce dei risultati ottenuri e delle limitazioni incontrate nello sviluppo della tesi, sono state individuate le seguenti linee future di ricerca:

- Sviluppare il modello di ottimizzazione con lo scopo di automatizzare il processo di formazione e cálcolo del costo delle coalizioni;

- Approfondire lo studio delle funzioni di costo delle infrastrutture per migliorare la informazione disponibile nel modello e la qualitá globale dei risultati economici;

- Estendere la applicazione della metodologia a casi di studio piú complessi, caratterizzati da un numero maggiore di utenti o dalla introduzione di nuovi usi nel sistema, come la produzione idroelettrica, l'itticoltura o gli usi ricreativi.

- Esplorare le possibilitá offerte dalla applicazione della teoria dei giochi a sistemi caratterizzati da risorse insufficienti o soluzioni cooperative economicamente inefficienti o instabili. Si propone l'approfondimento dello studio dei giochi di bancarotta (Fragnelli et al., 2008) che hanno dimostrato una certa utilitá nella applicazione a situazoni di assegnazione di risorse insufficienti o scarse. 


\section{BIBLIOGRAFÍA Y REFERENCIAS}

Aguilera F. (1997) Economía del agua: reflexiones ante un nuevo contexto. En López-Gálvez J. y Naredo J. M. (eds.), La gestión del agua de riego, 235-259. Fundación Argentaria-Visor, Madrid.

Andreu Álvarez, J.; CAPIlla RomÁ, J.; SANCHIS PASTOR, E.;. (1996). AquaTool , a generalized decision-support system for water resources planning and operational management. Journal of Hydrology, 177, 269-291.

Andreu Álvarez, J.; Solera Solera, A.; Capilla Romá, J.; SÁnchez Quispe, S.T.; SANCHIS PASTOR, E.; SERRANO CASTILlO, E. (2003). AQUATOOL: manual del usuario. Instituto de Ingeniería del Agua y Medio Ambiente-UPV.

BARRAGÁN, J; CRESPO, C.; DONOSO, G; EsCOBAR, J. (1998). Mercados e instituciones de aguas en Bolivia. UDAPE (Unidad de Análisis de Políticas Sociales y Económicas). La Paz, Bolivia.

BAUMOL, W.J ; BRADFORD D. (1970). Optimal departures from marginal cost pricing. American Economic Review, 60, 265-283.

BAUMOL, W.J. (1977). On the proper cost tests for natural monopoly in a multiproduct industry. American Economic Review, 67 (5), 809-822.

Brown Thomas, C. ; Diaz Gustavo, E. ; Sveinsson Oli, G. B. (2002). Planning water allocation in river basins. Aquarius: A system's approach. Proceedings of 2 nd Federal Interagency Hydrologic Modeling Conference, Subcommittee on Hydrology of the Advisory Committee on Water Information, 28 Julio-1 Agosto, Las Vegas, NV, EEUU.

CABEZAS, F. (1987) Trasvases intercuencas y regulación conjunta, caso Tajo-Segura. Riegos y drenajes, 15, 22-31. 
Carles Genovés, J; García Mollá, M. (2003) La coherencia de las instituciones y los modelos de uso del agua. Los instrumentos económicos en la gestión del agua en la agricultura, Ed. Mundi Prensa, pags. 115-127

CARR, D.P.; UNDERHILL, H.W. (1974). Los métodos de simulació en el aprovechamiento de los recursos hídricos. Organización de las Naciones Unidas para la Agricultura y la Alimentación (FAO).

CEDEX (2008). Guía técnica para la caracterización de medidas. Centro de Estudios y Experimentación de Obras Públicas, versión 2.6, Madrid.

CHJ (2002a) Documentos XYZT de la Presa de Arquillo. Ofiteco-Confederación Hidrográfica del Júcar, Valencia.

CHJ (2002b) Documentos XYZT de la Presa de Loriguilla. Ofiteco-Confederación Hidrográfica del Júcar, Valencia.

CHJ (2002c) Documentos XYZT de la Presa de Benagéber. Ofiteco-Confederación Hidrográfica del Júcar, Valencia.

CHJ (2002d) Consultoría y asistencia para la redacción de los estudios de seguridad, normas de explotación y manuales de operación y mantenimiento de las presas de Arquillo de San Blas, Benagéber y Loriguilla. Ofiteco-Confederación Hidrográfica del Júcar, Valencia

Collazos, G. (2004): Sistema soporte de decisión para evaluación y optimización económica de sistemas de recursos hídricos. Tesis Doctoral, Universidad Politécnica de Valencia.

Commissione Interministeriale Per la Politica Dell'Acqua Nel MEDITERRANEO (2002). Gli strumenti económici per la gestione della domanda d'acqua nel Mediterraneo. Forum avanzato de la gestione de la domanda d'acqua nel mediterraneo, 3-5 Octubre, Fiuggi, Italia.

CONTRERAS, J. (1997) A Cooperative Game Theory Approach to Transmission Planning in Power Systems. Tesis doctoral, Universidad de Zaragoza. 
DeIDDA, D. (2006): Metodología para el análisis de los costes de los servicios del agua basada en modelos de simulación: aplicación a la cuenca del río Turia. Diploma de Estudios Avanzados, Universidad Politécnica de Valencia.

DiAZ , G.E. ; BROWN, T.C.; OlI SVEINSSON (2000): AQUARIUS: A Modeling System For River Basin Waer Allocation. Department of Agriculture, Forest Service, Rocky Mountain Forest and Range Experiment Station, Fort Collins, CO, U.S.

Dinar, A. ; MoretTI, S. ; PAtrone, F. ; Zara, S. (2003): Applications of Stochastic Cooperative Gamesin Water Resources. XV Italian Meeting on Game Theory and Application (IMGTA), 12-16 Julio, Urbino, Italia.

Donoso, G (1999). Análisis del mercado de los derechos de aprovechamiento de Agua e identificación de sus problemas. Revista de Derecho Administrativo Económico, Facultad de Derecho. Pontificia Universidad Católica de Chile. Santiago, Chile. pp. 295-314.

DufF, I.S.; REID, J.K. (1979), Applications of path compression on balanced trees. Journal of the Association for Computing Machinery 26(4), 690-715.

EASTER K.W. ; ROSEGRAND M.W. ; DinAR A. (1998): Markest for Water: potencial and performance. Kluwer Academia Publisher, 298.

EINY, E. ; MONDERER, D. ; MORENO, D. (1998): The least core, kernel and bargaining sets of large games. Economic Theory, 11-3, 585-601.

ESTRADA LORENZO, F. (1994): La garantía en los sistemas de explotación de recursos hidráulicos. CEDEX, Centro de Estudios y Experimentación de Obras Públicas, Gabinete de Formación y Documentación, Monografias, Madrid.

Evans Miranda, F.J. (2002): Asignación de costos en la expansion del sistema de transmisión mediante teoría de juegos cooperativos: aproximación del kernel. Magister en Ciencias de la Ingeniería, Pontificia Universidad Católica de Chile, Escuela de Ingeniería, Departamento de Ingeniería Eléctrica, Santiago de Chile.

FARIÑAS, M. (1999) Ósmosis Inversa. Fundamentos, tecnología y aplicaciones. Ed. McGraw Hill.

FERNÁNDEZ PÉREZ, D. ; ReVILla CoRTeZÓN, J.A. (1995): políticas tarifarias para la gestión del agua urbana. Revista de Obras públicas, enero, 3.339 , 33-46. 
Fragnelli, V. ; García-Jurado, I. ; Norde, H. ; PAtrone, F. ; Tijs S. (2002): Balancedness of Infrastructure Cost Games. European Journal of Operational Research, 136, 635-654.

Fragnelli, V.; IANDOlino, A. (2004) A Cost Allocation Problem in Urban Solid Wastes Collection and Disposal. Mathematical Methods of Operations Research, $59,447-464$.

Fragnelli, V.; BranzeI, R.; Ferrari, G.; Tijs, S. (2008). A Flow Approach to Bankruptcy Problems. AUCO Czech Economic Review, Charles University Prague, Faculty of Social Sciences, Institute of Economic Studies, vol. 2(2), pages 146-153, September.

García Mollá, M. (2000): Análisis de la influencia de los costes en el consumo del agua en la agricultura valenciana. Tesis Doctoral, Universidad Politécnica de Valencia.

GARrido Colmenero, A. (2000) Ventajas y limitaciones del uso del mercado en la asignación de los Recursos Hídricos. X Jornadas de Derecho de Aguas, 23 y 24 de febrero, Universidad de Zaragoza.

GATELy, D. (1974). Sharing the Gains from Regional Cooperation: a Game Theoretic Application to Planning Investment in Electric Power. International Economic Review 15 (1): 195-208.

Giglio, R. ; Wrightington, R. (1972): Methods for Apportioning the Cost among Participants in Regional Systems. Water Resources Research, 18(3), 476-482.

GILLIES, D.B. (1953): Some theorems on n-person games. Ph.D. Dissertation, Department of mathematics, Princeton University, Princeton, N.J., EE.UU.

GORDON, R.L. (1954): The economic theory of a common property resource. Journal of Political Economy, 75, 124-142.

GROTTE, J.H. (1971): Observations on the nucleolus and the central game. International Journal of Game Theory, 1-1, 173-177. 
HANSEN E. (1994): WEAP - A system for tackling water resource problems. Water Management Europe, 74-5,

HARDIN G. (1968): The tragedy of the commons. Science, 162, 1243-1248.

HARSANYI J.C. (1962) Bargaining in ignorance of the opponent's utility function. Journal of Conflict Resolution 6, 29-38.

Holler M. ; Li X. (1996). Efficient Public Good Pricing: An Applicaion of Cooperative Game Theory. Working Paper Faechergruppe Volkswirtschaftlehre from University of Hamburg, Institute of Economics.

HowITT R.E. (1993). Resolving Conflicting Water Demands: a Market approach. The Water Economic Symposium, Grupo Aguas de Barcelona S.A. , Barcelona.

HOWITT R.E. (1994). Empirical Analysis of Water Markets Institutions: the 1991 California Water Market. Resource and Energy Economics, 16, 357-371.

HowITT R.E. (1998). Spot Prices, Option Prices and Water Markets: an Analysis of Emerging Water Markets in California. K.W Easter et al., Markets for Water: potencial and performance, Boston, EE.UU.

HowITT R.E.; Lund, J.R.; KiRbY, K.W.; JenKINS, M.W.; DrAPER, A.J. (1999). Integrated Economic-Engeneering Analysis of California's Future Water Supply. Center for Environmental and Water Resources Engeneering, University of California, Davis, EEUU.

JAMES L.D. ; LEE, R.R. (1971). Economics of water resources. McGraw-Hill, New York, EEUU.

HudSON, H.E.; HAZEN, R. (1964).Droughts and Low Streamflow. Handbook of applied Hydrology, 18.1-18.26, McGraw-Hill, New York, EEUU.

KAHAN, J.P. ; RAPOPORT, A. (1984). Theories of Coalition Formation. Lawrence Erlbaum, Hillsdale, N.J., EEUU. 
KIL SEONG LEE, NAMIL KIM (1999). Segment based cost allocation method in a large pipe network system. International Conference on Water, Environment, Ecology, Socio-economics and Health Engineering (WEESHE), 18-21 October, Seoul, South Korea.

Lall, U.; Miller, C.W. (1988): An Optimization Model for Screening Multipurpose Reservoir System. Water resources research, 24(7), 953-968.

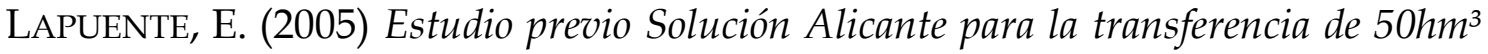
al sistema Vinalopó-Alicantí. Ingeniería y Gestión Ambiental S.L., Confederación Hidrográfica del Jucar.

LEE T.R. ; JURAVLEV A.S. (1998): Los precios, la propiedad y los mercados de asignación del agua. Serie Medio Ambiente y Desarrollo, 6, Comisión Económica para América Latina y Medio Ambiente, Naciones Unidas.

LIPPAI, I; HEANEY, J.P. (2000) Efficient and Equitable Impact Fees for Urban Water Systems. Journal of Water Resources Management and Planning, 126(2), 75-84.

LiTTLECHILD S.C; THOMPSON G.F. (1977). A simple expresion for the Shapley value in a special case. Bell Journal of Economics, 8, 186-204.

LitTlechiLd S.C.; VAIDJA, K. (1976) The Propensity to Disrupt and the Disruption Nucleolus of a Characteristic Function Game. InTERNATIONAL JOURNAL OF GAME THEORY, 151-161

LoeHman E. (1995). Cooperative Solutions for Problems of Water Supply. Water quantity/quality management and conflicts resolutions: institutions, processes and economic analyses. Westport, Preager Publisher, 301-319.

LUND J.R. (1993): Transation risk versus transation cost in water transfers. Water resources research, 29(9), 3103-3107.

MiCHENER, H.; YUEN, K. ; SAKURAI, M. (1981) On the Comparative Accuracy of Lexicographical Solutions in Cooperative Games. International Journal of Game Theory, 75-89. 
MIMAM (1998). Libro Blanco del Agua en España. Ministerio de Medio Ambiente, Madrid.

MIMAM (2000). Plan Hidrológico Nacional. Ministerio de Medio ambiente, Madrid.

MIMAM (2002). Estudio de utilización conjunta de los recursos hídricos superficiales y subterráneos en las cuencas media y baja de los ríos Júcar y Turia. Informe final, septiembre 2002, MS Ingenieros-Confederación Hidrográfica del Júcar, Valencia.

MIMAM (2007). Precios y costes de los servicios del agua en España. Informe integrado de recuperación de costes de los servicios del agua en España, artículo 5 y anejo III de la Directiva Marco de Agua. Ministerio de Medio ambiente, Madrid.

MMARM (2008). Instrucción de planificación hidrológica. Ministerio de Medio ambiente, Madrid.

MOPT (1993). Plan Hidrológico nacional. Memoria. Ministerio de Obras Públicas y Transportes, Madrid.

NASH J.F. (1950). Equilibriom Points in N-Person Game. National Academy of Sciences of the United States of America 36, 48-49.

NeWLIN, B.D.; JenKINS, M.W..; LunD, J.R.; HowITT, R.E. (2002). Southern California Water Markets: Potential and Limitations. Journal of Water Resources Planning and Management, 128(1), 21-32.

OWEN, G.T. (1993). Characterization of a Game Theoretical Cost Allocation Method. Tilburg Working Paper, Tilburg-Centre of Economic Research.

Pulido VelazQuez, M. (2003): Optimización económica de la gestión del uso conjunto de aguas superficiales y subterráneas en un sistema de recursos hídricos. Tesis Doctoral, Universidad Politécnica de Valencia.

RAMSEY, F. (1927). A contribution to the theory of taxation. Economic Journal, 37, 47-71. 
RANDALL, A. (1981). Property entitlement and prices policies for a maturing water economy. The Australian Journal of Agricultural Economics, 25, 195-220.

RANSMEIER, J.S. (1942). The Tennessee Valley Authority: a case of study in the economics of multiple purpose stream planning. Vanderbilt University Press, Nashville, TN, EE.UU.

ROGERS, P.; DE SILVA, R.; BATHIA, R. (2002). Water as a social and economic good: How to use prices to promote equity, efficiency, and sustainability. Water Policy 4, 117, Elsevier Science.

SANZ, M. (2000) La desalinización de agua de mar por Osmosis Inversa. Caso práctico: I.D.A.M. de Bahía de Palma. I Congreso AEDyR, Murcia.

SCHMEIDLER, D. (1969). The nucleolus of a characteristic function game. SIAM Journal of Applied Mathematics, 17, 1163-1170.

SECHI, G.M. ; ZUDDAS, P. (2002). The optimization package WARGI:Water Resources System Optimization Aided by Graphical Interface. XXVIII Convegno di Idraulica e Costruzioni Idrauliche, Potenza, Italia.

SECHI, G.M. ; MANCA, A.; Sulis, A.; ZudDAS, P. (2004). Complex water resources system optimization aided by graphical interface. VI International Conference of Hydroinformatics. Singapore.

SHAPLEY, L . (1953). A value for n-person games. Contributions to the theory of games II. Annals of Mathematical Studies, 28. Princeton University Press, Princeton, , New Jersey , EE.UU.

SHAPLEY, L . (1971). Core of convex games. International Journal of Game Theory, $1,11-26$.

SHAPLEY L.S. ; SHUBIK M. (1954). A method for evaluating the distribution of power in a committee system. American Political Science Review, 48, 787-792.

SORE OSORIO F.A. (2003). Definición de un sistema troncal eficiente usando la teoría de juegos cooperativos. Magister en Ciencias de la Ingeniería, Pontificia Universidad Católica de Chile, Escuela de Ingeniería, Departamento de Ingeniería Eléctrica, Santiago de Chile. 
TARJAN, R.E. (1972). Depth first search and linear graph algorithms. Society for Industrial and Applied Mathematics Journal on Computing 1(2), 146-160.

TORReS, M.; MedinA, J. A. (1999). Desalination in Spain, a Race for Lowering Power Consumption. IDA World Congress on Desalination and Water Reuse. San Diego, EEUU.

TuCKer, A. (1950). "A two-person dilemma". Stanford University Press

Unión Europea (2000). Directiva 2000/60/CE del Parlamento Europeo y del Consejo por la que se establece un marco comunitario de actuación en el ámbito de la política de aguas. Diario Oficial de las Comunidades Europeas (OJ L 327), 22 de diciembre 2002.

USACE (1994). "Hydrologic Engineering Center's Prescriptive Reservoir Model, Program Descripcion ". US Army Corps of Engineers, Hydrologic Engineering Center, Davis, EEUU.

VALERO, A.; UCHE, J.; SERRA, L. (2001) La desalinización como alternativa al PHN. CIRCE - Centro de Investigación de Recursos y Consumos Energéticos. Universidad de Zaragoza, Centro Politécnico Superior.

Von NeumanN, J. (1928) Zur Theorie des Gesellschaftspiele. Mathematische Annalen, 100, 295-320.

Von Neumann, J.; Morgenstern, O. (1944) Theory of Games and Economic Behavior. Princeton University Press, Princeton, New Jersey, EE.UU.

WESSON, W. (2000). Un nuevo recuperador de energía rompe la barrera conceptual de la ósmosis inversa. I Congreso AEDyR, Murcia.

Yates, D.; PurkeY, D.R.; Sieber, J.; Huber-Lee, A.; Galbraith, H. (2005) WEAP21--A Demand-, Priority-, and Preference-Driven Water Planning Model: Part 2, Aiding Freshwater Ecosystem Service Evaluation. Water International, 30, pp. 501-512. 
Young H.P. (1980) Cost Allocation and Demand Revelation in Public Enterprises. Working Paper WP-80-130. International Institute for Applied Systems Análysis, Laxenburg, Austria.

Young H.P. ; OKADA N. (1982) Cost Allocation in Water Resources Development. Water Resources Research, American Geophysical Union, 18(3), 463-475.

Young H.P. (1994) Cost Allocation. Handbook of Game Theory. Edited by R.J. A Aumann and S. Hart, Elsevier Science B.V., 2 (34), 1194-1234.

YOUNG R.A. (1995) Coping with a severe sustained drought on Colorado River: introduction and overview. Water Resources Bulletin, 31(5), 779-788.

YounG R.A. (1996) Water economics. In L.A. Mays (ed), Handbook of Water Resources, McGraw-Hill, 3.1-3.57.

Zara S. ; DinAR A. ; PATRONe F.; PARRACHINO, I. (2006) Cooperative Game Theory and Its Application to Natural, Environmental and Water Resource Issues. XX Congreso mundial de matemáticas, sección de teoria de juegos, 10-12 junio, Zaragoza.

ZERMELO E. (1913) Über eine Anwendung der Mengenlehre auf die Theorie des Schachspiels. Proceedings of the Fifth International Congress of Mathematicians, 2, 501-504.

ZOLEZZI CID J.M. (2002) Asignación de costos de transmission vía juegos cooperatives y formación de coaliciones. Tesis Doctoral, Pontificia Universidad Católica de Chile, Escuela de Ingeniería, Departamento de Ingeniería Eléctrica, Santiago de Chile. 